\title{
HEAD-HUNTERS ABOUT THEMSELVES
}


Dedicated to the Memory of

the late Monsignor H. Tillemans,

Archbishop of Merauke 


\section{VE R H A N D E L I N G E N}

VAN HET KONINKLIJK INSTITUUT VOOR TAAL-, LAND- EN VOLKENKUNDE

92

J. H. M. C. BOELAARS m.s.c.

\section{HEAD-HUNTERS ABOUT THEMSELVES \\ AN ETHNOGRAPHIC REPORT FROM IRIAN JAYA, INDONESIA}


The preparation and publication of this book were partly financed by the residual balance of the former "Nieuw-Guinea Stichting" (New Guinea Foundation), a fund based on a gift from the late Dr. S. J. Esser for the sake of promoting the study of the culture, and especially the languages, of the autochthonous population in the interior of Irian Jaya.

(C) Copyright 1981 by

Koninklijk Instituut voor Taal-, Land- en Volkenkunde,

Leiden, the Netherlands.

All rights reserved, including the right to translate or to reproduce this book or parts thereof in any form.

Printed in the Netherlands.

ISBN 90.247.2498.8 


\section{AUTHOR'S PREFACE}

Every book has its own personal story and my book on the Jaqaj people is no exception. I collected my initial data at the time when the Dutch government was responsible for what is now Irian Jaya, a province of Indonesia. At the time that I worked in the field and gathered my information, I enjoyed the enduring interest and support of the late Mgr. H. Tillemans, m.s.c., archbishop of Merauke. I wish to dedicate this book to his memory.

A first summary of my studies, written in Dutch, appeared in 1958 under the title Papoea's aan de Mappi. Further research in the area persuaded me that some of my previous views needed correction and that publication of more data was necessary as well. In 1969 I finished the Dutch draft of the present book. For its translation I was very fortunate to have help of my colleague Mr. M. van Dijck. It appeared that the text was too long and had to be reduced to better, workable proportions. That was my homework for the following years. The final draft was corrected by my friend Dr. W. Beek, former teacher of English at several colleges, and finally retyped by Father A. Bodden, m.s.c. I owe all of these people my sincere thanks for the many hours spent on this work.

Thanks are also due to those who, in the various phases of the preparation of this publication, gave their comments and suggestions, especially Dr. J. van Baal, now emeritus professor of Anthropology of the Utrecht State University.

I sincerely hope that the present work, apart from being a contribution to the body of anthropological information generally, will be of some use to the missionaries and the government agencies working in the Jaqaj area. My Jaqaj friends, if any of them were able to read this book, would hardly be expected to rejoice in the recollections of their past. Their eyes are on the future. All I wish for them is that part of the old strength and energy of their ancestors will stay with them. They will need it on the difficult road to a new way of life.

J. B. 
J.H.M.C. Boelaars - 978-90-04-28723-5 Downloaded from Brill.come4/26/2023 01:45:47PM via free access 


\section{TABLE OF CONTENTS}

Author's Preface . . . . . . . . . . . . . . . V

List of Maps . . . . . . . . . . . . . . . . . XII

Foreword by Professor J. van Baal . . . . . . . . . . XIII

Introduction . . . . . . . . . . . . . . . . . 1

Location; name of the tribe; neighbouring tribes; physical characteristics of the area and the people; origin; first contacts with the Government and the Mission; fieldwork; informants; interpreter; orthography; terminology; maps.

\section{PART I. SOCIAL FRAMEWORK}

Ch. I. Territorial Organization . . . . . . . . . . . 12

1. Territories . . . . . . . . . . . . . . . . 12

2. Imu . . . . . . . . . . . . . . . . . . 14

3. Sub-groups: qari . . . . . . . . . . . . . . 17

4. Landholding rights. . . . . . . . . . . . . . 21

5. Land using rights . . . . . . . . . . . . . . 27

Ch. II. Kinship and Marriage . . . . . . . . . . . 31

1. Kinship terminology . . . . . . . . . . . . . 31

2. Marriage regulations . . . . . . . . . . . . . 32

a. Incest and marriage prohibitions . . . . . . . . 32

b. Marriage opportunities . . . . . . . . . . . 33

c. Marriage arrangements . . . . . . . . . . . 34

d. Divorce . . . . . . . . . . . . . . . . 39

e. Polygyny . . . . . . . . . . . . . . . . 41

3. Other relationships . . . . . . . . . . . . . . . . 43

Adoption; ménaqaé; nakaèri; naröm; ndajin; takwèk; kaki.

Ch. III. The Settlement and Daily Pursuits . . . . . . . 47

1. The settlement . . . . . . . . . . . . . . . 47

Men's houses; women's houses; patterns of settling. 
2. Daily pursuits . . . . . . . . . . . . . . . 50

Hunting; fishing; collecting; gardening; breeding; social contacts; forms of authority: poqoj-radé or leader, akiaqradé or adviser/counsellor, joqbera-radé or spirit intermediary/seer.

\section{PART II. THE LIFE CYCLE}

Ch. IV. Pregnancy and Birth, Body and Soul . . . . . . . 61

1. Pregnancy and birth . . . . . . . . . . . . . 61

The monthly period; pregnancy; conception; the fetus; food arrangements; twins; sterility; abortion; delivery; the afterbirth; care of mother and child.

2. Body and soul . . . . . . . . . . . . . . . 66

Ch. V. Youth . . . . . . . . . . . . . . . . 73

1. Infancy . . . . . . . . . . . . . . . . . 73

Breast-feeding; name giving; baby care; walking and talking.

2. Childhood and coming of age . . . . . . . . .

In the house; in the settlement; atmosphere of fighting; children's play; accompanying parents; boys; orphans; entry into the men's house; homosexuality; piercing of the ear lobes; grown-up boys.

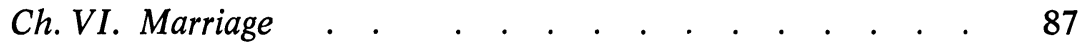

1. Boys and girls . . . . . . . . . . . . . . . . . 87

2. Ideal male and ideal female . . . . . . . . . . . . . 88

3. Initial contacts . . . . . . . . . . . . . . . 91

Usual courtship; critical songs; love medicines; terminology tom, jamba; special cases.

4. Sanctions . . . . . . . . . . . . . . . . 97

5. The marriage ceremony . . . . . . . . . . . . . . 98

Ch. VII. Married Life. . . . . . . . . . . . . . 100

1. Akiaq and the newly-wed . . . . . . . . . . . . 100

For the husband; for the wife; for both; sexual intercourse; use of abusive language; suspicions; a pre-contact case.

2. Relationships within the nuclear family . . . . . . . 104

3. Aspects of social contacts . . . . . . . . . . . . . 106

Liberality and hospitality; singing; dancing; humour; story-telling; abusive language. 
Ch. VIII. Illness and Death . . . . . . . . . . . . 112

1. Jaqaj notions concerning disease and its treatment . . . . 112

2. Old age and other causes of death . . . . . . . . . 116

Omens; medicines to kill others.

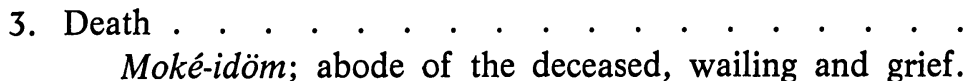

4. Mourning . . . . . . . . . . . . . . .

Treatment of corpses; mourning dress; abstinence;

dirges.

\section{PART III. HEAD-HUNTING PRACTICES}

Ch. IX. Historical Data . . . . . . . . . . . . . 125

1. Intra-tribal warfare . . . . . . . . . . . . . 125

The war of Képi versus Moïn.

2. Extra-tribal warfare . . . . . . . . . . . . . 134

a. Exact data . . . . . . . . . . . . . . . . 134

b. The case of Togompatu . . . . . . . . . . . . . 136

c. Other data . . . . . . . . . . . . . . . . . . 144

Ch. X. Training, Motivation and Preparation . . . . . . 145

1. Training . . . . . . . . . . . . . . . . . 145

Play of the boys; imitation of the adults; advice; practice.

2. Motivation

Tambi-èr; jamé-èr; head name?; maqati-èr.

3. Preparations for a raid . . . . . . . . . . .

Time; weapons; decorations; incitements; peacemaking; war canoes; mock raids; decision making; provisions; departure.

Ch. XI. The Raid

Atmosphere; scouting expedition; choice of participants by the joqbera-radè; attack; return to the bivouacs; beating the sides of the canoes; heads and souls; ménaqaé and nakaèri; cannibalism; return to the settlements; head tree?

Ch. XII. Festivities Following the Head-Hunting Raid

1. Ro or Ndat-jamé, the termination of mourning .

Removal of trestles and mourning dress; piercing of the ear lobes. 
2. Taw-jamé, the wedding-feast . . . . . . . . . . 172

Account of heroic deeds, general approval.

3. Batik-jamé, the pig feast . . . . . . . . . . . .

Kinds of insignia; pressure of acceptance; selection of the pigs; gathering of materials; sago grubs; okom.

4. Taker-jamé, the age ceremony . . . . . . . . .

Special feasting grounds?; decorating of children; cutting hair; advice; daggers; fibre skirts; killing of pigs.

5. Presentation of the marks of honour . . . . . . . .

The presentation; kuj-wir; young men; great procession; ornithomancy; appeal to the sun; return of guests; challenge to enemies.

6. Raèp-jamé, the jaw feast .

\section{PART IV. STORIES AND MYTHS}

Ch. XIII. The Origin of Things . . . . . . . . . . 197

1. The journey of Tomönringgaqaé, the tidal wave . . . . 198

2. Mato, the earthquake . . . . . . . . . . . . . 199

3. Baqaröm and the ground spirits . . . . . . . . . 201

4. Metéoqom and the fish, Qaqap, Mapur, marshplants . . . 201

5. Mopön makes the moon . . . . . . . . . . . . 203

6. The sun and the moon . . . . . . . . . . . . 207

7. The sun casts down its skin . . . . . . . . . . . 210

8. The mother of Bakui . . . . . . . . . . . . . . . 214

9. The journey of Ujndöm . . . . . . . . . . . . . . 215

10. Aqamé . . . . . . . . . . . . . . . . . . 219

Ch. XIV. Life of Mankind . . . . . . . . . . . . 220

1. The journey of Ajré, the entry of the stone axe . . . . . 220

2. Ujnaki, the good husband and the bad husband . . . . 224

3. Taémenu, a woman in search of a husband . . . . . . 227

4. Jaqandi, the discovery of the real woman . . . . . . 229

5. Jaboq and Timon, the first fight . . . . . . . . . . . 231

6. Janggeron and Daw, the deceiver is deceived . . . . . 233

7. Joqoj, the punishment of a murderer . . . . . . . . 235

8. Makubonök and Ndumènd, theft revenged . . . . . . 237

Ch. XV. Spirits and Shades . . . . . . . . . . . . 239

1. Rakao, the spirits win . . . . . . . . . . . . 239

2. Awaq, the jaqar loses . . . . . . . . . . . . . 240 
3. The jaqar . . . . . . . . . . . . . . . . 242

4. Mioqop and the aburit . . . . . . . . . . . . 243

5. The aburit . . . . . . . . . . . . . . . . . . 243

6. Okomit and the shades . . . . . . . . . . . . 245

7. The shades and the boys . . . . . . . . . . . . 247

8. Shades appearing as birds . . . . . . . . . . . 248

9. Ujoqot, the falling star . . . . . . . . . . . . . . . 249

\section{PART V. OPINIONS AND ATTITUDES}

Ch. XVI. Power and Spirits, Beliefs and Practices . . . . . 252

1. Power and spirits . . . . . . . . . . . . . . 252

2. Beliefs and practices . . . . . . . . . . . . . 257

Ch. XVII. Concluding Remarks . . . . . . . . . . 267

1. Akiaq-wir, counsellors . . . . . . . . . . . . 267

2. Poqoj-wir, war-leaders . . . . . . . . . . . . 270

3. Joqbera-wir, seers . . . . . . . . . . . . . . 271

4. Sun and moon . . . . . . . . . . . . . . . 272

Notes . . . . . . . . . . . . . . . . . . . 274

Appendices

I. Division of work . . . . . . . . . . . . . 286

II. Names of the groups . . . . . . . . . . . . 288

III. Bakui - in-wu . . . . . . . . . . . . . . 292

IV. Recurrent Jaqaj terms . . . . . . . . . . . 294

Illustrations and Maps 


\section{LIST OF MAPS}

1. The Jaqaj Area.

2. Area of Képi.

3. The Fights of Képi.

4. The Raid on Togompatu.

5. The Journey of Ajré. 


\section{FOREWORD}

The author of the present book, Dr. Jan Boelaars, is a missionary who, from 1951 to 1968, worked in the southern lowlands of the island of New Guinea, in the part now called Irian Jaya. In this area his Congregation, the Missionaries of the Sacred Heart, had been active since 1905, gradually extending its work from the Marind-anim coast first to the Merauke hinterland, later to the Digul district and the Mimika coast. During the war all activities north and west of the Digul river had to be suspended. After the war they were resumed. For the Mission's work among the Jaqaj of the Mappi district this implied that the missionaries had to start all over again. Pre-war contacts had been fairly superficial here. The Government had scarcely begun to bring the area under control when the Pacific war started, which, to the Jaqaj, presented a welcome opportunity to renew the head-hunting practices for which they had always been notorious.

Law and order had hardly been restored when, in 1951, Boelaars arrived in the area. He had been trained in anthropology and linguistics, and it was decided that he should be charged with anthropological research in the area. The New Guinea Government, which was as anxious as the Mission to become better informed about the unruly Jaqaj, subsidized the work for a number of years. Unfortunately, Boelaars was not completely exempted from pastoral duties, and this combination of tasks hampered the speedy progress of his studies. Nevertheless, in 1956 he was able to return to The Netherlands to write his report, which appeared in printed form in 1958. The book had definite merits, but was not the all-round ethnography which had been hoped for.

In the meantime Boelaars returned to the Mappi district as a missionary. Here he stayed until 1960, when he went to Merauke. After a second furlough he was stationed in the Digul district, where he did research among the Mandobo, a tribe settled in the territory between the Digul and the lower Kao rivers. His contributions to their ethnography appeared in 1970 (Mandobo's tussen de Digoel en de Kao, Assen: Van Gorcum). Yet, he could not forget the Jaqaj. His 
experiences among them during his second stay had persuaded him of the desirability of a more adequate description, a view which he found confirmed when, in 1967 and 1968, he passed another year among the now Christianized Jaqaj.

Back in The Netherlands, he wrote the first draft of the book being published here. However, it was a long time before the final stages were reached. One factor responsible for the delay was the fact that he had to return to his regular work, now as a staff member of various colleges for the training of priests in Indonesia. Another delaying factor was the translation of the text into English. We need not dwell on all this. All that matters is that, through the years, Boelaars persevered, finally to enrich anthropological science with a wealth of valuable data on the social and religious life of a highly interesting people, and with a vast and really unique body of information on their warlike past.

This does not imply that Boelaars' description is adequate in every respect. It has certain weaknesses, some of them due to the fact that the author, in spite of his training, has never developed into the allround methodologist who is keen on answering in advance the questions provoked by his findings. None the less, we must not blame him too much for this. It is by no means certain that a more methodical worker would have been more successful in writing this book than Boelaars. The combination of fieldwork with pastoral duties during a period of, initially at least, rather compulsory adaptation to new norms of behaviour - the hand of the mission teacher often pressed heavily upon the villagers - must have been anything but conducive to that free exchange of information which is the basic condition for anthropological research. Bearing this in mind (I have witnessed occasionally some symptoms of the tyrannical behaviour of these village teachers myself), it is actually amazing that the author has managed to collect such widely varied information on numerous topics which, from a native point of view, it must have been highly unattractive to discuss. In spite of these serious handicaps, Boelaars has managed to open up a new world to us, a world disturbed by astounding acts of everrecurring violence, and yet also a world which had a place for more humane feelings and virtues. He has succeeded in letting people talk about themselves. Even in translation the style of their stories often testifies to their authenticity.

In addition, the book fills a gap, or, to be more precise, it makes us aware of a gap. The Trans-Digul area is, to an important extent, a white 
zone on the ethnographic map of New Guinea. We are well informed on the Mimika, fairly well on 'Frederik Hendrik Island', and, thanks to Boelaars, on the Jaqaj. But we know fairly little of the Asmat, next to nothing of the people dwelling along the Casuarine Coast, and (what is the worst of it) of the numerous Awju tribes in the interior. The gap is decidedly lamentable, because the available information testifies that we have here a type of social organization which differs markedly from that prevailing in the central mountains and the lowlands east and south of the Digul river, which - if Strait Marianne is considered as a branch of the Digul - figures as a kind of dividing-line between the patrilineally organized tribes of the eastern lowlands, and those of the Trans-Digul area organized in ambilateral, non-unilineal, territorial groups. A really amazing fact is that the Jaqaj also have this TransDigul type of organization, whereas linguistically they are closely akin to the strictly patrilineal Marind-anim and Boadzi. Besides, they may be presumed to have originated - like the Marind - from the southern foot-hills of the central mountains. What has happened for them to have adopted such a different type of social organization, and for their mythology to differ so widely from that of the Marind, while at the same time they have persisted, like the Marind-anim, in institutionalized homosexuality? Questions like these are unanswerable as long as we remain utterly uninformed about the cultures of the Awju and other tribes of the area. Here lies an inviting field of investigation for the proponents of urgent anthropology.

There is every reason, then, to thank the Royal Institute of Linguistics and Anthropology (Koninklijk Instituut voor Taal-, Land- en Volkenkunde) for its preparedness to publish the present text in its Verhandelingen series. This text constitutes an important contribution to our knowledge, and will no doubt provide a strong stimulus for further research in this isolated area, which still holds many secrets which, disclosed, promise a better understanding of the perplexing diversity of cultures that is characteristic of this part of the Papuan lowlands. There is not a second area in the world where cultural diversity has assumed such extreme proportions as exactly here. The opportunity for research is still there. But time is short. The wind of change is blowing everywhere.

J. van Baal emeritus professor of anthropology 
J.H.M.C. Boelaars - 978-90-04-28723-5 Downloaded from Brill.come4/26/2023 01:45:47PM via free access 


\section{INTRODUCTION}

North of the continent of Australia lies the second largest island in the world, usually called New Guinea. The western part of it belongs to Indonesia and is nowadays called Irian Jaya. It is divided into a northern and a southern half by a large range of mountains. The southern part consists of a vast lowland through which two large rivers, the Digul and the Islands River flow. They descend from the mountains in the north to empty themselves into the Arafura Sea.

Between these two large rivers many other rivers are found which originate in the swamps and also find their way to the Arafura Sea. The names of these major swamp rivers are the Asuwé, the Pasuwé, the Qondu and the Mappi. It is the river Mappi in which we are interested here, because all along the tributaries on the right-hand side are the settlements of the tribe which is the subject of this book. Today this tribe calls itself Jaqaj (pronounced Ya'hry). This name was first heard in 1937 by Father C. Meuwese, m.s.c., as it was used by the neighbouring tribe, the Awju, when they spoke about their arch-enemies on the river Mappi. Jaqaj was not, however, a name used by outsiders only. The members of the tribe themselves also used this name. During my research, the great war-leader Jaèndé, a native of the village of Képi, used the word when he spoke about the founders of the tribe (called Babaé). He opposed them to the sun (called tapaq), stating: "Babaé Jaqajre, Tapaq kandire", i.e. "the founders of the tribe are human beings, the sun stands apart". The fact that Jaèndé used the name of his tribe, Jaqaj, in this sense, shows that he understood it to mean "human being".

The neighbouring tribes of the Jaqaj are as follows. East of the Jaqaj, a part of the just mentioned Awju people inhabit the left-hand side of the river Mappi. To the north of them, another group of the Awju people occupies the head-waters of the Asuwé, the Pasuwé, and the Qondu. To the west, the Qondu tribes close the circle around the Jaqaj. All these neighbouring tribes have been the objects of the head- 
hunting raids of the Jaqaj. Only one Jaqaj village is situated outside the Mappi area. It is the village of Jodom on the left-hand side of the Digul river near the junction of this river with the river Kawarga. The Jodom people had fairly frequent contacts with the inhabitants of the south coast, the so-called Marind-anim. ${ }^{1}$

The territory of the Jaqaj tribe has been described by the late Mr. A. Perk as follows: "Numerous rivers intersect the scenery and during the rainy monsoon the rivers regularly overflow their banks and often flood large areas for several months. These flooded areas are large, especially in the northern district, but gradually decrease towards the south. The part of the country above high-water level is characterized by low rolling hills; real valleys in the terrain are rare. Exact data about the climate are poor, but oral information confirms our personal experience that there are not any lengthy, strongly marked dry seasons. There are periods of dry weather but even then there will be spells of rain from time to time. ${ }^{2}$ The soil is, generally speaking, either sand or loam. The fertility of the soil in the north is, generally speaking, inferior to that in the south. This can be gathered from the natural vegetation, which in the north consists of fairly sparse and thin-stemmed low wood, while towards the south trees are larger in diameter. The fertility of the soil in the north can be described as moderate to poor and in the south as moderately productive. The greater part of the country consists of lowland rain forests and nearly everywhere the upper layers of the soil consist of humus. The thickness of these layers varies very much and depends on the density of the jungle. The impression is that the mineral reserves of the soil are rather poor, especially in the north. Although there is a large variety of wood, valuable types are found only sporadically." ${ }^{3}$

The first impression the tribesmen made on an outsider has been formulated by the physician Dr. Harahap, who took part in an expedition to the Mappi territory in 1933. He writes in his report: "The next day we went up the river Mappi and towards seven o'clock in the morning we arrived at a Mappi settlement. Here the people did not run away (like they had done on the Digul). We clearly saw how all the women and children were sent into the forest, while the men (some four hundred in number) armed with bows, arrows and spears calmly awaited our arrival. Looking at the scenery from the river, a stranger could hardly guess the presence of a settlement, for everywhere there were dense jungle and bushes. The natives awaited us standing on the banks in their little canoes. When we drew near 
to the opening in the brushwood, cut out as a kind of 'city gate', the natives posted themselves under cover in the wood. The whole terrain consists of dense forest with high trees. Here and there parts have been cleared in order to provide space for the barrack-like houses which are some forty yards long and some six to eight yards wide. All the houses are in remarkably good condition. The people are of average height, while the build of their bodies betrays exceptional strength and toughness. The whole appearance of the Mappi radiates strength, courage and blood-thirstiness. Everybody walks about stark naked. Bodily ornaments are very sober." ${ }^{4}$ Technical data concerning the physical appearance of the Jaqaj are not available. To a layman in physical anthropology their stature is neither tall nor short. Their skin is a chocolate brown, the hair is crisp, and the broad-winged nose has a deep base. The lips are not too thick and there is some prognathism. Among the adults the lean angular type dominates. In 1956 the total Jaqaj population was 8,742, according to a survey made by the physician W. Bakker, who conducted an anti-framboesia campaign among the Jaqaj from May until October of that year. ${ }^{5}$

Data about the origin of the Jaqaj tribe are scarce. The Jaqaj themselves tell a detailed story about a journey made by one of their ancestors, Ajré, which may refer to the origin of these people. ${ }^{6}$ The story relates how Ajré came rowing down the Kawa (= Kao, a northeastern tributary of the Digul), crossed the river Edera, arrived at Joda (= Jodom) and from there visited the rivers in what is now the Jaqaj territory. The way this myth speaks about these rivers shows clearly that they are the rivers as they exist today. Ajre provided the people with stone axes, roofing made from leaves, the canoe, and the canoes on trestles in which the great warriors were laid in state after their death. Ajré also instructed the people of this country in head-hunting and taught them how to celebrate the festivities following a headhunting raid. It is possible that this story contains some traces of the historical origin of this tribe. If it describes a historical journey, the Jaqaj must have come from the north and taken the country where they now live by forth from the people who inhabited it before them. There are several pieces of evidence which might prove that this supposition is correct. In various settlements (Monana, Mur, Moïn and Rèp) there are coconut trees which are said to have been planted by the Awju. A man of the Wajpaqari group at Masin said that in former times the Awju used to live on the Miwāmön river, but that they retreated from there after exchanging children with the new 
inhabitants, the Jaqaj. Thirdly, there is a story which says that the Awju of the Nambéomön district fled to the other side of the river Kawarga. Father J. Verschueren, m.s.c., held the opinion that the Jaqaj invaded the Awju country and that the two tribes first lived together in a kind of "symbiosis" in the period following the invasion. According to this theory the Awju were either massacred or driven away by the Jaqaj at a later date.

It was not until the beginning of the twentieth century that the government of the Netherlands East Indies started with what is called "the pacification" of the outlying district of New Guinea (Irian Jaya). One of the first tasks of the Dutch government was to put a stop to the head-hunting raids of the Marind-anim who went hunting for heads far beyond the border between the Dutch and the British administrations in New Guinea. The Marind also penetrated the territories of the tribes across the Digul. Once the strict measures of the pacification program forced the Marind to stay in their villages on the south coast, the Jaqaj, who lived further inland, were able to extend their own raiding territory towards the south and the east. They even became an increasing threat to the regions on the south bank of the river Digul, which had already been brought under government control.

In 1936 the so-called "Mappi Post" was built on the hill Tamao near the outlet of the river Mappi into the Digul. Military personnel were garrisoned there. The people of the Mappi district soon became aware of the trading possibilities with the coastal areas which were in close contact with western civilization. Their desire for iron-ware was so strong that they sold their own children to the Marind at Okaba on the coast. There were regular contacts between the two tribes and it could not escape the attention of the Papuans that the presence of Dutch government officials had brought a certain amount of peace and security to the area south of the Digul river. This was an element which attracted the Papuans who lived in the interior. Several groups of people who felt threatened in their own territories moved and settled in the area which was under the control of the government. This migration caused much unrest in the areas "invaded". Repeatedly, police patrols were ordered to chase the invading Mappi back to their own country. There were quite a number of skirmishes on the Digul, but their purpose of frightening the Mappi people and making them stay away was not achieved.

Dutch missionaries of the Sacred Heart (m.s.c. = missionarii sacratissimi cordis [Jesu]) had been working on the south coast for about 
thirty years and from their coastal footholds they extended their tours of duty into the unknown parts of the island. Early in the 1930's Father W. Thieman discovered various Mappi settlements on the Digul river, and soon managed to post native teachers (from the Moluccas) in these settlements. In 1936 Father J. Grent and Father P. Rievers entered the Mappi area to explore the territory and its people. In the course of the same year the Catholic mission, aided by the government, opened three schools at Korombuag, Ragagai and Refadup (Jatan). The first attempts at penetrating into the area had been made, but a difficult future awaited both the government and the mission. They had their centres at Tanahmerah, a place situated high up the Digul river. The officials of the government were supervised by an AssistantResident who had his head-quarters at Tual (Kei Islands, South Moluccas). The missionaries were in similar circumstances. Their bishop also resided in the Kei Islands. The southern part of New Guinea was an outpost for both the government and the mission.

In 1937 Father C. Meuwese, m.s.c., parish priest at Tanahmerah, began regular journeys to the Mappi territory two or three times a year. He either travelled by the government steamer's regular service between Tual and New Guinea, or he sailed in his own motor-boat Paulus. Whenever his motor-launch broke down, Meuwese had to use the native means of transport, the canoe. When he ventured from the Mappi post into the interior he had to depend on native oarsmen. This affected both the speed of his travels and often even his destination. The natives showed little willingness to visit enemy settlements whose names the priest knew but not their exact location. In the first period of Meuwese's travels they "happened to lose their way" or denied that settlements with such names actually existed. The rowers often gave misleading information about the distance, or they refused to take the missionary to the more distant settlements under the pretext that the people were bad and dangerous. Once they accompanied him in great numbers, hundreds of them, but upon arrival at the settlement ransacked the place. For the missionary this was a very unpleasant surprise which provided a bad introduction to these Mappi people.

In order to enable missionaries to work among the people on the Mappi, a study was made of the languages of the tribes living in this area. In 1949 the linguistic expert from the mission, Father P. Drabbe, m.s.c., came to the Mappi territory. He collected his findings in a grammar, ${ }^{7}$ which also contains a list of some four hundred words. Drabbe found that the language of the Jaqaj tribe belongs to a larger 
group of languages which includes those of the Marind and Boazi tribes, and can be distinguished from all other languages spoken in southwestern Irian by a prefixal conjugation of the process word. ${ }^{8}$ In his analysis of the language he stated that there are two dialects: "The first is spoken near the rivers Oba and Miwāmön; the second near the Nambéomön, the Mābur and the Bapaé. The differences in conjugation are slight; the differences in vocabulary are rather great." 9 The Jaqaj were able to understand one another's dialects. The people living in the northern part of the Mappi district also differed in character from the southern Jaqaj. The people in the south were less bold, less self-contained, and less conservative than the people in the north. In the past, both the northern and southern groups used to exchange children and adopt them. As for the rest there were no direct links between them.

From the first moment that the Dutch army and the missionaries entered their country, the Jaqaj were suspicious of change and very reluctant to adapt themselves. This animosity showed up especially in their behaviour towards the teachers who were posted by the mission in the Jaqaj settlements. It is not surprising that the Jaqaj were reluctant to part with their traditions and that they hesitated to place their confidence in strangers. The Jaqaj saw the teacher as a stranger who had forced himself upon them and had taken away their own authority in the settlement. The first teachers, in turn, could not be blamed for failing to see that these people possessed an acceptable system of ethics, because day after day they were confronted with examples of a cultural ideal which to them were an abomination of all civilization. The government usually sided with the teachers. The teacher was assumed to be right and the difficulties arising from his measures could only be imputed to the "ignorance" and "unwillingness" of the Jaqaj. In these early days of contact the Dutch officers and the missionaries did not appreciate the fighting spirit of this tribe, which included and was supported by a whole system of regulations protecting their mores. The fight against head-hunting was foremost in the minds of the government officials. After the war Mr. R. den Haan, head of the local government at Tanahmerah and the district officer of the Mappi territory, sought the cooperation of the mission. $\mathrm{He}$ and Father C. Meuwese made a number of arrangements which were put on record in a note. The note clearly states that measures should be directed against the various customs that encouraged or promoted head-hunting. The memorandum mentions explicitly the 
wedding-feast (during the course of which a head was hung from the arm of the bride), mourning garb (which could be cut off only by a man who had captured a head), and peace ceremonies (which could not be held unless both sides had seized an equal number of heads). The note also deals with the fight against pederasty, burial above the ground, child marriages and those cases in which physical force was used to make young and immature girls live with older men. The execution of the plan was postponed until the new government assistant, Mr. F. Maturbongs, arrived in the Jaqaj area. He implemented these measures with great ability and zeal.

I arrived just in time to witness the great peace festivities between the Jaqaj and their former enemies, the Awju, organized by Father J. Verschueren in July 1950. The feast was celebrated at Képi, chosen to become the main village of the Mappi subdivision. This event symbolized the end of an era. In a certain sense, therefore, it is true that I arrived on the scene when the "original culture" had ceased to function. I nevertheless feel justified in writing this text because the pristine culture had not yet become part of history. The social and economic life of the Jaqaj had been influenced by the abolition of head-hunting and their own free choice in decision making. Yet the culture remained intact as to its other components. The old headhunters were still alive and were valuable sources of information as well as loyal leaders of the Jaqaj during the period of contact and transition. Although the religious aspects of the old culture were changing due to the influence of the Catholic mission, there were at that time only a few converts to the Christian religion.

I collected the data for this book mainly during the years 1951-1957. Through the office of native affairs of the Dutch government I received financial assistance which resulted in my earlier book, Papoea's aan de Mappi, published by De Fontein, Utrecht (1958). I spent another period among the Jaqaj from April 1958 until August 1960. From January until December of 1967 I was back again in the Jaqaj area.

My early work and research depended a great deal upon the work of my missionary colleagues and the Dutch government officials who had opened the area. As mentioned above, the linguistic work of Fr P. Drabbe was very useful. Father C. Meuwese was the first missionary in the area since 1937. His journal notes were a great help in reconstructing a more accurate picture of the original culture. From 1951 until 1953 Father J. Verschueren aided me in my work. He not only gave me his "Mappi Memories" but drew my attention to many 
data which, through further research, became detailed enough to provide much material for this book. To these three great missionaries I owe a personal debt of gratitude. During the time of my research Mr. F. Maturbongs was district chief of the Jaqaj-Awju regions. $\mathrm{He}$ really deserves the title which the people have given him: "Father of the Jaqaj". He gave me a copy of his own report on head-hunting practices which dates from the first years of his work among the people during World War II. Because of his personal integrity and his intimate knowledge of the pre-contact situation I quote him in this text as one of my most reliable sources.

Another source of valuable information were the first teachers who came to the Jaqaj from the Moluccas in 1940. Father C. Meuwese gave them a questionnaire concerning their early experiences and their extensive replies are now kept in the Catholic mission archives at Képi. Foremost among these teachers were S. Jamco, H. Kelanit, B. Rumlus, H. Jamlean, S. Effroan and P. Kadmaerubun. I also personally interviewed H. Kelanit, P. Kadmaerubun and S. Rumlus after I had read their replies to Meuwese's questionnaire.

My fieldwork was concentrated on the villages of Képi and Dagimon on the Oba river. In Képi I worked out a five-generation genealogy of all the families. Wherever possible I also drew into my research the other Jaqaj communities on the other tributary rivers. With the aid of Father Drabbe's linguistic studies I was able to learn the Jaqaj language sufficiently well for conversation purposes and was able to record their information while they were interviewed.

When I first arrived in Képi a young man, Jabajmu, ${ }^{10}$ became my interpreter. His family relations were valuable. He was the son of the village counsellor of Képi, Tambim, and his mother's brother was Jabaqaj, a leader of one of the village moieties. His sister was the wife of the war-leader Jaèndé. He himself had married the daughter of Jaro. Jaro and Jaèndé were the leaders of the other moiety in Képi. With Jabajmu's assistance I recorded some life histories and other information which will be referred to throughout this text. The main accounts are: the life history of Jaèndé, war-leader of Képi; the life history of Jacobus Jabajmu, my interpreter; the age ceremony as related by Jaèndé; the account of the war between Képi and Togom as reported by Jaèndé; advice given by village counsellors; 42 war songs dictated by Japomené of Képi; 27 mourning songs dictated by the woman Ndaman of Képi; and stories and myths of Képi, Moïn, Dagimon and the Nambéomön area. 
I tape-recorded the songs and had them analysed by the late Dr. J. Kunst, the famous musicologist at the Tropical Institute in Amsterdam.

In 1953 Mr. F. Capetti became assistant district officer of the Mappi area. During the three years of his administration we discussed every aspect of the Jaqaj's daily life as well as the policies of both the government and the Catholic mission relative to the Jaqaj people and their education. I owe a great deal to these discussions. Much later, in 1967, I had the good fortune of getting Jaro's account of Jaqaj warfare and their celebrations after the raids. Jaro was Képi's leading head-hunter. At that time he was approximately sixty years old. His son-in-law, Maqaomi, who assisted Jaro in telling the story, was about forty years old and had witnessed the last years of the pre-contact situation.

During my travels into the Bapaé district (1967) I was accompanied by the former teacher P. Kadmaerubun. He had worked in the Nambéōmön and Bapaé districts since the pacification. His personal relationship with the village leaders and the people provided me with excellent introduction and liberal access to their information. Notes and songs gathered in these areas helped me to check information gathered in the Képi area. To the Jaqaj leaders and all the Jaqaj people I owe a debt of gratitude since this book records their information.

Finally, I must add some remarks about orthography and terminology. In my spelling I follow Father Drabbe. It is an orthography adapted for use by teachers and missionaries rather than the more detailed exigencies of the linguist. Fr Drabbe confined his spelling to the characters of a standard typewriter. He used the letter $Q$ to indicate a strongly retracted velar stop combined with a scraping sound. The word Jaqaj must be pronounced YA'HRY (end $y$ as in "by"). Often the $\mathrm{Q}$ sound is not heard. The name of the Odamun river is actually pronounced Qodaqamoqon. It is helpful to remember the following:

a - all variations between the a in French "avoir" and English "task";

$\bar{a}$ - the same vowel but noticeably lengthened;

é - all variations between English "pit" and French "thé";

è - all variations between English "there" and "bed";

e - all variations between the two vowels of English "mother";

i - the sound of the French "si" or English "sea"; 
- - all variations between the o in English "November" and "not";

ö - all variations between the French "peur" and English "perfect";

u - all variations between English "mood" and "put";

$\mathrm{g}$ - initial sound of English "get";

j - initial sound of English "yes";

ng - final sound of English "king"; and

$t$ - sound between stop and fricative.

Further clarification should also be made concerning the use of technical terms in this book. The word "village" is used only to indicate territorial clusters of houses formed since the period of pacification. For this reason the word "settlement" is most frequently used and indicates the largest group of houses in the pre-contact period. Each group of people in such a settlement could also have its own bivouac in the neighbourhood. In either case, however, there were separate houses for men and women, the sexes living strictly separately. In the post-contact era these communal houses were replaced by family dwellings in villages. I use the term "village head" to denote the man in authority who is officially in charge of a village. I use the term "leader" to indicate those who occupied positions of authority in smaller groups in the pre- and post-contact periods. The word "swamp" indicates areas regularly flooded by tides and used as fishing-grounds. The word "marsh" describes the areas with sago groves.

I must apologize for not being able to give in this text all the scientific names of the plants and the animals which are mentioned in various contexts. I had no scientific material available. Accordingly, I use only descriptive terms and the usual Jaqaj names for both plants and animals.

The wedding-festivities following a head-hunting expedition are more like an official recognition of a marriage concluded much earlier by the bride's official presentation of sago to the groom. I distinguish, therefore, between the marriage ceremony and the wedding-feast.

When writing the text, I often found it particularly difficult to be consistent in the use of the present and past tenses. Part of the data presented here concern a way of living that belongs to the past by now, especially those connected with head-hunting practices, whereas other data refer to conditions of life that have not changed. Sometimes texts are translations of stories or statements of the Jaqaj themselves, and frequently they speak about past events in the historical present 
tense, simply because what happened then stood out clearly in their memory or because they themselves had played a part in them.

In order to avoid conflict and involvement in arguments concerning terminology for magic and religion, I have avoided the words "religion", "magic", "taboo", "rites" and "ritual”. I prefer terms such as "ceremony", "medicine" and "abstinence" with their more general meanings.

The map of the Jaqaj Area (Map 1) was originally drawn by the Patrol Officer K. H. Zevering. I adapted my spelling of local names to his (with the exception of Jaqaj instead of Jakaj). Rev. A. van Loon graciously prepared the other maps which are found in the book.

The photographs were chosen from the collection in the archives of the Missionaries of the Sacred Heart (M.S.C.) at Tilburg. 


\title{
PART I \\ SOCIAL FRAMEWORK
}

\author{
CHAPTER I \\ TERRITORIAL ORGANIZATION
}

\section{Territories}

In the introduction to this book I have mentioned two dialects in the Jaqaj language: one is spoken in the southern district of the Nambéōmön, Bapaé, and Mābur rivers, and the other in the northern district of the river Oba and its tributaries. The boundaries of these areas more or less coincide with those of administrative units initiated by the government. The villages in these districts ${ }^{1}$ have been mapped ${ }^{2}$ as situated along the rivers. They are combinations of earlier settlements of groups living in that area. Thus, for example, the groups now living together in the village of Jatan had landed properties on the river Nambéōmön but were spread over several settlements. The two districts can be subdivided into several territories.

The Jaqaj themselves distinguished between the territories of the Nambéōmön-wir, the Mābur-wir, and the Bapaé-wir in the southern district and the Ribu-wir, the Oba-wir and the Miwāmön-wir in the northern district. The word wir means people, i.e. people living on the rivers of that name. These territories are further subdivided. Every river has two parts: upstream or enöm-muku, the head of the river, and downstream or enöm-amarao, the mouth of the river. In the northern district such a subdivision is clearly demonstrable for the rivers $\mathrm{Oba}$ and Miwāmön. On the river Oba they distinguish between the upper-course villages of Masin, Wajru, Kandajmu, Rajöm and Moïn and the lower-course villages of Képi, Toba, Waman and Dagimon. On the river Miwāmön a similar distinction is made between 
the upper-course villages of Kadöm and Wanggaté and the lower-course villages of Rèp, Enèm and Kogo. In the southern district the upper course of the river Nambéomön belongs to the villages of Katan and Jatan and the lower course to the villages of Mandaw and Mur. Mur used to be called Ragagai and was situated down-stream, south of Mandaw. On the river Bapaé we find, on the one hand, the villages of Hāgam, Gogojāmön and Ima, and on the other hand one village, Koba. On the river Mābur there is only one village, Monana. The little village of Kapagojnd was originally situated between the rivers Mābur and Bapaé. After the pacification the inhabitants of Kapagojnd first joined the people of the village of Monana, and later those of Koba.

These sub-divisions were split up into areas belonging to a number of settlement groups. The boundaries of these areas sometimes had strategic functions. They were often the sally-ports for common raids or the most vulnerable spots to attack. When the people of the present village of Mur were still living at Ragagai, they had built a number of bivouacs on the west bank of the river Mābur. These bivouacs were a zone of defence against the attacks of the groups who later settled at Monana. The boundaries of these areas have not always been the same because the groups who once communally owned a certain area did not necessarily remain faithful to each other. A population survey of the existing villages could, therefore, be misleading. The pre-government situation was rather different. For example, the groups who now live in the village of Togom on the river Emete used to live on the river Poré. From there they made conquests and captured plots of land along the river Emeté from the groups who now live in the village of Emeté. In a later discussion of the formation and disintegration of groups it will become clear that property rights could either be transferred to those who stayed or remain with those who departed. It also happened that whole groups of people were massacred by neighbouring groups, who then divided the property among themselves.

It is wrong to assume that each group owned only a certain corner of an area. Within an area a group could assert its rights to several plots of land found in more than one place. This led to the possibility of mobility within the same area. Sometimes several other groups moved together, if their various properties happened to be in the same neighbourhood. The map of the area of Képi ${ }^{3}$ distinguishes three places within the area where one or more groups of this village owned part of the land. When they were at war with the settlements on the 
river Miwāmön, the groups of Képi used to live on the land south of the present village site. When they were in conflict with the people of the present-day villages of Togom and Moïn, they lived north of their present-day village on the river Nanggéao, which is a tributary of the river Emeté. In these different places each group of Képi occupied its own property.

The situation before the pacification must have been as follows: the settlements, buaq, were not always in the same places and the same groups did not always stay together. Groups were always on the move. They moved from one corner of their area to another or even crossed boundaries, an act which often led to changes in the alliance of the groups living in that particular area. Sometimes a group gave part of its own property (or certain usefruct rights) to war-leaders with whom it wished to stay on friendly terms. Sometimes a group that had been weakened asked to be admitted into a stronger group, simply for the sake of survival. As a result of this the stronger group became a co-user of the land of the weaker group. This alliance meant that the stronger group took upon itself the defence of the land belonging to its weaker partner. In the past the dynamic element prevailed and it is only recently that government influence has succeeded in stabilizing both village sites and area ownership.

\section{2. $\operatorname{Imu}$}

As far as the present village groups are concerned, I know of three lists ${ }^{4}$ which record all groups and one list which is restricted to the groups found in a small number of villages. A survey of the three lists shows that sometimes a group took its name from a place or a river, e.g. the Kunda-wir or Kunda people, but that the majority of the group-names end in either èmu or imu. The word èmu was translated by Drabbe in his grammar as: his, her, their grandfather (grandmother, grandchild). ${ }^{5}$ The group-name of the Aqaoèmu, one of the groups living in the village of Képi, could therefore be translated as "Aqao-hisgrandchildren", or as "Aqao-their-grandfather". The name says that the members of this group had Aqao as their grandfather. The people themselves, however, failed to see that the word could be split up in this way.

In the example just mentioned the word aqao in Aqaoèmu could also mean: land tortoise. It is obvious, however, that our thoughts should go to the name of an ancestor, even in those cases where the 
original meaning of these ancestor names has been lost. An argument in favour of this view is found in a parallel case, viz., the term qari, ${ }^{\mathbf{6}}$ used to indicate the sub-divisions of the imu. Thus there is at Képi a Tambim qari within the Kamaqa imu. This qari is named after the man Tambim, who was still alive at the time of this survey of the population.

Until now I have spoken about "territories" and "areas" and have pointed out that they were occupied by groups who lived together in more or less stable units. From now on I shall call these groups imu. These imu are made up of sub-groups called qari. Such qari associated to form an imu because of kinship, or because of intermarriage, or because of the fact that they shared common boundaries. The process of integration among sub-groups of an imu could be in a more or a less advanced stage. Later on we will see that the degree of integration had an impact on the use of certain kinship terms. ${ }^{7}$ The formation of an imu can be illustrated by describing the historical process of the origin of the four groups of the village of Képi, as reported by the informants Jaèndé, the leader of the Ikimu, and Maqaomi, the village head of Képi.

Képi did not always exist as an independent settlement. Further down the river two groups lived together at the present site of the village of Toba. These two groups were the Qabunimu and the Qajimu. Bakui, a man of the Qabunimu, came to the area around the place now called Képi. He inspected the fishing-grounds, the water plants and the opportunities for planting coconut trees and bananas. He spent the night there and returned to Toba. He told his elder brother that he intended to settle at Képi. Thus a small group separated from the Qabunimu of Toba. When they settled at Képi, they first called themselves Qajbeqojmu and later Ikimu. This Ikimu group gradually developed into an imu in which three sub-groups could be distinguished: the Temaqajrimu, het Wanggajmu and the Qobönbania. At the time of my investigations these three sub-groups formed a unit under the leadership of Jaèndé. The sub-division was accounted for by the fact that the Wanggajmu remembered that they all descended from a woman belonging to one of the groups which later formed the village of Moïn. Similarly, the Qobönbania were the descendants of a woman who, like Bakui, had also left the Qabunimu group of Toba and had moved to Képi.

Yet another group broke away from the same Qabunimu of Toba and moved to the area of Dagimon. From this Dagimon group some 
men moved to Képi and settled there as a separate unit alongside the members of the Qabunimu who had left Toba. This whole group later adopted the name Marapèmu. The Marapèmu then split up into the Oab qari and the Kemaqaj qari. Thus both the Ikimu and the Marapèmu descended from the Qabunimu of Toba.

Some men from the other group that lived at Toba, the Qajimu, also separated and settled at Képi, calling themselves Aqaoèmu. These Aqaoèmu were later divided into two parts, each with its own leader. One part called itself the Métar qari, after its leader, Métar. The other section, under the leadership of Moqojd, did not adopt the name of its leader, but called itself Bapajmu and later settled in what is now the village of Emeté. Within the Aqaoèmu further segmentation took place. The Métar qari, the Qodé qari and the Toqoné qari formed separate units. The Qodé qari later joined the Eré qari who came to Képi from Emeté, while the Toqoné qari split up again into two parts. One half kept the name of Toqoné qari but separated from the Aqaoèmu and joined the Ikimu. The other half, calling itself the Ndapé qari, also separated from the Aqaoèmu. They joined a new grouping which by now had also separated from the Aqaoèmu and adopted the name Kamaqajmu. These Kamaqajmu split into the Qow qari and the Mujpön qari. The Ndapé qari joined the Qow qari. They were later joined by the Tambim qari who had come from the village of Emeté.

The history of the groups can be summarized as follows:

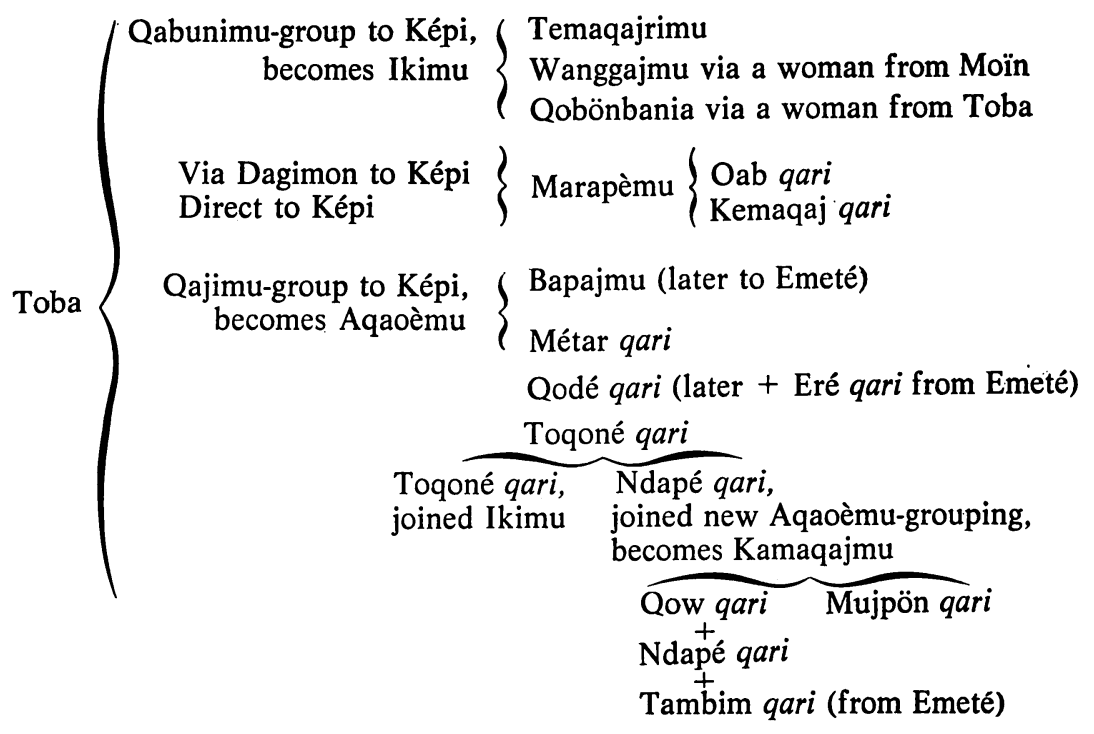




\section{Sub-groups: qari}

The origin of the various imu and qari had an impact on marriage prohibitions and relationships with neighbouring villages:

a) Jaèndé would not give his permission for marriages between the Ikimu and the Marapèmu, in spite of protests by the younger generation. His refusal was based on the fact that both groups descended from the Qabunimu of Toba.

b) The Wanggajmu, because of their descent from a woman of Moin, were in closer contact with the inhabitants of Moïn.

c) Via the Tambim qari the Kamaqajmu maintained more special relations with the village of Emeté.

d) The Aqaoèmu leader, Jaro, had special authority over the land which had been added to the communal property of the Eré qari because it had been derived from the qari which he himself belonged to; his influence was less where other lands (for example those of the Métar group) were concerned.

The various ways in which groups originated make it difficult to determine exactly where the distinction between the imu and the qari lies. The sub-divisions of the Ikimu call themselves $i m u$, whereas the sub-divisions of the Aqaoèmu call themselves qari. Similarly it is hard to determine how large a qari really is. The Mujpön qari of the Kamaqajmu counted thirteen fathers of families. At the same time the Tambim qari embraced only those who descended from Tambim's own household. Kinship seems to be the key to understanding the constitution of a qari. Kinship, the relationship by blood, is expressed by the words kab daqandamön, blood-one-with, or by the term bor, relative. In blood relationship the Jaqaj distinguish the line of the generations and therefore speak of one's family tree, wir-dé, or literally "men-tree". Furthermore, they distinguish in a wir-dé whether the descent is via one's father, the wir-bor, or via one's mother, the taj-bor. This bilaterality leads to a differentiation between the é-qari, a grouping via one's father, and of a wu-qari, a grouping via one's mother. Even as a child, each person can choose whether to join his or her father and his people or feel more at home with the relatives of his or her mother.

Marriage is one of the decisive moments: then a choice must be made between the é-qari and the wu-qari. But even this choice is not definitive. It is possible to follow one's father's people for some time but then join the relatives of one's mother, or vice versa. In addition to these two possibilities, the Jaqaj may make still another choice: 
he need not follow either his father or his mother, but may join the father or mother of his spouse. This means that he joins the group chosen by his spouse. By way of exception, it is even possible to make a choice in favour of the group of a friend or a neighbour who are neither consanguineals nor affines but with whom one is very friendly or in close contact (e.g., because their property lies side by side or because a head-hunting raid has brought about partnership).

Consequently the qari has nuclear members and new-comers (those who are not related by blood or affinity). The choice either for the father's group or for the mother's group, or for a third possibility, means that a person also accepts the rights and duties of a member of that particular qari. The result of the choice made by the individual always includes the use of certain plots of land. A person either lives on the land of his father or on the land which belongs to his mother, or on that which is owned by his spouse, and so on. This does not mean that there are no other considerations involved in joining a certain qari. When discussing education, it will become clear that both the father's people and the mother's people do everything they can to influence the child in his eventual choice and try to make him opt for the qari they themselves belong to. Sympathy and antipathy, and actual situations and events play their parts in the final outcome.

The genealogies of the qari of Képi inform us as to how and why the members made their choices. The results of this inquiry can be summarized in a diagram. At the left side are the names of the qari with their sub-sections. After each name are the numbers of the men and the women who follow their fathers or their mothers, their husbands or their wives. Only married individuals are included because, as already mentioned, at marriage the qari choice becomes more or less definitive. Marriage as such, however, does not alter the choice made before. Each of the partners keeps to his preference. The partner acquires a secondary right (accompanying his or her wife or husband) to the property of the other. Only in cases in which an individual does not follow either his father or mother but sides with his spouse, does he or she no longer make use of the property of one of his own parents but goes instead to the property belonging to the group chosen by his spouse.

We see that out of 236 individuals 140 , or about $2 / 3$, followed their fathers, and about $1 / 3$ followed their mothers. It seems that following the father is the rule. This is confirmed by the reasons given to explain those cases in which the mother was followed. Among these 87 cases 
there were 7 cases in which the father had died early and the children had returned with their mother to the latter's relatives. In 40 cases the father had moved to Képi. Therefore, his own property was elsewhere and was taken care of by his original qari. Although his children were allowed to gather food on these lands belonging to their father, they still lived at Képi and stayed within their mother's group. In 16 cases the sago groves of the mother needed the defence and management of the eldest son, because her own brothers did not have any sons of their own. In those cases the daughters also followed their mother. In 4 cases the group of the father had ceased to exist. The members had then chosen to follow the group of their mother. In 18 cases the group of the father had such a great number of members that a livelihood was much better guaranteed if the children followed the group of their mother. In 2 cases dissensions within the group of the father had made the children decide to look for support with the group of their mother.

\begin{tabular}{|c|c|c|c|c|c|c|c|c|}
\hline & & \multicolumn{2}{|c|}{ Father } & \multicolumn{2}{|c|}{ Mother } & \multirow{2}{*}{$\frac{\text { Husband }}{\text { female }}$} & \multirow{2}{*}{$\frac{\text { Wife }}{\text { male }}$} & \multirow[b]{2}{*}{ sum total } \\
\hline & & male & female & male & female & & & \\
\hline \multirow[t]{3}{*}{ Aqaoèmu } & Métar & 13 & 14 & 6 & 8 & 4 & 1 & 46 \\
\hline & Qodé & 6 & 3 & 5 & - & 1 & - & 15 \\
\hline & Eré & 5 & 4 & - & - & - & - & 9 \\
\hline \multirow[t]{3}{*}{ Ikimu } & Temaqajr & 7 & 5 & 5 & - & - & - & 17 \\
\hline & Qobonbania & a 7 & 4 & 8 & 15 & - & - & 34 \\
\hline & Wangga & 9 & 10 & 3 & 2 & 1 & - & 25 \\
\hline \multirow[t]{2}{*}{ Kamaqajmu } & Qow & 11 & 12 & 4 & 3 & 一 & - & 30 \\
\hline & Mujpön & 4 & 11 & 7 & 9 & - & - & 31 \\
\hline Marapèmu & $\begin{array}{l}\text { Oab } \\
\text { Kemaqaj }\end{array}$ & 6 & 9 & 6 & 6 & - & 2 & 29 \\
\hline \multirow[t]{2}{*}{ Sum total } & & 68 & 72 & 44 & 43 & 6 & 3 & 236 \\
\hline & & \multicolumn{2}{|c|}{140} & \multicolumn{2}{|c|}{87} & & & \\
\hline
\end{tabular}

It is important to remember, however, that the choice of the qari in which one wishes to live and work does not imply that one loses the basic rights and duties in the group to which one is related by blood, 
but which has not been opted for. The fact that a choice need not be definitive is an element pointing in that direction. It would be impossible to choose another qari later on if there were no grounds on which this choice could be based. The choice of a certain qari does imply actual co-operation. By co-operating one expresses the wish to belong to that particular qari. If some day one no longer makes any use of the opportunities which are available in the qari that was not opted for, the rights for claiming the use of these opportunities weaken. If later on that person wishes to avail himself of the opportunities which are to be found in the qari not chosen, he will have to carve a place for himself, as it were, inside that qari. He will have to take special care to regain his basic rights in that group, which will be very difficult. The basis of the descent system is, therefore, the recognition of the blood relationship between a particular person and his father and mother. That the principle of affiliation to a qari is ambilateral in any generation implies that both parents are feasible for the affiliation (and even other people). The choice, however, is not a definitive one. Therefore, the system may be termed an optional descent-group system. ${ }^{8}$

A qari may embrace a great number of relatives and even many non-relatives. The Jaqaj felt that it was necessary to have a man to whom the leadership of the qari could be entrusted. This man could be either the eldest member of the group or the strongest. He must have the power to keep the qari together. In the same way an imu is made up of several qari and these qari can be mutually related by blood but are not necessarily so. The imu overarches everything and everybody. The imu is responsible for defending the rights of the several qari that belong to it.

It could happen that inside an imu the different qari fought among themselves, but as soon as they had to take a stand against another imu they formed a common unit. Similarly, inside a certain area several imu might be at war with each other, but they would become allies as soon as the rights of a particular imu were violated by an imu of another area. Consequently the imu also had to have a leader who was the leader of one of the constituting qari. Inside an imu the leaders of the qari formed an informal governing body. Similarly, the leaders of the various imu within an area were an informal governing body or council. When the Jaqaj spoke of a qari or imu leader, they said of him "he is there" (arép éarnaé). They also referred to him with terms like poqoj-radé or radé-poqoj (in the plural poqoj-wir or 
wir-poqoj) "big" man/men. The special functions of these leaders will be discussed below. ${ }^{\circ}$

\section{Landholding rights}

A member of a qari or imu identifies himself by using the name of that qari or $i m u^{10}$ and stands up for the communal rights and interests of its members. These interests are mainly the communal use of certain plots of land. The right of disposing of the ownership of the plots of land is in the hands of the wir-dé, the offspring of those who first occupied the land in question.

The Jaqaj still remember the names of those ancestors who first entered a certain area. These ancestors rank among the so-called babaé. These babae are believed to still live on the land they once occupied. This genealogical link between them and their offspring is the real foundation on which the individual groups base their rights to certain plots of land. For the Jaqaj it is this tie with the babae which also holds certain imu together. In Képi this does not always tally with the actual situation. The history of individual cases, however, does not fundamentally alter the rule. The imu cannot part with the rights to its landed property precisely because of this tie with its babaé.

The rule is that the whole area belongs to the whole group of blood relatives who live in that area. This accounts for the fact that in the beginning all relatives were admitted to all the land. As the number of these relatives grew, certain plots of land became cultivated more and more exclusively by particular qari. Eventually all the plots of land came under the command of one or another individual qari; this implied that members of other qari could no longer enter this property. The violation of the borders of areas and plots was a recurrent cause of fights and wars among the various qari of the same $i m u$, or between the qari of different imu.

Ownership of land was further complicated by the fact that the land belonging to one qari could be further subdivided (for example, between an elder and a younger brother). It was precisely this type of division of property which made it possible for a qari to split into sub-groups. Because of land ownership one brother could separate from his other brothers, found a new group with his own offspring, and adopt a new name. Apart from this claim by occupation, there was another type of claim, viz., that by conquest. This claim was based on the sweat and blood of the conquerors and it was nearly as 
strong as the claim based on occupation. The right of use is part of the right of disposal and control, but it should be mentioned separately for the sake of clarity. An individual of another imu or qari can obtain from the controlling group certain rights to make use of plots of land to which he, properly speaking, does not have admittance. For example, a person may have permission to reserve for himself a tree on someone else's property and use it later to make a canoe. Similarly, a person may get permission to build a fence or a pig trap on someone else's property.

This pattern of disposal and control is also felt in the right of inheritance. In each new generation the children are confronted with the property managed by the qari of both their fathers and mothers. The rule of procedure can be formulated as follows: a child (either a son or a daughter) considers the lands of his father and mother as belonging to him as well. The child realizes that these rights will in time be inherited by his or her children. A "child" is any individual who has been born biologically to a certain set of parents or who calls himself a child of these two parents through adoption. It may happen that natural children appeal to the difference between themselves and adopted children, but certain parents may also show a preference for an adopted child over their own child. Ideally, however, the Jaqaj adhere to the principle that "all children" have equal rights to the property of both the father and the mother. It is equally possible that one of the parents, who comes from elsewhere, has given up his or her land. In that case only the land of the other parent will eventually pass on to the children. If one of the parents marries a second time, the children inherit only the property which belonged to their own father or their own mother. The exercise of this right of appropriation is, of course, dependent upon the children having joined a certain qari.

Theoretically speaking, the Jaqaj recognize these rights as they are here described. Practically speaking, things may be quite different. Among the Jaqaj rights are determined less by legal titles than by the strength of actual positions of power. Individuals and groups consciously manipulate their personal power and strength in order to form, together with others, a stronger group. This new group consequently acquires rights which no separate group could have obtained on its own. It is not only true that the rights are actually in the hands of the strongest men of the group, but it is also true that the strongest people create their own rights. Among the Jaqaj the fact of power 
tends to overrule the notion of law. To illustrate this I will give some examples. The concrete details of these cases show how complicated various situations can be.

a. Whenever someone leaves his own qari and joins another qari, the question arises as to whether or not he is able to retain his rights to certain plots of land. If the person who leaves is strong enough to ensure his rights to certain property, this property will eventually come under the control of his new qari. If he is unable to retain his rights it will eventually be lost and will not be inherited by his children.

A clear case of this is that of the man Tambim who came to Képi. Originally he belonged to the Kandajmu of the village of Emeté. He moved to Képi and took his second wife, Panöm, from the Kamaqajmu (the Qow qari). He had "brought along" the land he had inherited from his father Oaqam at Emeté on the river Waperin. ${ }^{11}$ His brother Maper, who had stayed behind at Emeté, did not visit that plot of land any more. Other plots of land which had belonged to his father on the river Tioqoé ${ }^{12}$ were retained in part by Maper. After Maper's death his son Jawat also came to Képi and "brought" these plots of land under the control of the Kamaqajmu of Képi. The property which had belonged to Tambim's mother, Nada, lay near the river Qotombenöm. ${ }^{13}$ Near that same little river the great chieftain of the Ikimu, Jaèndé, had his mother's father's property. Tambim retained the property which had belonged to his mother and at Képi he ensured himself of the strong support of Jaèndé, to whom he gave his daughter Utejr in marriage.

b. Complications are possible when claims are based on conquest. This is illustrated in the following case. The Jatéo people had been massacred by groups from Képi, Dagimon and Emeté in a joint raid. Only very few people had escaped death. One of these was a woman called Raput. She was subsequently admitted to the Dadimu group at Emeté. Tumaj at Képi is the son of her son's daughter (SoDaSo). Another woman also escaped the massacre at Jatéo. Her name was Namomar and she had a son at Emeté whose name was Badejk. A third woman who had survived was Jabaq and she too had a son, Jamank, at Dagimon. These three men, Tumaj, Badejk and Jamank, put forth claims to the lands of the Jatéo group because they were the legitimate descendants of these people. At Emeté, however, there was a man 
called Bajmaqaj who was a member of the Qomimu. He owned land next to the former Jatéo property and his ancestors had added part of the Jatéo property to their own after the massacre at Jatéo. With an appeal to the right by conquest Bajmaqaj vindicated his claim to his Jatéo property. He told the assistant district officer that Tumaj of Képi had gathered sago in that part of the sago groves which, according to the right of conquest, belonged to him, Bajmaqaj.

The task of the government in native matters was mainly to try and ensure peace and order by maintaining the status quo. Accordingly a fine was imposed on Tumaj. He came to me and made a complaint. At the same time Bajmaqaj turned up. Both parties stoutly maintained that the property in dispute was theirs. Later they reached a compromise which allowed Bajmaqaj to keep his part of the Jatéo grounds, provided that he allowed Tumaj to put up a pig trap on the same plot of land. When I asked whether the descendants of the Jatéo people who survived could still assert their rights to the lands which had belonged to their ancestors, the answer was that every descendant could stand up for his rights if he wished. When I went on asking whether such a person would get back the property from the conquerors, the answer was, "If he is alone, he will not get anything. If he happens to have many sons, perhaps he might ..." This shows that the Jaqaj recognize the close connection between kinship and landholding rights, at least in theory. In practice, however, this right is a matter of power. As long as the claimant cannot maintain claims for his rights, he is treated as if he did not have any rights at all and might be chased away like an intruder. If, however, his power grows and he becomes a menace, the conqueror will readily permit him to set up a pig trap but will not withdraw automatically. If the claimant grows even stronger, an agreement will have to be reached and the property will have to be divided. If the claimant is stronger than the present owner, he will be able to take back the property. It is obvious that this complicated process of acquiring and reconquering land may be affected by other factors as well, such as marriages between the disagreeing parties, or the adoption of each other's children.

c. There is also the right of custody or guardianship, which leaders exercised in order to defend property belonging to orphans. The leaders sometimes returned such property to the legal heirs once they had grown up, but the opposite could also happen. The following case shows that this could lead to difficulties. 
Tapaqajmu of Képi invited Eré of Emeté (the father's father of Jaro, the leader of the Aqaoèmu) to come and pound sago on his land (i.e., on the lands of the Qodé qari). Jaro had visited these lands with his relatives ever since he was a child. As an adult he fought against the people of Togom in order to keep these plots. At that time the legal descendants of Tapaqajmu, Mari, Kapo and Adaj, were still children. Jaro therefore looked upon their lands as his property. By the time of my survey, however, these legitimate descendants had grown up and had begun to stand up for their rights. They wanted Jaro to give up his guardianship and to stay off their land. When Jaro heard about this, he became so angry that he threatened to move to Emeté and return with his people from Emeté in order to destroy them.

This was how things were done in former times. A right proceeding from kinship clashed with a right emanating from the defence of the lands against enemies. Jaro, however, realized that his own claim was less strong than that of the hereditary title holders. He therefore accepted an agreement which allowed him to gather sago freely from this land during his lifetime. His children, however, would cease to have any rights after their father's death. When data on this case were checked later, however, Jaro's children were not resigned to this agreement which had been accepted by their father. They preferred a division of the property as a better solution of the case.

d. There is another case in which a similar situation was solved differently. Two men, Jandit and Jamaq, both from Képi, contracted an exchange marriage. ${ }^{14}$ Jamaq had sago groves from his father Mendo (Ikimu) and his mother Baqajo (Aqaoèmu). When the marriage arrangements were made, Jamaq granted Jandit the right to come and collect sago on his land, particularly on the plot of land called Téj. ${ }^{15}$ In itself this was nothing extraordinary, for a husband is always allowed to gather sago on the lands belonging to his wife and these lands are always the property of his exchange brother-in-law. The woman who was given to Jandit by Jamaq as a wife, however, was not Jamaq's own sister but an "exchange sister" 16 given to him by her foster parents. In such a situation it appears that it was not selfevident that the husband could go and collect sago with his wife (i.e. with the bride giver). The reason why Jamaq granted this right to his exchange brother-in-law is characteristic of the original practice. Jamaq said, "Jandit, your property at Pètim is too far away and the enemy lives there in the neighbourhood. You are welcome to come 
with me and collect sago at Téj, which is nearer to the river Oba." This land Téj, however, was not to be passed on to the descendants of Jandit. This confirms that the descendants of Tapaqajmu were quite within their rights to refuse Jaro permission to enter their property, although their father had granted this right to Jaro's father. There is, however, one great difference. Jaro had defended the land in question with his own blood. This could not be said of Jandit.

e. Another possibility was that some sections of land might be given to another group. This was sometimes done on certain terms. Thus there was a transfer of land by a group leader of Dagimon to the Ikimu of Képi, on the condition that the people of Dagimon retained the right to there cut sago leaves and sago-leaf ribs for roofing for their houses. When working on that land they also had permission to cut down sago trees if necessary and pound their pith. What the people of Dagimon said about this "cession" is typical. They said, "We will not put any obstacles in the way of the Ikimu when they visit that land as long as they remain our friends". In the final analysis they continued to look upon these sago groves as their own property.

f. Another example of a cession of land "on certain terms" concerns fishing-grounds. Near the place called Moqonoqat, ${ }^{17}$ the river Tip belongs partly to Képi and partly to Togom. The people of Togom use this part of the river for fishing with fish poison. At the time of my survey Jaro ordered one of the weirs to be opened because, he said, the people of Togom had no right to put any weirs in that part of the river. The boundary of their property was up the river near the place called Qajperoni, and there some trees had been chosen as boundary markers of the respective fishing-grounds. Jaèndé, however, said that Jaro himself had given part of the river in question to the people of Togom. Earlier I had seen people from Togom fishing in that part of the river with fish poison, while at the same time people from Képi had been working more to the south in the same river. In the presence of Jaèndé, my young interpreter Jabajmu told the people of Togom that they were not allowed to pull out the grass plants in that part of the river in order to have more space for their weirs. He said that the grass plants must remain untouched so that the people from Képi could continue to come there to catch cray fish in the swamps. This is a clear example of how such situations existed. The people from Togom were tolerated although the people from Képi 
sometimes said: "Togom is here illegally". Nevertheless, a leader had admitted them. The younger people, however, thought of the future and did not wish to lose their rights to this plot forever. They claimed that a significant action or symbol should remind the users of the fishing-grounds that this land was not theirs. Therefore it was said, "Do not pull out any grass plants".

g. It is also important to realize that members of several qari can be found together on the same piece of land, each on the basis of his individual rights. Thus a man could be gathering food in one place because he follows his father, whose land it is, and he could be there with his wife, who belongs to a different qari, but who is admitted to the land. On the same land there may be a widow who follows her children, who have a right to come there because it was also the property of their deceased father. If the land is situated near a river or swamp other people from yet another qari may be at work there. The various methods of fishing create the possibility that women are fishing with their fishing baskets while men (perhaps from an altogether different qari) are at work in the same place renewing their weirs. These facts explain how a plot where people work together in a peaceful atmosphere may suddenly become a battlefield, if a conflict between qari breaks out.

\section{Land using rights}

The post-contact situation relative to hunting- and fishing-rights is quite different from the pre-contact period. If nowadays the question is asked as to how far the hunting- and gathering-grounds are open, and to whom they are open, the answer is often that both members of the village itself and members of other villages may enter this property. They say that hunting is free, and that fishing is free on the river. They say that if relationships are friendly, everyone may gather the ordinary products of the forests like fruit, eggs, edible plants, and binding-material. The only restriction made is that if someone else has marked out something for his private use, this should not be touched or taken away. Such a reservation can be made on trees ${ }^{18}$ to be used for building a house, or on certain plants in the swamps. Similarly, one should stay away from a pig trap constructed by someone else and the fish traps in the swamps constructed by other people. Usually a reservation is marked by cutting away the undergrowth 
around such a tree. The people of the village will then discuss who did this. Thus the identity of the man who put up this reservation mark will become known and his right will be established. A tree for a canoe may be marked and similar signs can also be placed elsewhere, e.g. on a woodchicken hill or déjaq, on certain fruit-bearing trees (i.e. the amutaq), on the nest of a hornbill or téaqao, or on a tree having many nests of the little birds called maqanaw. In addition a huntinghut or dato, found in a tree or in the swamps, indicates the presence of private hunting-grounds. All these rights pass from parents to children, both male and female. This is how the situation is at present. In the past, a man who intruded on the property of somebody else could either be a friend or an enemy. In the former case, he had permission to hunt on that land; in the latter case hunting on the property of somebody else was an act of hostility. In former times merely being seen on foreign land, near the sago property of someone else, automatically gave rise to suspicion of theft. Therefore, one did not venture out beyond one's own land or its surrounding woods. Even today when a quarrel begins among members of different groups, the opponents tell one another to venture no longer on the property to which they had admittance while their relations were friendly.

Hunting-rights are more or less strictly maintained with regard for the methods used in hunting.

a. He who walks through the forest with a bow and arrows in search of birds and small animals will usually not be troubled unless he enters, without a good reason, sago groves which belong to somebody else.

b. He who is hunting pigs must respect the existing boundaries. Pigs should be looked for in sago groves or their immediate neighbourhood. If the hunter is pursuing a pig in his own sago groves and the animal escapes to the sago groves of someone else, it depends on the relations between the two owners of the adjoining sago groves whether or not the hunter may freely and without danger to his person continue his pursuit of the pig.

c. If several persons hunt together, they should know on whose land they are going to hunt. If the owner of the land does not give his permission, the hunt will be looked upon as trespassing. Even if the owner has given permission, he is not entitled to any special share of the game.

d. If a collective hunt is prepared for by hedging in a certain piece of land with a fence of trees, the rights to this piece of land must be 
considered. These rights determine who will be invited to join the hunt. Those who are invited co-operate in hedging in the area or have already done their share on a former occasion. They will get a share of the game.

e. He who erects a small fence, jataka, in the sago marsh, from behind which he intends to shoot pigs, may do so only on those plots to which he has rights of use. The same applies to the building of traps to catch bigger game.

Rules of garden use were different. Gardens were laid out on lands which belonged to the qari of the gardener. They were the property of that group and were inherited by the sons and the daughters of the gardeners. These gardens, however, were usually cultivated for a relatively short period and then the grounds were left fallow again. If left fallow for a longer time, another person of the qari could go and work on this plot.

What one earns by personal labour on a piece of land is private property and can be divided among one's relatives. Thus coconut trees are the personal property of the men and women who planted them. Both parents plant coconut trees for their children. The sons receive more trees than the daughters. The eldest son seems to have a special position. Personal motives count in the allotment of the trees. The last will of the deceased must be respected. Formerly, strangers to a group could get permission to plant coconut trees on its land if these "outsiders" stood in a special relationship to the group. The owner who granted permission took the care of the coconut trees upon himself. The soil around the trees, however, did not become the property of the man who planted the trees. The planter decided who would eventually inherit the trees after his death. If such a decision was not made, his children divided the trees among themselves. If they could not reach an agreement, the dissatisfied party simply cut down the disputed trees. This was not an occasion for further quarrels because everyone realized that there was no other solution to the problem, as there was no one who could settle the dispute. If any sago trees are planted they automatically become family property and the rules of inheritance as depicted above in the discussion of landholding rights are followed.

To these data on hunting- and collecting-rights I must add some further information on what is called no-man's-land. One does not find any in the territory regularly occupied by the Jaqaj and must look for it in the area between the mouth of the river Oba and the 
river Mappi. They say that there an extensive sago territory is still available. Concerning the fishing-grounds they say that there is property which is so overgrown with rushes and weeds that it is inaccessible to canoes. The owners do not come there any more. In such cases the rights of possession cease to exist. If after a short time (for example, after a fire) such grounds become accessible again, the former owners will try to reassert their rights. If such grounds have been lying fallow for a great number of years, they can be occupied by anyone. When making my survey of the hunting-grounds, I learned to my surprise while crossing the land between Gogojāmön and Togom, that my Jaqaj companions were able to indicate very clearly the boundaries of the various properties in the forests and on the plains. 
CHAPTER II

KINSHIP AND MARRIAGE

\section{Kinship terminology}

The preceding chapter has shown that the qari and the imu are superstructures which are supported by a sub-structure of consanguinity. The rules governing the behaviour of kinsmen can best be discussed on the basis of kinship terminology. Some generally recurring terms are:

$\mathrm{FaFa}, \mathrm{MoFa},=$ api;

FaMo, MoMo, = éni;

$\mathrm{Fa}, \mathrm{FaBr}, \mathrm{MoBr},=$ naé;

$\mathrm{Mo}, \mathrm{FaSi}, \mathrm{MoSi}, \mathrm{FaBrWi}$, = naw;

Elder/Younger Br, male parallel or cross-cousin, = namön/wèk;

Elder/Younger Si, female parallel or cross-cousin, = namun/wowk;

Child, BrChild, SiChild, Child of parallel or cross-cousin, = maq;

Grandchild, Brgrandchild, Sigrandchild, Grandchild of parallel or cross-cousin, $=$ api.

All affinal relatives are addressed or spoken about with the common term for an in-law, aröm, ${ }^{1}$ even if they are of another generation. This simple, basic structure undergoes alterations in the practice of everyday life, because certain relations may necessitate the use of a different terminology. These terms will be discussed later on in this chapter. Here I shall mention some general guide-lines.

In the exchange marriage system the term mendaq is used among the four partners instead of terms of kinship or affinity. The trend towards patrilocality ${ }^{2}$ explains the following facts. A woman calls the parents of her husband "father" and "mother" and they call her "child". Even the FaBrWi is called "mother". A married woman's brothers-in-law call her "elder/younger sister" and she calls them "elder/younger brother". The sisters of her husband, however, call her nokon ${ }^{3}$ and she calls them nokon. The exchange system and patrilocality cannot prevent the relations between bride-givers and bridetakers from becoming stressful. In such cases a husband calls his wife's 
brothers and sisters and their children "relatives-in-law". The children who follow their parents in this usage then do not call their MoBrWi "mother", but "relative-in-law". Several social relationships (adoption and partnership in head-hunting among others) can also be expressed by other terms as well. The terminology is, with the exception of the affines, a generational terminology ${ }^{4}$ and is of the Hawaiian type. ${ }^{5}$

The extent of the classificatory use of terms cannot be formulated in strict rules. One must consider the concrete, actual circumstances. A third cousin living in the settlement is nearer than the daughter of a sister who lives in another settlement, with which relations are bad. Perhaps she will be called "wife of ..." instead of "child". Within one's own generation the terms for the consanguineal relations can be replaced by personal names. Affinal relatives are neither addressed nor spoken of by their personal names. If necessary, one will ask someone else to say the name of the person being discussed.

\section{Marriage regulations}

Under this heading I shall discuss the following subjects: marriage prohibitions, marriage opportunities, divorce, monogamy and polygyny. Here I shall confine myself to a sketch of the social framework. The nuances necessary to complete the picture will follow in Chapter IV and subsequent chapters.

\section{a. Incest and marriage prohibitions}

Sexual intercourse between father and daughter, or between mother and son, was said to be inconceivable. Intercourse between a father and a foster daughter, or between a woman and her foster son, was not entirely improbable. A distinction is made between a child who has been a member of the family since birth, and a child adopted at a later age. A child adopted as a suckling infant or as a toddler is looked upon as being one's own flesh and blood, and in that case sexual intercourse is said to be unimaginable. As to a child who was ten years old when it was adopted, a further distinction is made. If the child was an orphan, related by blood to the family into which it was adopted, it falls in the same category as the natural children. If it was a stranger (e.g., brought home from a head-hunting raid), the future of the child will depend on the parents who adopt it. If the child is a girl, she will be kept in the family as a future (second) wife for the husband or the son. Another possibility is that she will be 
kept as an exchange sister for the son. In that case, she will be looked upon as a "sister" of the son and as a real "child" of the parents. In the former case, she will be available to the father as soon as possible and then she will be inviolable as far as his sons are concerned. If the child is a boy, he will be the husband or the exchange brother of one of the daughters of the family into which he was adopted.

Intercourse between sons and the wives of their father (if the latter are not their own mother), though conceivable, is considered to be a crime. Such a discovery demands the death of the son and the adulterous wife. ${ }^{6}$ It is not looked upon as incest, but as an unprecedented interference with the rights of the father.

Sexual intercourse between brothers and sisters (children of the same father and mother) is conceivable, but it is looked upon as so shameful that it must be punished with the death of the two persons concerned, who are executed by the relatives themselves or by their relatives living elsewhere. Intercourse between half-brothers and half-sisters and between a brother and a foster sister, who was adopted by the family during childhood, did occur, but had been forbidden on pain of death. In the village of Toba such a case occurred in 1955, and Jaèndé of Képi declared that only the presence of the civil government had prevented him from killing the couple. I was also told that if parallel or cross-cousins had intercourse, they would be guilty of incest and run the risk of being killed by their relatives. Intercourse with $\mathrm{FaBrWi}$, MoBrWi, FaSiHu, and $\mathrm{HuBr}$ did occur. Such transgressions were strongly opposed, because they brought about fights within the local group. Homosexuality, which is not uncommon among both sexes, is subject to the same rules of incest that apply to normal sexual intercourse, for just the same reasons. The Jaqaj want to avoid any difficulties caused by sexual intercourse between family relations who must co-operate for their daily existence in the group.

I conclude, in theory at least, that there is a maximal bilateral extension of incest prohibitions, because marriage is forbidden with any relations, however remote, with whom an actual genealogical connection can be traced in any line. There are also other social connections which bring marriage prohibitions with them. They will be discussed in the section dealing with other types of relationships. ${ }^{7}$

\section{b. Marriage opportunities}

Members of a qari or an imu, living either in the same or in a different 
settlement or buaq, who are not related by blood, may marry among themselves. At Képi, I found among the Aqaoèmu four cases of imuendogamy, among the Ikimu one case, among the Kamaqajmu two cases and among the Marapèmu eleven cases. The great number of such marriages among the Marapèmu can be accounted for by the fact that this imu embraces several members who came from Dagimon (from a different imu therefore) to Képi to join them. Consanguineal exogamy is the only decisive rule. Although the rule of exogamy was strictly obeyed as far as the next of kin were concerned, marriages with distant relatives did occur. The rules of exogamy were violated most frequently by powerful leaders. Others might try to do so, but then one could expect sanctions to be imposed by the leaders. The Ikimu leader of Képi, Jaèndé, had openly broken the rules of exogamy in each of his marriages and everyone knew about this. Jaèndé himself ascribed the early deaths of his wives to these violations of the rules. These marriages that were contrary to the rules of exogamy occurred most of all among relatives who belonged to different qari and imu, but who had landed property in each other's neighbourhoods.

More marriages took place between groups living together in the same settlement or buaq, than between groups of different settlements. In Képi, there were marriages between every imu and everyone of the other three imu. The three imu of the Aqaoèmu, the Ikimu and the Marapèmu preferred marriages with the $i m u$ of the Kamaqajmu, which was closely connected with the nearby settlement of Emeté. They received fresh blood from Emete and these people preferred to join the Kamaqajmu group. Although there was a strong tendency towards buaq endogamy, it is certain that marriages were also contracted between imu of different settlements. ${ }^{8}$ There was even a term for it, $k a k i$, which means "relative in another, distant settlement". ${ }^{9}$

\section{c. Marriage arrangements}

Marriage by sister exchange was preferable, i.e. a man gave his sister in marriage to another man and received the latter's sister in return. This was called kinemeneng-kakon, i.e. they have been put at their mutual disposal. Both the two men and the two women address one another as mendaq, exchange partner. The married couple, who have taken one another, as the Jaqaj say, also address one another by their personal names and speak about each other as "my husband", radé anokondin, and "my wife", taw anokondin. The children of two exchange marriages call each other natu. 
Exchange marriages not only establish a liaison between two men and two women but also between the two different qari that the men belong to. The exchange establishes between the two qari the relationship of affinity. The members of these qari address one another as aröm. If the qari concerned belong to different imu groups, the marriage results in a bond between these imu. When, however, two imu enter into contact for the sake of an exchange marriage, only the qari which are directly involved in the marriage look upon one another as affinal relatives in the strict sense of the word. The other qari of these imu are not involved. If, however, within various imu several qari feel strongly united, the whole imu of one party will enter into an aröm relationship with the whole imu of the other party. Thus certain marriages can lead to stronger co-operation between two imu groups, although only two qari are directly involved. Therefore, if the leader of one imu refuses to enter into more friendly relations with a hostile $i m u$, he can veto the wedding of one of the members of his own imu with a member of the other imu. The stronger the ties between two $i m u$, the stronger the mutual support.

The arrangement of a marriage is in the hands of the parents of the exchange partners and their respective relatives. These relatives are the wir-bor, the relatives of the father, and the taj-bor, the relatives of the mother. Their duty is to check to make sure that there are no incest prohibitions and also to see if the candidate has the qualities they desire for the benefit of the son or daughter. The future qari of the marriage candidates, as such, is only of secondary importance. For one candidate this can be the é-qari, the group of his father, and for another it can be the wu-qari, the group of his mother. All this depends on which qari the individual candidates have chosen to follow. These qari study the case especially from the point of view of their qari, i.e., from the point of view of landholding rights. It is understandable that the qari leader has a strong voice in these matters. The same also holds true on a higher level; the imu leader has an important part to play in the decision. While the personal initiative of the man or the woman who is getting married can be important, he or she must always consider their next of kin, their qari and their imu standing behind them.

In order to understand the various forms of exchange marriage, it is important to remember that the Jaqaj use classificatory terms in their kinship terminology. The terms for "brother" and "sister" not only include one's own brother or sister, but also half-, foster-, and 
step-brothers and -sisters as well as the children of one's father's brothers or sisters and one's mother's brothers or sisters. The Jaqaj therefore have a more general term for exchange sister, nati. There is no such term for exchange brother. This difference seems to be based on the fact that a man who gets married need not necessarily have a sister of his own to give in exchange. He is only expected to acquire an exchange sister, nati, by services rendered to parents who happen to have a girl to spare. The woman, however, is not obliged to persuade her parents to give her as a nati to a willing young man, so that she may get married through him. That young man has to make himself acceptable to her parents. The parent who gives his daughter as an exchange sister to a young man is called natik, the giver of an exchange sister. The young man will always have to remember his natik. A young man looks for a nati first within his own qari or imu group. If he does not succeed he can join another qari or imu if that group promises to give him a nati.

In addition to this type of exchange marriage, there are other possibilities which are derived forms of the mendaq marriage. First of all, there is the so-called kokebekao marriage, which is a marriage through "taking the place of". It is an exchange marriage in which the place of one of the partners has fallen empty and is taken by somebody else. When one of the male partners of such an exchange marriage dies, a substitute is sought to take his place. If the substitute already has a claim to the nati of the deceased as his own nati, he need not make any extra payments to enter this foursome. He now "gives" the nati in his turn, after she has already been given by his deceased predecessor, and receives from her husband his sister (the widow) in return. If the new partner has no right to treat the sister of the deceased as his rightful nati, he must offer compensation in return. This compensation can be made by giving goods, but he can also give one of his own sisters to a member of the family he marries into and thus contract a double exchange marriage. The first marriage is a replacement of the deceased predecessor and the second one is an exchange marriage with another man of the qari of the deceased, to whom he gives his own sister.

Thus one might have the exchange marriage $\mathrm{A} \times \mathrm{X}$ and $\mathrm{B} \times \mathrm{Y}$. $A$ and $B$ are the men, and $X$ and $Y$ their respective sisters. $A$ dies and $\mathrm{X}$ is left behind as a widow. Now a man comes forward whom we indicate as $\mathrm{C}$ and he wishes to marry the widow $\mathrm{X}$. If $\mathrm{C}$ is not entitled to $\mathrm{Y}$ as his exchange sister, he will bring in his own nati $\mathrm{Z}$. Now $\mathrm{C}$ is 
the substitute of $\mathrm{A}$ and receives from the relatives of $\mathrm{A}$ the widow $\mathrm{X}$ as his wife. Therefore, they give him $\mathrm{Y}$ as a nati and thus $\mathrm{C}$ can contract an exchange marriage with $B$ as the substitute of $A$. To the relatives of A, however, (e.g., to a younger brother of the late A, viz. D) he must give his sister $\mathrm{Z}$. If this younger brother of $\mathrm{A}$ marries $\mathrm{Z}$, the new man $C$ is said to be not only the mendaq of $\mathrm{B}$ but also of $\mathrm{D}$. The sister $\mathrm{Z}$, given by $\mathrm{C}$ to his second mendaq $\mathrm{D}$, is called by him a ramumendaq, which literally means leg mendaq, or secondary exchange partner. In a diagram:

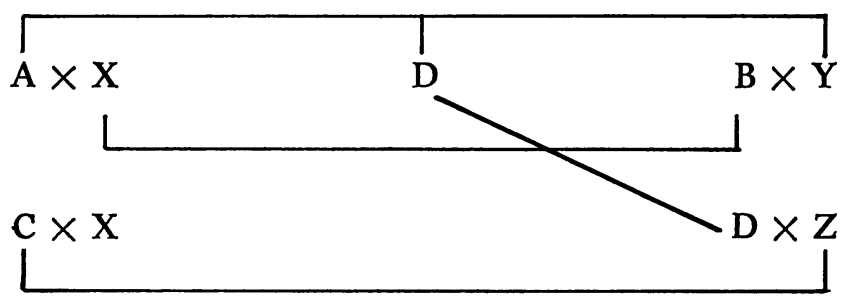

This form of marriage, in which there is not only a substitution but also a second exchange marriage, is called kinebepqano, which can be translated as "they have put one extra".

There is another form of marriage in which the man is not able to offer a girl as an exchange sister, but in which he gives goods instead. This form is called jakatep-nati, "goods as an exchange sister". This means that this too is an exchange marriage, but the man who provides the bride is satisfied to receive goods instead of a wife in return. If a man cannot give a woman in exchange, he will later try, by whatever means he can, to provide his bride-givers with a woman and thus make his marriage into a real exchange marriage. The goods earlier given in return for his wife will be returned to him. The general idea is that if goods are given and not an exchange sister, the exchange marriage is still deficient. A real brideprice is inconsistent with the Jaqaj's idea of exchange.

An exchange marriage is taèm-amön, i.e. a right relationship established between two men. This term is derived from the word taèm, which means sago-leaf sheath and refers to the rinsing-gutter for the sago which consists of two sago-leaf sheaths fitted together. Taèm-amön means "sheath with" and can be freely translated as "the joint of the two sheaths has been made". In all these cases the Jaqaj distinguish between marrying in and marrying out, i.e., they say of a daughter-in-law, that she marries in, and of a daughter, that she marries out. 
That an exchange marriage is the marriage preferred by the Jaqaj is obvious from a survey of 143 marriages in Képi. Of these marriages 102 were exchange marriages: 51 had been contracted by giving one's own sister and 51 by giving a classificatory sister in exchange. There were 34 cases in which goods had been given instead of a girl and eight cases in which a "replacement" had been made. There was only one case of a double exchange marriage. If one of the partners does not live up to his obligations and does not come forward with his compensation, the marriage is said to be amör-ain-amön, without a compensation in return. Other expressions connected with the way marriages are contracted are as follows. Tambim of Képi approved of the marriage of his foster son with a woman of the same family from which his eldest son had received his wife. This way of marrying was called janggor-boqamön rap-ain-amön mabondeba-an, to keep the path clean, without any dirt. Tambim, however, wished his other sons to open up new paths elsewhere and not to continue the path of the first two sons, oakebeptajkirok qajkire.

It is clear that in practice mistakes are made in marriage arrangements and they give rise to difficulties. Parents can be too hasty in giving their permission for a wedding, forgetting to first consult their respective relatives. These relatives can later raise objections to the marriage. It may appear, after all, that the two parties are related by blood, although the parents themselves thought they were not. In such cases the imu leader can also veto the intended marriage. During the months which precede the marriage, the exchange sister of one of the men may die or be stolen. It can also happen that the man in authority as far as the nati is concerned, withdraws his approval of the exchange, because the man to whom she has been given as an exchange sister does not behave himself. In Képi there were cases in which a man personally married the woman who had been given to him as an exchange sister. It is obvious that quite a number of alternatives are possible between men who interchange their nati. Because of these alternatives it is often possible for men to get the woman they individually prefer. Of persons who do this they say nati kéoberamberuk, he has transferred his nati.

The parties who wish to marry can also take the initiative, without waiting for arrangements to be made by their respective parents. Thus a woman can seek shelter with a man. Such a woman is said to have fled to him on her own initiative, tom-amön verpakit. The man too can take the initiative and make advances to a woman. They say of 
such a man jamba-amön, he took the initiative. In both cases the relatives of the two parties will try to interfere as soon as they learn about it. Also, an exchange of two women often does not take place simultaneously. In every village there are marriages contracted in which one party has to wait for years till his partner in the exchange marriage comes of age. The various possibilities and difficulties mentioned above account for the fact that marriage arrangements form the main topic of village gossip and are a common reason for quarrels and fights.

\section{d. Divorce}

The consequences of an exchange marriage are felt on all levels of life. The two men who have contracted an exchange marriage may stay together and have their fireplaces beside each other in the men's house. Their wives will then have adjoining fireplaces in the women's house. The men will go hunting together and the women will fish together. Each of them looks after his own family but shares whatever he has with the other party. This co-operation is not difficult at all, because the wives contribute to the households of their brothers. This alliance of the two exchange marriages is valued so highly that in theory, if one of the parties does not live up to the marriage obligations, both marriages can be dissolved. If one of the men deserts his wife, the other can also reject his wife. Thus the original situation is restored to the point where it was before the exchange contract was made.

In practice things are usually different. When one of the two exchange partners can clearly be proved responsible for the break-up of his marriage, while the other marriage is still a happy relationship, the brother can take back his divorced sister and still keep his own wife. He is even supported by the relatives of the guilty party. In due course he may give his sister to another member of the group of his bride-givers. The Jaqaj prefer to see the alliance between two families continued once it has been established. When one of the partners dies, for instance, the contract is not really terminated; the two qari repair the loss by replacing the dead partner by a brother or a sister.

My informants always mentioned an act of adultery on the part of the wife as the first and most important reason for a divorce, although not all cases were judged in the same way. One false step often resulted in no more than a severe thrashing of the wife. If a husband, however, discovered that his wife had a regular affair with some other man, 
this discovery might lead to divorce proceedings. Divorce was not accomplished simply by repudiating the wife or leaving her to her extra-marital partner. A man who had good reason not to trust his wife tried to catch her and her lover committing adultery and then kill both of them. He might also publicly accuse the man. This accusation would lead to a fight between him and the adulterer. Each man would have his own supporters who would join the battle. It could also happen that the man and the woman who had been caught in the act of adultery escaped to another settlement. They would stay there until they got news that they could return to their own settlement; successful negotiations were necessary to restore the peace between the two families of the guilty parties. Sometimes peace was restored and the guilty man kept as his wife the woman with whom he had committed adultery. In other cases the adulterous woman returned to her lawful husband.

A wife, in turn, need not put up with the infidelity of her husband. If she felt strong enough and was able to count on the support of her own people, she could accuse her husband of adultery. If he started to beat her up, she could raise such a commotion that the whole community would know what was going on. If her husband's side lost the ensuing fight, he would not be certain whether or not he could retain his own wife. If she did not come back to him, her relatives could give her in marriage to some other man.

Adultery was not the only reason for divorce. The laziness or sterility of the wife, or the laziness and hard-handedness of the husband, were reasons enough to break up the marriage. In the former case a husband might repudiate his wife and in the latter case the wife might elope. This happened especially in marriages in which the husband had not yet captured any head, but nevertheless treated his wife roughly or was too demanding. It was equally possible that an attempted divorce did not work. If a woman ran away from her husband because he had treated her badly, but the actual beating she had received had not been so serious, her relatives might bring her back to her own husband once she had calmed down. This was usually done if the husband had always been thoughtful and had never forgotten his in-laws when he came back from a hunt, or if he had always been good at rendering them services. It is impossible to formulate general rules. Everything depended on a variety of circumstances. The fighting power of the parties and their vested interests both influenced the question as to who was going to win or lose. 
After a divorce the separated parties lost their rights to use the lands of their ex-partners. They did retain their own personal land rights. The children were another problem. Sometimes the guilty party had to leave the children to the partner who was innocent. It also happened that the children were divided between the two parties or that, with the children as prospective nati, both parties were able to marry again. I also know of cases in which the offended party tried to kill the small children of the adulterous wife with the help of his relatives; this resulted in the death of one or more of the children.

When one of the partners died, the following were the consequences for the remaining spouse. If the wife died, the husband could keep the children under his care and bring them up with the help of his other wives or his relatives. If he had left his own settlement and had followed his wife to her settlement, he could now choose to return to his own settlement. In this case the relatives of his late wife might demand that one or more of the children remain with them. The husband himself could stay in the settlement if he wished, but this usually only happened if that settlement had promised to give him another wife. If the husband died, the wife moved from the house which her late husband had helped to build to a house which was the property of her own father or brother. The small children who needed their mother went along with her. The older children had to make a choice. They could either join the qari of their late father or they could join their mother's qari. Both qari did whatever they could to persuade the children to join their own group. Marriage interests and the restoration of earlier violated relations also played an important part in these questions. The widow often stayed with the relatives of her late husband if she had been promised another husband from that same qari or imu. If the man had more than one wife, each wife could stay if she was going to remarry into her late husband's group.

\section{e. Polygyny}

Polyandry was inconceivable among the Jaqaj. How often polygyny occurred in the past is difficult to say, because in the genealogies the informants were unable to make a distinction between the simultaneous and successive polygyny of persons already dead. It is certain that a man who was successful in head-hunting, a poqoj-radé, could afford to have more than one wife. My genealogies list instances in which a man had six wives. I have heard of instances in the distant past in which men had up to ten wives. One man was even supposed to have 
had fourteen wives. It is fairly improbable that he had all these wives simultaneously. Because polygyny was the privilege of important men, an ordinary man had to be satisfied with only one wife, and had to take care that she remained faithful to him and was not stolen from him by one of the more important persons.

At Képi in 1953 out of 75 men there were 44 who had more than one wife. Of these 44 men, 35 had second wives who came from neighbouring villages. Only nine men had second wives from Képi itself. Data about the younger generation cannot help us here because they were under the influence of the Catholic mission. In checking the genealogies for cases of polygyny it was possible to determine where the women came from. Polygyny was not a question of levirate or of sororate. Polygyny was connected with the career of a man. His prestige and power could grow and thus he could enforce certain arrangements. If he was highly respected by women, any woman could take refuge with him because he was powerful enough to win the ensuing fight. Having more than one wife added to his standing and provided him with the food he needed to maintain and strengthen his relationships with his relatives and friends. If there was a fight, these relatives and friends would help him. As a rule these secondary marriages also required an exchange of women.

The Jaqaj allow for a wife to be replaced by another woman if she loses the favour of her husband. In this case, however, the first wife is not completely repudiated. Young men were of ten given older women in marriage. After these men had captured their first heads they could keep these women as their first wife or as a second wife. The new head-hunter could also hang the head he captured on the arm of a young woman who would then become his only or his first wife. The older woman was then given back to her family.

Every marriage of a man was legal. Although the Jaqaj speak of kamioarup, or the primary wife, and of maémeta, or the second wife, this does not mean that the second wife was merely a concubine. The children born from a second or third marriage had the same legal position as the children born of the first wife. The kamioarup took care of the man in the real sense of the word. The maémeta sent him food, but most of all she took care of the children. If the man visited the women's house to see his wives he had to sit down near the fire of his primary wife. If he set out in his canoe, the primary wife sat with him while the other wives had to find places in another canoe.

If any distinction was made in the relationships this was ascribed 
to the man's personal preference. Such a preference was often connected with the way in which he had received the wife, or with the special sympathy which had grown between him and one particular wife. The actual procedure of marriage arrangements (by exchange, by elopement) and the wife's fertility and her ability to work had more influence on her preferential treatment by her husband than her place in the numerical sequence of his marriages. A childless primary wife had to put up with the fact that her husband, who loved his children, also included their mother in this love although she was only one of his secondary wives. If one of the secondary wives was good at gathering sago or catching fish, the man was sure to notice this and to show his appreciation. The husband could have intercourse with any one of his wives. If each wife had her own opportunity in due time, there would be peace in the woman's house. Moreover, the wives were well aware that jealousy was of no avail because they knew from experience that life was more pleasant for all if they accepted the given situation and helped one another. Nevertheless, there were cases of jealousy and quarrels. In order to prevent such occurrences from becoming the rule and thus making the situation increasingly unbearable, the husband would give each wife a thorough beating and restore peace and order. If, however, the wives took a unified stand against their husband he had serious difficulties. He might be able to get some food from his sisters but shame often restrained him from appealing to them. A husband achieved a higher rank by hunting many heads. A woman gained a privileged position by being extra diligent in the care of the family, the gathering of food and the bearing and bringing up of children.

\section{Other relationships}

The reciprocal relationship of an exchange marriage provides the ideal pattern for many other Jaqaj relationships. In the first place there is the relation between the biological and the social parents of a child that has been adopted. In addition to the term for father, $\dot{e}$, the language has the term jando-é, foster father, parallel to the term $w u$, mother, the term jando-wu, foster mother. In the same way maq, child, has the parallel term jando-maq, foster child. ${ }^{10}$

Adoption is a regular occurrence among the Jaqaj. The immediate cause can be the birth of twins, or the wish of a parental couple to provide their son with a nati, an exchange sister. Adoption can also 
be a means to restore friendly relations after there have been hostilities between two groups. In due course I shall discuss the individual cases. For the present it is necessary to see how, through adoption, relations are established between parental couples. To the Jaqaj the real parents and the foster parents contract, as it were, an exchange marriage. The children of these two couples are looked upon as if they were cousins. The members of an adoption relationship address one another with the term natu. This term is also used when they speak about one another. Not only the parents of the two families call each other natu but the children of the two marriages also address one another with natu (as is the case of children in two exchange marriages). Adoption therefore is seen as a secondary type of exchange marriage between two married couples. The result in both cases is that the prohibition of sexual intercourse is extended to all children of the two marriages.

In Képi all cases of adoption were recorded. In a total of 74 families there were 26 adopted children: 14 boys and 12 girls. In eighteen cases the child came from a nearby village and the terms mentioned above were used. In two cases it was said that the child had been paid for and originated from another tribe. The natu terms were not to be applied. In five cases the child was adopted because its mother had died and these children were adopted within their own family. Finally, in one case the child himself returned to his own parents and the relationship came to an end.

Another relationship which is similar to the reciprocity pattern of an exchange marriage is the relationship between two married couples, of whom one husband had stabbed an enemy on a head-hunting raid, while the other had cut off the victim's head. This joint activity on the battlefield made these men "relatives". It was as if they had become exchange brothers-in-law. They addressed one another with the term ménaqaé. The man who stabbed the enemy would later, during an initiation ceremony, pass on the hair name, taker-éké, to the son or daughter of the man who had beheaded the victim. This made him, as it were, the foster father of the children of the beheader. The two parental couples and their children used the term ménaqaé when they addressed each other or spoke about each other. Whether or not the relationship of ménaqaé resulted in a marriage prohibition between the children of both couples is not certain. Answers to this question varied, probably because the ménaqaé relationship usually united people who were already closely related otherwise (e.g., classifi- 
catory brothers or brothers-in-law). Such relatives were always together on the battlefield. There were exceptions, however, to this rule. Nonrelatives might also become each other's ménaqaé. In such cases a marriage between their children might have been forbidden. It is certain, however, that the two married couples who had entered into a ménaqaé relationship would help their children to find a nati (exchange partner).

A similar relationship also obtains between the head-hunter and his wife on the one hand, and the owner of the jaw of the captured head, and his wife, on the other hand. The lower jaw was separated from the skull after it was roasted. This jaw was presented to somebody else. The wife of the receiver wore the jaw fastened to a ribbon on her back. The two married couples thus entered into a relationship of nakaèri. They and their children addressed one another as nakaèri. The same term was used when speaking about one another. This term was rarely used in Képi. The reason was, as will be shown later on, that a nakaèri was preferably a man from another settlement. This might account for the reason why a marriage between the children of nakaèri was possible. The presentation of the jaw was a public matter. The partners to this nakaèri relationship counted on mutual assistance, although not as strongly as in the relationships discussed above.

A naröm relationship was established between those who adopted each other's names. The act was accompanied by a small ceremony. The friends offered each other sago, first putting a piece into their own mouths. Therefore this relationship was also called baj-rag-amör, sago-pieces exchange. When one of the friends died, his skull was taken to the house of the other to be kept there as a treasure. The transfer of a skull need not be the result of an already existing relation. It might also be the starting-point of a new relationship. If, for example, two groups wished to make peace they would present each other with a woman or with a child, but they could also offer the skull of a famous leader of their group to the leader of the other group. The beneficiary then adopted the name of the deceased leader whose skull he had received. This name was his so-called skull-name, muku-éké.

There was also the takwèk relationship, which existed between two men (or the takwowk relationship when the partners were women) who were born on the same day. They addressed one another as takwèk or takwowk. 
Finally, there were the ndajin relationships which were found between parental couples who had granted each other the privilege of naming their child after one of the other parents.

Those who moved to another settlement joined the qari/imu of their marriage partner in that new settlement. This did not mean that they renounced their ties with their own relatives. They also retained their own land rights and it was always possible for them to return to their own native settlements. Relatives in other settlements were called kaki. It was a term which indicated the relationship itself but it was also a term of address. The use of the term did not exclude the use of the other more usual terms in the kinship terminology. The kaki relationship was important both in times of war and in times of peace because a $k a k i$ was a vital link between two settlements. Those in a $k a k i$ relationship found both safety and food when they visited each other in hostile settlements. If their respective settlements were enemies, these relatives kept each other informed about the intentions of the people in the settlement they lived in. This information enabled the $k a k i$ to escape whenever hostile actions broke out. They simply hid in the forest till the fighting was over or they took refuge in another friendly settlement. It was also possible that a kaki stayed in the settlement to wait for the attack and participated in the hostilities. If he did so he would abstain from fighting against his own relatives. During the fight he could also protect his own relatives by standing up for them if they were attacked by his co-villagers. If the settlement wished to make peace again, the kaki acted as intermediaries. Whenever there were feasts, the kaki were among the first guests to be invited. They were the ada-wir, the invited ones. If there were any kaki who were unable to participate, they would not be forgotten. These abaqa-wir would be presented with food taken home from the feast by the ada-wir. To the other inhabitants of a settlement these outsiders were simply strangers and not kaki. In times of peace kaki restrained themselves from any hostile action which might have repercussions on the members of their own settlement. When settlements were at war all non-kaki were enemies to be killed and beheaded. 


\section{CHAPTER III}

\section{THE SETTLEMENT AND DAILY PURSUITS}

\section{The settlement}

When in pre-contact times the Jaqaj settled somewhere for a longer period of time, they often chose a strategic point where their fathers or grandfathers once had planted coconut trees. If there were no such trees, they would soon plant them themselves. Around the settlement they planted a dense strip of banana bushes. It provided the community with fruit and the women with a latrine area. This strip of banana bushes also served as a defence ring. Behind it they could take cover when the settlement was attacked. In times of danger they also built a fence of tree branches and shields in which only narrow openings were left. To further protect the site, the approaches to the settlement were kept narrow and winding, that is, if the settlement was situated in the forest, a rather unattractive place to people who, like the Jaqaj, love the sun and the wide vista of the open plain.

The Jaqaj distinguished between a temporary settlement, péoqowbbuaq, and a more or less permanent one, buaq. The latter was "more or less permanent" because the Jaqaj were continually on the move. When they moved, the groups that had constituted a permanent settlement now dispersed, each of them settling in a temporary residence in the neighbourhood of their sago- and fishing-grounds. Every settlement consisted of one or more men's houses and, at close quarters, one or more women's houses. The houses were thus situated so that every man could keep an eye on the women's house in which his own wife (wives) was (were) lodged. One should not assume that in a permanent settlement the different men's houses (with their conjoint women's houses) always stood close together in a small site neatly surrounded by banana bushes. This might be the case in a small settlement, but when the settlement consisted of several groups, more space was needed. Each group wanted its own corner. The same held true, and even explicitly, in the "temporary" settlements near the sago- and fishing-grounds of the various groups. A rule of thumb in site selection was that the distance between two settlements should 
be short enough to hear the sound of the head-hunting trumpet (a kind of wooden trumpet), the call for help coming from an adjacent group.

The Jaqaj distinguished between a house on the ground, moqonwuri; a house on low piles (c. two feet high), jambu-pauaq; and a house on high piles (five to seven yards high), pauaq-wuri. More important, however, is the distinction between the men's house, qaindaw, and the women's house, wuri. The men's house ${ }^{1}$ was a long large structure built on the ground or on short piles, with a slightly bent roof of sago leaves, job, which descended to about a yard from the ground at the two sides of the house. In these side walls were openings which could be closed with a couple of sago-leaf sheaths. In the front and the back-walls were small entrances which, in case of need, could be defended by one man standing behind his shield. The space within the house was subdivided by small fireplaces, each with a lattice above it where firewood was stored. These fireplaces were arranged in two rows to the right and left of the central corridor of the house. In this house the men lived, smoked their pipes, discussed the events of the day and devised plans for forthcoming head-hunts or retaliation raids. The spears were hung on the walls and the shields stood below them. The adults always had their daggers near at hand. The skulls of the victims of former raids hung from the ridge-pole. Two married men usually shared one fire, providing room for some young men who had to sit on the side near the corridor. The men's house showed a clear division into two parts. The Jaqaj therefore spoke of amaqowt-amaqowt or amandaq-amandaq. In each of these halves, men of certain groups had their places. One of them was the leader who had his fireplace either in the centre or near an entrance. The direction in which the men's houses were built was a matter of strategy. The leaders wanted to be able to see their own landed property. For the same reason, every settlement had an observation post constructed in a tree high above the ground. No stranger would venture into such a settlement without having a sound reason. Only when he happened to have relatives, $k a k i$, in the settlement could he safely enter it. His relatives were warned by the look-out and they provided a safe conduct into the settlement.

The women's house was usually built on piles several yards high. The door could be reached by a tree-trunk in which notches had been cut. This door was the only opening through which the house could be entered. This house ${ }^{2}$ was also divided by means of small fireplaces, 
i.e., by circles of women who belonged together, although every mother had a fireplace of her own.

Kinsmen called each other bor. This term, however, has not only the meaning of kinsmen but also indicates the two sexes in opposition to each other. The opposition between wir-bor, men, and taj-bor, women, was clearly noticeable in daily life. The men went hunting together, janggo-an, and the women had days when they went fishing together, kumör-an. Men and women were always separate; they never stood in a circle together to talk. Women and men were also separated when singing and dancing. Even if some task required the co-operation of many, the sexes remained separate.

In my time Képi still observed pre-contact practices. Not far from the present village there were four small settlements which had been built in earlier times by the four imu of Képi on the river Nanggéao, ${ }^{3}$ a tributary of the river Emeté. The Aqaoèmu and the Ikimu lived on the Togom side, and the Marapèmu and the Kamaqajmu lived on the Moin side of this little river. Each group had its own place. The majority of the Aqaoèmu stayed at Kupeqaé, the Ikimu at Apaw, the Kamaqajmu at Oaqatemoqon and the Marapèmu at Ebéababa. In each case the women's house had been built near the men's house of the relevant group. At Kupeqaé, the members of the Aqaoèmu lived with their leader Jaro and some Ikimu members who owned nearby sago groves. At Apaw some members of the Aqaoèmu had joined the Ikimu whose leader, Jaèndé, had an interest in certain plots of land which belonged to the Aqaoèmu, as well as in certain lands of the Ikimu. Some Kamaqajmu also lived in that settlement because of their nearby lands. The houses of the Kamaqajmu at Oaqatemoqon and the Marapèmu at Ebéababa constituted a unit around their leader Jabaqaj. Here too, the proximity of their sago groves was a decisive factor. Obviously, each imu built its own men's house, but the possibility that certain members of various imu would build a house together was always open. For this reason we may infer that those who lived together in one and the same house were interested in the same or neighbouring grounds.

The building of the new government controlled village of Képi was arranged by the district chief, F. Maturbongs. He let the people both choose a site where to build the new family houses and select their neighbours. In comparing the arrangement of the houses in the four old settlements on the river Nanggéao to the plan for the new village of Képi, we find that in the new village, where the immediate 
proximity of landed property was not an influential factor, the pattern of settlement was defined by imu membership. ${ }^{4}$ Within each imu the various qari had their own quarters. Further, close kinship determined who joined whom in the same house or as neighbours. Father and son, brothers and half-brothers, parallel- and sometimes cross-cousins, and even brothers-in-law were found together. At Képi, in 18 cases out of 42 families, the widowed mother lived with her son, in 10 cases with her daughter, while in five cases a widowed sister was found living with her brother's wife. The mother or sister was lodged in the house which her son or brother had built for his wife and children. A widow, however, never joined her own married sisters, probably to avoid becoming the second wife of her sister's husband.

\section{Daily pursuits}

The manufacture and upkeep of his hunting-gear received a man's continued attention. A man might have two or more bows, $m i$, and quite a number of arrows, mat. These arrows differed in shape according to their specific purpose. There were arrows for shooting birds, fish, pigs and for warfare. The shaft was always a cane and the arrow-heads were made of palm-wood, except that of the arrow for pigs which always was made of a broad piece of bamboo. The bird arrow had a pointed head with several barbed hooks. The war arrow was small and light, which made it easy to take along to the battlefield in great numbers. The arrow-head was always fixed to the shaft by a rattan tape wound round the shaft. This wicker-work has a standard pattern which allows each man to have a variant of his own which in turn enables him to recognize his own arrows. The bows were usually made of palm-wood. This wood was first split and then scraped with shells and rough leaves to polish the surface. Bows made of bamboo were rather exceptional.

To hunt wild pigs the Jaqaj built a fence, jataka, of piles and leaves and laid a piece of sago pith near this fence. By moonlight they waited until a pig came to eat its fill of the sago. Then they shot it from behind the fence. Occasionally they also built a little hut near this fence, jataka-wuri. Another method of catching pigs was by means of a trap, top. They dug a hole and put some sago on the floor. Then they constructed a large flap with one end resting on the ground and the other on a high but shaky support erected in the pit. The flap was weighted with pieces of wood. When the pig ate the sago it touched 
the support, the roof fell down and the pig was trapped. For the hunting of birds a hut of foliage, dato, was made in the swamps or in the neighbourhood of a spring. From this hut they shot the birds that came to drink.

A settlement was not a real Jaqaj settlement if there were not a great number of skinny dogs, qaké, nosing about around the houses. The men were strongly attached to these animals because they used them when hunting. The loss of a good dog affected them so much that the owner and his friends went into mourning as if a relative had died. The animal was put on a scaffold and the men abstained from the food which they thought had caused its death. The dogs knew their masters and refused to follow anyone else. In the eyes of the Jaqaj, a dog that had special talents owed these qualities to an excellent dog's soul which after its death had passed into that dog.

The Jaqaj had some fifteen different kinds of spears ${ }^{5}$ made of various kinds of wood and nearly all provided with barbed hooks. They used to make an abundant number of spears because these were their main weapons and many spears were lost during a fight. A spear was often left behind on the battlefield, planted in the ground as a symbol of victory. A warrior often planted the spear which had killed somebody in the well near his home settlement, expecting his wife to praise her fine husband in front of her companions. ${ }^{6}$ They also had daggers, made of the shin-bone of a cassowary, wajrip, or the jaw of a crocodile, nanggoradé.

In addition to spears and daggers the Jaqaj made shields, ${ }^{7}$ qobun. They were cut out of the plankroots of large trees and adorned with carvings. White and red dyes were used to bring the motifs in full relief so that they could be seen from a great distance. The Jaqaj also made war trumpets, puk, and drums, $k i n d o{ }^{8}$ The manufacture of these instruments took much time; a massive block of wood had to be hollowed out slowly by fire. Not all kinds of wood could be used for making drums. As a rule the mitebo wood was used for this purpose. Only those kinds of wood that do not easily split were chosen, because the hull of drums and war trumpets had to be thin. The skin of the lizard, téin, was used as a drum skin, èmber, which was affixed across the opening with a sticky tree-sap. Before using the drum pellets of resin are put on the skin and then heated by burning firewood. This made the wet skin shrink and braced it before and during use.

The rough work on a new canoe, jun, ${ }^{9}$ was done in the jungle. A tree was cut down, hollowed out and given the rough shape of 
a canoe. This being done, the canoe was dragged to the water by the carver, his brothers, brothers-in-law and his head-hunting friends. A path along which the canoe could be dragged was cut open and small branches were laid on the ground across which the canoe could be rolled. The canoe was then hauled through the marsh to the village and there set on dry land where the work was finished. The inside was smoothed and the bottom of the canoe flattened. The maker felt with his fingers, one hand on the inside and the other on the outside, the thickness of the hull. When the work had to be interrupted leaves were put on both ends of the canoe to keep off the sun, which might cause the wood to split. When finished the canoe was scorched on all sides with burning coconut leaves. Then the canoe could be launched. Small canoes were used for fishing only. The building of a larger canoe was a lengthy and tiring job, especially when it had to be done with a stone axe and fire. Such large dug-outs were of great importance to the Jaqaj because they used them in warfare. Ideally canoes should last for at least as long as a man's life, and therefore they were well cared for. In pre-contact times, such a canoe was always pulled ashore and put under a roof to protect it from the sun and the rain. Such canoes were also adorned with carvings. The motifs of these carvings on the bows of the canoes were obscure. As the carving-work was roughly done, I was unable to determine either the exact forms or their meanings. The sides of the canoes were adorned with a meanderlike motif of the same kind as that found on shields. It consisted of a wide band patterned in white and red and divided by black lines. A canoe was not only a means of transport but also a means of burial for men and women. The corpse was laid out in an old dug-out which was placed on trestles in the open air. Here the corpse was left to decompose. These canoes on trestles could only be pulled down after a head-hunting raid had been held.

Oars were made of a special kind of wood, baq, and therefore called $b a q$ as well. They were six to seven feet long. The top end was pointed and the lower end had a broad blade, approximately eight inches wide and twenty inches long. The blade was adorned with carvings. The motifs were the same as those on the shields. The blade of the oar had to be broad because the oar was also used as a punting pole when crossing the marshes or swamps.

Each sex had its own methods of catching fish. The men made long, funnel-like fish traps, kakap $^{10}$ of thorny rattan and put them in the swamp. They also set up traps behind a weir ${ }^{11}$ of leaves, wambé. 
Another method of catching fish was by spearing; the men roamed through the swamps near the settlement using only a spear, $q \bar{a} m$, made of bamboo which had several pointed heads standing slightly apart. Sometimes they shot the fish from a small platform, abakaèp, on the bank of the river. When doing this, the man first laid a number of green leaves on the bottom of the river, so that he could better distinguish the fish. When the swamps became dry, men and boys pricked the mud with thin spears in search of small water snakes, manggi. The women almost exclusively used a large conical fish basket, ${ }^{12}$ enèm. The manufacture of these baskets was a woman's job, but not every woman was clever enough to be able to plait the lianas in such a way that the basket tapered into a point at the lower end. With these baskets the women searched for small crayfish and other small water animals in shallow water. This method of fishing was called pedajn-an. Usually they collected a heap of weed, uraqam, in which the crayfish liked to nestle. After some days they turned the uraqam over in their fish baskets and then picked the little animals out of the weed. Sometimes the women fished in a group. They formed a large circle in the swamp and scooped up the fish with their baskets after driving them to the centre by closing their ranks and walking to the middle, kumör-an. During the dry season, men and women repaired the weirs in the smaller rivers which still contained water. Then the men rubbed the qomaq root as a fish poison into the water. The women closed the gates in the weirs with their baskets and collected the poisoned fish. At the beginning of the wet season, when the rising water carried the fish up the small rivers and swamps, men and women worked by the light of torches, mapör, and caught a lot of fish, mapör-an (plate 10b).

The Jaqaj lived on the sago they found in the area where they had settled. This sago grew in the shallow valleys among the hills and on the banks of the little rivers. Usually the Jaqaj did not spend any time on the upkeep of their sago property. At most they cut away the underbrush which hindered the growth of the sago trees. In the clearings formed by the harvesting of ripe sago trees the groves are restored by nature. A full-grown tree might yield some 300 lbs. of sago meal, baj. The pith was broken out of the tree with a sago pounder, $i k$. The fibres that were freed were soaked with water and wrung out by hand. For this purpose a gutter ${ }^{13}$ was built by means of sago-tree leaf-sheaths, taèm. One of these leaf-sheaths was set at a slant and another was laid on the ground like a small canoe. At the top of the slanting gutter 
a sieve, pur, was attached. It was made of the fibre of a coconut tree found between the tree trunk and the branches. The liquid, squeezed out of the sago pulp, flowed through this sieve, retaining the rough fibres and allowing the water mixed with the sago flour to flow into the gutter on the ground. Here the flour settled on the bottom. Finally, the layer of sago was rolled up and put into a bag, $i b a$, made of rushes. In this sago bag, which acted as a mould, the still wet sago was drained and dried near a fire into a block. From such a block a piece could be broken off and roasted in hot ashes. On the outside a thick skin, baj-poqoteki, was formed. This skin was peeled off and eaten. It was also possible to scrape off some flour from the block and put it in nibung leaves, qob. After these leaves had been filled with sago flour, they were tied up with a fibre string. Often this meal was mixed with coconut water, coconut meat, fish, meat or sago grubs. This thick bar was baked in hot ashes. In the course of this baking process the leaves singed away. The sago bar, baj-kida, was broken into pieces, divided among a group of people and eaten.

Sago was the staple diet of the Jaqaj. It was eaten twice daily, in the morning and in the evening. A block of sago, when dry, weighed about 50-60 lbs. and provided a family of father, mother and four children with enough sago for two weeks. In the remnants of harvested trees, or in unripe trees deliberately cut down for this purpose, the sago beetle, mboné, laid its eggs. These eggs developed into grubs, qondin, which were eaten as a delicacy in all their stages of development from larva to beetle. They were eaten fresh or roasted, just as they were, or mixed with sago. Moreover, sago groves provided a place to hunt pigs.

The Jaqaj derived their food from sago pounding, fishing, and hunting (pigs, cassowaries, birds, cuscus, rats and mice), supplemented by coconuts, fruit and vegetables (leaves, stalks, roots, young shoots of bamboo, sago and nibung palms). Apparently they had little interest in gardening. In the past, only the planting of tobacco, tamangkjaq, was done on a relatively large scale. In former days, the men of Képi killed quite a number of men from Togom in the tobacco garden, where they had given them permission to come and gather tobacco leaves. At head-hunting festivities it was the custom for the two groups sharing a men's house to throw packs of tobacco leaves to each other.

In the southern district the Jaqaj also knew of another stimulant: kava, in Jaqaj called wari. This stimulant was probably borrowed from the Marind people. Only older men chewed this plant. In the 
past, every parent would also plant some coconut trees for his children. It was very seldom that anyone planted sago trees. They knew of sweet potatoes, taro, and sugar-cane, i.e. déka, toqomi, and mék respectively. Still, in spite of all this, gardening among the Jaqaj is not worth mentioning.

Every older man (and often older woman) had a pipe. ${ }^{14}$ It was made of bamboo and consisted of two parts: a bamboo stem, one inch in diameter and about fourteen inches long, and a small piece of bamboo fixed in the upper end. In the small bamboo piece they inserted a rolled leaf of tobacco. In the thicker stem the fibres of young palm leaves functioned as a kind of filter. When saturated with nicotine these fibres eventually could be smoked as a substitute for tobacco. In the glaze of the stem they scratched ornaments which looked very much like lengthened human figures.

The Jaqaj also had the regular task of providing enough firewood, réka. In pre-contact times this entailed a lot of work, for their only tool was the stone axe. Making fire was not easy either. They sometimes did this by pulling a rattan bow-string rapidly to and fro under two sticks on which they had placed their feet. Another method of making fire was by moving the end of a piece of bamboo shaped like a chisel through the hollow part of a split piece of bamboo. In both cases, they placed a bit of fine fluffy sago-fibre at the point where the friction was strongest. This fluff would catch fire. Making fire demanded a great deal of exertion and the Jaqaj never allowed a woodfire to go out. Even in their canoes they took fire with them, so that they need not make it on their way. For this purpose they coiled together the fibres of a coconut; this lay smouldering in the wind on the bow of the canoe.

Both men and women shared in the care of utensils and ornaments. The men made water tubes, ndun, for themselves and their wives. They cut a bamboo stem as thick as a man's upper arm and some six or seven foot long. The coating was chipped off with an axe and the underlying wood was scraped and chiseled until the bamboo tube was equally thin everywhere. The septa of the bamboo were pierced with a stick. Sometimes the tube was painted with qajtépé, a dye from a fruit of that name. From a hard kind of wood, $i k$, the men made sago pounders. The sago pounder looked like a pickaxe. The beating surface of the crossbar was burned out to form a pit with sharp edges. The shaft was about three feet long. Both pieces of wood were tied together with an oblique piece of wood. The men also made clips, i.e., small 
round bars which had at the lower end, as it were, a saw cut by which the sieve and the edge of the sago gutter were squeezed together. These were things a young man made for his beloved.

The women made mats of rushes, kabi; they plaited bags for carrying sago, iba. Every woman made her own perineal band of tree bark, maqaw-roqoj, and from young sago fibres she twined strings for making skirts, roqoj. A time consuming task was the manufacture of women's mourning costumes which completely covered their bodies.

The men made a fibre "tail", ék, for themselves as their anus cover. They also gathered the material they needed for their own ornaments and those of the women. They sometimes made long journeys across enemy territory to the sea to gather the much coveted shells near the mouth of the river Odamun. The larger shells were hung on a string around their necks or their waists (especially triton shells, mbé). Other shells were cut into a curled ornament, gajngga, ${ }^{15}$ which the men wriggled through a hole in the septum of the nose till it stood up on both sides of the nose like "the tusks of a boar". Around their necks they hung strings of dogs' teeth. The Jaqaj used to paint their bodies when they went on a head-hunt, and afterwards when they celebrated their successes. As a red dye they used either burnt earth, ao, or the dye made from the qajtépé fruit. For a white dye they used the lime from burnt shells. To decorate themselves on festive occasions they shot birds of paradise. They put the whole bird with all its feathers on their heads. During the singing and dancing the feathers colourfully fluttered above the swaying heads. ${ }^{16}$ For the costly marks of honour ${ }^{17}$ given to great head-hunters they needed beads, which were taken from the fruit called abé.

The men did the fighting and saw to it that feasts were properly celebrated. The women contributed their share by raising pigs, batik. Among the banana bushes and the coconut trees the half-tamed pigs searched for food. Worms and vermin were found everywhere and thus the pigs also cleared away any wasted sago or discarded vegetables. In the morning and in the evening the women called their animals, fed them a piece of sago and thus established a personal bond. Utensils were private property. Those of a strictly private nature were deposited in the place where a man was buried or laid in state (his hunting- and fishing-gear, his weapons, drums, etc.). Things which the deceased had used in common with others (a canoe, domestic utensils, etc.) were retained for use by the others. Pig traps and weirs were inherited by the children of the deceased as were the pigs and 
the dogs. The qari or imu had its say in this matter.

In a Jaqaj settlement there was little activity during the daytime. In the men's house one or two old or sick men stayed. Occasionally a man might come in to get something he needed for his work. In the women's house it was slightly busier. Here the old women watched over the little children. Everyone, however, who was in the prime of life left the settlement in the early morning. Some families went out to gather sago. Groups of women fished near the settlement. Men checked their fish traps in the swamps or their pig traps in the forest. Several men might be out hunting, others might be away visiting a nearby settlement. The boys went with the men and the girls with the women. Everyone had his own responsibilities in collecting the food for the day. The life of the adults, however, was never free from tension. Misfortune could occur at any time. The men might be away taking revenge elsewhere. The women could become the objects of a hostile attack anywhere. Within the community itself peace might be disturbed by all kinds of conflicts. There could be cases of theft or adultery. Nobody really trusted anybody else and cases of discord were a daily occurrence. Tempers could flare high, inevitably resulting in the challenge to a fight. Usually a suspicion voiced aloud was enough to cause an argument which might lead to a fight. Someone might accuse a fellow-villager of pounding sago on his land or of emptying his fish traps. Even if guilty the culprit would deny it. If he was innocent he would feel that his honour had been injured. In both cases an altercation followed, and it might grow fiercer and fiercer. Fresh accusations flew to and fro and soon one of the parties could be accused of adultery. If at that moment someone took up arms, the whole settlement went into an uproar. Sometimes they forgot the real cause of the fight. Any opportunity to renew existing feuds was embraced because former defeats were not forgotten and revenge was always foremost in their minds. It was hard to say beforehand who was going to stand up for whom. An unimportant side-issue, which initially did not play a role at all, could suddenly become the main issue in the general dissension.

Certainly in the past there was also a continuous tension between the men and the women of the settlement. The men's house used to be open to the women on certain occasions only. Although by daylight the men were free to visit their own wives in the communal women's house, the two dwellings remained separate units which kept their secrets from one another. When the boys took up residence in the 
men's house they were told to keep silent about what happened there. Yet the men realized that fighting against the solidarity of the women's house was difficult. The women knew how to enforce their will and they had powerful weapons at their disposal. All food provisions were stored in the women's house. In their house the meals were prepared and they could withhold food. In married life much of the initiative rested with the women; they could refuse to have sexual intercourse with their husbands. Sometimes the men defended themselves by eating secretly that which they had hunted that day. Occasionally they gathered their own sago. But they could not resist the women for very long. Physically the men were able to master the women. Violence was the ultimate way of asserting their wills, even if this meant that they had to kill their own wives. The women realized this and they observed certain limits when resisting the men. Officially, the segregation of the sexes was maintained. In the subsequent discussion of the contacts between the sexes before marriage and of marriage and family life, I shall define the limitations of this segregation more precisely.

In these tensions and conflicts the authority of the leaders of the qari and the imu was a stabilizing factor in the communal life of the people. Personal prestige and not heredity gave authority to these individuals. Yet this prestige was founded mostly on physical strength and the readiness to fight. It gave substance to their right to interfere in decisions about membership, marriages, boundaries of property and all struggles connected with the correct use of the land. They could take upon themselves the guardianship of orphans. They arranged property to be used for the celebration of festivities. They displayed their authority not only within their own group but also when in contact with other groups. They could transfer rights to certain plots of land to outsiders and above all they were the leaders when the group's property had to be defended against others. In subsequent chapters we will see them asserting themselves in the fights among the settlements and in the head-hunting raids.

The Jaqaj came to recognize three basic forms of authority:

1. the poqoj-radé or leader;

2. the akiaq-rade or adviser/counsellor; and

3. the joqbera-radé or spirit intermediary/seer.

The word rade means "man" in the singular. Its plural form is wir, which denotes both "men" and "people". The corresponding female terms are taw (sing.) and taj (pl.). The adjective poqoj means big or 
great and may be used either before or after the noun with the same meaning. In either case it means literally "the big man", or more freely translated "the leader". The term poqoj-radé has already been mentioned in our discussion of qari and imu. It is not entirely clear whether they derive their authority from their capacities in matters of war or from some other sort of appointment to this position by a predecessor. In Képi the Kamaqajmu leader, Jabaqaj, did not have the same authority as Jaro or Jaèndé because he did not have any captured heads to his credit. At Emeté the poqoj-radé was appointed by his predecessor. It seems that both ways led to the advancement to leadership functions.

The second important leadership function is that of the akiaq-rade ${ }^{18}$ (or its female counterpart, the akiaq-taw), an adviser or counsellor. The word akiaq has many connotations. It denotes incidental advice as well as cultural interpretations handed down from generation to generation and explanations of sanctions traditionally associated with social events (e.g. stabbings, killings, etc.). Occasionally the term tibu is used to replace the word akiaq. It has the same basic meaning, viz., that of wisdom based on the knowledge of traditional lore. The authority of the akiaq-radé/taw, unlike that of the poqoj-radé, depends upon appointment by a former akiaq-radé/taw. He (she) chooses a younger member of his (her) own group who displays diligence, openmindedness and docility towards his or her elders. Such a candidate must be willing and able to learn everything about landholding rights and the complicated marriage regulations, as well as about the central importance of head-hunting in the lives of the Jaqaj. At regular intervals the old counsellor will summon his chosen successor in order to pass on his akiaq to him. This successor need not be the former akiaq-radé's (eldest) son. The criterion is always his ability; this is ultimately the reason for his acceptance by the whole group. The pedigree of the akiaq-radé is always remembered. ${ }^{19}$ If an akiaq-radé dies unexpectedly, the group has to go on without a replacement. They may even put themselves under the akiaq-rade of another group living in the same settlement. The exact relation between the radépoqoj (i.e. war-leader) and the akiaq-radé/taw (i.e. counsellor) is not completely clear. There are poqoj-wir who also function as akiaqradé. ${ }^{20}$

At Képi I had the opportunity to record much of the akiaq of the man Tambim. My interpreter Jabajmu was his second son and had been chosen as his successor. There was another akiaq-radé, Jaèndé, 
but unlike Tambim he was also a poqoj-radé, a war-leader. The leader of the Aqaoèmu, Jaro, was primarily a great war-leader. He was rather talkative, especially when he was angry, but his people did not call him an akiaq-radé. In the village of Dagimon, Jānda, the leader of the Qamoropimu, was also the counsellor. He used to walk through the village shouting aloud his akiaq in long monologues which were met by a surprising silence in the houses he passed. From him also I received several pieces of information.

A third bearer of authority among the Jaqaj is the joqbera-rade or joqbera-taw. The exact meaning of the word joqbera is unclear. The joqbera-wir/taj appear in the lives of their fellow men at critical moments. They announce the birth of a child that will not be normal, they have to fetch back the souls of sick people, they are questioned by men who wish to go on a head-hunting raid and want to know whether it is right for them to join in, or whether they had better stay at home. Before the raid they "catch" the souls of the future victims, they bestow their blessing on the men who set out, they can place a ban on certain grounds, etc. Unlike the akiaq-radé who is appointed, the jogbera-radé gains his authority on account of his recognized ability to enter into contact with the invisible powers. It is obvious that not every imu or qari can have such a joqbera-radé or joqbera-taw of their own. Actually, only the name of one person in the generation of Tambim was mentioned for all the groups living at Képi.

I was not able to get any information about the female intermediary, the joqbera-taw. I wonder if among the "wailing" women who were always present at a deathbed there were some who deserved to be called joqbera-taw. At Képi, these women were always midwives. When asked why, they pretended not to understand the question. 


\section{PART II \\ THE LIFE CYCLE}

\section{CHAPTER IV \\ PREGNANCY AND BIRTH, BODY AND SOUL}

\section{Pregnancy and birth}

As soon as a girl has given the wedding-sago, baj-naki, to a young man, she is looked upon as his wife. Every time she has her monthly period she must inform her husband and on those days both must abstain from eating fish and the man from smoking tobacco. The akiaq says, "Woman, when you bake fresh sago, make it known if you have your menstruation. If you do not tell your husband, he will beat you. Your husband might eat fish and smoke; if he wishes, he is allowed to smoke sago fibres (the filter in his pipe)." The woman is not allowed to go fishing in the swamps because her blood might drive away the fish. If a wife does not inform her husband about her menstrual period, he will take it so ill that he will beat her up, because he is put to shame in front of the other women who certainly know about his wife's menstruation. The akiaq continues, "Men, if you divide fish while your wife has her monthly period, your legs will swell. When you work, your eye will no longer be steady, you will get weak and become very thin. Observe the abstinence."

After a wife has been given to her husband by her parents, the couple join in some of their daily activities (e.g. gathering sago and laying out a garden). As soon as a wife becomes pregnant, kandöm kubèn, she informs her mother(s) and sister(s) and presses them to spread the news around. Obviously, the community as such appreciates children and the spreading of the news is an important means of preventing abortion. 
According to the Jaqaj, the sperm is contained in a tube, kikenör, which runs from the hollow of the knee to the scrotum and the penis. The function of the testicles is to effect the erection. But, so they say, these organs do not produce any fluid. In the seminal fluid they distinguish two component parts: the bōt-dépi, which is secreted first and penetrates deepest into the female organ; and the dépi, which is discharged afterwards. They think that only the bōt-dépi causes fertilization; the dépi is of less importance. When an enemy was beheaded and later cut to pieces, they first cleaned the skin on the inside of the thighs. There the dépi is found, they say; the bot-dépi is supposed to be found nearest the male member because it always comes out first. The woman also contributes a fluid during the coitus and this is called kabaqaé. The Jaqaj thought that this too originated in the upper legs. They knew nothing of ovaries or Fallopian tubes. They were convinced that a child is conceived by the "sticking" of the böt-dépi, which can only be effected by frequent copulation. In every case a newly born child was carefully studied. If it resembled the father, the male fluid had prevailed; if it resembled the mother, the female fluid. If the child did not resemble either parent, it was thought to be the product of adultery. The reactions of the parents and their family determined whether the child was accepted or killed. Pregnancy announces itself by the cessation of menstruation. They said that the monthly bleeding stops because the blood coagulates when the growing process begins in the $u w a$, the womb. Some women have the uwa near the backbone, jomé-ja, and therefore have difficulty in becoming pregnant. Other women have the uwa near the bladder, benön, and get pregnant easily.

The Jaqaj believed that the vital principle moke originates in the abode of the dead. Early in pregnancy the parents ask the spirits of the deceased, idöm, for a "child", moké-maq, which will give life to the child. This arrival of the soul is an event which they compared to adoption. They said, "This child is quick to get ill, probably it just dropped in" or, "This child will die, it wishes to go back to the abode of the shades". Or, "They really have given this child, or else it would have died". The transfer may happen through the intermediary of birds, snakes and lizards, which are invoked and even spared during that period, although at other times they are hunted and shot as usual. So they said, "When the cockatoo, amani, cries, it is not the bird itself but the vital spirit. It cries and passes from the bird into the mother". Although the soul of the child must come from the idöm (the deceased), 
the idöm were also feared precisely because of their relation to this new life. A mother warned her daughter, "Daughter, do not go far away during the night to relieve yourself, stay in the settlement and relieve yourself on a leaf. In the morning you may throw it away at the edge of the settlement. A shade might get hold of your navel-string. If you go to relieve yourself, leave your fibre skirt hanging over your anus, lest a shade should throw his scrotum, wamba, at you. You would die from it." "Throwing of the scrotum" means having sexual intercourse.

The Jaqaj were well aware of the successive stages of development of the foetus in the womb of the mother. When I asked my informant Jabajmu how they got to know all these details he answered, "Our people slaughtered so many women on their raids in order to take the heads of the unborn children from the wombs, that they know quite well how the development of a child in the mother's womb proceeds".

The Jaqaj watched over the well-being of mother and child. The akiaq says: "Woman, you are not allowed to pull loose anything that has got jammed, or else your blood might contract and that is bad, for you would become thin. If your belly is swollen you should not eat much sago, or else you might fall and have a miscarriage. I command you very sincerely: do not carry too heavy a load of firewood, etc." During her pregnancy a woman must abstain from various kinds of food. The abstinence is called toqomör. The akiaq says: "If you eat any large fish, the delivery will be the death of you and your child. Do not eat any cassowary or a long-legged hen, your child might be backward (walk slowly). Do not eat cuscus, your child might become short of breath. Do not eat birds whose sounds are like the crying of babies, for these animals might pass on their own crying to the baby. Do not eat fish whose scales resemble the scabs of small wounds on the head of a child, your child might have similar wounds on its head. If you encounter a snake, maybe it is the vital spirit of your child, and the snake might carry away the spirit and your child would die. Do not look up at a tree that is split at the top, you might give birth to twins. Do not eat any of this forbidden food. Comply with the rules of abstinence and your child will be all right." Twins can be the result of the extraordinary potency of the father. Jaèndé, so they said, had more twins than others because of this. Twins can also be the result of intercourse which took place after the child had already started moving in the mother's womb. 
The Jaqaj tried to find out whether the child would be a boy or a girl or whether the mother was going to have twins. The mother will say, "Woman, you walk with heavy legs, it is going to be a boy; if it were a girl, you would have less difficulty in lifting your legs when you are looking for food or when you walk through the village". They also examined the stools of a pregnant woman: when they were round, the woman would have one child; when the stools were flat, the woman would have twins.

The parents were so occupied with the child that they even spoke to it in the womb and expected help from it. They would say: "Child, I am now going into the swamp, give me some fish so that I can eat it together with you. Darling, hold the pig so that I can shoot it from behind the fence." Therefore, men and women wanted to touch the belly of a pregnant woman or asked a man whose wife was pregnant to do this for them. They would say: "Jabajmu, tonight I am going to hunt pigs; lift your child so that it may hold a boar".

A sterile woman, ndim-taw/taj, was suspected of having eaten or chewed certain twigs or leaves before or after her marriage. A miscarriage had to be explained and everybody searched for a reason. People whispered to one another concerning the explanation. They were not satisfied unless they found clearly demonstrable causes such as a fall or a blow that the pregnant woman had in a fight. The usual explanation of a woman, that she unknowingly slept on her belly, or that she was the victim of the shade of a deceased person, would not protect her from being suspected of wilful abortion. The Jaqaj knew methods of aborting a child by using physical violence and these methods were strongly rejected by the community. A woman who committed this crime kept it a secret. She was afraid that her brother might kill her because she did not live up to the rules of the exchange marriage. She also feared that her husband would reproach her with, "Who will now replace us after we are dead? Who is going to take care of us when we are old?" Sometimes a woman resorted to abortion because she was ashamed that the child was illegitimate. The possibility of illegitimacy was one of the reasons for making inquiries in the case of a miscarriage. If a woman was forced to confess to adultery because the evidence was obvious, a fight between her husband and the accused ensued. This fight was a bloody one and relatives of both parties joined in it.

Once the child began to move in its mother's womb, caution increased. The husband refrained from sexual intercourse. If the child 
was in an incorrect position the mother of the pregnant woman tried to turn it. When the day of delivery drew near, the woman started plaiting ribbons which she used to lace up her belly after the delivery. She was advised not to go far away and to see to it that she was not alone when her time was near. Her mother said: "When the child becomes quiet, your time is near. If the brains and the nails are fully grown, you will be confined."

Confinement took place in the women's house or (in the Nambéōmön district) in a confinement hut. At night the husband and his brothers lighted a fire outside and kept watch, lest a spirit should swallow the blood. The women who massaged the woman's belly spoke to the child in the womb, "Whether you are a fishing net (a girl) or a bow (a boy), appear quickly". The child was urged to hurry by the suggestion that there was no time to be lost, "The men are almost back from their raid; the festivities are drawing near. The village is starting to move away from here, they will leave us behind." The woman in childbed was told, "When your child starts moving, breathe deeply. Think of yourself. Once you have given birth to your child, you will feel fine. When the child has thrust out its head, kneel and you will give birth. After a little rest the pain will start again and you will bring forth the afterbirth, kao." If the afterbirth did not come easily or only partly, the women tied a string to it in order to prevent it from being drawn inside again. If the afterbirth did not come out, a spirit or shade was blamed. The woman died. A miscarriage was called modi-maq, a child like a small lizard.

After the placenta was expelled the umbilical cord, jandoao, was cut off with a sharp splinter of sago rib and the end of it smeared with ashes. The stub of the umbilical cord on the child's belly dried up and fell off. This stub was sometimes kept and hung on the wrist of the baby. When the child was a little bit older, this piece of the umbilical cord was burnt and eaten by the child in order to make it strong. The afterbirth was put in a carrying-bag and buried. When the hole had been filled up, a fish basket and a shield were laid on top, and around it arrows were stuck into the ground lest the shades should come to eat the afterbirth. If the afterbirth was laid in running water or if a coconut tree of banana bush was planted in the hole where the afterbirth had been buried, the woman was not expected to have any more children.

For some time the woman stayed indoors in her own corner, which was partitioned off with a mat behind which she and her baby had 
some rest. As soon as the moon was new she came outside again. She went to take a bath; she burned the palm leaves, qob, on which she sat, and the coconut fibres with which the baby was cleaned. She warmed herself near the fire, decorated herself with a triton shell, mbé, on her back and went with her child to the houses to show it to the people of the settlement.

The female relatives brought her qaqaé, swamp plants. The new mother was not allowed to eat fish but had to eat the meat of game found in the forest. Thus the husband had to go hunting. This abstinence from fish was called akumör, and it was also observed by the husband, the parents and furthermore all those relatives who wished to show their sympathy. After the end of the akumör period the relatives of the husband and wife went fishing in order to reward those who had abstained for their deprivations. The voluntary submission to abstinence of their relatives must be recompensed later on by a distribution of sago grubs and pork and by rendering the same services to them in similar circumstances. The parents remembered who pounded sago during the period that the mother herself could not do this, who was present at the confinement, who acted as midwives and cut the umbilical cord, who gathered swamp plants for the mother and the child and who buried the afterbirth. They knew who joined them in their abstinence, who helped the father to provide meat during the akumör period, and who went along to fish when the period of abstinence was over. All these persons had shown an interest and thus had laid a basis for later claims on the child.

There was a special practice for women whose children died one after another. The woman was to dress up and hold a dancing-spear, qajapo. Some children must hide. The woman then came rowing to the landing-place for the canoes. From there she danced to the settlement, brandishing the spear as if she wished to stab the children. The children must throw dirt at her. She said (addressing the shades), "You have to give me children and when I give birth again, you must not let the baby die". The purpose of this ceremony seems to be a show of courage and strength, proving that the woman was worthy to have strong children.

\section{Body and soul}

The Jaqaj distinguish between body, watoq, and soul, moké. They also distinguish between the outside, rumba, and the inside, moka. 
The word rumba is synonymous with the word rumb, which denotes the rind of a fruit, the bark of a tree, or the skin of a human being or an animal. In contrast we find the word moka, which indicates the core, the marrow, or the interior of man and animal. There is only one further distinction to be made as far as the word moka itself is concerned: in man and animal the Jaqaj distinguish between male and female and express this with the masculine moké and the feminine moku. Watoq is used for body, but it really stands for the trunk as opposed to the head, muku. In the eyes of the Jaqaj it is self-evident that the head is the most important part of the body. In figurative speech the word for head is also used to indicate what is the most important part of something, for example in the compound énöm$m u k u$, the head of the river, the source. As far as human heads are concerned, there is a difference in appreciation among the Jaqaj of the heads of relatives and those of non-relatives. The skull of an ancestor has lasting value. The skull of a deceased relative is cleansed after the fleshy parts have decayed, and is then kept in the house as a treasure, or carried on the back of one of the women of the family. Such a skull protected against illness and could be used to enter into contact with the shades. It could also be used as a pledge of friendship in the naröm relationship, or as a security for the maintenance of peace. A skull captured on a head-hunt had no such value; it was only a war trophy. I never heard it said that the head was the part of the body in which the soul resided.

Both male and female Jaqaj decorate their heads. Several motives play a part: the wish to look impressive and, for the males, the wish to gather courage by looking like a large boar. Dress also stresses the difference between men and women and among men it indicates differences in rank by the use of various marks of honour. The Jaqaj looked upon ornaments as a kind of "medicine"; they increased a person's strength. If we compare the men's weapons, shields and canoes with their dress adornments, the idea of "medicine" appears to be the same in both cases. The way the women decorate themselves seems to be an imitation of what the men do. body.

Here follows a list of notes about the various parts of the human 1. The hair, muku-rumb, was paid attention to when somebody was ill and during the age ceremony for the children. In both cases the hair was shaved off but in the latter case replaced by ornaments. The hair of a captured head was used to decorate 
spears and to make waist-bands, qowa, for the great head-hunters. 2. The face might be painted for celebrations. They made use of a butterfly pattern, rur-doka $k .^{1}$ By painting the parts around the eyes in bright colours the eyes looked like the black dots on the wings of a butterfly.

3. The eyes, kind, may represent a person as is stressed in the advice: "The wedding sago should be given under the eyes of the sun, tapaqkind-kan".

4. The ear is associated with using one's brains. A stupid person is a person without ears, mono-ain-mbék. The expression mono-koame, there is an ear, means, "we too are able to think".

5. The nose, tamangk, was specially adorned by pieces of a shell and claws of birds. Tamangk qana, hard nose, is a sombre and determined face.

6. The mouth, mèm, is always associated with eating. Mèm rènggèm$b a k$, big mouth, does not refer to an impudent person but to a glutton. The mouth has a special function in the custom of taking a mouthful of water and sprinkling this over the face of a person who has lost consciousness. The gestures of putting out one's tongue or of spitting on the ground in front of somebody's feet are insults, which lead to fights. The tongue is also said to be a delicacy (just as is the ball of the thumb) for cannibals.

7. Shrugging one's shoulders was not an expression of ignorance but of fear. In the presence of men, women may stand together with hunched shoulders as a token of decency, but the men know better. They say, "If they were alone with a man, they would all too much like to have sexual intercourse".

8. Chin rubbing or nose rubbing, as among the Asmat, is not a Jaqaj custom of greeting. They used to lay their right hand in the left hand of the other, who then clasped the first man's fingers. Men kiss each other on the cheeks but do not kiss any women, not even their own wives. Women usually do not kiss one another.

9. Breath is not associated with the notion of spirit. Breathing proves that somebody is still alive.

10. Women adorn their upper arms and the place between the breasts with scarifications. The girls gladly suffered any pain in order to have these marks. The men are greatly interested in the breasts, abur, and in the size of the female genitals, jo. The women in turn gossiped about the bellies, kandöm, and the anuses, mo, of the men. These parts of the body always turned up in my list of words of abuse. 
11. Children were not allowed to touch the inside of their mother's thighs. The "inside of the thighs of his wife" was the place where the ancestor Kapaqait took the seeds for planting vegetables. The pubic hair of women and the fibres of their perineal bands were smoked in the peace pipe. They said that the hymen should remain untouched until after the first menstruation. Sperm and urine could be used as medicine. The myth of Ujoqot relates how he created a human being by smearing his sperm on a coconut.

12. The anus, mo, had a special cover, a tail, èk, of fibres. Whenever a man was ill, he would always ask whether he was lying decently. To touch a man's anus was either an appeal to his strength or a very serious insult. Breaking wind proved that one had eaten too much. If it happened in the presence of men only it did not matter, but in the presence of women, especially in the presence of one's own wife, it could be perilous for them or her. Women incurred the risk of being killed if they looked at the excrements of their husbands. Husbands feared their endless reproaches about eating too much.

13. The penis, paqadi, or the pubic hair of a man drew less attention. They did not wear any shame cover. The term paqadi, penis, was often heard as an expletive. The most stupid thing that a person could do, they said, was to hurt his own anus or penis.

14. The fluid oozing out of a decaying corpse was not used for any special purpose. The only thing that happened after a corpse had decayed was that children were told to trample the ground where the burial platform had been. This was done so that they might become the worthy successors of the deceased.

15. Body odour, especially that of the armpits, was believed to have a special defensive power against spirits. A person's shadow did not get any attention. One was free to go and stand on another man's shadow.

In order to understand what the Jaqaj mean by moké, soul, we should not begin with this word but with another, viz. bana, which has a wider meaning. Drabbe explains it in his word list as follows: "Bana: the spirit which procreates, or perhaps which animates the child after frequent cohabitation of husband and wife". The difficulty in this explanation is the first word spirit. What is a spirit in the eyes of the Jaqaj? A bana is always a living being which, like man, thinks and acts. It can adopt any shape. The Jaqaj speak of a moqon-bana, a ground spirit, and a muj-bana, a water spirit. Thus a bow, or a tree 
from which a bow is made, can be a bana. The sago which is so important in life, or a bird which has a special task (passing on messages), can be a bana. The jaqar and the aburi (ground spirits) are bana and the shades of the dead are bana. Drabbe reports that "bana is also used for watches and engines. There is a noise inside these things, they do something: the hands move and the pistons move up and down." Drabbe continues, "bana-maq, literally child of a bana, is the bana in a human being". This then is another name for moké, which I have translated as "soul". When Drabbe explains moké, he says of it, "soul, vital spirit, the same as bana". Behind this latter bana, however, he places a question mark. Here is the same caution that he showed in his explanation of bana as "a spirit which procreates, or perhaps animates the child". Men and women together can beget a living foetus, but if this foetus is to become a living being endowed with reason and will-power, capable of acting on its own initiative, the interference of a bana is needed. They do not say that the bana enters the foetus. It is all very vague. All that can be said for certain is that in the foetus a bana-maq (also called moké-maq) makes its presence felt. To clarify the relationship between this mokémaq and the body, one can think of the word moké as it occurs in the compound jo-moké, clitoris, that part of a woman which activates her to cohabit with a man. Further, one can think of the word moké in the expression which describes the sun as a "great soul", moképoqojerép, and the moon as "almost a great soul", moké-arépaqatoqowmb. The Jaqaj say that when a person dies, the soul, moké, leaves the body and this causes the "outside" to die. The soul of a deceased person, bana/idöm, however, is still thought to be corporeal. Whenever the soul of a deceased person appears, it does so in the shape of a human being or, as a Jaqaj put it, "in the shape of a little man". This soul does not die; it disappears into the forest or it enters the ouw tree. It can come back during the night to hunt for heads among the living. Eventually it will go to the abode of the dead, éamaé-moqon.

The origin of the soul is shrouded in feelings of fear and awe. Although in some cases the bana-maq exerts a favourable influence, the frightening aspect dominates. The bana-maq of a child (its moké) is said to be not only in the child itself, but also with the father and the mother and in the food. The Jaqaj contend that the soul can appear in various shapes outside the human body. It may happen that you meet $\mathrm{A}$, and yet feel dead certain you meet $\mathrm{B}$. The shooting star, 
the frog sitting on the bow of the joqbera-rade who has come to fetch the soul of a sick person, etc., are all various shapes which can be adopted by souls. Nothing is said about the shapes in which the souls of the head-hunters appeared to the joqbera-radé, when the latter, on the eve of a raid, catches the souls of the people of the settlement that is going to be attacked in the morning. Similar vagueness and uncertainty prevail in Jaqaj notions concerning the idöm, the souls of the deceased. There are benevolent idöm, such as those who give a soul to a child, or those of deceased fathers who help their sons, or those who help a woman run away from a bad husband, or those who provide a joqbera-rade with the medicines he need. Far oftener, however, mention is made of idöm who harm or cause trouble to human beings. The idöm may strike husband and wife while they are having sexual intercourse in the forest, cause trouble for a pregnant woman, devour the afterbirth, cause the death of children, carry off living persons or attack people who have been left alone somewhere. In many conversations with Father Meuwese he stressed the fact that fear of the idöm was extremely strong among the Jaqaj, at least during the first years of his dealings with them. It was as if they were especially afraid of the shade of a beheaded relative, who would not leave them alone until they had revenged his death. The idöm have their abodes in hollow trees, in iron wood or banyan trees. When it is dark they make a whistling sound. Yet the Jaqaj do not feel themselves powerless vis-à-vis the idöm. They can "lead them up the garden path". Often the idöm are so stupid that they may kill one another by mistake. The Jaqaj have medicines against them, they can shoot at them and drive them away, or use fire to keep them at a distance. I know of unequivocal statements which state explicitly that the idöm are real, human beings, that they can marry with other shades and that they can be conjured up.

Here I must record that in addition to the word idöm the Jaqaj also used the word toqojia, the souls of people who had been decapitated. They were supposed to stay in the neighbourhood where their heads were captured. The blood that flowed over the arm of the head-hunter established a special relationship between the killer and his victim's soul. This soul would stay behind him and follow him when in due course he set out again on a raid. It would capture the souls of new victims for him, so that he would have another chance to secure heads. The presence of the toqoija heightened the prestige of a headhunter in his own community and was also the reason why young 
women were so afraid to dance with a freshly cut-off head. Jaèndé told of an incident which occurred during the night after the raid on Togumpatu; the toqojia attacked his little daughter so that she fell into the fire. It is one of the instances which bear witness to the belief of the Jaqaj that souls live and act in or near men. 


\section{CHAPTER V}

\section{YOUTH}

The child is taken care of by its mother. When the child is a boy, the period of maternal care extends until he is about ten years old. If it is a girl, she will stay with her mother until her wedding.

\section{Infancy}

Among the Jaqaj, the maternal role is a serious responsibility of social concern. A mother is worried when she does not have enough milk for her child. She says, "Exchange sister, elder sister, younger sister, you had better nurse the child. My breasts are dry." They ask her, "Have you not drunk any water?" She replies, "I am drinking water all the time. But why do not my breasts swell? Let my child be suckled by you every day; the child needs the breast or else it will die." From the beginning the child is given other food too. This food is first chewed by the mother herself. It may happen that the child refuses such food. The mother then says to the other women, "You chew the sago, you chew the fish, and the meat. The child refuses to eat the sago I give to it; it might eat if you chew it. Do the same with the sago grubs and the wood worms. Otherwise the child might go hungry."

Soon after the child is born the father, the mother, grandparents and other relatives, in fact everyone who is interested in the baby, puts forth a name which they also use. Which of these names is finally accepted generally depends on the course of the life of the child itself. If he happens to fall ill, the name commonly used till then will be replaced by another one. If, later on, a child shows more sympathy for his father's than for his mother's relatives, a name given by the former will prevail. Finally, the child's peergroup contributes to standardizing the use of one particular name, simply by using it more often. It is also possible that the child himself intimates that he does not like a certain name. A name usually refers to an event or a person by which or whom the giver wishes to be remembered. If a child is named after the place where the mother experienced the 
first signs of life in her womb, the child becomes, through that name, the namesake of the ground spirit, jaqar, of that place. Sometimes a joqbera-rade is asked to give a special name to a child. This is the custom when a child shows a peculiarity invariably ascribed to a specific origin of the soul. The spirit intermediary can give an explanation about this origin and consequently a special name.

Even before a child is born, the parents are sometimes asked to part with that child. Nowadays this is done especially when a woman is expecting twins. In the past, one of the twins might be killed. If its life was spared, the child was given away. This is the practice today. But if parents part with a child, they will not give the child to somebody who neglects his own children.

At the end of the mother's period of abstinence, she returns to her daily routine. If she goes fishing she entrusts the child to the care of a grandmother. After some time the child will start crying because it gets hungry and the mother then returns to the settlement because her breasts have swollen. The Jaqaj interpret this as evidence of the very close relationship between mother and child. They say, "The child knows that its mother is in the swamp and is about to come home again, so he begins to cry. The mother feels that her nipples are getting wet, so she knows that her baby is crying."

Guests too are expected to respect the frailty of a newborn baby. The father will not immediately give his drinking cup to a guest after using it. If he did so at once, the baby's soul might pass from the father to the guest, which would result in illness for the baby. A guest will see to it that he stays away from the mat on which sago is kept. The dirt of his feet might get mixed with the food of the baby and harm its health. Similarly, the guest avoids stepping on the branches of the swamp plants which lie on the floor, "for he might step on the neck of the baby".

When a child cries, the mother rocks it on her lap and sings a lullaby. An old woman, Ndaman, gave me the text of such a song. She spoke about herself and other old women who are famous wailing women who officiate at a death. The mother tells the child to pass on his crying to others, to become quiet like a fish and let certain birds do the crying. The text says: "Pass your crying on to the white cockatoo, let him cry that white cockatoo, go away crying. Pass on your crying to the iron wood, to the lizard that climbs the tree. Go away crying from the lips of the mouth, let the cockatoo, the wood pigeon take away the crying. Sit down by the tree in the water, qaröm- 
fish-child, and stop crying. You had better think of crawling, stop crying, be quiet now. Pass on your crying to (the women) Ndaman, Qajreku, Tomai, and Panöm, let your grandmother cry, pass it on to me, stop your crying."

For the first seven months the baby remains with its mother all the time. The Jaqaj are very much afraid of the shades during that period. Both father and mother carry the child in their arms and blame each other when anything happens to the baby. When the child is so young, they do not carry it on their shoulders, which would cause the legs to stand wide apart. They look forward to the day when the little one will be able to walk around. The mother tries to shorten the period of crawling by rubbing ashes on the child's knees. Everyone is enraptured when the child takes its first steps. He is encouraged and massaged. When the baby falls, he is held and rocked for a few moments so as to prevent harmful consequences. As soon as the child is able to walk freely, the concern of the parents lessens if a fall is followed by a clamorous reaction. The child may be scolded and blamed for not being careful enough.

Parents, brothers and sisters take delight in teaching the child to talk. ${ }^{1}$ Every step forward is encouraged and every failure corrected. Yet laggards may be mercilessly laughed at and reminded of peers who make better progress. As soon as the child shows any signs of understanding, the parents start to make their demands. It is no longer tolerated that the child soils his mat or the skirt of his mother. They do not hesitate to slap the child to cure it of bad habits.

The husband is warned against resuming sexual intercourse with his wife before the baby is able to crawl. The akiaq says, "When the child had not grown strong yet, when the child did not crawl yet, the father made her pregnant again. He damaged the road of the child. Let us hope that his next child will not be lame because of what he did. He who behaves like this, behaves wrongly."

\section{Childhood and coming of age}

The Jaqaj divide the years of youth into two periods. Small children who are not yet sexually mature are called koekètapa, which can be translated as "he is scarcely out of the shell yet". Concerning adolescents they say poqoikèn kipiao, "they have grown up". The small child is completely under the authority of the parents, especially his mother and the women who live with her in the same house. The 
parents tell the old women to look after their children when they are away. They may add one or two of the many pieces of advice that are sometimes heard, "Mother, the children are not allowed to go to the outskirts of the settlement, a snake might bite them; a shade might kill them. Do not go to the landing place of the canoes, lest they be drowned. See to it that the children do not press each other too hard. Keep the door locked, do not let them go out. When we get back, then open the door. Mother, chew some sago for the child, do not let it starve. If it is thirsty, let it drink. Do not fall asleep during the day. There are many children. They might do foolish things. Do not let the child stand in the middle of the house. When we get back, you can have your sleep. See to it that the children do not quarrel, that they do not get burned; they are naughty and wild. Do not let them step on the fire during the day. Do not let them eat any dirt; if there is any sago, chew it well before giving it to them. Mother, the child of that woman is lame: do not let the other children push it, it might break its neck, it cannot crawl yet, it is lame. Attend to it."

The mother sleeps on one side of the fire. The youngest child lies beside her, then the child which follows in age. The line of sleepers is closed by one of the elder daughters. On the other side of the fire is the sleeping place for the husband's mother or widowed sister. One of the other grown-up girls has her sleeping place beside this woman. At night everyone wraps herself in mats. The door of the house is closed tightly, because outside the spirits of those who died recently may roam about. If anyone has to go outside, she carries a torch to protect herself. In the morning, the mother roasts bars of sago for her husband and one or more relatives who live with him in the men's house. One of the children is sent to carry this food. Then the mother distributes roasted sago among her children. If one of them protests clamorously because he is dissatified, he can expect to be slapped and scolded by his mother. Ultimately however, the child will have his wish, although he will be told that his next ration will be smaller, a threat rarely carried out. When a grandmother sides with a child in an argument, a quarrel among the women could be the result, and the husband may have to step in. Sometimes a grandmother flees to her relatives. She takes the child with her and withdraws it from the authority of its parents for some time. This again can cause tension among the relatives, but when the child is returned some days later all things will be straightened out automatically. Parental authority is not undermined by such trifles. Small 
children are still too dependent on their parents and they cannot afford to be disobedient for a long time. Besides, the relatives do not have the right to keep a child indefinitely in their house against the wishes of the child's parents. The flight of the grandmother with the child and the shelter which is given to them serve a practical purpose; such a flight protects the child from the furious outbursts of the adults. Such an event does show, however, how all the kinsmen concern themselves with the education of a child, and how they are constantly trying to win the child's affection for their own branch of the family.

As soon as the children can find their way about, they go out into the settlement. They follow the older children and play in the sand or in the water. On these scouting expeditions they learn from the other children the names of all they see. Their parents warn them not to enter other people's houses, for they might be suspected of trying to steal something and this might entail great difficulties. "If your father is away fishing, if your mother is away fishing, do not be naughty, do not cry, or else a snake may bite you. Do not fall into the water. Stay in the house, so that no crocodile will bite you. Do not touch the fishing line, do not touch any fish. Keep away from the sago. Do not steal, that would be wrong. Don't let the other women say of you, 'The child of that woman is a thief'. Don't steal. Do not take someone else's fish trap, bananas, taro, coconuts, sugar-cane, or potatoes. If somebody gives you permission, it is all right, then you may gather his coconuts or his bananas. Take your share and put it aside, and it will be all right. To steal is wrong. If the sun sees you, he will say, 'Is he taking that to the owner?' The sun will witness whether the coconuts or the bananas are taken to the owner or not. If this is done he says, 'It is all right.' If you go in for stealing, you are to die young. It is bad. The man who does not steal, who does not lay hands on somebody else's property, will live long. Thieves will die quickly."

The children watch how a canoe is hewn out, how bows and arrows are made, or how a fishing basket is plaited. They look on when a house is built or a pig slaughtered. Their daily environment is no longer the family as such but the whole settlement, and they participate in everything that happens there. Little by little they learn how to address the different relatives and get abreast of the various relationships they will have to deal with in adult life. Gradually they get to know the various relationships with other people, each of which has its own rights and duties. 
The actions of the adults may involve the children, especially when quarrels end in fights and they have to join the losing party in its flight. They see the wounded and those who were killed. The immediate causes of dissension are discussed in their presence. At first they are fairly unaware of the backdrop of such fights, but before long they understand everything about it, and get involved in fights with the children of the opposing party.

Growing up does not take place in an atmosphere of idyllic peace and quiet, as is well illustrated by Jabajmu of Képi. Jabajmu said, "We stayed at Képi; a moon went by. Then we moved to Qajma. They built a new women's house. The Marapèmu and the Kamaqajmu lived there together. We stayed there for two months. Then the men went on a head-hunting raid to the river Poré. They killed three women and one man of the Janoqojmu. The heads were taken to the settlement and they were smoked in the men's house. They danced. Then we moved to Abaqajnamön (i.e. the Ikimu, the Aqaoèmu, the Marapèmu and the Kamaqajmu). At Abaqajnamön we stayed for a long time. I had just begun to crawl. We left for the river Ribu and settled at Nèpermumu. The Marapèmu were all there; there were also some people of the Aqaoèmu and the Ikimu who had followed us. Others remained at Abaqajnamön. A moon passed and then the Ikimu said, 'Let us go down the river, let us move'. We left, and on our way had to make many night stops untill we reached the hill Tabuaka, on the Digul, not far from Tanah-merah, where houses were built for the women. Some went fishing, others went to gather sago. My eldest sister took me to the little pier and I crawled on my knees across the pier and fell into the water. Utejr jumped into the water and pulled me out. The water had come into my mouth. She held me upside down and took me home. My arms and legs did not move any more. I lay down as if I were dead. The women said, 'The child is dead'. My father came home from fishing. Japaqajtéamu, my elder brother, was with me. Father asked him, 'Why has your elder sister left?' He answered, 'Little brother has fallen into the water. For fear of you our elder sister has run away'. Father and mother were angry. They said, 'Come home and we will give you a sound thrashing'. Utejr passed the night in another house. The next day father called her back, 'Let her come home again, I am not angry any longer'. I recovered.

One day my father and mother left to pound sago. When they returned the leaders said, 'We go on a head-hunting raid to the Awju'. 
Two days later they left; they rowed up the river Edera and raided the Awju. They came back with heads and started shouting. The women began to dance. Men and women had been killed. Two children had been taken from the Awju for adoption: Rèmpeqomu and Qajnaj. We stayed at Tabuaka. They said, 'The day after tomorrow we will go back to our settlement'. Some left. A man from the settlement of Toba told the people of Képi, 'The people of the Nambéomön have gathered to attack you. You cannot go along that way; they will kill you'. The Képi people began to dance; they said, 'We are not frightened, we will go that way'. The next morning they rowed up the river Oba, the men in front and the women in the rear. The men from the Nambéomön were on the river banks; they went into their canoes and went for the people of Képi. The Képi people rowed toward them and attacked them. The men of the Nambéomön fled due to fear. The Képi people shot one man with an arrow and rowed past the people of the Nambéōmön, shouting, 'Men of the Nambéomön, you are detestable cowards, you do not have any daring, but we have'.

We reached Képi and stayed there for a long time; it was the dry season. I began to walk. At that time Jaqanda came to the men's house with a fish. També asked him, 'Did you perhaps steal that fish from my trap?' Jaqanda did not answer. He waited for Temejmoqon. Temejmoqon came back from pounding sago when the sun had set as far as the top of the trees. Before Temejmoqon had a chance to eat anything, Jaqanda told him the story. He said, 'També was angry with me today'. Temejmoqon got up and with a spear he stabbed També, who was sitting near the fire. He himself escaped to the forest. My father put me on his shoulders. Nabe stabbed my father with a spear. Darkness fell. My mother was hit by an arrow. Father escaped with me to the bush on the opposite side (of the river). We stayed in the garden. The Marapèmu came to look for my father. When they were close by, my father said, 'Here I am'. Then we went home again.

My father was told by the people of Emété to come to Emété. They said, 'Your wife will certainly die at Képi. When she dies, we will kill the Képi people'. Then we left for Emété and stayed there. We stayed five months. I could already walk by myself through the house and the settlement. While the scar healed (from the arrow that wounded my mother) we stayed at Emété. When the scar was healed, the people of Képi decided on a war against Rèp. My father went to Képi with the men of Emété. They said, 'Tomorrow we will attack 
Rèp'. Father went along; I stayed behind at Emété with my mother. They went on a head-hunting raid. They killed some people of Rèp; they came back with the heads to Képi. Father came with the men from Emété. Three days later we returned to Képi where we stayed to live among the Képi people. Képi was continually at war with Rèp."

The days of tension and unrest alternated with days of relative peace. Even though outside the settlement wild scenes took place, this did not prevent the children from playing their games among themselves. In these games they imitated the adults. Little boys stood in a row on a fallen tree, each with a stick in his hand. They moved the sticks in a uniform rhythm, as if rowing a canoe. Little girls diligently pounded fallen banana branches with sticks as if they were pounding sago. They filled coconut shells with sand, turned them upside down and thus got balls of "sago", which they shared with their friends. They made a small platform out of palm-leaf ribs and under it they put some "real" firewood. They roasted some shavings of wood on it for fish. A mother sometimes gave them a piece of real fish and then the children lit a real fire and roasted the fish. When after a heavy rain shower a stream of water flowed through the settlement like a river, they dammed up the stream and divided it into plots which they staked out as "fishing-grounds" for each of them. Girls wore little mats of rushes; boys caught flies in a trap they made. They made a heap of sand representing a pig which they neatly divided and distributed in the right order among the "family relations". In this game, so they said, there had to be a division into two groups who mutually exchanged meat. Or the boys went to the swamps and behaved as if they hunted crocodiles. One of them acted as if he had been bitten, he hid somewhere and the others started looking for him. When they found him, the victim was carried away and "buried". He was "wept over" and then "returned to life" again. In the dry season when there was plenty of reed, the boys divided into two groups who shot at each other with reed shafts. After an "attack" the assailants strategically withdrew, only to return quickly to attack again and again. In the village the bigger boys played another kind of mock war. They had their own bivouacs. They stalked one another and "cut" each other's throats. They pillaged each other's bivouacs and put the loot on show in front of them. Older people sometimes joined the game by passing on messages. "Heads" of clay were made and roasted over a fire...

At full moon the children played a game which expressed the mutual enmity between shades and humans. A group of "shades" sat together 
in the centre, the "human beings" dancing around them all the time singing the same words, oara-banggé, the two names for cucumber. Suddenly the shades jumped up and tried to catch one of the fleeing humans. Then the latter became shades, so that the game started all over again with a reversal of the roles.

From early childhood on the children joined their mothers in the canoe when they went fishing. They sat on their mothers' shoulders when they went to the sago area. There a mother put her baby on some dry leaves and the child watched how the mother handled the sago. A mother advised her daughters, "Daughter, when you are in the swamp and there are children with you in the canoe who are talking all the time, you must get angry and beat them and ask them, 'What are you talking about?' Or else your little child will become crazy. If the child goes mad, it will die. If you are quick in getting angry it cannot go crazy. If it has stopped talking nonsense, go home quickly. Close to his home a child should not talk rubbish. He may do so when far away from home. Similarly, when you are on top of a hill gathering wood with your child, do not let the children crawl from behind between your legs. The child should not touch the inside of your thighs or else it will die the next day."

The small boys received a bow from their fathers and they shot their toy arrows at anything that moved in the forest. The girls sauntered behind their mothers, imitating what they did. Father and mother both pointed out the edible plants and warned the children against everything that might be bad for them. The children listened to conversations about the rainy and dry seasons, about the level of the water and the methods of fishing and hunting, and quickly picked up the meaning of all these things. They saw which fellow villagers worked together and thus learned about the ties which held the social and economic life together in a coherent structure. For the time being they hardly participated in the life of the adults except by rendering small services. As they grew older they gradually learned what would be required of them. They learned about sickness and death. The mortality rate among children was very high: $33 \% .^{2}$ Because of its frequency such a death made relatively little impression on the community. Compassion increased as the child grew older. The mother, however, was always grief stricken by the death of her child and her primary reactions were uncontrolled. But she too soon resigned herself to it, so much so that often she could not recall exactly how many children she lost when they were still young. Usually the death of a 
child was ascribed to the spirits of the dead. The sick were taken care of and nursed in the women's house, where children at a very early age became acquainted with the basic facts of illness and death.

As long as the boys were small no attention was paid to their sex. They walked around naked whereas the girls wore fibre skirts from early childhood on. When she was fishing, a mother did not mind if her young son took her fibre skirt and kept watch over it on the river bank, while she was in the water with no more than a leaf to cover her genitals. Not until a boy was about ten years of age did he become conscious of his own sex. He then joined his father and brothers rather than his mother and sisters. At this age boys were able to find their own way around. They foraged for extra food and became less dependent on their mother and, consequently, they were often very disobedient. If they got a beating they ran away and tried their luck with other relatives elsewhere. The time had come for them to escape the surveillance of the women, although they were not yet burdened with tasks by the men.

Talking of this period in his own life, Jabajmu said, "We were at Idömkira. Father and Mother were out gathering sago. Some older women had stayed behind in the bivouac to take care of the little children. We left to gather fruits. Then a bigger boy said, 'We will paint the sago red with these fruits'. This being done, we went to the bivouac; the little ones in the middle, some bigger boys in front and in the rear. The old women had closed the door. They were humming in order to lull the babies to sleep. We asked them to open the door. A door was opened. We entered with the red sago in our hands. They asked, 'Where do you come from?' We said, 'We have been in the neighbourhood'. Then they said, 'Where did you get that red sago?' The little ones did not answer; the bigger ones said almost under their breath, 'We got it from the Japanese, they are close by'. [About 1943 the Japanese did indeed penetrate almost as far as Masin]. We, the little boys, did not dare to laugh; the older boys had told us not to do this. The women cried, 'Where are they then?' We said, 'They have gathered here in the forest, they will be here soon'. The women threw open the doors and took to flight in wild haste; they dragged along some children, left others behind and hid among the thick reeds near the landing place of the canoes. Then we all shouted, 'It is not true; it is all stuff and nonsense'. The women came back; the babies were crying. The women seized some sticks to give us a beating, but we had already vanished. We laughed and laughed, all day long. The 
women called us names and said, 'We will tell your fathers by and by'. We went on laughing. They could not come after us because of the babies. They kept raging at us. We went to catch shrimps on the edge of the swamp. We skewered them on sticks and roasted them in the men's house. We burned nearly all the firewood. We ate and distributed and we ate again. In the afternoon we heard voices and the paddling of oars. We ran. We climbed up a tree; that was our men's house. Elder and younger brothers sat with each other.

The women immediately began to tell what had taken place, 'Those naughty boys have deceived us. They said that the Japanese were close by. We were about to flee in the canoes. Then they ran away. They have been in your men's house; they destroyed your property there'. The men went into the men's house and they saw that nearly all the firewood had been used. They started to rage. We kept quiet up in our tree; nobody dared to whisper even a single word. The men said, 'Let them come home and we will teach them a lesson'. We were not hungry. The men went on raging. All the time people were coming home and the same story was told to them all over again. It began to grow dark. Some of us said, 'Let us go'. We went to the women's house; everybody went and stood near his own mother's door and slipped inside when he thought the right moment had come. Then the noise began all over again. The old women went on calling us names. Some of us were slapped by our mothers. Other women were more kindly disposed towards us. The men came and stood at the door of the house; they had sticks in their hands. They shouted, 'Come outside, you rascals'. Some of us answered from inside, 'Father, grandmother asked us where we got the red sago. They got frightened so quickly'. The men said, 'We will forgive you this time, but do not try any of these jokes again or else you had better stay in the bush and sleep there; then you will not get any food any more'."

At this age children play more complicated games. They build huts in the trees, or divide a piece of land into plots and imitate the daily lives of the adults. They fight among themselves, and stage mock head-hunting raids, imitating the festivities of the skull feast with coconut shells. They even perform the initiation rites on pieces of wood that stand for the neophytes. Presenting each other with marks of honour, they prepare themselves for adolescence in all its various aspects.

Among these boys there are always orphans who have lost one or both parents at a more advanced age and have since then been taken 
care of by a relative. Such orphans, however, are not adopted into the family in the same way as children who have been adopted shortly after birth. The foster parents feel that they have less authority over these boys than is the case with children raised by them from early infancy. Feeling this way, they do little to supervise these orphans. Consequently, these children have to find their own way more independently than others and this often results in robbing and stealing. Even boys who are not short of anything at home are sometimes guilty of such transgressions. In such cases action can more easily be taken through the existing family relations. This is especially true when the boys have grown old enough to understand the necessity of conforming to the requirements of the older generation if they wish to get married some day.

Eventually the day comes when the boys are ordered to leave the women's house and to go and sleep in the men's house. From now on they are no longer allowed to enter the women's house. In the men's house they sleep at the edge of the central passage. They get their food from their fathers or their maternal uncles. Now they listen to the usual conversations about wars and learn about head-hunting raids which are being planned. They have been admitted into the community of the men and accordingly change loyalties. A father can order his son to go and sleep during the night with a certain man who will commit pederasty with him. The father will receive compensation for this. If this happens regularly between a certain man and the same boy, a stable relationship arises, comparable to that between father and son, mo-é or anus father and mo-maq, anus son. Such a boy is allowed to consider that man's daughter as his sister and she will be "awarded" to him as his exchange sister for his future marriage. Any further insight into this practice as to frequency and actual involvement is difficult to acquire. The men were uncommunicative on this point. Officially the custom was supposed to be a secret from the women and even among the men it was not discussed. The word mo-é, anus father, was such a cutting word of abuse that it could lead to serious trouble. Once a man of Rèp called one of the leaders of Képi this on the battlefield. Although the hostilities had already stopped at the time of this insult, the men of Képi now started a crushing attack on the settlement of Rèp. Fr Meuwese said to me that the Jaqaj had told him that these boys were looked upon as "women for the night".

At this age the boys start wearing a tail of fibres in imitation of 
the grown-up men. In these years the boys and the young men go through the initiation ceremonies which will be described in full in Chapter XII, section 4, headed Taker-jamé. Because these ceremonies do no take place at regular intervals, there is not a special age for the ceremony. Boys of various ages may pass the ceremony at the same time. At the same feast the young men are officially admitted into the ranks of the warriors by being handed head-hunting knives.

When a boy is on the brink of manhood, he has to undergo some minor operations, viz., the piercing of his ear lobes and nasal septum. In the Nambéōmön district piercing the ear lobes is done after the burial platforms are pulled down. On the Oba river the father himself performs this operation on his child without any formality. When a boy feels the hair of his beard coming through he simply asks someone to pierce his nasal septum. There are men who have never had this done. But whoever wants to wear a large shell in his nose does not mind the pain of the operation. The boy sits with his head between the knees of the "surgeon". The man who pierces the nasal septum warms his finger tips and rubs the nose until this is warm too. Then he pushes a sharp pin of nibung palm wood through it. In the hole made in this manner a small piece of wood is stuck. Afterwards this thin piece will be replaced by a thicker one. Gradually the opening becomes wide enough for a piece of bamboo to be pushed through. The girls of the Miwāmön and the Bapaé districts submitted to this operation as well; the girls of the Oba river did not. Kadmaerubun, the teacher at Monana, added that the boy is led away by his mother after this treatment. Fr Meuwese told me that the operation always resulted in a serious swelling of the nose and a bad inflammation. I was told that a boy who wept only once during his operation would only marry once (because his wife would have a long life). Less spectacular but equally painful was the operation making two additional little holes in the tip of the nose and another two a little higher up in each nose wing. Into these holes the Jaqaj insert the claw of a bird as a decoration at feasts.

Once he has had his nasal septum pierced a boy is allowed to accompany the men to war. The mothers try to stop them, but the boys are encouraged by the men. Moreover, the boys are eager to take part in adult life. They go along to the battlefield and the men provide them with arrows and spears and urge them to behave bravely. It is not only in battle that a boy begins to assert himself. In everyday life he begins to attract the attention of his community by the way he 
behaves. His name may be mentioned either because he has stolen something or annoyed a woman, or because of his positive contribution on such occasions as building houses or cutting trees for canoes. On his own initiative he may go to another settlement for some time. Sometimes he has a large share in the more important affairs of the family: providing food and protecting common property or the name of the family. If his output and fighting strength are worthwhile, a marriage arrangement is initially considered. Marriage will make him a full member of the community.

In the same way, the efficient and diligent girl's work makes her accepted in the settlement as a capable member of the community of women. In the women's house she is the companion of her mother, with whom she shares the responsibilities for the daily meals of the family. 


\section{CHAPTER VI}

\section{MARRIAGE}

The main marriage regulations have been discussed in Chapter II. Here we shall examine how the marriage actually comes about and how this affects everyday life. The special wedding-feast, held after a head-hunting raid, is discussed in its proper place in Chapter XII. The separation of the sexes does not prevent men and women, and boys and girls, from meeting each other in the course of everyday life. This can be inferred from the advice given to young people on how to behave towards the opposite sex. And it is evident because information was obtained on the ways in which young people "dated" each other, and the good humour in which these love affairs were discussed. The separation of the sexes functioned to establish and defend marriages, and safeguard the rules for married life. Usually pre-marital and extra-marital intercourse did not occur so frequently that a regular loving relation was established.

\section{Boys and girls}

Little boys are allowed to kneel facing one another to try to touch each other's genitals in a kind of stabbing game. Among children the word paqadi, penis, is sometimes used as an expletive. One can laughingly call one's friend joqajo-maq, which has a meaning akin to "bastard" or "son of a bitch". The girls are told from a very early age onwards to sit decently and not to play with anyone else but their "brothers" and "sisters". Sexual interest really begins when boys are about fourteen years old and among girls when their first menstruation approaches. Everybody knows about the existence of the hymen, èmber, and they think that it is broken in the course of the first menstruation. Sexual intercourse prior to this event is strongly disapproved of. "But", a man of Képi said, "the more a girl grows up, the stronger her sexual appetite will be. She has a clitoris, jo moké, and when her desires are roused, this will start to itch, baqaé kopoa. When a girl has sexual intercourse for the first time her breasts will tilt upwards, but after 
having had intercourse several times her breasts will sag and they say of a girl, 'She is no longer a virgin, qanu'." A man can, if he wishes, have social contact with any member of his own sex but this permission is not granted to women. Free contacts with other women, not related to her, might too easily offer a girl or woman the opportunity to pass a message to a man. That was possible, for example, when women of neighbouring settlements went fishing together, or during the feasts celebrated after a head-hunting raid. A girl could not leave the house alone or set out to gather food all by herself until she was married.

To the young man the following advice was given, "If you come back with fish and share it with others, a man who happens to have a daughter will be inclined to give her to you. If your mother has prepared some sago and you eat it alone you will not get a woman. People will say, 'He is a glutton'. Do not speak to the wives of your father's brothers, you may speak to your father's sisters. If you meet women on your way, ask them where they come from, lest they should say that you are bad; that you have a stiff neck (i.e., you do not greet). If you do not ask anything, they might think you are after some woman or other. [This formality was explicitly said to result from the necessity of warning everybody of any dangers which could be lurking anywhere. "Where do you come from?" meant, "Is it safe up there?" "Where are you going?" meant, "You had better tell me, I might know of some danger threatening where you are going".] If you wish to have a woman, watch out. Do not approach any wives of your next of kin, and as far as the others are concerned, take care that the woman you are after is all by herself. Do not have any dealings with a woman who solicits you. Afterwards she might mention your name. Do not stare at women. It is enough to see them at a passing glance. If you watch them, their husbands might suspect you. He who coaxes a woman away and has intercourse with her in the bush will die. It could lead to a fight. Contract an exchange marriage. When the sun has let its morning light shine on the transfer of the sago the arrangement is all right."

\section{Ideal male and ideal female}

The boys discuss the qualities of the girls as the girls do those of the boys. "The school children", my interpreter said, "do not understand how adults can be so stupid as to marry a woman who has scabies, 
because you can smell this rash, especially when it rains". A wellshaped woman attracts attention and the boys will watch her without letting her know that she is being watched. Not only beauty attracts the interest of a young man; the temperament and the character of his future wife are also important. The ideal wife must be modest, faithful, not talkative, kind and most of all she must be a hard worker. She must offer a guarantee that she will take good care of her husband and their children. For this reason it is also desirable that her family has sufficient property. Conversely, the chances of getting married are a great deal less for a girl who is meddlesome, suspicious, fickle, talkative or snappish. Such a girl will find it hard to attract a fine young man. This is even more true if she is lazy, boy-crazy or indolent. A young man wishes his future wife to be good at dancing and skilful at plaiting. She is expected to have steady hands as a midwife. She should know how to act resolutely in cases of illness, while a fair knowledge of medicinal herbs is always an asset for the family. These qualities will make a woman highly respected if she happens to become widowed. Another source of respect is her ability to give sound advice or enter into contact with a dead person as a female intermediary. However, if such a woman abused her special power, waw, she would be feared. She might be able to induce young men to have intercourse with her. Such a dangerous woman would never get married again.

The ideal husband is a lean and hardened warrior. He also must be a hard worker in ordinary life. The girl expects him to go hunting regularly and to bring home much game, for he not only has to provide for his own family but must be generous to his relatives. Such sharing of food is the primary means for maintaining good relationships. It will strengthen everyone's position. Such a husband will be able to build a strong house where his wife and children will feel safe and enjoy at least a minimum of comfort. A good husband must also be able to build a canoe, because a canoe is indispensable in the swamps. A girl also wanted her future husband to be a good head-hunter. She wanted him to capture a head as soon as possible, so that she could hang it on her arm during the bridal feast. Later on in the course of their married life, he would be expected to bring home many heads for their children. Her safety and that of her offspring depended on his ability to defend himself. She wished to be the wife of a great head-hunter, for that gave glamour to her own existence as well. Moreover, a strong husband would be able to attract women who would alleviate the task of providing food. A husband has to be strong, brave, 
diligent and generous. He has to be able to act firmly. He should be trustworthy and inclined to co-operate with others. A woman is less keen on a man who is frail of body or a coward. Someone who is too timid to stand up for his own interests, or who is known to be mean, self-willed or stingy, will remain unmarried longer than a more sociable type. A girl hesitates most of all to marry a man who is insolent, hot tempered, harsh and ambitious. She does not wish to marry a glutton, because he will make great demands on her energy. She does not like a trouble-maker, because he is sure to endanger her own safety, either because he was quarrelsome or a dangler after women. A man will be appreciated especially for his talents as a story-teller or a song leader, or as a maker of spears, shields and drums. A young man who has already been selected as the successor to a wise counseller is a very desirable candidate.

There is one phrase everyone likes to hear: aq jamämbèk (said to a man) or aq jamámbuk (said to a woman). These words express the cultural ideal of the Jaqaj, for they mean "being hot". When said of a man, it can be translated as: You are a man who is able to fight for your own interests and those of your relatives. You are a man who does not think of giving up when circumstances are difficult... You know how to manage things. When these words are said to a woman, they mean: You work hard. You are energetic; you know how to manage things and you have a tongue of your own. All interests entrusted to your care are safe with you.

In this culture, the differences in sex have resulted in a contrast between the sexes. Separate housing facilities turn the men into a group opposed to the women as another group. This is the wir-bor as opposed to the taj-bor. The men did everything possible to prove they were "real men". In a similar vein, striving after their ideal, the women tried to be "true women". They made great demands on their husbands, but they also knew what the men expected of them as wives. The men recognized the women as equals. This is partly explained by the biological functions of a woman (the bearing and bringing up of children) and partly based on the fact that the women were in control of the sago that the men needed for their sustenance. The men felt that they had to watch over the safety of their wives and the defence of their property. This task did not leave them enough time to gather sago and prepare any meals. In return for this sense of security the men demanded that the women recognize their superior masculine strength. 
One can also consider this the other way around and agree with the late Fr Verschueren that the women made a benevolent gesture toward their men, allowing them to take on airs of importance because they knew all the time that they, the women, were the ones who were really in control. I do not believe that this is entirely correct. The women gladly shared in the fame of their husbands. The men for their part refused to be trifled with. Their "game" with the enemy was a game of life and death and the physical well-being of their wives and children depended on the outcome of this game. I prefer to see this duality of the sexes as follows: each sex is superior to the other precisely on the level where they contribute their own particular share and from that vantage point they look down upon the opposite sex as the weaker partners who can be exploited. At the same time, it is obvious that co-operation, in spite of this duality, leads to harmony and allows each sex to be uniquely itself and self-respecting.

\section{Initial contacts}

Love making was done secretly. If an affair became public, the reactions of all parties were immediate. The outcome of their subsequent fight and peace parleys decided whether or not the affair was approved. Only cases of love making which fitted into the pattern of the balance of power had a chance of such approval.

Apparently, without any fixed purpose, a young man may saunter through the village and pass many women and girls. As he walks along a girl may cast "a long look" at him, kind kubopomom, or smile at him, qaé kubéanggonöm, and then cast down her eyes, kind kuboktupumok, or raise her eyebrows, kindud kuhopoaqanak. The girl may lay her hand on the back of her head, jando kubepqain, and the boy will immediately understand this sign of willingness. Then the girl will look in a certain direction or point with her hand, jandoamön kukubira, or point with her foot, ramuamön kupéoqoromok. The boy will find her, for he knows that her land lies in the direction pointed out. Circumstances may allow a girl to make overtures to a boy. She may hand him a piece of sago and hold his hand for a moment. She may casually stick out her tongue. She may raise her fibre skirt a little if she can do so inconspicuously, or she will laugh loudly. When it is dark, she may throw a piece of sago or some sand at a passing man, or she may simply cough in order to attract his attention. Early in the morning, she may walk past a certain house and in a loud 
voice tell the woman there where she will be that day. This piece of information is meant for the boy or man who happens to be in the vicinity at the moment. Finally, presenting some sago grubs or a little mat or bag is an invitation. This present is handed to the boy by an intermediary, usually a girlfriend who is a relative of the boy.

A wise boy will wonder, however, whether a trap has been set for him. The girl might take a witness with her to catch him in the very act and thus force him to marry her. He will be cautious and before he keeps the appointment he will investigate thoroughly whether or not the coast is clear. To be safe, he may ask a girl of his own group to come along and stand as look-out. Among themselves the young men talk freely about sexual matters. These are part of the ordinary things of everyday life. Yet they are careful not to tell too much about their private escapades. Once a relationship has become public this changes. They tease each other about their future wives when the arrangements for the wedding have been made public. The Jaqaj have their own songs, called tom-èb, about forbidden intercourse on the initiative of the woman. The function of these songs is to expose sexual transgressions. Their sarcasm can be caustic. Some examples follow:

1. "That of the little girls playfully opens and closes like the fireflies. That of the little children playfully opens and closes like little stars. Playfully the branches of the qaéjaqap tree are blown apart: they are blown apart. Playfully the branches of the namenom tree are blown apart: they are blown apart. You should close what you have there, close it from the inside: with the outside of your vagina skin you should close what you have there."

Explanation: The woman Oqoba saw little children walking around naked. In their play they opened and closed their thighs. It was as if the branches of a tree were blown apart. In this play the insides of their private parts became visible: they lighted up and went out like fireflies or twinkling stars. The woman's song tells the girls how to behave properly.

2. "Boy, your thing is but small, your penis is really very small. Lad, that thing of yours is but very small, your penis is but very small. You had better penetrate far into her, you had better penetrate deeply into the little hole of the ajo bird. Penetrate deeply into her thing, into the little hole of the kaèm bird: you penetrate deeply. In the settlement of Mujké, in the village of the black one, the bread tree dances. In the village of Japaqan the bread wood bend down." 
Explanation: Temejmoqon had heard that a woman had tried to have intercourse with a little boy near a bread tree. In order to put her to shame he composed this song. The boy is too small and the vagina of the woman is compared to the little hole pecked by the ajo bird in a tree. This incident took place in the village of JapaqamMujké, the settlement of Tambim. It happened near the bread tree, the branches of which were swaying in the wind (dances).

3. "Penetrate deeply into the private parts of your mother on the platform of the eucalyptus bark. There penetrate into the canoe crack, the new bamboo. There penetrate into the canoe slit, the new reed." Explanation: A woman of Képi had run away. All the young men of the settlement had pursued her and after capturing her they had taken her in the marsh on a platform of eucalyptus bark. The vagina is indicated as the slit of the canoe, or as the beak of the canoe. The new bamboo stands for the penis of a young man.

The Jaqaj make use of the symbolic value of certain words in order to indicate possible marriage candidates or those persons who have ventured upon a love affair. Qoté, a certain bird, or ujoq, parrot with coloured feathers, refers to an unmarried woman; ajo, a white parrot, indicates a light-skinned man; anggöt, a black bird, indicates a dark-skinned man; éköm, a fish, means an albino or a light-coloured man. By means of these words certain information is passed on without mentioning names. For example: "There is a large tree at Kupeqaé and beside it there are bushes. In the bush next to the tree ujoq has settled. She came flying from Abaqajnamön." The meaning is that the eldest son of Jaro of Képi had intercourse with a girl from Tambim's group. Kupeqaé is the place of residence of the Aqaoèmu. Their great leader is Jaro; hence the tree. Beside him his sons stand like bushes around a tree; the first bush next to the tree is the eldest son. Ujoq stands for the young girl. Here the girl comes from Abaqajnamön, the usual place of residence of the Tambim qari.

In matters of love everyone is left completely free. If a young man does not wish to have any dealings with a girl who forces herself upon him, he can get rid of her by saying loudly in front of her house that he does not want to be pestered any more. In the community of men and boys a young man should not brag about his ability to seduce a woman, for everybody knows that this is a very tricky business by which little credit is gained. If a woman is caught in the very act, she realizes that she cannot tell her relatives that she is innocent. Such a woman will often offer herself to the man who caught 
her in the act and thus buy him off so that he will keep silent about what he has seen. She herself will certainly not say a word about what happened.

It occasionally happens that a young man is given an older woman to keep him satisfied. Conversely, there were elderly women who were on the look-out for young boys in order to seduce them for sexual intercourse. These elderly women used the higher powers ascribed to them and thus frightened the young people. Often a young man has to be satisfied with such an old woman because he cannot expect to receive a young woman before he has had success in a head-hunting raid.

A boy usually waits for the girl to make advances, but this does not mean that he always remains completely passive. Since there are no means which lead straight to his goal, the boy will make use of all kinds of devices which work from a distance. Thus he can spy on a woman he loves while she urinates. When she has left, he will rub his breast with her urine. If the skin starts to itch, he is sure that she will soon fall in love with him. Another boy will go to a tree in the forest where birds of paradise are found. He then pronounces a formula and goes on calling the name of his beloved until a bird of paradise answers. Then he will go home satisfied, for he is sure to win her love. It also happens that a boy or man in love speaks a formula over the hind leg of a pig and then has the meat delivered to the woman or girl. Young men may also call in the help of an older woman who takes the girl, if she is willing, to a rendezvous in the bush on an appointed day. A man can also gather food scraps or dirt or things which have been used by the woman he loves. He will mix these things with mint. In the dark he will sneak up to the wall of the house behind which the woman lies asleep. He makes a hole in the wall and blows the mixture he has made in the direction of the woman. The woman will then soon come to him. A man who fails to find a woman who makes advances to him can throw taj-rara, woman medicine, into the well where the women of the settlement fetch the drinking water. The whole settlement will then come under his love charm and many new relationships will result, giving the man new opportunities.

The most efficient means, however, to get a woman, is to acquire a piece of her perineal band, maqaw-roqoj, which she wears under her fibre skirt. This is possible if a woman who lives in the same house as the girl will act as an intermediary. Sometimes after an affair 
the lover gets a piece of this perineal band from the girl herself as a pledge of faith. If subsequently this girl is seen with another boy, the owner of the piece of the perineal band will tell her that he has laid the piece in poison. This will frighten the girl, for she might get ill. The charm is effected by putting the perineal band behind the bark of a tree. The sap of the tree will soak it and the smell of the soaked perineal band will drift toward the settlement and the girl will fall ill. The true lover of the girl, or the one who is eventually going to marry her, looks for this piece of perineal band to wash it, so that the girl will recover. The hunt for such a piece of perineal band is a source of much displeasure and sorrow. The girl often regrets what she has done on the spur of the moment, or that she did not pay enough attention to what was happening when this piece was stolen from her. Until the piece has been recovered, the girl will remain disturbed and there will fall a shadow over the marriage she is to contract. Often there will be a lot of fighting between the two lovers of the woman, especially if the possessor of the band refuses to return this pledge of her love even though he is offered payment for its return. The relatives of the lovers will stand up for their own party and the relatives of the girl will fight for the man they have elected as the future husband of their sister or daughter. All this shows that every "engagement" can be broken off. The new candidate, usually after a fight, has to pay compensation to the "first lover".

The Jaqaj use the terms néamön and qaqaèb for sexual intercourse. The first term, e.g. in the expression ké-o-néamön, has the connotation of "he had sexual intercourse with"; the second term, in e.g. ké-qaqaèb, means "he penetrated". The Jaqaj clearly indicate whether or not intercourse is extra-marital, and whether or not it took place on the initiative of the man or the woman. Thus they say, taw tomamön kéqaqaèb, "he had intercourse with a woman who asked for it". They add arup kunae, "she wanted it herself". On the other hand, there is also the term taw jamba-amön kéqaqaèb, "he had intercourse with a woman at his own request". The latter term, jamba, can mean "rape", but not necessarily so, for the word means either "he molests her" or "he courts her".

It is understandable that girls are warned tom mateba, "do not take the initiative in extra-marital intercourse", and boys jamba mateba, "be careful not to offend a woman". A girl who refuses a man or does not want to get married is called an ènèn-taw. When a man marries a woman who is a blood relative they say: "he committed 
incest", kéboqobom, and also mo-aqan kéobekudök, "he has entered her by the anus". It was also possible for a man to take a woman by her arm, marep-kéképitök, or for a woman to take hold of a man's arm, marep kukupitök. If this happened, the man accompanied the woman to a house where he could count on the support of his female relatives. Soon the relatives of this woman would become alarmed and demand that she be returned. If the man had taken the initiative, he would have warned his own people beforehand about what he was going to do. If his relatives stood by him in the fight which followed and they won the fight, he could keep the woman and they would start to discuss the marriage arrangements. If it appeared to be impossible to defend the woman in the settlement itself, he would carry her off. If the woman had taken the initiative, marep kukupitök, "she took hold of his arm", this had to be proved by the man. If she was a widow the man had to persuade her people that he had not had any sexual intercourse with her while her husband was still alive. As long as the matter was not settled by mutual agreement the woman enjoyed the right of sanctuary in the house of the woman where he had lodged her. Delivering her to her relatives might lead to their killing her. If a marriage arrangement was reached the man kept the woman on the conditions that were agreed upon.

Finally, I wish to mention one case that took place after pacification and that clearly demonstrates the kind of troubles a young man may get into. The young man, Menggaé of Rèp, acquired with payment, jaketep-amön, a woman called Joté. Her father was not present when this happened, so he could not give his approval to this marriage. When he returned from his journey, Joté was already pregnant. During a feast at Moïn at about the same time, Menggaé met another girl, Aré. After the festivities Aré fled to Rèp and sought shelter with Menggaé, tomamön uerpekit, "she fled at her own will". Aré's relatives at Moïn demanded that Menggaé give a woman to Moïn in return and thus establish an exchange marriage. Menggaé was able to acquire an exchange sister, nati, from a relative in the village of Toba. Thus the arrangement was made. This had brough about a very complicated situation: Menggaé already had Joté, who was pregnant, but for whose wedding her father still had to give his permission. On the other hand, there was Aré in return for the exchange sister from Toba, for whom he still had to pay compensation to the natik at Toba. When Joté's father came back, he approved of the wedding of Menggaé and Joté, but he did not approve of the arrangement with Moïn. Menggaé then 
returned Aré to Moïn and paid a fine to her family and sent the nati he had acquired from Toba back to his natik.

The idea that marriage arrangements were carried out as easily as the general rules suggest is completely wrong. In practice, time and again the group leaders intervened and exerted their influence when a decision had to be made as to how the general rules were to be applied to concrete cases.

\section{Sanctions}

Those who broke the rules were afraid that the people whose rights had been violated would take action against them as soon as the infraction became known. It is understandable that no young man liked the idea of being suspected. Therefore we often heard the akiaq: pipi mateba, "don't suspect". A suspicion is not immediately voiced in public. The small group of persons who are interested will first try to catch the suspect in the act. Once they have the evidence they need, they will no longer keep silent. The relatives of the girl or woman will call the young man to account for what he has done. A young unmarried man defends his innocence and even challenges those who have accused him to a fight.

But things could also take a different course. If a family hears that their daughter is involved in an affair, they call her to account. The girl will deny it. Then the boy who is supposed to have had intercourse with her, is called to account by his family. He too will deny it. The men will then await the results of further interrogation of the girl by the women of her group. If these are positive, they will say to the boy, "You had better confess. Do not beat about the bush". Thus if the girl confesses, the boy is questioned again. They may put a dagger to his eye or a spear at his side and threaten him. If his relatives fail to get at the truth, the exchange partner, mendaq, of the brother of the boy is called in. If the relations between the two of them are good, the boy usually confesses to the latter. It depends on circumstances whether the boy is forced to pay a fine or an exchange marriage is finalized. If an unmarried woman becomes pregnant, she is forced to tell the names of all the men who have had sexual intercourse with her. These men will then be called to account for what they have done.

The fights which accompany such a controversy are caused by the rage of the party that feels wronged, but also by the guilty party itself 
as it attempts to have the compensation reduced to a minimum. All old affairs may be revived again and they determine who is going to help whom. The wounds that are inflicted also count when the decision is eventually made. Even if a guilty party is able to avoid a redress of the fact that he used force and won the fight, this does not imply that he can press on and have his will.

If a girl or a married woman has dealings with several men, her relatives (or husband) can withdraw their support from her. The woman then becomes a common prostitute and nobody cares who has intercourse with her. They say of her, "She wants it so herself!" Her relatives do not attempt to arrange a wedding for her, and if she is married, her husband will not try to keep her with him. She has become a "utensil". She does not belong to any group any longer unless they can make use of her as a means of exchange with a hostile settlement. She might be taken to another settlement, which has paid for her, and killed and eaten like a pig. The payment given to the relatives of such a woman was regarded as compensation. Jaèndé of Képi told me that he himself disposed of such a woman in this way.

\section{The marriage ceremony}

When both families have reached an agreement, the parents - or in their absence the people who are the guardians - order the girl to roast a bar of sago and take this early in the morning to the young man she is going to marry. This bar of sago is called baj-naki, wedding sago. The common advice, akiaq, runs "Younger sister, the sun calls to you when you hand over the wedding sago, and he says, 'Granddaughter, you must present the sago, so that the exchange marriage may come about. Not stealthily: you have to hand the sago in the correct manner'." Therefore the Jaqaj say that this event should take place tapaq kind-kan, under the eye of the sun. When the sago has been delivered, both the bride and the bridegroom must turn their faces aside as a sign that they have not yet had sexual intercourse. Usually the girl holds the bar of sago in the middle and the boy puts his hand over her hand and thus accepts the bar. If the girl holds the bar at the end, this gesture means that she has been forced, that she does not want him as a husband. The boy will then retire full of shame. New arrangements have to be made. When a man comes to another settlement in order to accept the bar of wedding sago, the girl can lay a piece of iron wood on top of the sago she offers. She 
thus expresses the wish of her relatives that the man should come and live in their settlement. In a real exchange marriage, the other settlement will make a similar demand on the other bridegroom. The boy accepts the sago and divides it among his companions in the men's house. According to Maturbongs, the young man kept part of the sago and took it with him on the next head-hunting raid.

From the moment that the baj-naki has been given, the kinship terminology for spouse, exchange brothers-in-law and affinal relatives are used. The man and the woman may have intercourse, but they are not allowed to be seen eating together in public; they certainly should not be seen eating meat together. From now on the young man is expected to let his wife have a regular share of the game he has hunted. He is expected to help her father in the cutting of a canoe or the building of a house. When the new husband shoots a pig shortly after he received his wedding sago, he will take the whole pig to his bride givers. The relatives of his wife then accompany the girl to the house of the husband's mother. There she has her own fire on which she roasts the sago for her husband. Girls were not always keen on marrying the man selected by their relatives.

Fr Meuwese stressed that young girls could be given to older men, especially to those who had reached the rank of important leaders. He had often seen how these young women were dragged forcibly to their new houses and stabbed in the legs with a spear if they were unwilling to walk. 


\section{CHAPTER VII}

\section{MARRIED LIFE}

\section{Akiaq and the newly-wed}

After his marriage a son remains with his father in the men's house or he stays with one of the brothers of his mother. The young man received all kinds of advice about what is expected of a husband. Thus a father may say to his son, "Boy, when you have taken a wife, do not be lazy. Whatever she may order you to do, do it for her. If you do not do what she says, she will feel unhappy. If your wife is glad to have you, she in her turn will do what you command her to do. If you are rude, she will be the same to you. Getting angry will not do. You and your wife must be good to one another. If you are too much of a nuisance, she will start looking for another husband. If your wife goes fishing, you must go to the bush and cut firewood. When she comes back, she will be pleased and she will think that her husband is not lazy, that he knows how to work. Follow my example, otherwise your child will go hungry and cry for fish. If you go to the forest, you must gather palm leaves for your wife, lest she must ask others to do this for her. Imagine if someone gave her leaves which are wet with urine. You would be put to shame, and so would your wife. If you come home empty handed, someone might say to your wife, 'Your husband has not gathered any leaves because he was chasing other women'. If your wife comes home from fishing, do not immediately ask her for sago. You must let her eat first. She knows quite well that you have stayed at home with the children and that you are hungry. If during my lifetime you give your wife a beating, I will throw it in your face and ask who taught you that. I have never beaten your mother. If I hear of it again, I will come at you with a spear. You must not get angry with your wife. If you beat your wife, she will grow as thin as a rib. Other women will say she is thin because her husband is always beating her up with a stick. Do not beat your child. If it is thin, it is because you have beaten it with a piece of wood."

The newly married man is also told by his relations to be good to his in-laws. He should not be jealous or upset if his wife gives part of the 
fish she caught to her parents and her brothers and sisters. If he is good to his wife and liberal with his bride-givers, they may think of giving him another wife or of putting an exchange sister at his disposal so that he can marry a second wife, even though his first wife is still alive.

The wife is lodged with her mother-in-law and she must adapt herself to the new surroundings. Therefore, before her marriage her mother will advise her not to be suspicious of the women in her new family nor to cause them trouble. If she follows this advice, they will be good to her and take her side if she gets involved in a quarrel with her husband or with some women in the settlement. About her relationship with her husband, her mother will tell her, "Girl, if you have taken a husband, be good to him and he will do the same for you. Do not be lazy. If you work hard, your husband will love you. Be good to your husband and children. As husband and wife you must be good to one another, so that you may grow old together. If you are a nuisance to your husband, he will beat you all your life until you are old. Be not sour-faced in the company of your husband, you must be quick and happy to roast some sago for him at his first request."

The Jaqaj woman has to remember the circumstances in a men's life. It is in this context that the following counsel given by a father to his daughter is of interest. "When I am dead, you must take care of your elder and younger brothers. They must be able to come to your house and you must roast some sago for them. When you come home from fishing or sago beating, you should not be cross, but kind. Every morning you must be quick to roast some sago. If an elder brother stays at home during the day and gets hungry, do not wait till he asks you for food; be thoughtful of him. When you come home, give some fish to your elder brothers, give some to your husband and some to your younger brothers and sisters. Do not keep your husband waiting, but quickly prepare his sago, so that your husband and your brothers will have finished their meal, in case anybody should start a fight in the settlement. Then they will be able to fight bravely."

The newly married couple are admonished as follows. "Sleep with your wife under a roof, or else a shade might carry off your souls. A man who uses his wife without further ado in the forest will die. On a boar's path, on a cassowary path, it does not matter where, or on a kangaroo path, do not do it, because these are the paths of the shades. On the path of a mouse or of a snake, do not do it, do it under a roof." The counsel given reflects the thoughtfulness normally observed in 
sexual intercourse between husband and wife. The husband usually waits for his wife to take the initiative. She can show her willingness through special solicitude or through a word of interest. Forcing a woman or treating her contemptuously is expected to be avenged by the jungle spirits, aburi, as soon as the husband ventures out in the forest alone.

A good wife sympathizes intensely with her husband in the dangers that threaten him during fights and warfare. The least scratch he sustains leads her to lamentations. When he is wounded, she takes him into her own house to nurse him carefully. A wise husband, in his turn, pays much attention to his wife. He cannot do without her, although he will not openly admit this. To all appearances he cares more about the children than about their mother. In the past, he went head-hunting for his children. Their weddings are one of his principal worries, long before they reach the marriageable age. If the first child is a boy, membaq-arèp, this child is especially dear to him because he is both son and heir. Young people of ten have to marry someone they had not chosen themselves, so that they had to break off all sexual alliances they had before their weddings. A husband will try to recover any pieces of his wife's perineal band which may still be among the possessions of her former "suitors". On her part, the wife sometimes refuses to have sexual relations with her husband until she is sure that he has renounced all his former girlfriends. The consummation of marriage is not without problems.

The exchange brother-in-law watches closely how the new husband behaves towards his wife. If he beats his wife mercilessly, the exchange brother-in-law will warn the relatives, who call the husband to account. Difficulties often originate from the husband's demand that his wife be completely faithful to him. The least ground of suspicion gives occasion to severe punishment. In the opinion of the men, such a thrashing may serve as a kind of preventive measure. The newly married wife has to listen to elaborate advice on this subject. A wife who is railed at by her husband may not shout back at him. If she did, or if she felt strong enough to reproach him, her husband might begin to suspect her. He might think that she would never feel so secure and self-confident unless she was sure that another man wanted her. The warning on this point says, "If your husband takes a stick (to beat you), do not call him any names, èt mateba, for someone might pass by and hear you. He will not come to help you, but he will say, ' $\mathrm{He}$ is beating her because 
she has called him names'. If you women abuse your husbands frequently, they will no longer defend you."

In the past, it sometimes happened that a man, when he left the settlement, ordered his young wife to stay in her house. If he happened to come back unexpectedly and he saw her somewhere in the settlement, she was sure to get a sound thrashing. At night, too, a woman could not be sure of what her husband might be up to. He could put her to the test by coming to her house and behaving as a man who wanted to seduce her. He would push an arrow through the floor close to her sleeping place. If she responded to the invitation by coming out of the house, the husband would certainly stab her with his spear. If a husband caught his wife when she was committing adultery, he had a right to kill her.

A wife need not tolerate the infidelity of her husband. She may reproach him for it and if he then beats her she will cry loudly for help. This makes the whole matter public and that is what the husband wishes least of all. Since such reproaches often lead to fights between families, the wife is repeatedly told not to be suspicious, pipi mateba. The women watch their husbands' movements, but they do not speak up until they are certain of infidelity. A wife can also try to force her husband to renounce an illicit relationship by providing less food for him. If, however, the intruding woman is not married, the position of the wife is weak, because her husband could take this "intruder" as a second wife. In contrast to her husband, an adulterous wife is always in the wrong, even if she has an affair with an unmarried man.

If someone caught another man's wife in adultery, he would go to the men's house and search for the pipe of the wronged husband. Having found it, he would remove the fibres from the long stem. When the owner of the pipe came home and started to smoke, he would immediately know what was going on and start making inquiries at once. If, on the other hand, the wife had been molested against her wishes, she could draw a circle of mud around her navel and thus return to the settlement. Her husband and brothers would immediately investigate the case and start a fight with the culprit.

In former times conjugal infidelity could lead to very awkward results, as the following story shows. This story highlights the contrast between the serenity of the akiaq and the barbaric cruelty to which conflicts can lead. Qadaq of Képi married a woman called Ndaman. Years later, she persuaded a man Qajmaj, also of Képi, to carry her off to the settlement of Moïn. In advance she informed her sister, Mirepu, of her 
plans and asked her to bring her children by Qadaq to a safe place. Mirepu took two children of Ndaman's in her protection. She also tried to get the third child from the men's house, where it slept with its father, Qadaq. The news of Qajmaj and Ndaman spread more quickly than Mirepu could act. Qadaq would not give the child to her. On the contrary, he came fully armed with his relations to the women's house where Mirepu and the two children were staying. He demanded the children. Mirepu, however, assisted by her own husband, Qomb, put up such fierce resistance that Qadaq and his people did not dare to take the children from her. Then the great war-leder, Manip, went to the house of his wife, fetched his war ornaments and decorated himself completely. Then he made his appearance on the scene. Qadaq then took this third child, the one who lived with him in the men's house, and gave it to Manip. The latter conferred with Jaèndé. At the command of Jaèndé, Manip took his child to the people of Moïn. Moïn passed the child on to Togom. There it was killed and eaten. Some ten years later the two adulterers returned to Képi and Ndaman went back to her husband, Qadaq.

\section{Relationships within the nuclear family}

The relationship between parents and children was strongly influenced by the relations of the family with other people. An exchange marriage had a strong impact on the relations between the children of the two marriages involved. There were other ties as well, such as those of foster parents and head-hunting relationships. All these adults participated and interfered in their own way in the education of the children. Father and son(s) worked together building a house, digging out a canoe, and making fishing- and hunting-gear, weapons or drums. The father also pointed out the boundaries of the imu and qari lands to his sons. He showed them the coconuts which he planted and the trees he reserved for future canoes. On trips with their fathers the boys heard the stories connected with the hills and the swamps. They also learned how many heads they must capture to revenge the family's losses of the past.

All this strengthened the ties between father and son and at the same time the gap between mother and son widened. The boys' growing physical strength intensified their feelings of superiority over the weaker women. A boy might help his mother, but he would not tolerate a curt command. He might be very rude in his retorts. I heard comments like 
these: "My mother ... o o I gave her a beating yesterday ..." and "My mother ... I got rid of her already ..." Initially the boy feared her sharp tongue and a furious and strong mother might beat a recalcitrant son but in the long run she became more and more submissive to him. She acknowledged his growing strength as a reliable guarantee for her own safety. The way she behaved towards him during his childhood might influence the way he behaved towards her in her old age. Occasionally a boy had more positive relationships with his grandmother, who took his side when he was naughty, than with his mother, who worked day by day for him.

If her son was absent for a while, a mother might weep when he returned and the grown-up boy would accept embraces from her. In spite of this show of affection he might beat her a few hours later if she did something he did not like. Although boys and men pretended to feel contempt for the women, the women knew that the men would come back to be nursed by them in cases of illness. Then the women would use this opportunity to scold them. Once her husband had died, a mother relied more on her sons than on her daughters. She admired her sons and would be proud to be the mother of a great warrior.

A father was also interested in the education of his daughters. Not only did he give them good advice, especially regarding their future married life, but he also looked after them, guarding and helping them. In return he expected to be helped by them. He brought them the tree fibres for their perineal bands. He was angry when they behaved indecently. He also pointed out to them the boundaries of the family plots of land. A father was not ashamed to express his love for his daughter, saying a word of praise when she was good to him. It was, however, not customary for him to embrace her.

The relations between mother and daughter became more intense when the menstruation or pregnancy of a daughter induced the mother to impart the traditional warnings. As discussed above, children grew up together until they were about ten years old. At that age they were expected to stand on their own legs and to contribute their individual shares to the common board of the family. As they approached the marriageable age, both groups of relatives tried to have their say in the marriage arrangements, since not only parents had a voice, but also their qari and their imu. The only thing the young people themselves could do was to confront their relatives with a fait accompli. But such a fait accompli could, in pre-contact times, lead to sanctions which endangered their own lives. 
As long as children were small, parents and relatives were in complete control. What happened to the children if their parents' marriage broke down through divorce or death gives convincing proof how dependent children really were. The opposite was true once the children had grown up and their parents had grown old. The parents then were at the mercy of their children. Fortunately, children usually were not merciless with their aged parents.

Among brother and sisters relative age was always an important factor. The elder brother or sister helped the younger ones and taught them to walk and to speak. They kept watch over them. They expected in return that a younger brother or sister would repay this concern for them by being obedient and by rendering little services. Jabajmu told me that when elder and younger brothers went somewhere on a visit, the elder ones always entered a house first. On such occasions, the younger ones were not supposed to say anything unless they were asked a question. A special tie exists between a brother and sister who are destined to become each other's mendaq in a future exchange marriage. Thus I once heard a brother say to his sister, "Even though you happen to be my mendaq, I will beat you up if you do not do what I tell you".

Finally, there is the relationship between grandparents and grandchildren. They called each other api. Grandmothers were specially entrusted with the care of the toddlers. The grandfathers, through their wives' stories, often became subjects of hero worship in the young generation. In their old age grandparents counted on their grandchildren and expected some kind of reward and care from them, especially when their own children were too preoccupied with their individual affairs.

\section{Aspects of social contacts}

Whenever someone shoots or catches a pig he decides, often in consultation with his wife, who is going to have a share in it. The dead pig is often left in the forest. The wife sends her brothers to fetch it. Most of the meat is distributed among the parents and the brothers-in-law of the spouses. A man will first offer a piece of meat to his wife's mother and then to his own mother. Then the brothers and sisters of his wife are remembered, and finally his own brothers and sisters will receive their shares. The hunter himself does not eat any of the meat for fear of being called a glutton. The manner in which a pig is divided makes it possible to determine the pattern of friendships. The children publicly deliver the portions so that everybody can see and check how the pig 
has been divided. Jealously they watch to see if one person gets more than another. If somebody is passed over purposely and gets nothing, this is noticed by the others with malicious pleasure. This is extremely painful for the victim, for in this society everyone lives from hand to mouth, and a piece of meat is always welcome. Far worse, however, is the fact that the omission signals his exclusion from normal participation in the social fabric. Unless he is aware that he has given adequate reason for being excluded, he will feel wronged and ashamed and will brood on revenge.

Both husband and wife are responsible for the proper reception of guests from other settlements. A guest usually does not feel at ease in surroundings where almost everyone is a stranger. Moreover, he is afraid of the people because they have secret formulas and are able to harm unwelcome guests. Even when he has relatives in the settlement he is still uncertain about the attitude of the others and especially about the attitude of the leaders, who might use the opportunity to take revenge on him for past wrongs committed by his fellow villagers. In such a self-contained settlement the arrival of a stranger is always an event. He is greeted cordially by his relatives. If it has been a long time since they have seen each other, he will be kissed on both cheeks and given a lengthy embrace. If a guest is accompanied by his wife, he goes to the men's house and sits near his relative. His wife is entertained in the women's house by one of her relatives. If a whole group of guests visit the settlement, the enthusiasm among the relatives is even greater and without delay the leader of the hosts will cheerfully order the women, "Come on, roast sago and fish for our guests".

They quickly gather food in great quantities and offer it to their guests. Everyone wishes to be generous towards the guests and soon food is stacked in front of each guest. A guest politely declines this offer of abundance and says, "I have brought my own food with me". The guests always share their own food with their hosts. Together with their hosts they smoke and talk a lot. The stranger will not say anything which might discredit his hosts. On the contrary, he praises everything he sees or hears. Thus the day is passed sociably and pleasantly. When darkness falls the guest will sleep near the fire of his relative. On one of the following days, guest(s) and host(s) will set out hunting. A guest's wife, if she has come along, will go fishing with her relatives. After their stay, no matter how long or short it has been, they return home loaded with gifts. They are seen off by their relatives, who accompany them to the landing stage of the canoes. The hosts make the 
guests promise to come back again soon and then cordially say goodbye to them. As soon as he arrives home the guest goes to his own sago groves to collect great numbers of sago grubs. At the first opportunity he sends these to his hosts as an expression of his gratitude for the liberal reception. On both sides the people look back on such visits with satisfaction, because they strengthen old ties on which they can depend in case of need.

While a Jaqaj goes about his daily work (making a spear, a bow, or an arrow) he often hums. When he returns from the swamp, he sings standing in his canoe. There is no real festivity unless there is also singing and dancing. Singing and dancing continue for hours on end, day and night. Men can be seen standing together in small groups around a fire. The men's songs are sonorous and they are accompanied by many drums. ${ }^{1}$ Nearly every man has his own drum. Women, though good dancers, often prefer sitting in a large group with their babies in their laps. The songs of the women sound shrill and they are accompanied by only a few drums which they must borrow from the men for the occasion. A man may have a song-name, a pidoq or éb éké. Such names were given by fathers or friends. Often they were the song-names of deceased persons with whom there was a certain resemblance. ${ }^{2}$ Birds and trees, or the subject of a song, were also given such a song name.

In both male and female groups, there is always one person who starts the song. He (or she) sings one line and then the others join in. The Jaqaj distinguish three kinds of songs. They speak of the tok-éb, fighting songs, nama-éb, mourning songs, and tom-éb, love songs. The structure of all three is the same. Every song consists of several stanzas of short lines. These lines are usually divided into two groups, each with its own content or subject, which may be interrelated. Whatever the subject is, it is always important that the persons or things about whom (which) the song is made, are indicated by two names, pidoq, in such a way that one name is used in the first line and the other in the second. To an outsider these songs are difficult to understand. This is primarily due to the succinct manner of expression and the use of short catchwords. To understand a song, it is essential to know the incident that provided the subject matter for it. Fighting songs are arranged in cycles. At Képi, before the people started such a "sing-in", they first discussed what they were going to sing about. They chose a particular head-hunting raid and then started the song about a particular incident which occurred in the territory raided. Then followed a song about 
something that had happened on the way back. Finally, there were songs describing the arrival in the home settlement. Father Meuwese said that during such nights of song sessions several men would drop out and sit at the edge of the group where they then dozed off. He had often been struck by the fact that towards dawn everybody was again present and that they all sang very enthusiastic songs as the run rose.

During a feast when the guests are formally received or when captured heads are carried in procession into the settlement, the people dance as they sing. The ordinary dance, tatè, consists of various body movements. The dancers bend their knees outward while making shuffling movements with their feet. The drummers alternately place the front of one foot near the ankle of the other foot. Those who dance with spears in their hands surround the drummers and make the same steps at a much more rapid pace than the drummers. They also tend to lift their legs higher and as soon as the final yell has been shouted, they thrust their spears into the ground. Finally, standing on their toes, they rapidly move their knees to and fro. The women lift their breasts with their hands in a quick up and down rhythm.

There are also dances ${ }^{3}$ which are performed merely for the sake of the dancing itself and are not done as a kind of accompaniment to singing and drumming. This type of dance is common among the women only. The women usually dance as described above, but they keep their arms bent over their heads while their bodies bend forward. They dance in a circle and alternately look to the left and to the right from below their armpits, as if they were looking at their shadows. A swaying cadence of their festive skirts accompanies their movements. They wear birds of paradise on their heads and they paint their upper bodies and legs in striking colours. The men also "dress up" for the occasion and even the children are painted. The Jaqaj's feeling for rhythm and collective acting is evident in both songs and dances.

An important part in social communication among young and old is played by the humour in which the Jaqaj excel. First of all, there is that type of humour which is akin to what we might call "malicious pleasure". It does not indulge in any form of cruelty, but enjoys the comic aspects of mistakes and the disproportion of deviant situations. A typical case is that of the spirits who thought they had killed a man, but had actually captured one of their fellow spirits. ${ }^{4}$ When somebody has a slight accident, the first reaction will be a spontaneous outburst of laughter. The Jaqaj like pulling each other's leg and frighten each other just for the fun of it. It is fun to beat somebody who is clearly 
bent on getting a thing by stealing it from under his very nose. They know how to imitate personal peculiarities and ridicule typical sensibilities. They delight in reviving funny events of the past by a single word. They amuse themselves covertly when anyone commits a blunder or gives a completely wrong answer to a question, rejoicing in advance of the song they will compose in commemoration of the event. The Jaqaj are fond of songs mocking an individual's idiosyncrasies or failures. Fr Verschueren once built a windmill on top of a wooden tower in order to charge a battery. The charging miscarried because the wind was not continuous. This event was commemorated in a song composed by Ndaman, the mother of the man who had helped to construct the windmill. In the song Qaépön/Tébaqaj is the song name, pidoq, of Father Verschueren. Ndaman sang, "Son-in-law, do not let the iron tree strike you. Child-in-law, you have married into the family, do not let the steel tree strike you. Your grandfather constructed it, Qaépön has erected it. Without wind he has built it, up there without wind he built it. Your grandfather has erected it, Tébaqaj has constructed it. Without wind he has erected it, high up there he has erected it, without wind."

A good story-teller, kéri bai, is a popular man in the village. $\mathrm{He}$ knows how to depict the adventures of the Mitak tribe who were able to walk under water, or those of the man from the Nambéōmön who was swallowed by a toothless crocodile. He cut open the crocodile's belly and thus returned to his village. Another story tells about the Jaqaj people in the marsh lands on the island of Jar. Their name is Qomi and they have never been seen by anyone, although traces of them have been found from time to time. When they know that they are about to be discovered they drop from the tops of the trees, if need be, and escape unharmed. The new houses they build suddenly look very old as soon as a stranger happens to come near. Their burning fires quickly turn to ashes, appearing to be several days old. Their footprints also appear very old. More important, however, are the myths told. A collection of them will be given in Chapters XIII, XIV and XV.

In the preceding examples I have spoken mostly about things which have a favourable influence on social relations: the distribution of food, ero; hospitality, adān; songs, éb; dances, taté; and jokes and songs. Very briefly, however, I must also mention a factor that had an unfavourable influence, i.e. competitions in abusive language, which were of frequent occurrence in the daily life of the Jaqaj. The women 
especially were good at this kind of abuse. It always referred to elements which threatened the social fabric of the community: gluttony and sexual misbehaviour. Some examples are: kandömoqowb: fat guts; aq maq-inden kéame kandöm renggèmbak: your belly makes you look pregnant (said to a man); qarapé-arép: glutton; aq nao arepade: you have lots of excrement; aq qaké-qamben: you are like a dog that is begging all the time; ringgi pop: fat arse; ringgi doq: red arse; qoqudqambo: you have pus in your anus/genitals; tom maq: son of a bitch; qaw jo pop: your mother has a large vagina; jo qajo-maq: your mother is a bitch; qapajmu-maq: your mother is a whore; kujo-taker-maq: your mother has pubic hair like that of a cassowary; aq kujo-qamben: you are as cowardly as a cassowary; aq batik-embék mono boraqaé: you are as stupid as a pig; aq qotaqarép/taqandömarép: braggart; potök-arép: cross-grained fellow. Expressions like these, forwarded in rapid succession, usually aroused long lasting ill feelings. 


\section{CHAPTER VIII}

\section{ILLNESS AND DEATH}

On the whole the Jaqaj are a healthy people, in spite of endemic malaria and yaws and recurrent influenza epidemics. To a somewhat lesser degree they suffered from diarrhoea, nao-muj; dysentery, nao-kam; and skin diseases, bumungk, of various kinds. Filariasis and leprosy were relatively rare, as was insanity, which was described as ko-oraq, "madness came over him".

\section{Jaqaj notions concerning disease and its treatment}

The Jaqaj blame the cold wind, the constant rain, and the smell of rotten things as causes of illness. From the end of the wet monsoon till the beginning of the dry season, when a cool breeze from the southeast starts blowing, many people suffer from influenza. They get high fevers, pneumonia, colds and headaches. The sick lie near the fire one moment and the next are sitting by the door in a draught. The hair of their heads may be shaved off, either completely or with the exception of two crossed bars of hair. Other sick persons tie a string around their temples, or let scratches be made on their foreheads with bamboo knives. Sometimes people flee the settlements and go to their bivouacs, but when other people there also fall ill they again go back to the settlement. The bites of animals and stings of insects, and also blows or stabs sustained years before during a fight, may be seen as causes of illness.

Usually a sick person is moved to the house of a relative. Twigs or shrubs are inserted in the front wall of the house (in former days the skull of a deceased relative was used as a pillow, as it was supposed to emanate healing power). Swellings or ulcers are sometimes opened to treat them with sap from various plants (among others, tobacco). The wounds are then covered with leaves or mud. Patients bitten by poisonous snakes report how they feel the poison, indök, rise in their bodies. The spot is treated with tourinquets and cuttings. The patient must chew the root of the kidu plant and swallow the sap. I once saw 
a woman pull at a string which she had tied to her toe where she had been bitten. In the case of intestinal troubles the Jaqaj drink a mixture of water and pounded bark derived from two trees called monom and wakéj. ${ }^{1}$ They also use a mixture of water and papaya flowers, but this is probably a new medicine, dating from after pacification. In the Nambéōmön district, according to Nejaqaé, they massage the belly of a child while saying, "Baqamön, you break up the nest of the bird kagi, clean it well with omu". In this formula Baqamön is the name of one of the babaé, the ancestors; kagi is a kind of bird; and omu is a kind of rush.

In the case of a chronic disease the patient might be given his own urine to drink. It was mixed with water and after it had been left standing for some time the upper part of the mixture was drunk. Sometimes the sperm of a brother of the patient was requested: it was mixed with water and then administered to the sick person. If he did not vomit, this was considered to be a good omen. If the patient survived, the donor was paid with a string of dog's teeth, tumi, a bow, or a spear.

Often a particular power, waw, emanating from either a man or an animal, was regarded as the cause of an illness. The following case, which took place at the time of my research, is instructive. The people of the village of Waman were the guests of the people of Képi. In the village of Képi they had a bivouac of their own. A woman of Képi began to feel ill. When asked why she was taken ill, she replied, "I have embraced a woman from Waman. Her waw struck me". The sick woman went to the bivouac of the woman of Waman and asked the girls where the old woman was who embraced her. They said, "There she is". The old woman came outside and said, "Child, it is not me, perhaps you are ill because your leader became angry with the people of Waman. He was so angry that even my own people of Waman took to flight." But other women told her, "Who knows, after all a waw might have gone out from the old woman".

Besides this particular power, waw, the Jaqaj also mentioned the influence or appearance of spirits and shades as causes of illness. These spirits and shades were mentioned above when I discussed the dangers a pregnant woman is exposed to. I once saw in the village of Dagimon how a little boy walked behind Jānda, a great head-hunter in that village. Jānda at once called the little boy to come to him, passed his hands under his own armpits and then held them in front of the boy's nose. They explained that Jānda was believed to possess an extraordi- 
narily strong waw, because the souls, toqojia, of the victims killed by him on his head-hunting raids, stayed behind him. The passing of the body odour from the head-hunter to the boy relieved the boy of the influence of the toqoija. In cases of theft a strong man could also call on his ancestors to catch the thief by causing him to fall ill.

Another case was that of Kab, a married woman of Képi. One night she disappeared and people set out looking for her. It turned out that she had swum across the river to the neighbouring village of Emeté. She then returned to Képi. Her reason was, "The shade of a recently deceased woman called me". The same day her mother heard Kab's child crying. She went to see what the matter was and found that Kab had disappeared again. The people of Képi started looking for her; time and again they called her name and her mother asked the spirits of the dead not to keep her but to send her back. The next day Kab returned to the village by another route and went into the house of a close relative of her husband. When asked what happened, the story came out bit by bit. The spirits, she said, had come to her and beaten her on the back of her head. Then they had taken her to the marshes. She had seen many of them there. She had seen them as clearly as if it were daylight. The spirits had offered her a banana, but she had refused to eat it. They had forced her to walk across all kinds of trees in the marshes. She had been able to come home by a roundabout route because the spirits had not yet wrapped up her body (i.e. they had not yet entwined the various parts of her body with ropes of rushes in order to reserve them for a cannibalistic meal). Moreover, Kab had not eaten the food which had been offered to her because she knew that she would die if she ate it. When she was found in the other house she was taken back to her own and beaten by her mother with a sago palm branch. People expected her to die but this did not happen, though from that time on there was always something strange about her.

In connection with spirits as causes of an illness, I must give more details about the male and female contact-persons, the so-called joqberaradé/taw. They were able to fetch back souls which had been carried off by spirits. They also learned from the spirits what medicines were effective in certain illnesses. Tambim, an old man of Képi, gave the following information about the man Oaqaj, whom Tambim had known personally in former days. Tambim said, "In former days, when Oaqaj was not yet a joqbera-radé, the wife of this Oaqaj, named Qonam, got a tumour. Oaqaj looked around for help. He took the skull of someone who died from an illness and also a piece of rattan from a platform of 
the dead. He burned the rattan to ashes and smeared them on his forehead. Then he went to a certain place called Baqabuaq. On his way, he hung the skull on a branch and continued to walk, but soon retraced his steps. Spirits came out of the ground. Oaqaj, coming back to the spot where he had hung the skull, fell down on the ground and heard a voice asking him, 'What have you come for?' He answered, 'I have come for my wife who is ill'. Oaqaj put out his left hand. The spirits told him, 'You must gather medical leaves, rara'. Oaqaj chose rapöt leaves. Then the spirits said, 'Let the leader Robāb open the tumour'. Oaqaj went back to the settlement, entered the room of Qonām, and smeared her forehead with the rapöt rara. Then Robāb opened the tumour and the pus was released. Then she ate some sago. From that time onwards Oaqaj was a joqbera-radé."

Another informant, Nejaqaé of Mandaw (a village in the Nambeōmön district), told me, "A joqbera-radé went to the bush and there he was suddenly knocked down. He then saw somebody resembling a fellow villager who was lying ill in the settlement. The joqbera-rade had his bow with him and at that very moment noticed a lizard or a frog on its top. He then took this animal to the men's house and gave it to the patient. In this way the soul, moké, or the strength, ngadé, came back to the sick man."

In addition to the joqbera-radé, the akiaq-radé, the counsellor, also functioned as far as sick people were concerned. If a man was often ill, the akiaq-radé payed him a visit and persuaded him to confess his crimes, especially crimes of adultery. If the patient did so, he was expected to recover.

The Jaqaj, however, did not uncritically accept the influence of spirits. At Képi, the leader Jabaqaj was said to have a very critical eye on this matter and if there was any deceit he would unmask the perpetrator. When the man Nabé was wounded, his relatives called an old woman, named Qabur, to see him. She examined the wound and said that the nails of a spirit were in it. Jabaqaj, who was also present, kept an eye on her. Qabur took a leaf kidu-rara, and with some fumbling she put some splinters of wood in it. She rubbed the leaf over the wound and took two "nails of the spirits" out of it, which she showed to the bystanders. She threw the leaf on the ashes in the fireplace. Jabaqaj took the leaf from the fireplace and showed the splinters to the people. Qabur fell silent and was ashamed. I was also told that when everyone in the men's house was afraid, hearing the spirits whistling outside, this same Jabaqaj went outside, captured in the darkness two 
young men who did the whistling, brought them inside the men's house, and told the men, "Here are your spirits".

\section{Old age and other causes of death}

The Jaqaj used to say to old people, "Tapaq baqapoao, you have become the sun". By this they meant that the old people had reached that stage of permanence which is pre-eminently applied to the sun, viz. the stage of tapaq maqati, the everlasting sun. Yet they also said that a grey-haired person had a muku idöm, " "a head like that of a shade". Of younger persons Jaqaj people told me, "They cannot die", binden oapeduane-maq. Sometimes, however, they foresaw that a particular person would not live long and then they said, "He has already been marked out". The snapping of a bow string was a very bad omen for the owner because it meant that this ngade, strength, had been broken. Also, if one of the pig's teeth, oana, in his necklace fell out, this was an omen that a man would not live long. Similarly, people sometimes worried about a falling star, kando, for it could be someone's ngadé. The joqbera-radé had to decide whose ngadé it was. He was paid for his information with roqoj, the fibres used as a filter in a pipe stem. Tambim said, in this context, that a joqbera-radé had some power but he could not always prevent death. He said, "When a certain man fell ill, Oaqaj (the seer) met the soul on his way. He caught hold of the soul with his hand, but the soul escaped. Oaqaj caught hold of it again, but the soul escaped again. He seized her again, but again she escaped, and finally she disappeared. Oaqaj went home with empty hands. He went to the patient's wife and said, 'Woman, start weeping. The soul of your husband has escaped, this man will die'. The woman began to weep."

Dreams often announced a death. Utejr, the wife of the Ikimu leader Jaèndé, dreamt that a man from Waman, who had recently died, offered her some fish on a string. She woke up with a start and felt the pains of a beginning miscarriage, which led to her death. Jaèndé blamed himself because he had not taken her to the house of her father, for there she would not have died.

The Jaqaj denied that the soul left the body during dreams. They believed, however, that this happens when a person loses consciousness. The cause of death they feared most was rara-wir-kinaqaèb, "the medicine to kill somebody". One of my earliest experiences in Képi was the death of the younger brother of the great Jaro. I was told that he had prepared such a "death medicine" for someone else and then had 
inadvertently stepped on it himself. A woman, Penöm, of Képi was supposed to have placed such a rara below the stairs which her husband used when entering the house. Her own father had given her the medicine and commanded her to place the medicine there, because her husband did not pay debts to him.

Nejaqaé of Mandaw described how such a medicine was prepared. The sap of leaves of the baqowp tree was squeezed into somebody's drinking tube or a piece of wood of the at tree was laid near someone's door with the formula (over the piece of wood), "Now you kill either the husband, or the wife, or the child". The persons who entered the house by that particular entrance were expected to catch a fever and die. To prevent this a younger brother of the sick person might call on all the leaders of the various groups and ask them whether or not they had placed a rara. Unless one of them unexpectedly admitted that he had placed the rara, the younger brother threw fruits of the boe shrub into the water, mentioning the name of a particular suspect. He did this several times, each time mentioning the name of another suspect, until suddenly a fish snapped at the fruit. This was a sign that the name last mentioned was that of the culprit. The brother then asked this man to take back the cause of death. The guilty man would take a draught of water and spit it out over the patient with the words, "You come to your senses", or else he could put some boe fruits in water and rub the patient with this mixture, saying, "Waw, go away". From Képi another method was reported by which a sorcerer took a piece of dogodip wood, rubbed it and stuck stones of kao and abe fruits on it with resin. While doing this he said, "You must kill one and not many". (The fruit-stones mentioned here are the same as those used to decorate the traditional marks of honour.) Having conjured the decorated dogodip wood he buried it pointing in the direction of his enemy's house. The occupant would then fall ill. The noxious effects of this technique were far worse if the sorcerer, after taking a bath, smeared himself with white clay and then placed the piece of wood near someone's excrements. Then an epidemic would break out and it would not stop before the man who had buried the piece of wood had personally dug it up, thrown the kao and the abe fruits into the river and dried the piece of wood in the sun. Only then would the illness stop. ${ }^{3}$

\section{Death}

When a patient's breathing stops and his navel no longer moves up and 
down, the Jaqaj say nit boraqaé, "the breath has gone", or moké kerium, "the soul has left". The stoppage of breath is the symptom of death. Jabajmu of Képi once asked me to ring the bell for the burial of a certain patient. I had, however, seen the patient a short time before and did not trust the message. I asked if the patient had already died. Jabajmu answered, "The breathing has stopped and only his heart is still beating". Verschueren told me that he had witnessed the burial of a person who must have gone through a similar experience but who managed to return from the grave.

The Jaqaj say of the soul qaj-pedu-ane, "he does not die", or quboaqan-kétak, "he has gone into the woods", or ouw kébokudök, "he has entered the ouw tree". After death the soul is called idöm and this idöm, shade, sometimes accompanied by other shades, returns to the settlement to capture other human beings. They make a piping sound. The advice is, "Close the doors tightly, lest the spirits (here the word bana is used) come in and cut off your heads". They said that at night the spirits look for food in those places where they used to go when still alive. They go "head-hunting" among the living. A husband who has died wants to take his wife with him and vice versa. Much information on this subject is contradictory. On the one hand, the Jaqaj say that the spirit will take a new wife in the abode of the idöm and that she will be the first woman to die after his death. On the other hand, they say that the husband just lives on in the abode of the idöm and that when his wife dies, her soul will go where the soul of her husband is waiting for her. When I asked whether the dead beget any children, they answered, "They do not think of children. They only think: are we satisfied? Is it beautiful here?" Tambim of Képi quoted the following statement by Oaqaj, a joqbera-radé, to his wife Qonam, "You need not go into mourning, you need not weep. With my own eyes I have seen people who died in the past. They are real people. Do not weep after I have died." Of a man from Képi it was said, Momé éamaé-moqon-aqan kétak, "Momé has gone to the éamaé-moqon", 4 which literally translated is the "he-is-there-country". The Jaqaj themselves do not know where that country is.

The mortal remains are called rumba, a skin. The soul, moké, is something in the body which leaves at death. Some say it leaves the body through the mouth and others say through the navel. If somebody is dying (usually in the women's house, because a man who is seriously ill is nursed there) his blood- and affinal relatives will assemble at his death-bed. A dying woman will simply lie on the floor, a dying man 
lies with his head in the lap of his wife. Beside the dying person a man or woman may lie down wrapped in a mat; others sit near his head or his feet. When the patient has lost consciousness they call his name. They try whatever means they can to resuscitate him: they may hold a piece of burning wood against his body, or pull at his feet or hands to make his joints creak. If it is a man who is dying they sometimes pull at his genitals, or a woman stretches on top of him to prompt a sexual reaction. When the breathing has stopped, a terrible outcry is raised. Women rip their fibre skirts from their bodies, others beat on the walls of the house or dance around the corpse. Everyone weeps aloud for many hours. The children get lost in the crowd and huddle somewhere in a corner. Women gesticulate wildly; a distant look can be seen in their eyes. All sorts of reproaches are addressed to the deceased. Or they say to him, "You first, I myself later, let us see each other again in the éamaé-moqon". The Jaqaj assured me that the gesticulation of the women, the beating on the walls, and the undressing all aim at preventing the soul from harming other people. The shouting of the name of a person who died is not done to call him/her back, for they say that only a joqbera-radé would be able to do this. Outside the house women dance dressed up in leaves taken from nearby food plants (bananas or garden plants). Sometimes the wife of a deceased man may dance inside or outside the house with the spear or the bow and arrows of her dead husband. She chants a mourning song that says, "He has hunted with them. He has done so much good with them. He will not use them any longer." Lamentations are also raised in other houses. A message is sent to other villages and one after another the relatives arrive. They have smeared their bodies with white clay, and have tied leaves to their foreheads. The women go almost naked. They come to pay their respects to the deceased relative. Everyone seems completely overcome with sorrow; tears run down their cheeks, their noses run, and even young men may be seen leaning against a pole, losing themselves in their grief without any inhibition. This goes on until the burial, which nowadays must take place within twenty-four hours.

In the Nambéōmön district, a young man may make a cut in his own finger and put it in the mouth of the corpse if the deceased was a powerful man. He wraps his finger in a leaf and ties it up with a string. $\mathrm{He}$ fasts until the finger begins to itch. Before long, the string and the leaf automatically fall of. This finger now will tell him when he will be lucky in a hunt, janggo-umé, when he will be lucky while fishing, jangk-umé, when he will win a fight, ora-umé, and it will warn him 
when there will be another death, babu-umé.

At Dagimon I was told that it is possible to conjure up the dead to come to the men's house. Then the conjurer says, "You are here, you have come now, soul-man, moké-radé. Now you have come into the men's house. I have called you, your soul which was in the forest, I have called you."

\section{Mourning}

The first teachers and the district chief $\mathrm{F}$. Maturbongs have provided some information about pre-contact care for the dead. Maturbongs expressly distinguished between the care taken of a deceased who had worn marks of honour during his lifetime, and that of a deceased who had not been considered worthy of such distinctions. A great headhunter had his head and chin shaved, and his corpse was painted as he would have painted himself for a feast during his lifetime. The corpse was then placed in a sitting position in the men's house. The mourning was accompanied by drums. Then the middle piece of the roof was removed to build a platform. On this platform they placed a canoe and built a roof over it. The men then moved to the two ends of the house. After the guests paid their respects and joined in the dirges, the body was laid in the canoe on top of the roof. Guests who were late because they came from far away could climb up onto the roof to see the corpse. A few days later the ornaments and the marks of honour that could still be used were removed from the corpse.

For a time the men could stand the smell of the corpse decomposing in the open air, but later on the stench became unbearable. Jaèndé gave an example of such a burial in the open air in his life history. His account differs only in this respect, that the canoe stood not on top but in front of the door of the men's house. He told about the burial of his father, Kamborö. "They put up the platform right in front of the door of the men's house. The men who slept at that side of the house moved to the other side. The worms crawled out of the corpse and came as far as the central part of the men's house. One worm crawled into the ear of a man called Jamaqamoqon and he died of it. The people moved to the hill Jaija and there Majaw died, Watop died, and Kakebaq died; they had got the smell of the corpse in their mouths while eating sago and they had swallowed it with the sago. They died of it. When the flesh had fallen from the bones, the men returned to Képi."

According to Maturbongs, the corpses of ordinary people were also 
decorated; the canoe in which they were laid down was placed at the edge of the settlement. There were also lamentations, but no singing or drumming. Only the next of kin put on mourning garb. According to the teacher at Jatan, S. Effroan, the corpse was not painted; decoration was limited to a new skirt, roqoj, and some beads. The corpse was wrapped up in a mat and carried out of the settlement to be put on a platform about one yard above the ground. When a corpse was carried away everyone first stamped their feet on the ground before funeral procession started. A dead baby was disposed of by placing its little body in a bamboo basket, ro, made by bending outwards the upper part of a bamboo branch. This was placed near the platforms or canoes on trestles, ndat, of adults.

The personal property of the deceased was hung from the canoe or the platform on which the corpse rested. If he had been a warrior, the heads he had captured, his weapons and his drum (after it was smashed) were placed with the body. If a woman, her roqoj, her sago pounder and her fishing-basket were hung from the canoe. For everybody a carrying-bag with roasted sago, meat and fish was hung on a forked stake nearby. A little fire was lighted near the corpse, and coconuts hung from all the platforms. In time these coconuts grew shoots which were planted by the relatives. After a head-hunting raid the platforms were pulled down. Although exposure on platforms or in canoes was the more usual form of disposal of a corpse, burial was a frequent alternative. The Jaqaj said that those women and men who had not taken any heads were usually buried in the ground. According to Meuwese, however, sometimes women were also put on a platform. They may have been the wives of great head-hunters.

When the corpse was carried off - with or without drumming and singing - the relatives followed. The women wore their worst skirts and were smeared with white clay. Some relatives could hardly walk because of their grief and had to lean on sticks. Verschueren describes how Jaèndé had to be carried in a mat behind the corpse when his second wife was buried. Later he lay prostrate on her grave for hours and then crept home on all fours. Once a woman, Namaqaj, abused the carriers of the corpse because they had not held the canoe upright. Tambim once forbade his sons to attend a burial because the people of Képi had not shown sufficient interest when his mother, Nada, was buried. According to the teacher Kadmaerubun, who came to the area soon after its pacification, when a man died, his wife of ten went to the men's house and put the string of her husband's bow around her neck. 
She begged the men to hang her so that she might be buried together with her husband. The men complied with her wish. If such a woman happened to have many children, her sister might be pressed to die in her place. Even the mother of a dead man might behave in this manner.

A man had to be carried out by men; a child was carried by the women; and a woman was carried by volunteers from among her relatives, both male and female. After the burial, a widow returned to the women's house where she retreated to a corner which had been partitioned off with mats. Her seclusion lasted until her relatives had paid those who had come to offer condolences with a pig. The widow in her corner took off her skirt and worked on her mourning garb. Without this she would not be allowed to leave the house, not even to relieve herself. This mourning garb consisted of a jacket, pukumo, the loose fibres of which reached down to the ground. On her head she wore a hood, qom, which hung far down her back. A man would take off his anus cover, ék, or his shell and put on a short vest, dodo-pukumo, with long ribbons hanging from it in front and back. Around each arm he wore two arm-bands and around his legs one band below the knee and one above the ankle. Both men and women wore sago fibres around their necks, naq-tin, through their ear lobes, mono-tin, and through their noses, mirip-tin. A man was permitted to go hunting, but he was not allowed to touch water. Friends carried him across small rivers. He also was permitted to go fishing, but only by spearing from a canoe.

If the deceased was supposed to have died from eating certain kinds of food his next of kin had to refrain from eating this kind of food. This abstinence was called tāqam on the river Oba. Drabbe calls it atini. The word täqam also has the wider meaning of "to be in mourning". Those subject to such a rule wore signs telling which food they were not allowed to eat. These signs were worn on a string around their necks. A piece of bamboo indicated a prohibition on meat, janggotok. A piece of the fire tongs, enggöb, indicated a prohibition on fish. A piece of shell, qajm, stood for a prohibition on coconuts. The prohibition on eating a certain kind of food also included touching it. Partaking in a particular tāqam depended on the closeness of the family relationship with the deceased. When I asked whether this täqam was of any use to the spirit of the deceased, the answer was a negative one. They said that the tāqam was an expression of how they loved the dead person.

Maturbongs said that for a man who had worn the great marks of 
honour, his wife (wives), children, parents, brothers and sisters went into mourning no matter what settlement they lived in. Their spouses might be requested to do the same. With ordinary people only the spouses went into mourning, although sometimes they were joined by their children and a few other members of the family. For an adolescent son or daughter, both parents went into mourning. If a child died very young, only the mother went into mourning.

Maqaomi and Jaro often referred to the atmosphere in the settlement. They said, "When a man has died, his coconuts may not be eaten. The case of a woman, a child or a wife is similar. The leader then says, 'Children, women, do not gather any coconuts, don't do it'. The leader strains his ears. He asks himself, 'What is so and so cutting there? Is it firewood?' Stealthily he peeps in; his arrow is on his drawn bow. The man who is cutting says, 'It is only firewood, just look; it is not a coconut, it is firewood. I would not dare to break a coconut for fear of being shot with an arrow'. The leader says, 'Firewood should not be cut in the house; you may do it in the bush'."

In the coconut garden and in the sago grove of the deceased, signs of prohibition were erected. Nobody was allowed to use these grounds as long as the next of kin (and also as long as the group leader) did not give their (his) permission to do so. Such a prohibition was still in vogue in 1967, when the wife of Obeqaméamu died at Képi. Her husband said that one reason not to go to these places was that they reminded him too much of his wife. When a death occurred in the settlement, nobody was allowed to go fishing or hunting that day. Sexual intercourse was also forbidden on such a day. Those who nevertheless had intercourse on that day were not allowed to come near the corpse. In the Nambéomön district, on the day following a death, a son of the deceased went through the settlement with a fishing-basket or poured some water in front of every door. This was a sign that daily life could resume its course. The carrying of a fishing-basket reminds me of an event witnessed by Verschueren at Kadöm. Women moved in a long line from one end of the village to the other. Every woman had her fishing-basket in her hands. The long row of women was followed by the men who sang to the accompaniment of their drums.

Several months later, the people started to collect the bones of the corpse. Maturbongs again makes a distinction here. After a headhunting raid the platforms of the great head-hunters were pulled down and the mourning signs worn by their relatives were cutt off. However, the termination of the mourning period for a less important person 
could be performed by any head-hunter at the request of the family of the deceased person.

The grief and sorrow for a deceased spouse could last for months. The wife especially, in her isolation, would of ten sing mourning songs for her husband night and day. If any widow (or widower) did not show sorrow long enough and too quickly appeared to be thinking of remarrying, this would be taken as a sign of selfishness. He or she who showed little grief was certainly not able to show any great love either. The next marriage partner ought to be very much on his/her guard.

When Qadaq died at Képi, his wife Ndaman loudly sang her songs of mourning continuously for over a month. Afterwards, she was willing to dictate these songs to me. I have recorded forty nama-éb, dirges. One of these follows here. Ndaman speaks as if her husband Qadaq, also named Jabön-Oapajt, is still alive. She tells her children that their father is on his way back from the hunt. The stars shine on his back. He wishes to have a fire lighted for him so that he can prepare his food and warm himself. A fire must therefore be lighted. The good bow which he used is now in the house of his wife and children. The song says:

"Children, your father wishes to have a fire, light it.

Jabön wants some fire, light it.

The stars shine on his back.

Offspring, your father wishes to have a fire, light it.

Oapajt wishes to have some fire, light it.

The stars shine on his back.

Jabön, the tiki bow is in the house of the younger sister and the children, the tiki bow.

Oapajt, the bako bow is in the house of the female decendants and the offspring, the bako bow." 


\title{
PART III \\ HEAD-HUNTING PRACTICES
}

\author{
CHAPTER IX
}

\section{HISTORICAL DATA}

Minor conflicts and quarrels between individuals, which do not involve the participation of their respective groups, are called mim. A more serious affair is a $n u$, a fight between groups within the settlement. In such a fight someone may be killed but neither head-hunting nor cannibalism are involved. Members of one and the same settlement are, in theory at least, blood- and affinal relatives. The prohibition on cutting their heads off or eating them is ascribed to the sun itself. Warfare between different settlements of the same tribe is called tok, ${ }^{1}$ which is here translated as intra-tribal warfare. Such warfare involves battles between members of two different settlements. From Jaèndés life story (see below) I learned that such battles could develop into full-scale wars in which whole groups of allies joined (e.g. Képi against Rèp, or Képi against Moïn, Togom and Wajru). Since such fighting was really head-hunting and cannibalistic by nature, it could also be called $k u j$ and translated as "head-hunt". The term kuj, however, is usually applied to an extra-tribal war raid in which whole groups of men and women from various Jaqaj settlements join. This will be described in section 2.

\section{Intra-tribal warfare}

Much of the information on intra-tribal warfare is borrowed from the life account of Jaèndé, one of the leaders of Képi. He told me about the battles between Képi and Emeté, Képi and Rèp, and Képi and Moïn. All these fights took place during a period of about fifteen years. Képi 
had six fights with Emeté, with a loss of one man and one woman from Képi and five men and four women from Emeté. Between these conflicts they made peace four times. Képi fought against Rèp eight times, which cost the lives of three men and one woman from Képi and thirty-eight men, four women and three children from Rèp. Because of these losses, the people of Rèp fled into the forest and did not turn up again until after the arrival of the first Catholic teachers. Képi fought six times against Moïn. On the side of Képi eight men and one woman were killed. Moïn lost four men, two women and one child. In the meantime, Képi also ambushed Togom, killing a great number of younger men. They also fought twice against Kogo, which lost five men and one child. Altogether Képi lost twelve men and three women in about twentyfive battles. The large number of people wounded was not even mentioned. The total number of persons killed shows that rarely more than a few men were killed in these fights. Only once, a great many people were killed, namely, when Képi staked everything on the massacre of Rèp, because this settlement had become too powerful and was becoming a threat to Képi. I had been at Képi for some time when they asked me, "Tuan [Indonesian for "Sir"], have you ever seen many older men at Rèp?" I had to admit that there were none. They said, "No, there are not any, we ate them all".

Normally casualties were relatively few in number because most fights took place in open spaces and were fought hand to hand. The open space enabled the participants to flee at any time. Before the fight they adorned themselves and then set out carrying both shields and spears. The vivid colours helped them to estimate immediately the strength of the enemy. The two parties knew each other's tricks and ruses. Besides, efforts to kill were repeatedly thwarted, because someone from the assailant's own ranks would stand up for an enemy who was one of his relatives. This description is only a faint reflection of what the situation must have really been like. Men of neighbouring settlements often took part in the battles of other settlements in order to help relatives living there. Finally, there were fights between the component groups of a settlement. More important than the loss of lives in such fights were the strong emotional reactions of the people. They formed a constant stimulus for new outbreaks of hostilities. Someone who has never heard oral accounts of such events cannot imagine the violence and the fierceness of the fights or the repulsive scenes that took place on or near the battlefield. The oral account delivered by Jaèndé of Képi and here presented is a good illustration. 
When necessary I will insert some explanations. I have chosen the fight between Képi and Moin because this story includes the cause of the fight as well as the account of the hostilities and the final peace settlement.

"In former times there was no war between Képi and Moïn. They celebrated all their feasts together. Then it happened that the men of Képi went up the river Oba and passed by the settlement of Moïn. They were going to attack Wajru. Oaqaj, a man from Moïn, and his wives were in their canoes and he was startled when he suddenly saw some men whom he did not know. The men from Képi went for Oaqaj and his wives with their spears and [pointed] oars. Oaqaj was frightened and fled into the bush. He was captured by the men of Képi who took him by the hand. I said, 'Wait a moment before you stab him. First you must investigate the case'. Jaro, the leader of the Aqaoèmu, said, 'Go ahead and stab him with your spears'. I shouted, 'No, do not throw your spears too quickly, he might be someone from Moïn'. The man said, 'I am Oaqaj from Moïn'. He added, 'You were after the men from Wajru. I was frightened and ran'. They returned to Oaqaj his axe, beads and carrying-bag, which had already been taken. Then the men of Képi went back home. Shortly afterwards, Maqajtoqon of Képi went fishing in the neighbourhood of Moïn. Some women from Moïn who saw him there said to their husbands, 'When the men of Képi were on their way to attack Wajru, Oaqaj and his wives fled for fear of them'. When the husbands heard this, they wished to revenge the disgrace of Oaqaj and went out for Maqajtoqon. Maqajtoqon saw them coming and began to shout [so that the people of Képi, who were in the neighbourhood, might hear him]. Tinggop, a man from Moin, hit Maqajtoqon with an arrow. The men of Képi, who had heard Maqajtoqon shouting, jumped into their canoes and went to attack Moïn. The men of Moin, however, had already returned to their settlement. Nevertheless, Képi wanted to attack Moïn. The Ikimu and the Aqaoèmu said, 'We must take revenge'. The Marapému and the Kamaqajmu said, 'No, don't do it'.

The men of the Ikimu and the Aqaoèmu rowed till they were near Moïn and shouted, 'Come on, shoot back'. But nobody from Moïn shot at them. Then the people of Képi went home again. One of them, the leader Manip, and another man, Qomb, stayed behind. They hid in the swamp and waited till dark. When night had fallen, Manip went into Moin. The canoes of Moin lay on the banks; he pulled them into the water so that they floated away [in these canoes Moïn could have 
pursued them on their way home]. He walked into the settlement. $\mathrm{He}$ threw his spear at the men's house and shouted, 'Oaremoqon' [possibly the name of the place where he had been born]. The spear which Manip had pointed at the man Mbaqaé flew through the men's house and stuck in a pole near the sitting-place of Mbaqaé. Manip had almost speared Mbaqaé to the pole. Then Manip went back to Képi. It was still night when he arrived.

The next day the Ikimu, the Aqaoèmu, the Kamaqajmu and the Marapému moved to Oqoté. ${ }^{2}$ They feared that the people of Moïn might destroy Képi's tobacco plantation near Oqoté. The people of Képi had caught some fish at Oqoté and were about to pile them up in the canoe when they looked up and saw some canoes coming from the direction of Moïn. The people of Képi roared, 'There are men in sight'. The men of Képi chased Moïn's canoes. Near the junction of the river Emeté with the Oba they began to fight. Tamaqao of Képi was hit in his thigh by an arrow. Képi attacked the men of Moin to take revenge, Moïn also attacked Képi. They chased one another. Moïn retreated in fear. Then Bojöm of Moïn stabbed Qait of Képi with a fishing-spear and Qait stabbed Bojöm in return.

Jaro intervened and said, 'That is enough, stop it'. But the people of Moïn ran past Jaro, and Monaqaé of Képi stabbed Jaébéré of Moïn in his shoulder. The latter had been standing there watching. Men from Moïn chased the men of Képi away because they wanted to help Jaébéré. The men of Képi jumped into the water. Qajmaj rushed at Tiaqap. Jaro hit Tiaqap with an arrow. He hit him in the arm. Ogoré too shot an arrow at Tiaqap. Tiaqap stabbed Qajāt with his dagger. The men of Képi said, 'He has stabbed Qajāt with his dagger'. Jaqajo also stabbed Tiaqap and dropped his spear. Then Wairamu stabbed Tiaqap with another spear. Tiaqap died on the spot. In their turn the people of Moin stabbed the woman Rapeti with a spear. She died. She was buried. Tiaqap was buried. I was not with them; I had stayed at home. Jabété came. He said, 'Our own people have killed our younger brother, Tiaqap, of Moïn'. I said, 'Is this really true?' He said, 'Yes, it is. The men of Moïn have killed Rapeti in revenge'. Then the men of Képi returned from Oqoté to Képi. There they fought among themselves. Six days later they went again to Oqoté. In the meantime Moïn had called the men of Rajöm, Wajru and Togom to help them. Manip of Képi went hunting one night. He killed a large sow and returned to the settlement. Those who had gone to fetch the pig had rowed past Oqoté before they looked up. People were speaking. Qajmaj of Képi 
went into the men's house to fetch some water. He asked the man Qadaq, 'Where were those men from?' Qadaq answered, 'There is nobody left behind. We are all here'. Qadaq told him, 'Brother, climb up the tree and look out'. He looked around and shouted, 'Older brother, there are enemies coming'. He shouted it to the people of Képi. 'The enemies are coming'. The people of Képi dashed out of the men's house with their arrows and spears. The two groups clashed at Oqoté. Men from Moïn split the shield of Jaro. They destroyed canoes and broke oars. Then the men from Togom who accompanied Moïn as their allies said to me, 'Jaèndé, you have nothing to fear from us. You go for the people of Moin; we, the people of Togom, have only come to see to it that they do not kill you'. The men of Moin hit Maqajtoqon right in the middle of a scar. They hit Jotegaé and Jabété. The Képi people fled in great disorder to Képi.

I laid Jabété in a canoe and in the dark we rowed to Kabombapé. The men carried Jabété to the men's house to his own fireplace where they laid him down. He said, 'Cut out the arrowhead'. He died. They buried him. The people of Emeté and Jarmoqojn came singing to Képi to take part in the burial. The leader of Képi stood on a platform with the axe in his hand. He gave the axe to the leader of the guests and laid it against his belly. Then he said, 'Be strong of hand'. When the leader accepted the axe he trembled all over. The men had to hold him. He was not allowed to use the axe for cutting down sago trees or other kinds of wood. He was not allowed to hew a canoe with it until he had killed someone from Moïn or its allies. The fight with Moin went on without a break. The men of Moïn, Rajöm and Wajru came as far as the Ribu river to fight. The men of Képi went to get the canoes they had hewn on the river Ribu. They got into their canoes. Manip said, 'Jaèndé, let us go. Moïn, Wajru and Rajöm are out on a head-hunting raid against Emeté. They have painted themselves. They have chased the people of Emeté from their settlement'. The men of Képi saw the place where the canoes had crossed the swamps. The people of Moïn had, indeed, gone on a raid to Emeté. Tamaqoj, Mari, and Nakiroqoj of Képi quickly joined the people of Emeté. They said, 'You, men of Emeté, must chase Moïn, we will block the river at Tépaqaiamön'. The people of Moïn returned from Emeté singing. The people of Emeté followed behind. The men from Moin approached the place where the people of Képi were hiding between the rushes. The little children of Képi became afraid. The adults sat quietly in their canoes. Moïn came nearer all the time. 
Képi started shooting arrows. The men of Rajöm said, 'Let us try and get past those of Képi'. The men of Rajöm rowed past. Képi chased the men of Moïn and Wajru. Those from Moïn jumped on shore near Kupeqaé. The older men called them back, 'Come back or else you will be killed by Képi, they will cut your throats'. Manip hit Mujpön with an arrow. He fell into the water. The men of Moin left him behind. Japaqaé stabbed at Mujpön with his spear, but he missed. Tiaéb hit him with his spear. They killed Mujpön with spear thrusts. He emerged from the water and was still alive. Jaro pulled him out of the water and laid him in the canoe. With Bekébai he rowed to the brushwood. També followed them in his canoe. He said, 'Are you afraid?' They answered, 'No, we are not afraid'. També drew his bow. They cried, 'Father, don't shoot at us'. També said, 'Who is that man?' They said again, 'A man from Moïn who has been killed'. També began to dance, 'Oh, those boys of mine'. He came near with his canoe; he looked into the canoe and said, 'Alas they have killed my menaqaé, the man who initiated me, and worst of all, still I am dancing'.

I and Jabéaq and the men of Képi went after the people of Moïn and we did not stop chasing them until they were as far as the junction of the river Emeté and the Oba. Then we went back to Képi. Those who had stayed at home, asked, 'Did they take to flight because of fear?' We answered, 'They fled away. They have not killed anybody'. The people of Emeté followed Képi in their canoes. Together they slaughtered Mujpön. Emeté ate the flesh. If Mujpön had not celebrated the taker-jamé, the hair feast, at Képi, the people of Képi would certainly have taken part in the eating. Béaqare cut the flesh into pieces while he said, 'It was you who stole my coconuts'. Then he asked the people of Képi, 'Who exactly is he?' They said 'Mujpön'. Then Béaqaré cried, 'Alas, then he was my son'. Emeté said to Képi, 'Let us first eat the flesh. We want to eat the head of Mujpön as well'. Then Emete went away. They had finished the head of Mujpön. The woman Qapai had eaten of the flesh in the morning and in the middle of the day she died.

Moï people came down the little river to gather sago at Oqoté. Képi and Emeté watched sharply. 'There they come', they said, 'there they are'. A man came rowing along with his wives. When they were close by, Képi and Emeté attacked Kaqajmu [the man in the canoe]. Kaqajmu jumped overboard when he saw the men. One of his wives was speared by the men from Emeté. They also stabbed the child. They said, 'Let that man get away, he is a leader; we have already killed his wife and his child; let him go'. The men of Emeté and Képi came with 
the heads. They carried the entire bodies. They came as secretly as possible for fear the men from Moïn would hear them. The people of Moin started the mourning song and returned to Moïn.

I said, 'My mother Jomeqaé [the second wife of Kaqajmu] has fallen into the water, bring her here, but do not cut off her head'. Jomeqaé was still alive and was sitting in the canoe. She had not been killed; Kén, the other wife of Kaqajmu, was dead. The child was dead. Jomeqaé turned to me. I wept. She said, 'When you were small, I did not dispose of you'. I said, 'Do not eat her [the other woman who had already been killed], she is my younger sister'. Jomeqaé said, 'Will you come to Emeté later on to see me once more?' I asked her, 'Are you all right?' She said, 'My back hurts very much'. I went to the river Ribu. I stayed there for two days. Then a man of Emeté, called Jaqain, came to tell the news, 'She has died; I buried her. You may give way to your sorrow'. Not long afterwards Jotainé rowed to Emeté to do some talking. There he heard that the Emeté people were about to chase those of Moïn out of their settlement. Jotainé rowed back to Képi. He said, 'Our women who have married in Moïn will be slaughtered as well'. The men of Képi - Békébai, Détab, Topéamu, Nakiroqoj, Jabaqaj and others - got up and left. Then it was night and they rowed to Moin in the moonlight. They wanted to warn the women. But in the meantime men had arrived at Moïn from Togom and Rajöm to join them in an attack on Képi. Those from Képi went into the men's house and greeted them. The latter returned their greeting. They asked, 'Who are you?' They answered, 'We are from Képi'. They went to sleep. When the cock crowed for the first time, the men of Moin stabbed Békébai [of Képi], they stabbed three other men of Képi, and stabbed the woman Namo. Friends of Détab told him, 'See to it that you get away', and he fled. Jabaqaj too was ordered, 'Be off with you'. When he fled someone tried to stab him but missed. Using a dagger, Taqaé stabbed Nakiroqoj who was sitting by the fire.

At the same time Japuk and his wife left Képi. They rowed to Kabut. He did not get a chance to check his pig trap because an uproar was raised at Moïn. Namaqat, who was married at Moïn, shouted. She called for Képi. Janggebaqao shouted, 'They have killed men of Képi in the men's house at Moïn'. The men of Képi rushed towards Moïn. In great haste they went there. Manip and I dashed forward uphill. The women of Moïn who were originally from Képi shouted on the hill as loudly as possible. Manip and I heard them. Moin might kill them too. When the people of Képi arrived at Moïn, Moïn had fled. The people 
of Képi began to weep. Only the entrails were still there, the flesh was gone, it had been cut to pieces by Moïn, Wajru and Togom. The flesh of Oatéaqaé was no longer there either. The body of Taméaqaé still lay there. The corpse of Namo still lay there. The people of Képi laid the bodies in their canoes and returned to Képi.

Some of Képi's men had been able to flee early in the morning. Jabaqaj escaped to Enamo. He crawled forward with a spear in his back. He answered the shouting of the people who were searching, 'Here I am'. The people of Képi came. The spear stuck in the centre of the lower part of his back. Others called for Topému. He came. They left Moïn and with great weeping they arrived at Képi.

Nakiroqoj stood on a hill. He said, 'Taqaé stabbed me'. He stepped into the canoe. They rowed on to Képi. They arrived at the mooring place and carried the bodies to the settlement. They dug a hole and buried the dead. Jabaqaj was laid down in the settlement. He wept aloud, 'Oh elder brothers, oh ancestors, oh my country' ... The people of Képi said, 'It is not so that Moïn has killed you, but rather that you yourselves have killed our own settlement; you yourselves have caused death for us' [because they had gone to Moin independently and had not first deliberated with them]. Then Jabaqaj died. They buried him. Men and women wept. Some men of Képi went to Emeté and said, 'Go into mourning, for Moïn has killed several people of Képi. The crocodile cannot stay under water indefinitely; they have struck first; we will take revenge on Moïn and kill them'.

The people of Képi moved to Abaqajnamön, even though they were still in mourning. From there some of them went to the Pore on a headhunt against the people of Moïn. The Kamaqajmu and the Marapému had left Abaqajnamön after the others. When they arrived at Képi, they asked the women, 'Where have your husbands gone?' They said, 'They have gone ahead fishing'. They had left me behind, for I saw that the men had left. I said, 'Qaiberot, let us go now. The other men have already gone ahead. We might have a chance of killing someone from Moïn'. We followed the others who had already arrived at Qaémémoqon. We spread our sleeping-mats. I and those who were with me heard the men talking. We quickly rowed towards those who had already arrived at Ipaqanao. We strained our ears. We also saw footprints. We did not miss the talking of the children. We followed the dirt on the water caused by washing sago. We found women of Moïn. The women of Moïn begged for pity, 'Oh, my father, Jaro, oh Jaèndé, my father, my elder brother'. We said, 'Now that we are here, we are 
going to kill you now'. Namaqat plaintively cried out, 'Oh, Qomb, Qajatu, oh Manip'. We consulted together and said, 'The sun does not die $^{3}$; let us kill them all. Aqaoèmu and Ikimu, you may kill Namaqat; Marapému and Kamaqajmu, you may kill Jabéréké’.

We searched the surroundings. Jaro kept his arrow trained on the path. Tambim was with him. Tambim said, 'Jaèndé, you go and search the path up there'. I went, leaving my bow behind. I scouted the other hill on the edge of the plain. Araoa came rowing in his canoe. He was checking his fish traps. There were also a great number of women and little children looking for little fish. Araoa looked at the path. Jaro pulled Tambim away from the path into the brushwood and said, 'They might see you'. Araoa passed by them. Araoa went away in the other direction. I stood and watched him. Unarmed though I was, I attacked him. I grabbed the back end of his canoe. Araoa missed me with his oar. I overturned the small canoe. I walked into the water and stabbed Araoa with his own oar. Tambim stabbed him with his spear. Qomb stabbed him. Japuk stabbed him. Topému and Oaraqaèmu stabbed him too. I held him under water. He emerged again. The women in the swamp kept quiet, as if they had heard nothing. Oarapaèmu cut off Araoa's head. With the bamboo knife they cut him up. The women said, 'What are those men doing there?' Aneman said, 'Shut up; Képi has not taken revenge yet, let them kill in retaliation. The men of Moïn will only get angry with us'. ${ }^{4}$ They went on looking for little fish.

The men of Képi stood with the head of Araoa at the landing place. Ogore hurried away with the head. He followed the path through the sago groves. He laid the head in a canoe. Kabai asked him, 'Who killed him?' Ogoré answered, 'I do not know. I have only been given this head by others'. The people of Képi stood at the mooring place. They started shouting. Those who were further away near the coconut trees came to the landing place. All stepped into the canoes and returned to Képi. As they rowed they beat against the sides of their canoes with the oars to signal that they had made a killing. They called upon the shade of Békébai, 'Rise, do not leave behind your children. Araoa has gone. We will go to Képi together'. ${ }^{5}$ They beat the sign of victory on their canoes. The women of the settlement heard it. They drew near to Képi and reached the landing place. They smoked the head in the centre of the settlement and took it to the men's house where they put it on the smoking-platform. The people of Emete came and said,'We are willing to eat the head'. I said, 'You are welcome'. They ate the fleshy parts. 
The skull was hung in the centre of the men's house. Then the fight between Képi and Moïn ceased for some time.

Later on, the people of Képi went to meet Moïn. Then a leader of Moïn, Tinggop, said to me, 'Younger brother, it is all over, I will come near with my canoe. You have taken revenge for Békébai'. He approached in his canoe. Tinggop said, 'Many have been killed already. Shall we go on being enemies? Let it not be so. Let there be an end to it'. In their turn the people of Képi said, 'Let there be an end to it'. Then the people said, 'A woman, called Jaqam, will come to Manip'. Jaqam came to Manip. Then the fighting was stopped. Janoqoj, a woman of Képi, was given as a present from Manip to Atéao of Moïn.

Then a leader of Moïn, Mujoqop, said to the people of Képi, 'So be it. Young people, listen to me. You people of Képi should make peace with the men of Togom for form's sake'. And to the relatives of Békébai he said, 'After all the people of Togom also cut up the flesh of Békébai together with us; now in your turn, lead the people of Togom up the garden path'. Tombai, a leader of Togom who had been offended by some young people of his own settlement, came to Képi at that time and said to a leader of Képi, 'Manip, for the sake of appearance I will give you a child as a present; let the people of Képi massacre Togom' ... etc. ..."

\section{Extra-tribal warfare}

The real head-hunting raids were different from intra-tribal warfare. They demanded lengthly preparation, much scouting and advance planning. All the people had to set out together (men and women of several settlements) for the raid. The fight culminated in the preparation of the captured heads and the return home for the victory celebration. Heads captured during inter-village fights are also used at these final festivities.

\section{a. Exact data}

Again, it is difficult to provide exact data about the total number of captured heads. The marks of honour are ranked from a mark for one head up to the sign of honour for fifteen or more heads. Jaèndé had ten heads to his name. Jaro had twelve. The leader Taquaj from Dagimon had thirty heads to his name. Some of them were trophies from intervillage warfare. The Jaqaj themselves say that a head was needed for 
every child who was admitted at the so-called taker-jamé, the hair feast. They also said that a young bridegroom had to hang a head on the arm of his bride during the wedding feast.

If we take this information literally, this would mean that in the course of one generation as many heads had to be taken as the number of children actually born during that period (e.g. for the period 19251945 about 8,000 heads). If every marriageable man needed one head for his bride, this would have required up to 4,000 heads per generation. Father Meuwese, the first to enter this territory, realized the impossibility of this. He also found the solution to the problem: "They made as if". The same heads were used for an age-ceremony and a wedding feast. Moreover, not only the man who actually captured the head, but also anyone who helped him kill the victim was entitled to make use of that particular head. This explains why Jaèndé mentions again and again who stabbed a victim. Everyone is mentioned by name and surname, so that proper credit can be given and the ensuing rights established.

Another noteworthy point is that the cut-off heads did not actually play a part in the age-ceremony, although they claimed that a head was needed for every child. Apparently, the warriors (the leaders, who had skulls to their credit, as well as those who had captured a head more recently) officiated. One leader performed the age-ceremony on several children. The same comment should be made about the end of the mourning period. Formally, a head was required, but actually any owner of a single head could terminate the mourning for all those who were related to him.

Another reason why the number required should not be overestimated is that the Jaqaj said that it was not necessary for everybody who went on a raid to bring back a head. The Jaqaj have the term baba-amön, which means "having gone on a head-hunting raid in vain". Actually, many men from a great number of settlements would attack one small Awju settlement. Such Awju villages were probably no larger than 70 people. It was impossible for all of the raiders to go home with a head of his own. This is not to deny that the regular attacks of the Jaqaj brought a reign of terror to their Awju neighbours. These matters should be seen in relation to their culture as a whole. In summarizing, I conclude that it was not the number of heads wich counted but the social ties and the promotion of status which resulted from a headhunting raid. 


\section{b. The case of Togompatu (Map 4)}

To give the reader a better notion of what happened during a raid in foreign territory, I shall reproduce the story of Togompatu, one of the last raids described by an insider, again Jaèndé of Képi. As an introduction to his account I must first say something about a discovery made by Fr J. Verschueren. In the archives of Képi, I found a sheet of paper which Verschueren had labelled: "Some stray notes about the Jaqaj mores, October 22, 1952". In these notes he says, "During a chat one night at Képi, when Jaro was in good form, which was not at all usual with him (Jānda, a leader of Dagimon, was also present), he told the following story. The Jaqaj used to have a buffer zone. This buffer zone consisted of groups of Awju who lived on the opposite side of the river Mappi. Their relationship with the Jaqaj was as follows: a) the Jaqaj were helped by these groups to find the difficult paths by which they could reach the real head-hunting area, viz. the Edera territory; b) the Jaqaj paid these groups of Awju every time they received assistance; the payment was made on the occasion of a feast which they celebrated together and which consisted of a plentiful meal; and c) whenever these Awju groups were attacked by others, they were entitled to the help of the Jaqaj and they could call them in. Often the leaders of such groups of Awju were taken along to Jaqaj territory to have a look around. The basis of these relations is more interesting: it was a skull. Once they were convinced that they were on good terms with a certain group, the Jaqaj gave to this group the skull of a Jaqaj leader (in the case of the Esaqha it was the skull of a man from Toba). The presentation of a skull to such a group was performed with great ceremony immediately after the skull had been taken down from the burial platform. A skull (with the lower jaw still attached to it) was presented to the Awju group. These Awju were told briefly and to the point, 'Take care of this skull and give it a place of honour. If anything happens to it or if you lose or break it, it will be the end of you as well. If you have any difficulties, you must call us and we will come immediately'. ${ }^{6}$ When, through the actions of the Dutch government, the Jaqaj realized that their raids to far-off districts had come to an end, they started to attack their allies, the buffer zones."

Thus it happened that a great attack was made on the group of Awju who had settled at Togompatu on the river Pasuwé. Jaèndé's story runs: "The leaders of Kandajmu (a village on the upper course of the Oba), Béréka and Japi, said, 'Jaèndé and Jaro must come; we men, women and children, are going on a raid to Togompatu and there we will join 
forces. Takéaq (of Rajöm), you row to Képi and speak to them, so that they may come'. They prepared ribs of nibung leaves to count the days until the day of the meeting. At Képi the men sat looking down the path from the men's house. They said, 'That is Takéaq. He is coming here'. Takéaq arrived and hurried to the men's house. I asked him, 'Elder brother, what have you come for?' He said, 'I have come to make you get into your canoes quickly. You and Jaro must come quickly'. He laid down the leaf ribs and said, 'You, Jaro and Kabai, must come with your wives. The younger people must follow you'. Then I appointed the men. They said, 'No, we will not come along. The police might catch us'. The boy called Japoméné trembled with fever. Nakiroqoj, Taqao and also Japoméné, even though ill, left with me. I said to him, 'Stay at home. The illness has got hold of you'. He made little of his illness and said, 'That sickness will pass as soon as I am up there'.

Takéaq went to Jaro who was at Qajopa near Képi and said, 'Jaro, come along on a head-hunting raid together with the people of Rajöm, together with the Unimu, the Janoqojmu and the Gako. The people of Kadöm, Wanggaté, Kogo, and Enèm are coming too. They come by canoe [via the Miwamön up the river Pasuwé]'. I went to Kabombapé near Képi and there I met the leader, Qaiberot. I said, 'Here is my child and my carrying-bag with ironware. I am taking with me only the smallest children who can be carried by my wives. The older children would have to walk by themselves, but they cannot go that far'. I entrusted my carrying-bag and the children Ngétown and Japaqajtéamu to Qaiberot. I told them, 'You are not big enough yet. You must stay at home'. I left with my people.

When we had come close to the river Kunda, the people of Rajöm were already coming towards me, singing as they went. Ndaméup had said, 'Do not throw any spears or shields. The children are still small'. Jomeqaé and Utejr, my wives, and Jakedon and Doqado, my children, had come along with me. The next morning the people of Rajöm gathered sago grubs, fish and nibung shoots. They also went hunting with their dogs. They killed a pig. I said, 'We will leave tomorrow, else we will be away too many nights'.

When we were about to leave, the leader of Kandajmu, Béréka, arrived in great haste. He told us about the raid that had been planned on Togompatu. He stepped into my canoe. He ate some fish and sago. Béréka said, 'Jaèndé, you follow. I will go ahead quickly to take the news of your arrival to the people in the settlement'. He quickly went on ahead. Béréka took the message and said, 'Jaèndé is on his way with 
his wives. Let the women go quickly and get gagaé (vegetables) and nibung palmshoots'. Men and women set out quickly. The people and I arrived at Ndoqajapé. There were many people at Ndoqajapé. The leaders said, 'Do not go to meet them with any songs; they have not come in great numbers. Jaèndé is there with his wives and their sucklings. Do not go to meet them' ${ }^{7}$ They pointed out a dwelling to me, 'That is a dwelling for you and Ndaméup and Takéaq'. They gave them nibung shoots to eat; they brought heaps of them. We spent several nights there. The Wajmu went fishing in the old settlement of Piaj. They gave fish: tauwi, kidu and umb. Japi brought a pig. He gave one foreleg to me. He gave one forleg to Jaro and a hindleg to Nakiroqoj and to Takéaq. The meat was for the men in the men's house. Half of it was for the men of Rajöm and the other half for the Kandajmu. The Wajmu broke camp first, then the Kandajmu followed suit, as did the Qanimu and the people of Rajöm and Képi.

We began our march. When we had a rest, they spread nibung leaves on the ground before me for the sake of my children. They showed a spot, 'Here we killed the man Jaqaqaé'. The spears stood stuck in the ground. We passed them and crossed the upper course of the river Obakam and went up to the hill, Kor. We reached the top and went down again and laid out our bivouac on the plain. It became quiet. The men told the women, 'Do not yet cut any wood, do not yet cut any nibung. Then the message was passed on to the leader Jaqajn in the most advanced bivouac, 'The wives of Jaro and Jaèndé are tired of standing up so long'. Then Jaqajn started to spread nibung leaves and was the first to sit down. Then he got up again and said, 'Let them spread nibung leaves on the ground and sit down'. The women sat down. Firewood was asked for. It was passed on to Jaqajn. He was the first to cut firewood. He went up to a tree, cut it down and cut off the branches. He said, 'Cut the wood for the bivouacs'. They felled the trees. Jaqajn said, 'Listen!' He buried strong herbs in the place where he stood. They said, 'He has buried the herbs, stick the poles into the ground'. They built the houses and got them ready. ${ }^{8}$ The mats were spread out. The Wajmu women made a very long house. Takéaq and I built a house together. When the women finished the house, they went to fetch nibung leaves. With these they covered the house. They cut down sago trees.

The next day I stayed at home with my wives. The leaders had said, 'You need not go to gather sago. The women of Janaqojmu will give it to you as a present'. They came back from pounding sago and gave me 
some sago. The Wajmu gave sago shoots, grubs, and meat from a wallaby. Takéaq came back and said, 'Here is your sago'. I answered, 'I have plenty of sago, you need not give me any, use it yourself'. The women of Rajöm brought me some sago. Béréka brought me some sago. His wife brought me a large piece of sago. Jaqajn brought sago in a mat. Because there was so much sago, Momeqaé and Utejr distributed the sago among the women of Rajöm and Kandajmu. The advice was passed on, 'If any people of Togompatu turn up here, do not be quick at throwing spears at them; let them come close safely'. I said, 'I think that I will be able to catch one before long'. We had already been there for quite a time when we started for Togompatu. Oakupaj, Mujonggé and Baganu of Moin went to their parents in the sago groves of Togompatu. They were three men who had been stolen from Togompatu when they were still children. ${ }^{9}$ They said, 'We have come to ask for some sago from the old folks. We have not come to hunt any heads'. They were lying. They stayed there for quite a time.

The leaders said, 'Let someone go to Képi, Emeté, to Toba and Dagimon to tell them to send people to come along for a raid'. I arrived at Képi and appointed several men to follow me. They did not come along. They went back and I said, 'Two men of Emete have followed me, the others did not come'. Again they said, 'First call the people of Képi'. The leaders of Képi said, 'No, the men back there will certainly refuse to come. They want to have a teacher. We will have to go to Togompatu alone'. Then all the leaders met and they agreed that it was about time to begin the attack. When this message reached the other bivouacs, people started to dance. The leaders said, 'Tomorrow you must first crush the heads of sago grubs'.10 The night went by. The next day the people entered their canoes to collect the sago grubs. They picked them out of the tree, laid them on a mat, and took them to the men's house. Jaqajn said, 'Leaders of Képi, come along'. Jaqajn was the first who took a sago grub by its neck and crushed its head. Then the leaders crushed the heads of the sago grubs. Men and women then went to the sago groves and ate sago grubs. The leaders too and their wives went to pick sago grubs from the trees. Before long they returned with these grubs. The young men started to shout. The Wajmu piled up the sago grubs in front of me. The Janaqojmu did the same. They took them to the house I had for my wives. I distributed them among the other bivouacs. They said, 'Tomorrow we will attack Togompatu itself. Today eat the sago grubs and finish them all, so that nobody will get killed'. They built a bridge across the river Togompatu. The next 
morning we marched on Togompatu, that is to say, we marched to the place where their sago trees are found. We crossed the river and laid out a bivouac. The leader said, 'You should not light any fires in the bivouac. First cut wood for the other bivouacs. Cut away the wood which is nearest and do it well, so that the people of Togompatu will not be able to come close and kill a man or a woman with their arrows'.

To the same three men from Togompatu they said, 'Tell your parents that we have come to make peace and that they must give a child to the people of Képi, another one to the Unimu, one to the Gako, one to the Kandajmu, one to the people of Rajöm and one to the people of Moïn. Tell them that we wish to have the children. If they give us these children, we will go back to our own territory. Say this to your parents'. They went to Togompatu and said, 'Parents, we have come to spend the night; you go and gather sago'. The next morning they went to pound sago; they squeezed the sago. Oakupaj and his people told their parents, 'Parents, they have come to get children. Give them children'. The people of Togompatu said, 'They are the ones who should pay us, because they got you in the past'. Then the men returned. They had been given meat and sago grubs. Oakupaj and those who were with him said, 'Our parents have said that they will not part with any children; they do not have any; the claimants are the ones who should pay them and give children, because they had to part with us in the past'.

From behind Togompatu the Wanggajmu (of Enèm) came to visit the Gako in the men's house. ${ }^{11}$ They said, 'Today you must attack the settlement'. One of them said, 'My ancestors came from Képi; I wish to visit the people of Képi'. His name was Janggebuaqai. He went to visit them. He came to the old people and said, 'Where are the men of Képi?' We got up, 'The two of us are here, the others are not here'. The men of Kogo, the Borému, the Baniému and also the men of Enèm came to this bivouac. They said, 'Are you coming to Togompatu tonight? We are coming too'. Janggebuaqai spoke to the men of Képi who, so to speak, were his parents. The people of Kogo said to the men of Képi, 'You were able to lick us, but Togompatu, will you be able to conquer that? You should not be afraid! You, men from Rajöm, are cowards. You will be bent over backwards by the men of Togompatu as if you were reed stalks'. ${ }^{12}$

When it was dark they began to dance. The leader of Rajöm offered his advice, 'Sons, if anyone gets stabbed by a spear, you must snap it 
off for him [so that he may have a chance to escape]. They have said about us: 'You are cowards, your women will go home as widows, because Togompatu is going to kill all of you'. They danced. The leaders said, 'You can take our word for it that the attack is going to be a success'. Ponaki came along and said, 'Here I am'. Ponaki went and stood on a platform. The men flocked together. They looked up at him. He began to speak. They listened. All the settlements were present, a big crowd. 'Sons, everywhere I have hunted people, although I was stabbed with spears, although I was hit by arrows, with the spear in my body I went at them. If any one of our people is killed, you must massacre the people of Togompatu to the last'. He asked the leaders, 'Sons, shall we march tonight?' I said, 'Father, let the sun be in the sky, we will take heads [too many people might be able to escape if they were hit in the dark]. Let their leaders be away fishing or gathering food. In the daytime we must chase them from their settlement'. Ponaki said, 'All right, I have faith in you'. He threw his shield to the men. He stood trembling on his legs because of the herbs he had eaten. The women danced and cried, 'Your mother, your mother'. ${ }^{13}$ All the women from all the settlements did this.

The next morning the women baked the sago for the men. They sang and danced and blew the war trumpet. The people of Togompatu heard it. Then the men smeared white clay on one another's backs, they stuck the nibung shoots in their arm- and leg-bands and in their hair, which made it look like the crest of a cockatoo. Everyone smeared red earth on his body and put on his ornaments. Then they drew up the battle array. 'Who is in the middle?' The men of Janaqojmu said, 'We are'. 'Who brings up the rear?' 'Wajpaqari'. 'Who takes the flanks?' 'Rajöm and Képi one flank and Wajmu the other'. We marched. We drew nearer. I heard the people of Togompatu blow their war trumpets. Jaro trembled all over because of the herbs he had eaten. We saw a man in the sago marsh. Jaro said to me, 'Younger brother, I am going to strike him down'. I said, 'Don't do it; it is only one man. The women have heard what we have said: we are going to march against the whole settlement'. The man of Togompatu was startled because the ground began to move. He looked at the water. He looked at the sago trees. He saw the leaves move. Where the first men were the sago leaves crackled. Then the man of Togompatu fled, struck with fear. He began to shout. He ran towards Togompatu.

We marched and shouted. The men of Togompatu heard it. They stood in the settlement waiting for us with spears in their hands. They 
had put on their ornaments. From both sides the men began to throw spears. Before long, Bakoroqoj got hold of a man of Togompatu. He stabbed him. Then Jaro stabbed the man. Thereupon the leader of the Janaqojmu stabbed a woman. He killed her. These men had been quick to make a killing. Women, men and children were killed by the leaders. Japoméné killed a pretty woman. Her child, frightened to death, escaped because Japoméné had no spear left. The woman had said to Japoméné, 'Let me become your wife'. He said, 'I am still too young to get married and I want to kill you'. Then he stabbed her. He cut off her head. When some men of Moïn came near, he first said, 'Brother-in-law, you cut off her head'. The latter said, 'Brother-in-law, you better do it yourself'. He himself cut it off. Quickly he cut through the muscles. He tore it off. I stabbed a man with my spear. The man died. The man who had been chased down by Jaro and his companions was called Téné. We returned with the heads. We had become afraid, because we had no spears left.

The men of Kogo heard the shouting and became afraid. They withdrew and fled together with the people of Togompatu. Only Jonggé, who was from Wajmu, came towards the people of Masin and said, 'Fathers, fear has gripped the men of Kogo'. The people of Masin asked him, 'Did the men of Kogo kill any people of Togompatu?' He answered, 'No, they ran away when they heard your screaming and war cries. I was with the people of Kogo. I have come from them'.

We returned with the heads. The women folded their mats. We left Moma behind. He was missing. The women wept for him. From there we went to Ngaowuri. We smoked the heads over the fire. We cut loose the lower jaws and tore them off. The women wept. They said that it was growing dark. The men said, 'You women, watch over the heads; we men will go and search for Moma'. We got up; we went out of the men's house. We looked up the path. There he was, Moma. He said, 'They have not killed me; I almost killed a couple of women and that is why I fell behind'. They danced and sang. Some went to fetch sago grubs. Others smoked the heads.

Jaraqaé was the first to leave for Ndoqajapé. He said, 'Bring the heads after me'. In that place my child, Jakedon, burned herself at the fire: her arm, her side and her jaw. The spirits of those that had been killed spoke to her in a dream. She got up and lay down near the fire. Then she burned herself. The women spoke some formulae over her while they smeared her with the ashes of a fibre skirt. The skin swelled; the skin of the arm burst open. 
The people of the bivouacs danced all night until the early morningbird started to sing. Large blocks of sago were distributed among the women. Everyone carried some of it. The men tied the spears together. The leaders were the first to get up. I said, 'I will go in front'. The men said, 'All right, you go in front'. I handed the little child Jakedon to Moqoèk. Jaqaépoqoj carried her. We passed the night somewhere on our way. I said to Jaro and Nakiraqoj, 'You follow with the heads. I will go ahead'. We passed Ngoröp; we passed Ndoqajapé. At Ngao we stepped into our canoes and ate our food; we threw out the water which had gathered in the canoes and laid our ornaments in them. I said, 'Nakiroqoj, put the heads in the stern. The women will have to stand in front'.

The people of Rajöm blew the war trumpets. We rowed past Rajöm, past the Poré, past Moïn. Near the Poré, I blew the war trumpet. The people of Moïn heard it and said, 'The leaders have come back'. Near the river Waké I blew the trumpet. I said, 'Jaro, let Jakind and Qobai get into your canoe, give your trumpet to Qobai so that he may blow it on his way to Emeté. We passed the outlet of the river Emeté [a little above Képi] and again I blew the war trumpet. The people at Bandaberok and at Tenemoqon said, 'Where does that sound of the war trumpet come from?' Near the little river Woki [just below Képi] I again blew the trumpet. They said, 'There they are; the leaders have come'. Nakiroqoj put on his ornaments; he put on his cassowary tail. Japoméné put on his cassowary tail. I put the red bird, mborön, on my forehead.

The women began to dance. When we had come close to Tenemoqon, the wives of the leaders came to meet them. They asked, 'Who made a killing?' We answered, 'Japoméné has killed. Jaèndé killed, but he did not get the head. Jaro and Nakiroqoj together killed a man. Japoméné killed a woman all by himself. The head of the woman is here in the canoe'. The women rowed back to the settlement and said, 'Japoméné has killed a woman; the head is there'. The women sang and danced; they cried for excitement over Japoméné, 'Such a small boy ...' Japoméné took the head and hung it in the centre of the men's house at Tenemoqon. The women surrounded him, dancing and singing."

According to Jaèndé the list of those that had made victims in the course of this raid, was as follows: Képi two men; Emeté three women, three children; Moïn two women, one child; Piaj two people; Kandajmu nine people. 


\section{c. Other data}

The real extent of the head-hunting raids of the Jaqaj cannot be established by existing data. The influence of these raids on the demography of the area cannot be evaluated. According to Father P. Hoeboer, m.s.c., the Jaqaj raided as far as the Upper Bian. According to Father C. Meuwese, m.s.c., they penetrated as far as the river Kao. Tabuaka, a man of Képi, was born on a raid close to Tanahmerah, viz. at Tabuaka. Jabajmu had been brought along on that raid as a baby. That raid must have been taken place around 1935. In the Mandobo language, spoken by a tribe living between the Kao and the Upper Digul rivers, the name for the people of the Mappi district is kop-kujung, i.e. "man-wild" or the wild people.

Finally, mention should be made of information according to which the Jaqaj crossed the southern estuary of the Digul to raid the villages of the large island called Kolopom (Frederik Hendrik Island on older maps). 
CHAPTER $\mathrm{X}$

TRAINING, MOTIVATION AND PREPARATION

\section{Training}

From early childhood on children were trained in aggressiveness. Jabaj$\mathrm{mu}$ told me about the squabbles and quarrels in his own peer group. Part of this story runs as follows: "After eating in the men's house, Jabaj [one of the younger boys] got up and took the cassowary dagger of the leader, Qaiberot. He stuck it into the string around his waist just as adults do. When the children saw this, they protested, 'You are using something of the adults and you should not; soon there will be no fish any more, stop it'. Jabaj said, 'I will not'. The other children said, 'You have not yet been initiated; you have not yet been given the dagger. The men will be angry with you'. Taröm was angry with Jabaj. They started to call each other names. Taröm said to me, 'Jabajmu, let us go home'. We descended from the men's house and took our arrows with us. Jabaj was still standing in the men's house with the dagger at his waist. Taröm shot an arrow at Jabaj. He missed him, but hit a young boy sitting next to him, who already had a wounded leg. He hit him right in the middle of the wound. Taröm and I ran to the house of my elder sister, Utejr. Utejr asked, 'What are you up to?' Taröm said, 'Mother, I shot a boy in his wound and therefore we have fled'. Jabaj came after us; he wanted to beat both of us. Jabaj said, 'You must dare to come outside and I will beat you up'. We said, 'You wait, you will see us at the men's house'. Jabaj entered the men's house. We went to the house of Taröm's mother. Taröm took one of his father's spears. The grandmother said, 'Leave it alone, you will break off the barbs. Why are you taking that spear with you?' Taröm said, 'Grandmother, a moment ago Jabaj was angry with us'. The two of us left the house. Taröm walked in front. The old woman cried, 'Jabaj, be on your guard. Taröm is coming after you with a large spear'. Jabaj said, 'Little boy, come on if you dare and we will fight'. Taröm said, 'Jabaj, now try to beat both of us. That is what you said just now'. Jabaj said, 'You had better be on your guard. Don't talk too big'. The friends of 
Jabaj said, 'Jabaj, shut up or else that little boy will throw his spear at you'. Jabaj and Taröm started bandying words."

This was how the boys grew up. They participated in the feasts following head-hunting raids and they imitated whatever they saw. Jabajmu tells about it: "One day all the people of Képi had gathered at Ndanggaèmdéjaq. The older boys said to us, 'Younger brothers, we are going to shoot lizards'. We shot a great many of them. Then the older boys said, 'We are going to build a men's house in that fine section of the bush'. We built a men's house of nibung leaves. We divided the fireplaces. At every fire one older boy sat with a younger one. The war-leaders sat in the corners and in the central part. We celebrated the feast of the heads. ${ }^{1}$ We cut off the heads of the lizards and smoked them over a fire. We impaled them on sticks and hung them from the roof. We distributed the heads in order to establish who was going to be ménaqaé to whom. We made remarks of honour out of leaves. We used white nibung leaves for the belt of human hair, qowa. Although it still was morning, we said, 'It is night, let us all go inside'. We slept. The 'leaders' said, 'Let us celebrate the hair feast ${ }^{2}$ in the right way. Tomorrow morning we will lead the children to the spring'. We got up. We decorated ourselves and went to the spring. We took with us blocks of wood which represented the children who had to go through the ceremony. We sat around the spring, placing the blocks on the ground. Near each 'leader' were as many blocks as there were children whose hair he was to cut off. Some went to gather the leaves the initiation candidates had to eat. We smeared them on the blocks.

There were all kinds of birds near the water. To us they were women and we cried to them, 'Hey women, you must prepare sago and meat for the candidates. Put the bamboo knife [which is needed for shaving the hair] in the sago bag'. Some of us went to fetch sago and came back with leaves. We distributed that 'sago' among the leaders. The candidates did not yet get any food. Those who knew how to plait an armlet tied a ribbon around the blocks. Others simply tied a string round them. Then they said, 'It is night already; we shall go back to the settlement'. So, singing and dancing we returned to the great house in the bush. We laid the blocks in a row. We called the 'wives' of the leaders and assigned them their places. The wives [in this case a few boys] cut some hair from the 'foreheads' of the blocks. Food was collested. The women danced. Many pigs were slaughtered [pieces of wood], the 'fat' [leaves] was hung on long strings.

Then we pointed to a number of small trees and said, 'Those are the 
female guests from this or that settlement'. Then we took 'fat' and carried it, stuck on the points of our arrows, towards the women, singing and dancing. We went back singing. Again we returned to the trees until their 'carrying-bags' were full. But we did not play cutting off the fibre skirts. We entered our men's house and made plans for the next day's celebration, the distribution of the marks of honour."

Once the boys were admitted to the men's house, they witnessed all that happened at close quarters. They heard the conversations about quarrels and fights. They saw how the weapons were made and kept in repair; they learned how to make weapons themselves. Moreover, once they began to take part in the songs ${ }^{3}$ about head-hunting, they became more and more imbued with the ideals of warfare and head-hunting, and dreamed of becoming great warriors themselves. The toys and games of the past now became serious matters. Some admonitions given to the youngsters in the men's house I recorded from the life story of Jaèndé. "If people of another settlement have killed one of your people and his death has not been avenged, you still have to kill a member of that settlement when you are grown-up. Even if this should lead to a long-lasting feud, you must go ahead and kill. It is good. It is wrong, however, to be the one who starts the killing by murdering someone of another settlement. Listen carefully: when another settlement says, 'Come, let us go on a head-hunting raid', you must say, 'No, we have already killed many of your people. You want to ambush and kill us'. You must say, 'If you give a girl as a hostage, we will come along'. Because you are brave, they will try to deceive you. When the women weep and say, 'Come, sons, come back, they are deceiving you', do not go against their wishes. Listen to the words of the women. The mothers will say, 'Sons, younger brothers, do not let my child get lost. Keep an eye on him. So many settlements participate in this raid. Somebody might slaughter him'. Also they will say, 'Sons, the rattan of the platforms of the dead is breaking down. Your fathers and brothers will fall to the ground. Quickly set out on a head-hunting raid'. All the time the women have been continent. Many months have gone by and they hardly walk any more. They still are in mourning, because the platforms bearing the corpses have not been pulled down. Listen to the words of the women. Some of your people will be killed. Others will live. The latter must say, 'Come, we know the akiaq which has been passed on to us by our grandfathers and great-grandfathers, we must go ahead and kill'."

The mourning customs referred to by Jaèndé weighed hard on the 
women and they sometimes had to wait a long time before their suffering ended. The socially approved occasion for discarding mourning garb being the triumphant return of a war party, the women often urged the men to set out on a head-hunt. It even happened that a desperate woman would enter the men's house to hang a fibre skirt in a place visible to everyone as a public accusation that all the men were like women. No man could ignore this. 4

The men, in turn, had their own ways to animate the boys and help them overcome their shyness. I have heard on two occasions that small boys were urged to shoot their nibung-rib arrows at a live enemy. In both cases the adults had tied the victim to a pole so that the children would not run any risk. The first case happened at Kogo. The first teacher saw a man dragging an old woman from her house. They tied her to a pole and the boys shot at her. Eventually the men stabbed the woman to death. She died of the dagger wounds but her body was neither beheaded nor eaten. They simply threw her body into the bush. The second case, reported by Father Meuwese, happened at Monana in 1943. This time the victim was a three year old boy. The later jailer of the Képi prison, Cornelis Makawak, a native of Monana, told me that he personally had taken part in the shooting. In the end a young man killed the child. Another man cut off his head and the flesh was eaten. The social contexts of the cases are unknown.

All this training got its finishing touch when the leaders handed the bamboo knives, tok, to the young men after the initiation of the children at the hair feast, taker-jamé. After this ceremony 5 they were allowed to participate more fully in the life of the adults. Finally, they were reminded that the social recognition of their marriages depended on their successes in a raid. Prior to that, as Maqaomi told, a leader might say to a young man, 'Why do you beat your wife? Once you have come back from a head-hunting raid, your may raise a stick against your wife'.

\section{Motivation}

What are the motives presented by the Jaqaj themselves when questioned as to why they went head-hunting? Every teacher, every missionary and every civil servant asked them this question. Various answers were given. Again, it is important to distinguish between raids against tribal enemies and raids against surrounding tribes. Accounting for their intra-tribal warfare they said tambi-èr, "because of peace". A 
more accurate translation might be "because balance has to be restored". Jaèndé stated this very clearly in the akiaq, the admonition quoted above, "If people of another settlement have killed some of your people and his death has not been avenged, you still have to kill a member of their settlement".

In the case of extra-tribal warfare they always answered jaméèr, "because of the feasts". These killings were necessary for the celebration of a wedding-feast, the age-ceremony of the children, the termination of the mourning period and presentation of marks of honour. These motives were referred to in the children's games. After cutting off the heads of small lizards, they imitated the hair feast and the presentation of marks of honour. Another motive appears in the words, "We divided the heads in order to establish who would be ménaqaé to whom". This relationship between the one who killed and the one who performed the beheading appears to have great social importance.

Among the Marind people of the south coast another reason was given. Every child must have an additional name, the name of a victim killed in a raid. ${ }^{6}$ Was this also a Jaqaj motive? The answer is not simple. The word muku-éké, skull name, is confusing. This name has nothing to do with the actual giving of names to children. The head captured in war established a bond between two men, the ménaqaé relationship. ${ }^{7}$ The children benefited from this relationship. One of these benefits was a "hair-name", taker-éké, given to the children during the hair feast. This name may have been that of an Awju victim, although they rarely ever knew the name of their victims. If the Jaqaj did not know the name of a victim, they did not give another name instead.

Personally, I do not remember ever having heard such a name. If someone had an Awju name, he had been stolen as a child from the Awju. According to the informants Nejaqaé and P. Kadmaerubun there was no such general rule about name giving. In my opinion, the functioning of a certain man in the public ceremony confirmed the special relation between that man and the particular child (calling each other ménaqaé). If a name did occur, it had been taken from war memories rather than from a victim. Thus my interpreter Jabajmu was called "they ambush" by his father because at the time of his birth Képi ambushed Togom. Such names, however, were given immediately after birth and not at the taker-jamé. The name a Jaqaj took most seriously was his pidoq or éb-éké, his song name. This name is an epithet of honour. It denotes that a man is acknowledged in his group and that 
his deeds, famous or notorious, are worth being commemorated in songs.

A last but certainly not the least important motive for head-hunting the Jaqaj expressed by the term maqati-èr. This term is translated "for the sake of being permanent". They wanted to be "permanent" as the sun was considered permanent. A comment on this motive will be given in the last chapter of this book, when all the data concerning Jaqaj head-hunting have been presented.

\section{Preparations for a raid}

There is no evidence that head-hunting raids were associated with any special seasons. P. Kadmaerubun suggested that for extra-tribal raids involving many participants from various settlements, the dry season was preferred. Personally, I found no evidence connecting headhunting with seasonal, solar or lunar changes. Teachers claimed that increased drumming in a village was an indication that a head-hunting raid was imminent. This drumming continued for days and nights. Not only drumming but also singing played a part in these preparations. Accompanied by drums, the Jaqaj sang their songs about former raids. During this time they made new weapons. All over the settlement men were patiently carving barbs on their spears and arrows, quietly humming to themselves. According to B. Rumlus, they muttered secret formulae during this work. Once finished, they tied rara, leaves and strings, to their new weapons to invest them with waw, higher power. Among these weapons one was a spear of extraordinary size. They called it qoqom. It was exceptionally long and had a small oval shield with open-work carving between the long barbed head and the shaft. I could not find any clear evidence that such spears had either a special meaning or function. ${ }^{8}$ They appear in photographs which show them stuck in the ground or in the well near the settlement (the so-called mar-pit, spear well). In the former case they served as a token of triumph meant to be seen by the enemies in their territory, and in the latter case as a source of pride for their wives at home..$^{9}$ Another special spear was the qajapo. Its use was restricted to married men. A qajapo was a spear without barbs. The upper half of the shaft was covered with a fine network of strings from which feathers of the bird of paradise were hung. This spear was seen more of ten among the Awju than among the Jaqaj.

The checking and repairing of decorations was another element of 
the preparations. Battle or festive dress included armlets, marep-maq (Nambéömön: marapoqajb), and leglets, ramu-maq. They were plaited from split rattan. The men wore their daggers in the armlets. They also attached young yellow-coloured shoots of sago branches to give them a colourful appearance. According to the teacher at Rèp, A. Rahawarin, these bracelets were worn during the festivities following a headhunting raid. During these festivities a woman was allowed to stick her finger into a man's band as an invitation to sexual intercourse. The custom corresponds to the myth about the women choosing their first real husbands 10 and the story of Ajre 11 concerning the presentation of arm-bands, which preceded the distribution of the marks of honour. Nejaqaé, an informant who normally did not hesitate to tell us about the sexual customs of the past, denied stubbornly that such liberties ever took place. In Chapter XII we will see that the act expressed a woman's wish to have her marriage arranged and not an invitation to immediate intercourse (see p. 194).

During the preparations the leaders - according to Jaro and Maqaomi - delivered various speeches on the necessity of the forthcoming head-hunting raid. The main argument put forward in these harangues was, our informants said, "The rattans on the trestles of the canoes of the dead are loose. The canoes will fall to the ground". In addition to this form of verbal incitement, the Jaqaj knew of more material actions conveying the same meaning. In the preceding chapter I mentioned how the people of Emete pressed valuables against the bellies of the leaders of Képi to persuade them to take revenge on the people of Togom, because they had killed a leader of Emeté.

The following instances were related by P. Kadmaerubun. Although relatives were bound to defend their kin, they could be approached for permission to wage war against their people. As a form of request for such permission their sleeping-mats were soaked with water, or one of the warriors might simply place his water tube alongside such a person's sleeping-mat. This person was free to protest and defend the immunity of his relatives. On the other hand, a man could invite his friends in another village to raid his own settlement. He then walked into the befriended village and, carrying a bag of sago, circumambulated the men's house. This was a formal invitation to come and kill his personal enemies. Usually such an invitation was only made by a leader. An invitation of a strictly individual nature could be made by any man by offering a new oar, some tobacco, a cassowary tail, arrows, a shield or a dagger to any individual warrior as an advance payment 
for the killing. Another practice was to touch the anus of one of the important leaders. This was the clearest and most urgent form of appeal to this leader's power.

While tensions increased within the settlement, there were other worries as well. Before they could set out on a raid, they had to make peace with neighbouring settlements with whom they were at war. ${ }^{12}$ Without peace, these enemies might attack their women while the men were away on a raid, the home settlement not being protected. Such a peacemaking between Togom and Képi Jabajmu reported in his life account as follows. "Manip, the leader of Képi, was invited to come to Moïn. Manip left Képi and went to Moïn. He entered the men's house and sat down near the leader of Togom. The leader of Togom asked him, 'Younger brother, would you like to have a child from me?' Manip said, 'Older brother, I would like very much to accept a child from you. You may offer me one'. The leader of Togom said, 'You go back to Képi now, I will return to Togom. I will spend one night at Togom. Then you come there and we will make peace and give you a child'. Manip went back to Képi. He told the people of Képi what happened, 'Tomorrow we will go to make peace with the people of Togom. Togom is going to give me a child. Some of you must go and take the message to Toba and Emeté'. Some men of Képi then rowed to Toba and Emeté. The men of Képi said to the people of Toba, 'Tomorrow you must follow us. We are going to make peace with Togom'. At Emeté they said the same. The following morning the people of Képi and their wives left. Képi went in front. The people of Toba, Dagimon and Emete followed them. Képi stayed behind on the hill Apoket. Képi made peace with Togom. At Taqajmoqon, the people of Togom came singing to the mooring place for the canoes. The people of Képi came singing through the swamp, the men in front and the women behind them. They went ashore. The people of Togom came singing towards the people of Képi. The people of Képi surrounded those of Togom. Then the leaders sat down together. They smoked tobacco which had been mixed with pubic hair. The sun climbed. Singing and dancing, the people of Képi went back to Apaq where they stayed together. There they made a bivouac. The next day the people of Togom came for a formal meeting. They gave the boy Kabigaèp to Manip of Képi." On the same occasion Képi also gave a child to Togom.

The first teacher of Monana said that those who asked for peace by giving a child also gave a piece of sago bark. Those who granted peace 
also gave a child and with it a piece of rattan. The exchange symbolized the restoration of the ties of friendship. After this, the two groups circled round one another, broke their spears and ended this game with an enormous yell. The relatives of the victims asked the killers for such precious things as nose ornaments, ngaingga, and triton shells, mbé. The men who had killed gave them these things because they feared the power, waw, of these relatives. Not until then did the peacemaking take place. After this food was exchanged.

Instead of a child a woman might be given. The lot of these women and children was uncertain. It could happen that the woman was given as a wife to one of the men and that the child was adopted. It was equally possible that the woman or the child was killed and eaten. In the latter case, the woman given was one who had been renounced by her own relatives as a common prostitute, and the child had been bought somewhere else and was now handed over as a peace offering. In these cases, payment or compensation was given to the relatives who had given the woman or the child.

An important part of the preparations was the making of war canoes. They were especially important when a raid was being planned against an extra-tribal settlement far away. These canoes were extremely large, of ten more than 30 feet long. The construction of the canoes was concluded with a feast. ${ }^{13}$ There were no festivities celebrating the completion of weapons or drums. A canoe was the concern of more than one person. It was the concern of a leader and his followers. While working on a canoe, they camped at a place where many trees were found which could be used for making canoes. Apparently every group, under the leadership of its most able men, cut out a large canoe for the group leader. When the canoes were finished they were taken to the settlement.

Guests, i.e. relatives from friendly settlements, were invited. Meat, sago, coconuts and fish were collected. The guests who had put on their ornaments, approached standing in their canoes and beating their drums. The canoes were so close together that the whole group was like a small island, floating towards the bank of the river. The hosts waited; they too were decorated in fierce colours. The arrival of the guests always took place towards the evening, the sun lighting up the golden shimmer of the swaying birds of paradise on the heads. Some women, the best dancers of the community, stood in their small canoes at a short distance from the bank, twisting and rolling their hips, enthralling the spectators with their balance and graceful motion. 
There was one critical moment in the reception of guests, namely, when guests and hosts were so close to each other that nobody would be able to escape if there were any sudden outbursts of hostilities. Sometimes the hosts threw coconuts and sago grubs tied to sago leaf stalks in the direction of the approaching guests. If among all these gifts of welcome there was also a piece of wood or a spear or arrow, the feast was forgotten and a fight broke out. If, however, everything went well, the leaders approached one another, embraced, kissed and addressed each other with the appropriate terms of relationship. Then the hosts moved aside and the guests came ashore. Dancing and drumming, they edged past their hosts who fell in behind. The whole dancing crowd moved through the village from one end to the other and back, the wives of the guests in front, followed by the male guests, then the wives of the hosts and finally the hosts themselves. After this, the male guests went to the men's house and the women to the houses of their female relatives.

In the evening, when everyone had eaten, the dancing began again and continued all through the night. In the course of that night the hosts and their male guests disappeared to the huts in the sago groves so as to start early the next morning to gather ripe sago grubs from the trees which had been cut down two months before. In the afternoon, it was the hosts' turn to come dancing and drumming in their canoes, ordered in battle array, towards the settlement where the guests were waiting for them. After a few strokes with the oars, the song leader intoned a song and everybody drummed and sang until the song ended in a yell. The canoes were then brought a little closer to the settlement with another few strokes, etc.

The next morning all the hosts worked feverishly on the decoration of their canoes. After all the new canoes were launched, their makers (the feast givers) rowed into the swamp. The oarsmen wore their ornaments and rowed along in the same rhythm, keeping close together. Children sat between the legs of the standing men. The guests stood on the banks, critically watching how the canoes lay in the water. The men rowed in their new canoes to the middle of the swamp where they stopped. The leader took a coconut, crushed the hard shell and distributed the meat among the children. Then the fleet of canoes turned in the direction of the settlement where their fellow villagers had been killed a short time before (or in the direction where the distant enemies lived).

Finally the canoes returned to the settlement where the festivities 
were continued with dancing and singing. Throughout the festivities food was distributed among the guests. After the feast the guests went and collected sago grubs, which they presented to their hosts as a gift. I was told that the chief event during this feast of the canoes was the breaking of the coconut, the distribution of the flesh among the children and the rowing in the direction of the enemy.Just as the coconut was broken to pieces and divided among the children, the heads of the enemies would be crushed and the brains given to the children. The purpose of a canoe was not really affected until the blood of newly captured heads had run into the canoe.

Maturbongs said that a "mock" head-hunting raid used to precede the real raid. A sham fight took place during which coconuts were thrown from the trees and adorned like real human heads. Afterwards, the leader went to get a real skull and laid it among the coconuts. He then said, "Coconuts are not real. We will set out".

The decision as to which settlement was going to be raided depended primarily on where they had recently lost one of their own people. Death had to be avenged. It was also possible that they decided this in a special ceremony. One night firewood was gathered with a lot of singing and dancing. A fire was made and the wood was piled all around it. The men formed a long row and walked round the fire. They made a couple of steps at a time, mentioned the name of a settlement and stamped with their feet on the ground in the direction of the fire. If, after mentioning a certain name, the fire suddenly broke through the pile of wood and blazed up, this blaze was an indication that the settlement just mentioned had to be raided.

The final part of the preparations was to collect the provisions: sago, dried fish, roasted meat. The leader then ordered certain men who had relatives in other settlements to go and tell them when they were leaving and where they would meet. The time of departure was indicated by a number of small sago ribs which functioned as a "calendar". During the nights of this period, glowing pieces of wood were thrown in the direction of the enemy. Temporary quarters for women and men staying behind were built in a secret place in the forest. These women, said Maqaomi, were given the following advice, "Stay in the bush, do not come to the settlement. Do not come to look whether we have come back yet. Just wait. When we come back, we will let you know and then you may ask how everything went on the raid and who was successful."

On the eve of the departure, all men had to refrain from sexual 
intercourse with their wives. In the men's house the leaders addressed their "sons". According to Maturbongs, the young men were told not to forget to take along the tree bark, dérumb, which contained a stimulant, and the head-hunting basket, $k u d$, in which to carry a captured head. Young men who had married recently, were told to take along the sago they had received at their weddings. The older men said to the younger ones, "I am already old, you will have to be brave and succeed me soon". It was hammered home to all of them, "We need not be afraid, for our grandfather is coming with us on this raid". This "grandfather", api, was the babae of the settlement, the founder of the group who had been the first to enter this special territory. They believed that he was still present among his people. In the evening the war canoes were partially loaded. This job was finished the next morning. According to Kadmaerubun, the joqbera-radé sprinkled the departing men and women with water. The men were all decorated as they left the men's house, the leader walking in front. No one was allowed to look back or go back once they were on their way to the canoes. None of those who stayed behind were allowed to cross their path. Those who stayed behind disappeared to their hiding place in the forest where they kept silent for fear of being discovered by their enemies. On distant raids to the Digul, Mappi or Edera many women accompanied the men as far as the border of the territory that was going to be raided. 


\section{CHAPTER XI}

\section{THE RAID}

After finishing the preparations and making a formal departure, the Jaqaj chose the routes to the site of the raid. Maqaomi and Jaro of Képi mentioned the main places they passed when they raided the Edera district: Toba, Kabé, Ménéamör (now called Cabang-tiga) Korombuag, and Jodom. They mentioned Korombuag where the first teachers lived but not nearby Tamao (also called the Mappi post) where the military had a station. Old Tambim of Képi once told me how, along the outer bank of the Mappi river, they rowed stealthily and cautiously past the Mappi post during the night and thus got into the Jodom area without being detected by the soldiers.

The atmosphere during these raids is reflected in the contents of the songs which were sung after the raids. These songs ${ }^{1}$ also outline the entire raid, from departure to return. The study of a collection of these songs makes it possible to reconstruct the meaning of the raid for the participants. The songs also demonstrate the fertile imagination of the Jaqaj, who in their poetry see their world unfolding itself before them.

1. The first experience is the long distance they had to row. The journey was monotonous. This song is put into the mouth of an Ikimu woman of Képi. She is also called a Temaqajr, after one of the sub-divisions of the Ikimu. She addresses her husband by his two names: Maper/Naékirop. She compares the river to an enormous crocodile. The river is like a nakumé road or a miaé road (paths in the jungle?) which have long straight stretches. She wishes to sing about her younger brother but her voice does not carry beyond the green wall of tall trees along the endless river banks. The text says:

"The Ikimu woman said, 'Maper, ahead is a nakumé path, long straight stretches to be rowed, long straight stretches to be rowed, like a crocodile which raises itself from the mud'. The Temaqajr woman said, 'Naékirop, before me is a miaé road, long straight stretches to be rowed, long straight stretches to be rowed. My younger brother, the successful Jomo, like a bent leaf he will come back quickly, like a bent 
leaf he will return quickly [with a head]. My song of praise I will make resound continuously; it gets stuck in the ngao tree, it gets stuck in the jao tree'."

2. Tomaj, the younger sister of Maqajteqon (here called Taqajr/ Oanèm) stops rowing. The great river is too restless. It comes from where the river makes no waves (from near a hill, called Oaqatemoqon, near Képi). The song names of the hill are Watöm/Jereqap. Taqajr is spoken to by somebody and his sister answers. The text says:

"Taqajr, your younger sister, who likes fishing, has put her oar in the canoe, because the waves wash into the canoe. Oanèm, your little sister, who likes catching fish, has put her oar in the canoe because the billows wash into the canoe. I come, father, I am one of the Watöm road, one of the quiet water, one of the quiet oar. I come, father, I am one of the Jereqap road, one of the calm water, one of the calm oar." 3. On their way, they make comments on everything they see. The text says:

"Qajaga said, 'The sparrow hawk sits on the driftwood which floats past us in the land of your father. You have a crown of white feathers in the land where the private parts of your mother were coveted'. Kamo said, 'The marsh bird sits on the wreckage which flows past us in the land of your mother. You have a ruff of white feathers in the land where your father's buttocks were coveted. Momi, your oar has no carvings. On the prop roots the tree bear is sitting. Kumait, your oar has no carvings. On the stilt roots the cuscus is sitting'."

4. The closer they come to the river Digul, the broader the river is and the more restless the water. The women who, like the men, row in an upright position, rock to and fro in the canoes. The trees on the banks have fallen down during an earthquake (Mato/Qaébag). ${ }^{2}$ The foam on the waves is like a string of dog's teeth on a dark skin. The text says:

"These many women of Qaepénéamu stagger in their canoes like beetles on long legs. The many women of Tébaqajmu stagger in their canoes like beetles on stilts. Near the Nambéōmön the growth of trees is short: Mato has cut them down, the trees are short there. Near Maqapukamön the stems of the trees are short; she has felled them, Qaébag has felled them. Near Tamao [Mappi post] a wave lays a crown of dog's teeth. Near Oami the surge lays a string of dog's teeth on the one preceding, it lays a string as of dog's teeth."

5. Near Tamao the waves increase and Mbaj/Mangi fears that he may be drowned. He urges Mero/Jabeki, a man from Moïn, to row as 
quickly as he does himself with his oar that has been adorned with carvings. Bulu is the Indonesian name for a bamboo species, renowned for its solid wood. The text says:

"Mbaj said, 'Mero, bamboo point, come on, we shall perish in the high waves'. Manggi said, 'Jabeki, bulu-point, come along, come along, we shall be drowned in the deep rollers'. Near Tamao the water churns; Mbaj rows with his carved oar, the water churns. Near Oami the water churns; Manggi rows with his adorned paddle, the water churns."

6. When they arrive at the river Digul, they remember the motorboat of the white people, those who do not descend from Ajré and have not come down the Kao (Kawa). ${ }^{3}$ Nevertheless they use the Digul, the "head-hunting road" of the Jaqaj. A canoe is tied to an oar stuck in the mud. The son of Qajmaqaé is Jaro of Képi. The text says:

"The son pulled his oar, the son of Qajmaqaé pulled his oar out of the mud, the canoe dashed off like a motorboat, it swept off like a motorboat. The off-spring pulled his oar, the son of Natemé pulled his oar out of the slime, the canoe dashed off like a motorlaunch, it swept off like a motorlaunch. Where foam and driftwood are found, where people who do not descend from Ajré use the head-hunting road. Where the breakers and the wreckage are, where people who are not of the Kawa, follow the head-hunting road."

Maqaomi and Jaro continued their story. When the head-hunters arrived at Jodom they built bivouacs there. If they are not going much further because they intend to raid the Awju on the river Edera, the women will stay behind here under the protection of some trusted leaders. For Képi this was always Tambim, the akiaq-radé. The task of the leaders now becomes more important. They go ahead, maqaéo-an, and enter the territory in order to scout one or another settlement of the Awju. They cannot afford to be seen or heard. Only after this has been done can a campaign be planned for a surprise attack. The greater part of the area bordering the rivers and the small streams is covered by dense sago groves. The warriors are always wary of sudden attacks. These scouting expeditions are also subject matter for the singers.

1. The men walk at some distance from each other and have agreed in advance on the sound of the bird they will imitate in order to keep up contact. The Awju have a lighter complexion than the Jaqaj. Unlike the Jagaj, they have planted much sago which, unlike the wild sago, is thornless. While they walk, the beads worn by the men rustle. The man whose song names are Tomön/Ringgaqaé ${ }^{4}$ is said to be like the 
qaröm fish; he is like a fish of prey among ordinary fish. He is like a head-hunting fish, whose song names are qaröm/aïb. The text says:

"Joqo, the warbling of the Taqajo you must listen for; Qoma, the warbling of the Koqojo you must listen for; Oana, the warbling of the Koqojo you must listen for. Younger brother, Maperéamu, the whistle, the lip whistle;

Older brother, you must whistle; Tomön, you must whistle. Latecomer Naékiröpéamu the sound, the sound of the mouth;

Older brother, you must whistle; Ringgaqaé, you must whistle;

Tomönéamu investigated the path of the light-coloured ones, he investigated the thornless sago groves. The pips rustled on the hip of the qaröm fish; Ringgaqaéamu investigated the path of the red-coloured ones, he investigated the smooth sago ground, the stones rustled, the little fruits rustled on the thigh of the aïb fish."

2. If they saw a bird (tat/ro) flying from the river Edera (Roaqaj/ Tumaj) they said that it was the soul of an Awju who before long was going to be beheaded by them. The bird was addressed, "You gather the fruit of the spear" or in other words: you get stabbed by the spear, the spear of the Képi man, Apaj, whose song names are Woqom/Jamén. $J o a / K a$ are the song names of a kind of wood. The text says:

"From the Roaqaj area the tat bird came flying and settled on the bamboo top. Hey, a light-coloured one's soul; his cheek shines, his jowls gleam. From the Tumaj region the ro-bird came and settled on the bulu-top. Hey, a red-couloured one's soul, his cheek shines, his jowls gleam.

You gather the fruit of the joa spear of Woqom. You gather the fruit of the joa spear of the true bow, gather it.

You gather the fruit of the $k a$ spear of Jamén. You gather the fruit of the $k a$ spear of the real bow, gather it."

3. They encourage each other. The text says:

"On the Roaqae road a voice is heard, the voice of someone sounds. On the Tumaj street a call is heard, the call of someone sounds. Japin, prick up your ears, you who have sharp eyes at night.

Qajneqaé, strain your ears, you who have sharp eyes in the dark, strain you ears."

Jaro told me that after such a scouting expedition the position of the Awju settlement was carefully mapped out. The scouts drew a map on the ground with lines and pieces of wood and stones, so that everyone could visualize the situation in its entirety. Once these scouts returned 
and explained the situation, the final preparations were made. They decided who went along and who stayed behind. This ultimately depended on the judgement of the seer, the joqbera-radé.

I have already pointed out how the leaders encouraged their "sons" before leaving by saying that Babaé will accompany them on the raid. In the Bapaé district a man called Kiaé told me that their Babaé actually appeared before a head-hunting raid, saying, "Look, I have already captured the heads without the people (the enemies) knowing it. You will all be successful; soon you will kill. I have now brought you the heads". Similar stories support the statements of the leaders. They firmly believed in the reality of the contact between the seer and the souls of the head-hunters as well as in the contact between the seer and the souls of the enemies. It did not make any difference whether the attack was launched on a neighbouring settlement of their own tribe or on a settlement of one of the surrounding tribes.

Maqaomi and Jaro placed this activity of the joqbera-rade after the scouting expedition. They went on, "The scouts said, 'They are there [the Awju]. The men of the settlement [Awju] are dancing in the daytime'. The leader [of the Jaqaj] then said, 'Let me first consult the secret powers'. He said to the seer, joqbera-radé, 'You first go into the jungle. Watch the soul's shades, banatoqoija, of those who are going to be beheaded'. Then the seer went into the forest to act as a contact man, joqbera-radé-an."

Nejaqaé (from the Nambéomön district) gave the following account. His story is supplemented with information provided by Maqaomi and Jaro, who are from the Oba district. Nejaqaé spoke as follows. "If, for example, the people of Toba have killed some people of Képi, the seer of Képi builds a dato, a little hut. Around five o'clock in the evening the seer dresses up and goes to the hut. The relatives of those killed in former days weep. The seer runs from the men's house at Kabombape (the residence of one of the groups of Képi) to Ebéababa on the opposite bank of the river. There he enters the little hut. In the hut he is met by the souls of the head-hunters of Képi and the future victims of the people of Toba. They make their presence known to him by ' $a$, $a h$ ' sounds. In the meantime, the people at Kabombapé have lighted torches. Then the seer puts the souls of the people of Toba into a little bag, japi. The souls of the head-hunters help him with his job. He shouts and runs back to the people at Kabombapé and enters the men's house. All the men have already entered in advance through the same main door. The seer is the last to enter. A fire is lighted. The seer hangs 
up the little bag. A noise can be heard from the bag. The seer demands presents from everyone whom he calls by his name. The leader gives the seer tobacco to smoke. He loses consciousness. When this happens the leader takes a mouthful of water and sprinkles it over the seer's face. He promptly recovers and begins to dance, saying, 'The souls [the future victims] are there [caught in the bag]'. Then all start dancing, swinging their spears and shields. Then they appoint the men who are to attack Toba and plan exactly where they are going to attack. That same night they leave in silence. The men remain in their canoes and hide in various spots in the rushes. They are continually on the look-out to see if any people of Toba are going to fish. Early in the morning, the people of Toba set out to go fishing. When this happens, the men from Képi suddenly emerge on all sides and attack a victim. The man shouts, is cut down and before Toba is able to react, Képi is off again. The body of the victim is taken along only if he is still young enough to be eaten. The corpse of someone who is old is left behind."

Maqaomi and Jaro also related: "After the announcements of the seer and after the dancing, the leader speaks, 'Tomorrow ... in the afternoon we will leave. The day after tomorrow when the morning bird, qojum, sings, we will be half-way ... from there you [he appoints certain groups] will go along that path and you [others] will take the other path. The canoes will be moored in this spot and over there. You will row in front, you [others] bring up the rear. The morning after that, when the morning bird sings, the men will sneak into the settlement. As it will not yet be light, we run the risk of stabbing one another while we are shouting. To prevent this you must say, 'I am from Képi, or from Rèp, or from ...'?' When there is more light they attack. Women and men are killed. Those who bring up the rear do the killing; those who are in the vanguard pursue those who flee. If they fail to catch up with them, they return to the settlement [and try to make a killing there]. Eventually the leader says, 'It is all over'. They return to the canoes with the captured heads."

This is the story as it is told without detail or embellishment. Actually, many terrible things happened. When the scouts set out, they not only tried to find out the position of the settlement, but also the strength and the number of the inhabitants (by finding out how long the men's house is and how many women's houses there are). If possible, they also tried to find out something about the way the people lived there. For example, they tried to find out who the leader was by questioning people of other settlements who were Jaqaj confederates. 
It was considered an extremely good omen if the first to be killed was the leader of the settlement while he opened the door of the men's house early in the morning. The first teachers said that just before the attack, the Jaqaj leader shot the first arrow in the direction of the enemy, saying, "Give them arrows of papo reed, and give real ones to us". 5 Another signal to begin the attack was throwing some burning pieces of wood into the air. According to F. Maturbongs, before the attack the younger men threw the wedding sago that they had brought along towards the enemies and said, "Today you will hang from my shoulder. I want to get married". In the attack the younger men stood in front with their spears and shields. The older men stood behind them with their bows and arrows. They shot their arrows first. If the Awju ran, they intercepted them and had the best chance of killing them.

At Képi, Jaro and Jaèndé once performed a sham fight for my benefit to show what could happen in such a raid. While they rushed at the enemy they held their shields with their left hands, horizontally at hip height, the carved side against their bodies. They also had extra spears in their left hands. In their right hands each had a spear ready to use. When facing an enemy they turned the shields upright so that they could look from behind them. During the fight they gradually pushed the shields forward with the toes of their left feet. They tried to split the shields of their opponents with their spears. If they managed to do this, the enemies fled and were stabbed in the back with the same spears. A spear or an arrow which entered a non-vital spot could be broken off and the victim could continue his flight. When an enemy fell after many people stabbed him, he was beheaded. This was not done by the man who hit him first, but by one of the co-stabbers who was asked to do this by the first stabber. To demonstrate this Jaèndé lay prostrate on the ground; Jaro put his left foot on Jaèndé's back, caught hold of his hair and pulled his head backwards as far as possible so that the muscles of the neck were strained. Then he made a gesture as if he were cutting through the muscles with his razor-sharp bamboo knife. He made only one stroke from the cervix all around the neck through the throat back to the bone. Then he made a rotary motion with the head and jerked it as if he were breaking Jaèndés neck. He then held up the head by its hair. Immediately after the beheading, someone would thrust his hand down into the opened trunk and pull out the victim's heart.

This last detail was related by Emanuel, the village head of Mur, and confirmed by Jaro of Képi. Still, it is rather incredible. It must be 
one of those tall stories told by veterans. It is true that the dead bodies were immediately cut into pieces, so it may have been possible for someone to pull out the heart of a victim.

Other gruesome stories tell how they set fire to the women's houses which were built on tall poles. The women and the children were caught and killed when they jumped down from the burning houses. There were fights over pretty girls. Some were eager to kill them while others wanted to take them home as brides. Some children were killed, others were spared. The men shouted their own group names as they stabbed their enemies, ignoring the appeals of their victim. However, instead of fleeing, the Awju might offer resistance. Sometimes they even managed to drive off the raiders. When the Jaqaj won the fight, they plundered everything they could take home with them. The banana plantations were destroyed and the coconut trees were cut down. As a sign of victory they stuck their spears into the ground (the spear-heads upwards) in the settlement itself or on the crossings which led into it.

On the battlefield the arms and legs of the corpses were cut off and taken to the place where the warriors assembled. Covered with blood and perspiration, shouting and roaring (or weeping with anger if they had failed), the men turned their backs on the settlement after an orgy of savagery. Some men ran ahead to warn the women at the halting place or (if they were not very far from home) the women in the settlement. The head-hunters returned to their canoes where they loaded the captured heads, the human flesh and the spoils of the plunder. They washed in the river and rowed away. The closer they drew to the place where the women waited for them, the louder the war trumpets were sounded. The women decorated themselves. Sometimes women fought among themselves, particularly if one woman taunted another that her husband or bridegroom would return without a head. The men in the meantime started singing their songs. The songs describe their emotions as they return after a successful raid. Below follow a few examples.

1. The man Apaj of Képi (his song names are Wogoméamu/Jamenéamu) came walking across a tree trunk (near the raided settlement) with a head in his hand. Baqamön of Képi (his song names are Qatöp/ Joqobé) wept, regretful that he had let an opportunity slip. The Jaqaj text uses the verb in the feminine form of the conjugation. He wept like a woman whose husband was refused a mark of honour (the tail of cassowary hair) and not promoted to a higher rank because he was not quick enough in attacking the enemy. The text says: 
"My elder brother Wogoméamu walks across a paqara-tree trunk; the red fluid flows down his hand which is famous. Your elder brother Jamenéamu walks across a mitebo tree trunk; the blood flows down his hand which is praiseworthy.

Qatöp sits and weeps over the cassowary hair tail [like a woman], he sits in the naqaé canoe, the small naqaé canoe. Joqobé sits and weeps [like a woman] over the ostrich hair tail; he sits in the mikur canoe, in the small mikur canoe."

2. Gaikebaj's ear was wounded by the Awju. His elder sister Qobuj, the wife of a man called Nauwèm/Toqobo, rolled in the mud out of pity. She was characterized as the green cockatoo (a simile often used for women). She was said to be without feathers, which meant that she had thrown off all her garments in token of mourning. The text says:

"Nauwèm, your green cockatoo walks to the land; through the ebb mud she walks to the land, through the ebb mud.

Toqobo, your unfeathered one walks to the land; through the tidal mud she walks to the land, through the tidal mud.

Younger brother, because she is longing for her younger brother, she walks to the land.

The girl, longing for the one who resembles an eye; late-comer, longing for her little brother, she walks to the land, the featherless one, longing for him who resembles an eye [who is beautiful as an eye]." 3. Certain great leaders such as Makoimu/Tomönéamu and Qawéamu/ Ringgaqaéamu, who were allowed to wear belts of human hair as marks of honour, were addressed. They were told that they would do well to spread their belts of human hair like mats in order to shield the captured heads (the heads of the spirits) of the Perajmu (one of the Awju groups). In this song the second name for Perajmu is Wapaqaékéamu. These two men in the song were widowers and therefore they are called orphaned and lonely people. The Jauwi-Qajneqop path is a path in the Awju territory. The text says:

"Makoimu, Tamönéamu, spread your belts of human hair as a mat; orphaned ones, spread your belts of human hair as a mat.

Qawéamu, Ringgaqaéamu, spread your waist-bands of human hair as a mat. Lonely ones, spread your waist-bands of human hair as a mat.

On the Jauwi path, spread them out here on the red earth, you spread them out; on the Qajneqop path, spread them out here on the fire-like ground, you spread them out.

With your belt mats you must shield the spirit jaw of the Perajmu. 
With your girdle mats you must shield the spirit head of the Wapaqaékéamu."

Singing such songs, the men returned rowing, dancing and drumming. Gradually they came near the place where the women were awaiting them. They blew their war trumpets and started beating the sides of their canoes with the oars. By means of these sounds they reported how many heads they had gained; there was one blow followed by a blast on the trumpet, two blows followed by a trumpet blast, or three blows and then a blast on the trumpet. This was called tao. It is remarkable that every informant mentioned tao when speaking about the return after a raid, whether it was within or beyond the tribe. The women were sometimes warned by a messenger that the men were returning. They listened to this tao and responded to these good tidings with hysterical screams. They finished their decorations and began to drum and dance towards the bank of the river. The men put on their marks of honour while still in the canoes. A man was allowed to put on the extra mark of honour which fitted his new rang if he had added a new head to his credit. ${ }^{6}$ Dressed up with colourful birds, decorated with lime and red earth, stamping their feet, roaring, and sounding their war trumpets, the men floated in close formation towards the bank where the women were waiting for them. Some women stood in their own little canoes and while dancing approached the men. From the bank the other women threw sago stalks with sago grubs. Everybody was extremely excited. A few women who just had heard the bad news that their husbands or brothers had been killed, rolled naked in the mud.

The blood-covered heads were in the bottoms of the canoes. By now they smelled rotten and were covered with flies. As the men stepped ashore they walked between the rows formed by the women, but the women soon joined their husbands or brothers. They threw their arms around the men's neck and grabbed the spears which had been used to kill. They danced with these spears and then gave them to the mothers of the killers, or to their own mothers. The captured heads hanging in the $k u d$ were taken to the meeting place. The $k u d$ is a rattan sling of the shoulder-bag type.

A strip of rattan was pulled through the nose and mouth of the captured head and then slung over the warrior's shoulder. The head rested in a "funnel" of plaited rattan. The Jaqaj believed that the soul of the beheaded enemy, toqoija, stayed near the head or in the blood that had flowed down from the head over the arm of the head-hunter. 
Afterwards, the soul of the victim would warn the men against dangers and it would help on other raids to kill new victims. Often, when the men arrived, the $k u d$ with the head was passed from woman to woman each of whom danced with the head hanging from her arm. Thus the whole group moved, turning and whirling, towards the living quarters.

A remarkable thing about the head-hunters' behaviour during the first day after their return from a raid was that they used to do everything by running and dashing to and fro. They danced around the men's house when the heads were brought inside. Then they made a fire to roast the heads and to prepare the human flesh so that it could be eaten. The ménaqaé relationship played an important part in the preparation of the heads. It was one of the ménaqaé who held the head in front of one of their children. This child had a dagger in his hand (although sometimes the mother held the hand to steady it) and cut out the eyes of the severed head. Afterwards the head-hunter who helped in the process would pierce the child's ear lobes.

Then the lower jaw was cut off and given to someone who had requested it. This put the owner of the jaw and the owner of the skull in the nakaéri relationship. The skull is a pivotal point for the establishment of permanent and functional relationships whose importance is seen time and again in the life and feast cycle of the Jaqaj. Once the jaw had been removed and presented to another man, the hair of the captured head was cut off. It was later on used to decorate a spear, to make one of the marks of honour (i.e. the qowa, a band for body decoration). Finally a hole was made at the base of the skull, and the brains were taken out and mixed with sago to be made into sago cakes. These sago cakes were given to the children. If, however, they spat out this food they were not forced to go on eating.

After all the fleshy parts were removed from the heads (the eyes were not eaten but thrown away) the skulls were placed on a platform constructed over a fire. The fire slowly roasted the heads and removed all the remaining flesh. This finished, a piece of rattan was pulled through the nasal cavity and the mouth and then fastened to the ridgepole of the men's house. The skull was neither painted nor decorated. ${ }^{7}$

In the meantime, the butchering of the bodies continued. Then the quality of the meat was discussed in very concrete terms. They said, "This is flesh of old people. It is solid, janggo-mbut. This must be the flesh of a young person. It has openings in it, janggo kobaqamukum. This flesh is tough and full of fibres, janggo bakukqambo. This one has flesh like a cassowary, janggo kujuapinden. This one could have grown 
old. This one has tender flesh, aböb, he would not have lived long". The balls of the thumb and the tongue were considered the choicest and most tasty bits. The genital parts were not eaten. The inside of the thighs of male victims were scraped off because they had been contaminated with semen. The blood was not used. "You cannot roast it", they said. They washed the blood away in the river. One informant told me that the hands of the victims were sometimes cut off and bent round a stick and roasted so as to have the fingers stuck to the stick. Such hands were hung over the entrance of the men's house. If a pregnant woman was killed the embryo was also butchered. Its head was chopped off and considered to be a captured skull.

Only gradually the excitement diminished. They made preparations to return to their proper settlements. Maqaomi and Jaro related this as follows, "Come on, let us settle everything; you go on ahead and then you others will follow. You from this or that settlement come after the others, etc. ... Finally, there were the people who would stay behind at Jodom itself."

The men and the women who had not accompanied the raiders, but had remained in hiding in the forest and the swamps of their territory, were warned by messengers. Their message said, "When you hear the blows on the canoes, tao, coming near, they will have arrived. You, women, must put on your festive skirts. Well, listen sharply [whether you can hear the $t a o$ ]". Maqaomi continued, "The old men [who had stayed behind with the women] say, 'Women, do not make any noise, prick up your ears, so that you will be able to hear the name of the settlement'. The messengers who passed along in their canoes were questioned and they shouted from their canoes to those on the banks. Those who heard a name would pass it on to the others. Then the men who remained with the women, said, 'Start dancing; tomorrow we will go back to the settlement and leave our hiding place. Tomorrow our people will come up the river and arrive at the settlement'." This happened.

Maqaomi of Képi told: "It was still dark when those who had been away on the raid turned up the river [Oba]. The women in front, the men following, drumming and singing. Some married people were told to step into the canoe of the younger men, because they had not enough man-power for the drumming and the singing. Near Qataqam the people of Waman turned off. They said, 'Goodbye, go singing and dancing to Waman'. Near Qaboga the people of Dagimon turned off. They said, 'Goodbye, go to the settlement with song and dance'. Near the Miwā- 
mön river Rèp, Enèm and Kogo turned off together and rowed up the branch of the river [Miwāmön]. They said, 'Goodbye, go dancing and singing to your settlements'. At last they reached the neighbourhood of Képi. Képi, Moïn and Rajöm were still together. Emeté, Moïn and Rajöm rowed on, Képi had arrived home."

Maturbongs called the festivities which followed immediately after the raid the muku-jamé, head feast. ${ }^{8} \mathrm{He}$ did not distinguish between the festivities in the meeting place (e.g. Jodom) where the women were waiting for their husbands, and the festivities in the home settlement itself. If they went far away and their women dwelt in a temporary settlement near by, the first celebrations (the preparations of the captured heads) may have been held there. If they raided a settlement which was not far away, they probably tried to get back home as soon as possible. Thus we hear in one of the songs that the heads in the canoes smelled, which can only mean that they had not yet been prepared or roasted. It seems that sometimes the heads were roasted in the bows of the canoes while the head-hunters were on their way home. In the latter case, the muku-jamé was celebrated in the home settlement.

Father Meuwese has always maintained that after their homecoming the Jaqaj hung the prepared heads on what he called a "head tree". He personally saw such a tree with heads (it was a pole with branches from which the heads had been hung) in the settlement of Osso on the river Ja. Actually, this settlement belonged to the Awju tribe. Yet, the Jaqaj people of the settlement of Jatan had told him that in former times they too used such a tree. This tree was cut down in the jungle and carried to the settlement where it was laid on mats before it was set up. When later on the missionary erected a large cross in Jatan, the people treated this cross in the same way as a head tree. Afterwards, however, Javaqaem, the village chief of Jatan, told me that they had never used any such "head tree". The people of the river Oba did not speak about it either. Namèk, the village chief of Mur, mentioned the tree in his story, but Maturbongs' description of the festivities after the raid does not mention it. One of the first teachers, H. Jamlean of Katan, reported that a branched pole was set up against the front of the men's house. The ends of these branches were tied to the main pole by ropes. The skulls were hung on this structure. The teacher Kadmaerubun could not give a clear confirmation of this fact. I cannot confirm or deny whether such a head tree ever existed, at least as far as the Nambéōmön district is concerned. The only thing that is certain is that ultimately the heads were hung from the ridge-pole in the men's house. 
CHAPTER XII

\section{FESTIVITIES FOLLOWING THE HEAD-HUNTING RAID}

\section{Ro or Ndat-jamé, the termination of mourning}

Maqaomi and Jaro continued their story by quoting the command of the leader: "Tomorrow the coconuts; today you can pull out the coconuts that have shoots; the qoqo are full; they have accomplished their task". The leader's words refer to the fact that when the honoured dead are lying in state in canoes on trestles, there is a prohibition on their coconut trees. The fruits are not to be gathered, even those which fall to the ground are not to be eaten. They are allowed to sprout where they fall. The qoqo, i.e., the piles of hunting-trophies erected at the border of the settlement, keep guard over the coconuts. When they are full they are regarded as having served their purpose. On the first day the men are allowed to collect the coconuts which have shoots. "Tomorrow", the leader added, "they may again start gathering the coconuts from the trees of the deceased". He continued, "Tomorrow we will pull down the platforms of the corpses, ndat; let us have a great feast; let the women who are in mourning gather salt, sleeping-mats, fish baskets, and carrying-bags to present to those who cut off the heads, so that they can pull down the platforms. The coconuts of the men and women who are in mourning must be piled up in front of those who made their spears descend on the enemy. Those who are in mourning must say, 'These coconuts are for you, because you pulled down the platform of my husband, or of my elder brother. It is all over now, you chased the enemy, you killed, you showed pity on us because there was a burial platform which by now you have pulled down'." Maturbongs, discussing the demolition of the platforms of the dead during the ro or ndat-jamé, pointed out that every settlement first completed the period of mourning for its own dead and then all the settlements communally joined in a feast celebrated in the settlement of the man who had taken the initiative in the raid.

Before a platform was pulled down the next of kin went to the burial canoe of their deceased relative or (in the case of women and people 
of less importance) to the grave to recover and bring home the skull of the deceased. Sometimes (in the Nambéōmön) the bones were wrapped in a new mat by the women. This parcel was kept for a while in the women's house and afterwards laid in the forest near the roots of a large tree. According to Kadmaerubun, the bones were buried in a hole in the ground. The women could go there for advice when a child was ill. The next morning the whole community went to the platforms to the accompaniment of songs and dances. They had been dancing all night. The mourning men and women were accompanied to the platforms of their dead. The relatives stood around the platform and the other members of the settlement formed another circle around them. The successful head-hunters cut through the rattans which held the trestles together, so that the canoe fell down and broke to pieces. Thus they went from one platform to another.

Each time a platform was pulled down a head-hunter also cut off all the signs of mourning worn by the male and female relatives. Maturbongs related that during this ceremony the leaders told the relatives, "Now you may go wherever you want to go, you need no longer remember the deceased". They told the widow, "Now you are free and you may look for another husband". The dress and other signs of mourning were thrown away in the forest together with the remains of the platforms and the canoes. They were left there to rot away. The heads which hung on the platforms were also thrown away together with the utensils that had accompanied the corpse. Finally, the children of the deceased were called. They were told to stamp with their feet on the ground where the canoe had stood. Everyone then went back to the settlement. The relatives of the widow's future husband sometimes offered some sago. The guests were fed and then went home.

Maturbongs mentioned yet another detail. He said that although some women insisted on waiting for a successful relative to terminate their period of mourning, there were others who did not wish to wait that long. They went to another village to find a head-hunter (from their family) willing to end their period of mourning.

In the Nambéōmön district the piercing of the ear lobes had a closer connection with head-hunting than it did in the Oba district. The village head of Mur, E. Namèk, told me that after the platform was pulled down an enormous heap of food was piled around the "head tree". Food was also hung on the tree itself. The children sat down on this pile of food and their ménaqaé pierced their ear lobes. The children were about thirteen years old at this time. At Képi, however, the father 
himself might perform this operation on his own child on any given day without any ceremony.

\section{Taw-jamé, the wedding-feast}

Maturbongs, Jaro and Maqaomi said that once the platform of the dead was pulled down the men and women met for the taw-jamé, the wedding-feast. The bridegrooms brought their skulls from the men's house, carrying them in the baskets, kud, which hung from their shoulders. They were accompanied by the other men, the brides by the women. A bride held freshly baked sago which was mixed with meat or fish. The two groups moved towards the open space in front of the men's house to the accompaniment of singing and dancing. There the two groups stood facing each other; the leaders, wir poqoj, were between the two groups.

One man and one woman at a time left their groups and stood in front of the leaders, opposite each other with their heads bowed. The leader ordered the woman to put out her hand. The man slipped the rattan noose (to which the head had been attached) over her arm and hung it from her shoulder, whereat she placed the skull in the basket with her hand. Sometimes he would slip a head on both arms of the woman. The leader held a peeled coconut in his left hand. He beat it with his other hand and with each blow he mentioned one of his heroic deeds. He shouted the name of his eldest son and told where he had gone head-hunting. An enumeration of heroic deeds like this was called pidoq. Jaro gave me an example. His eldest son was Apaj. His pidoq said,

"Apaj-ah! On the Edera I pursued a man, I stabbed him and cut off his head.

Apaj-ah! At Busuma buaq I stabbed a man.

Apaj-ah! At Koromé buaq, near Taqajmoqon, I stabbed a man together with the settlements of the Oba and the Miwāmön and I cut off his head.

Apaj-ah! At the mouth of the river Ia I killed a child.

Apaj-ah! At Qajtemen buaq I killed the Awju man, Qoroja.

Apaj-ah! Of Rèp I killed the man Jakepaq.

Apaj-ah! At Waman I stabbed the elder brother of Jarumb, Kajkān, who had killed the father of Jarejo.

Apaj-ah! I killed the man of Moïn, Tiaqab, who once killed Maqajteqon. 
Apaj-ah! I cut off the head of the man Aburraqaj of Moinn, after Bomön of Moïn had killed the elder brother of Baqamön, Qajao.

Apaj-ah! Of Dagimon I killed the woman Jaboq, because men from Dagimon had killed Japaqaj here.

Apaj-ah! Of Togom I killed the man Tené."

When he had finished speaking, everyone joined in with a loud shout of general approval. Such a shout is called mangger, which literally means tooth. The exhortation to yell is therefore called mangger-amön, with the teeth; such a yell was always a loud "wah".

When the last words had been spoken, the leader broke the coconut over the heads of the man and woman, so that its milk flowed down on their heads. The leader made the husband bite in that part of the coconut where the eyes are, and he made the woman bite in the other half. Then he told them to bite off a piece of the sago mixed with meat or fish and eat it. While they were eating the leader said (according to Maturbongs), "Now everybody has seen that you are married; let the wife be faithful to the marriage arrangement and not look at another man until her death. Let the man be faithful to the marriage arrangement and not look at another woman until his death." At that moment everyone began to dance. The bride danced with the skull on her arms until she was exhausted and then gave the skull to her mother, who danced even more wildly than her daughter. The young women were said to be afraid of the skull, unlike the older women who were more experienced. When everybody got tired, the skulls were returned to the men's house. According to Kadmaerubun, who witnessed such a ceremony at Ragagai, this feast was celebrated before the heads had been roasted. According to his report, the pulling down of the platforms of the dead did not happen before but after the wedding-feast. In the opinion of most of my informants the wedding-feast was the final ceremony in the festivities which followed in each of the settlements separately after the head-hunting raid. The great pig feast, the batikjamé, followed later and was always celebrated by all participant settlements together.

\section{Batik-jamé, the pig feast}

After several head-hunting raids were made, the Jaqaj began to think of the pig feast, batik-jamé. During this feast children, called taker-maq for the occasion, underwent the hair-cutting ceremony; young men 
were promoted to the status of future head-hunters, $k u j$-wir; and successful head-hunters were given their marks of honour. Maqaomi and Jaro began their story with the preparation of the feast. In all these proceedings an important question was whether the head-hunters themselves were prepared to accept the insignia or not. Everyone knew that the great Jaèndé of Képi once refused to accept the marks of honour due to him because he was afraid that he might not live long if he accepted them. ${ }^{1}$ It will be seen later on that of ten the men who were going to be presented with these insignia stood trembling with tension. Once I brought a mark of honour and tried to hang it around the neck of the leader Jabaqaj of Képi. He was frightened and refused to allow it. He said he was not entitled to wear it and added in the little Indonesian he knew, Nanti mati, "I will die".

A distinction must be made between (A) the insignia which could be made by any person for his personal use and (B) the more important insignia which were made by others and presented to him in a public ceremony.

A. The insignia which a man could make for himself were:

1. a bunch of cassowary feathers to hang from the left arm, after taking the first head;

2. a bunch of cassowary feathers to hang from the right arm, for the second head;

3. a bunch of cassowary feathers to hang from the back, for the third head;

4. a bunch of cassowary feathers to hang from the left hip, for the fourth head;

5. a bunch of cassowary feathers to hang from the right hip, for the fifth head; and

6. similar bunches for six to ten heads to be attached to the arms or the back but on a longer piece of rattan so that they resembled tails trailing behind the warrior as he walked.

Maturbongs said that a man having two to four heads was allowed to wear, besides the "tails", the poqoj-tok. This poqoj-tok was a small lath of bamboo about eight inches long and adorned with beads and feathers. The men who wore this mark belonged to the circle of the poqoj-wir, leaders. Their pig-hunting arrows were decorated with two red fruits attached with resin below the point on each side.

B. The insignia which should not be made by a man himself but by others for formal presentation during the post-head-hunting feast were: 1. Ramoq, presented after eight heads; a small gourd wrapped in a 
beaded net, decorated with bird of paradise feathers and hung by a ribbon from the man's neck at the back;

2. Tok, presented after twelve heads; similar to the poqoj-tok mentioned above, a small lath of bamboo five inches long with two nooses of wickerwork attached at the top and called kud because they resembled a flattened head-hunting basket, the lath and nooses covered with beads on strings and hung from the warrior's back; and

3. Oana, presented after fifteen or more skulls; a very simple necklace consisting of three boar tusks worn on the chest; it was assumed that after reaching this rank the warrior could retire.

Maturbongs reported that the men who were allowed to wear these last three insignia were also allowed to wear a girdle of human hair, qowa. According to Jānda those who wore the poqoj-tok, the ramoq, the tok and the oana were, after their deaths, entombed in canoes placed on top of the men's house. Less important head-hunters were placed in canoes on trestles at the edge of the settlement. Those who had not captured any heads (both men and women) were simply interred.

Maqaomi and Jaro related how, after some time passed, a leader addressed his people and exhorted his "sons" to ask those who had been successful on a recent raid which mark of honour they wanted. The affines of these head-hunters were encouraged to make him accept the honour because (so they said) if the consanguines asked the headhunter he might refuse. If those relatives "who had given the private parts of a woman to him" did so, it would be much more difficult for him to refuse. Both the women, wuri-inebaq, i.e. the affines in the women's house, and the men, qajndaw-inebaq, i.e. the affines in the men's house, had to do all they could to persuade him.

"One night, when it was dark and many were present in the men's house, the young people were told to get ready for a mock fight. Carrying sticks, they hid near the men's house. Then the question was asked by the male relatives of the head-hunter, 'Do you wish to have a ramoq?' Then he answered 'I a ramoq'. Another one was asked, 'Do you wish to have a tok?' He answered 'I a tok'. A third was asked, 'Do you wish to have a qowa?' He answered 'I a qowa'. After everybody had agreed to accept the insignia, the young people came to the men's house and started a mock fight. The women shrieked and hurried from their houses, crying, 'You men, what are you up to?' Someone answered, 'They are fighting'. The women crowded around the men's house. The men made a lot of noise and beat on the walls of the house [as if 
an enormous fight was going on]. The women became frightened. Some threw themselves to the ground, others ran to the bush outside the settlement. Then suddenly all the men gave a loud yell: uuuuh. The women understood that they had been fooled and they began to abuse the men, 'You with your large anuses, you have deceived us'. The men answered, 'Be quiet, did you see us, did you hear us? [which meant, did you find out about us?]'. They began to dance and told the women, 'We are going to have a feast and these men are going to be presented with a ramoq, with a tok, or with a qowa. Everything has been decided, the feast has started'. They then danced all night long until daylight. They said, 'Go and tell the news to the other settlements: we are going to have a feast; the warriors have been asked and they have accepted. Go and take the news to Dagimon, Emeté, Rèp, Enèm and Kogo'. The other settlements then said, 'There is a feast; we too must have one'. If there happened to be someone who refused to accept the mark of honour, his relatives from other settlements were invited and told, 'Come and help us [to persuade him]; you, affines, will be able to do this; we, his consanguines, cannot ask him'."

Before this feast was officially announced the leaders discussed everything with the pig-owners. They first made inquiries to see if there were enough pigs to be slaughtered. They preferred pigs with fangs so long that they almost touched the snouts of the animals. Once it was decided to hold the feast, pig traps were set up to catch new pigs for rearing. They smoked meat and fish in order to have enough provisions. Numerous sago trees were cut down so that sago grubs could be grown in them. Maturbongs mentioned a period of three months for the preparation of the feast. During all these months there was dancing and drumming every night. This dancing and drumming must also be seen as elements of numerous small festivities which were held in the course of these months. All these festivities were preparations for the pig feast. All kinds of materials from the jungle were needed for the feast itself. But every time they brought something to the settlement, they made this act into an event worth celebrating. Those who went to get things did so by drumming and dancing. When they returned, those who had stayed behind also started to drum and dance in order to go and meet the people coming home. Both groups joined and went in procession to the settlement.

According to P. Kadmaerubun the first ceremonial act was the festive gathering of the bamboo needed for manufacturing the tok insignia. Maturbongs said that the gatherers also had the making of head-hunting 
knives on their minds. These knives were also called tok and they were the knives to be presented to the prospective head-hunters. "One night", said Maturbongs, "the leaders went to the bush where the bamboo grows. They lighted a little fire near one of the clusters of bamboo stems and kept watch over it. If in the course of that night a fieldmouse or any other animal came near the bamboo, this was considered a bad omen, especially with regard to the young men who were to be promoted to the rank of head-hunter, the tok-wir. If nothing happened the young men were led to the bamboo cluster in the morning. The oldest head-hunter made the first cut in a bamboo. He gave the axe to someone else who also made a cut in the bamboo. The axe was passed from leader to leader until the last cut through the bamboo. It was caught by the young men who wrapped it in leaves and carried it on their heads to the settlement. The procession came to a halt in front of the men's house. There everyone fell silent and looked up. They all waited for a sign; this could be a bird flying over, or the sound of something falling down. Then the bamboo was carried into the men's house. They started dancing again and continued all through the night. In the early morning, the adults spread nibung leaves on the ground in front of the men's house and the bamboo was laid on these leaves. According to Maqaomi, first a newly captured head was laid on the leaves and over this head the bamboo was cut into halves before being laid down. Subsequently the young men were ordered to flatten the halves with their feet until they split. The leader took a piece of the split bamboo and handed it to those men who were to make the knives, tok, for the young men. He addressed the young men as follows, 'You must be courageous and defeat the enemy just as you have now defeated the bamboo. Your fathers will make the head-hunting knives which you will use on the next head-hunting raid'. If the bamboo was needed for the making of insignia, tok, the leader picked up the strips of split bamboo, raised a piece in his right hand and asked, 'Who wants to have this bamboo to make a tok for so and so?' One of the old men ran forward and grabbed it. Then the leader raised a similar piece of bamboo in his left hand and asked the same question and someone came running forward. This ceremony was repeated until somebody had been found for each candidate. The men who were to make the insignia entered the men's house and sat down on a new mat. During their work they were provided with food. They were not allowed to go far away or to go hunting or to take care of their pigs. All scrapings from the bamboo laths were kept on the mats. In the laths themselves 
figures were carved and two holes were made through which human hair was pulled and attached to the lath. This was done secretly by the old men who decorated the lath with coloured seeds and tied black feathers to them. When the work was finished, the laths were wrapped in leaves and hung up in the men's house near the sleeping-places of the makers. The finishing touch to these laths had to wait until shortly before the pig feast."

Maqaomi and Jaro said, "The leader said, 'Go and fetch the bark of the babuk to make bands; do it with dancing and singing. It is for the tok; fetch the white abé- and the red kao-fruits [to make beads]. The $a b e$ are here in the settlement, the kao are in the bush. Singing and dancing, you must bring the bunches; nobody should return without babuk bark'. The leaders themselves remained in an open space in the bush while the young men fetched the bark. When they returned the leaders said, 'Come along, that will do, return with singing and dancing'. As long as they were still in the forest, they did not dare to dance for fear of hurting their feet on the roots of the trees. As soon as they reached an open space, they flocked together and blew the signal on the war trumpets to call those who were still in the bush. They put streamers of uti [fine nibung] and miri [the leaf of a kind of pineapple] and qaqaé [a kind of rush] into their armlets and leg-bands. They danced towards the settlement, holding sticks or sago stalks in their hands as if they were spears. The women were told, 'You go from the settlement to meet us, singing and dancing'. Near the settlement men and women met; together they took the bark to the men who manufactured the tok or the ramoq. The makers stuck the bark in the roof above their sitting places. They said, 'Neither men or women are allowed to go home; let them continue dancing until the sun sets; then the women may stop to roast sago. When the sago has been prepared, you women must shout, "Come and eat, the sago has been roasted". Do not prepare one single bar of sago, but bring sago in a sago mat, sago with meat, with meat!' The men then went on singing all night long.

The leader said, 'Go and shoot a pig, so that we can eat it'. Others set out to shoot a white or a grey cockatoo for those who were decorating the ramoq. 'If you are lucky', the leader said, 'carry the birds home with singing and dancing. Nothing may be taken home unless to the accompaniment of song and dance, neither the bird oako, nor the cockatoo, nor the anangk, nor the qajp'. When the day of the feast drew near, these feathers had to be attached to the insignia.

One day the leader said, 'Take this message to the other settlements: 
the ramoq for so and so of Toba are finished. The marks of honour for so and so of Rèp, for so and so of Enèm, for so and so of Kogo, are all finished. Youngsters, the backs of your elder brothers, and also the backs of your younger brothers, are hurting [from working on the insignia in a bent position]. Collect fish, meat, sago fruits and edible rushes and lay them in front of them. The man who has not yet finished his work will finish the day after tomorrow'. Shortly afterwards he announced, 'Everything is finished, all insignia are ready'."

Kadmaerubun's report supports the information given by Maqaomi and Jaro. He said that shortly before the feast the marks of honour were brought out of the men's house where they had been kept wrapped up in leaves. The black feathers which had been attached earlier were removed and replaced by new white feathers. The old seeds were replaced by new ones and at this stage the so-called kud or pao was attached. Kadmaerubun said that the next ritual act for the Nambéōmön was to cut down a nibung tree. All the men set out dancing and singing to cut the tree and to carry it to the settlement. In the settlement the top was cut off and the fibres from the branches and leaves collected. The old women used these fibres to make the arm- and leg-bands worn at the feast.

On another day the men stayed at home and the women went to the sago groves, dancing and singing. In the sago groves they cut off the young sago leaves (or "branches"). The wives of the leaders took precedence in this work. The first wife of the main leader of the feast was the first to cut off a branch. These young branches were taken to the settlement and the women held them in their hands as if they were spears. As they approached the settlement, the men formally came to meet them. In front of the men's house the whole procession stopped. Everyone fell silent and the women looked up, awaiting a sign (a flying bird, etc.). Then the dance continued and afterwards the fibres were removed from the branches and twined into strings. They were used to make skirts, roqoj. They prepared the festive skirts for the wives of the leaders and for the wives of those men who had become ménaqaé.

On a later day the women set out in procession to the swamps to collect rushes for plaiting new mats. They were again formally received. They stopped before the men's house and stared upwards, continued their dancing and afterwards began their plaiting.

A special place was marked off by little sticks; here the shavings and the non-used portions of the supplies were thrown away. This place for refuse was called $k u h u$ in the Nambéōnöm district; on the river Oba it 
was called qoqo. The ordinary qoqo near the settlement had a function of its own: that of safeguarding the taboo on the coconut trees of a deceased person. ${ }^{2}$ It is uncertain whether this ceremonial qoqo for the feast had any analogous function.

After all preparations were completed everybody who was not busy working on the insignia or plaiting the bands and the mats set out to shoot pigs, to fish or to gather sago shoots. The daily harvest was divided among the makers of the insignia and the plaiters. The young people eventually set out once again and cut down a baq tree, and dragged it to the long end of the men's house where during the feast the tree was used as a bench for the old men to sit on during meals and the young men after their promotion to kuj-wir.

The invited guests were given a number of leaf ribs to count off the days. During the last days before the arrival of the guests, the settlement set out again to gather sago grubs and fresh edible rushes, the delicacies for the festivities. Maqaomi and Jaro related this in a very vivid manner, "The leaders said, 'Women, there is not much time left; we must speak about the sago grubs which have to be collected lest they crawl out by themselves. Do not think of anything else now. Tomorrow they have to be picked. If you need an axe [at the time there were very few axes] go and ask for it. Tell someone from here or yonder, "I need an axe to gather sago grubs". Let someone from that place come here [if he has an axe] and he will be able to go along himself to gather the grubs. He may then go back again for some time to his own settlement [until the actual reception of the guests]'. After the men and the women came back from the marshes the leader said, 'Women, tomorrow morning you must cut your hair and paint yourselves with lime and draw figures on your foreheads with red and white dye. Then relatives must give birds of paradise and feathers of the cockatoo to the women. They should also give beads and other ornaments'. While the women turned out singing and dancing the insignia, the ramoq, the tok and the qowa, were hung in the main corridor of the men's house.

The men joined the women in a cheerful mood. The leader ordered the women, 'You go now and gather edible rushes, qaqaé'. The men stayed behind in the canoes. The women went into the swamps and gathered the rushes. Men and women then returned together to the settlement; the women were in the bows of the canoes and the men in the stern. Some older and younger men stayed behind in the men's house and painted themselves white and red. They said, 'Give a long 
blast on the war trumpet [when you are near the settlement] so that we can receive you properly'. These men were on the look-out [to see whether the others were approaching] and said, 'There they are, they are close by. Let us go and meet them'. Together men and women arrived at the landing place and danced to the settlement. The women were in front and the men followed. The women entered the men's house and the old men showed the insignia to the women, 'This one is for so and so, and that one is for so and so'. Then the women buried the insignia under heaps of edible rushes. They emptied their carryingbags over them. The women did not eat any of these because they were intended for the guests to eat on their arrival or take home to their own settlement.

After the grubs and the rushes had been gathered the leader said, 'Tomorrow the pig sties have to be made'. Then they made a row of sties which ran parallel to the men's house." Maturbongs said that the sties were built on a platform about four feet from the ground. The following day the pigs of the settlement were caught and put in these sties. The women and the young men began a wild dance. They said, "Do not think that there will be no meat. You will eat it, fat and all! Dance with all your strength".

Very briefly Maqaomi and Jaro then related how the guests arrived. "The men and women 'of both sides' [the consanguines and affines of the men and women in the settlement] come to the feast". This was done in an impressive and formal manner, as described elsewhere. ${ }^{3}$

The next day (or days), Kadmaerubun said, the men went with their male guests from other settlements to gather sago (which was and still is a female task) so that this sago could be distributed after the pigs had been slaughtered. This sago was given to their ménaqaé, their headhunting companions. The women of the settlement and their female guests went fishing together. One or two days later, towards evening, they all returned singing and dancing to the settlement. The sago grubs which had been tied to the tops of the sago tree branches were then thrown to the guests as a foretaste of the delicacies that awaited them. They again welcomed the guests with singing and dancing.

In the story of Maqaomi and Jaro another gathering of sago grubs was mentioned. They made a sharp distinction here between the grubs which were still in their cocoons and those which had already shed them but had not yet crawled out of the trees as fully grown beetles. First they went to gather the less mature grubs, qondin-aput, and the second time they gathered the grubs which were nearly ripe, qondin- 
arép. They knew the sequence in which the trees had been cut down, so they knew the stage of their development. Their account terminated in a song which has explanatory value. "The leader said, 'Go ahead, gather the sago grubs, the young ones, qondin-aput, but not the old ones, qondin-arép'. He appointed some people and said, 'You and you, go and gather the sago grubs which are still in their cocoons, qondinaput-ere'. Someone asked, turning to someone else, 'Did you gather any sago grubs?' The latter said, 'Yes, I did, young grubs'. The other one said, 'You may not bring them secretly into the men's house. Go tomorrow, the feast is imminent'. Someone was ordered, 'Hey you, get up, [and gather sago grubs] as a present for those who are to be promoted, for those who will receive the dagger, or the spear, or the girdle of human hair, or the belt. Get up, so that the men who must shoot the pig may not refuse, and their wives do not remain without any meat or sago grubs'. Next morning before it is light, when it is still dark, when the cocks begin to crow and the morning bird, qojum, starts her song, then you must sing the qondin-song,

'In the great belly, in the great abdomen he bores a hole in the roro, in the sago bark, in the fibres;

Kabé planted the sago fruit;

Kabé planted the sago seed;

Oqoni planted the sago fruit;

Oqoni planted the sago seed'."'

Maqaomi explained that the song is about the Capricorn beetle, which bores holes in the sago bark and the fibres of the pith. The names Kabé and Oqoni are the song names of the mythical Mato, the wife of Tomönqambo. On her journey through the country she spread sago by sowing little fruits. The Jaqaj text speaks about kabé kupéaémin, which was translated by Maqaomi as "to lay down, to press", or translated freely, "to sow". At the same time, the women had to set out and gather fresh young sago branches. The fibres of these branches were needed to make the knots in the hair of the children who were to be taker-maq, and to make the roqoj, the skirts for the girls, and the ék, the tail-like anus cover for the boys. Hair decorations were apparently not specific to sex or age group. Fr Meuwese distinguished between two kinds of hair decoration: the young sago fibres which are braided into the hair so as to hang down on the back, commonly used for every feast; and the little knots of fibres which lay on the head and hung down to the neck, the adornment of the children taking part in the taker-jamé (see plate 14a and page 186). 
Maqaomi and Jaro then told how men and women set out for the second time to gather sago grubs. This time they gathered the qondinarép, the grubs which were almost ripe. Again they sang the qondin song. "After the song was sung they stepped into their canoes and were off [they were not allowed to linger]. They said, 'Women, you in front; we men will follow and we shall set out with song and drum'. The leader said, 'You go here and you go there, gather sago grubs, [and when you have finished] come back with song and dance. Get along, the women in front; the men watch out, wait for them. This is the way we gather sago grubs with our father's people, with our mother's people, with the people from other settlements'. Then the leader said, 'Relatives, these sago grubs are not for distribution, they are for yourselves. Do not give them away; they are for the feast'. The feast grubs were something special. They should not be mixed with the grubs which were given during the festival meal, qonoqomör, which could be exchanged with people of other groups. The latter kind of sago grubs were something else."

After the story about men and women who set out together to collect the ripe sago grubs, qondin-arép, Maqaomi and Jaro mentioned another detail. They said, "The leader says, 'Tomorrow we will go and cut wood for the okom. [The okom is a long stick used by women for loosening the bark of the sago trees. The lower end of this stick is sharpened like a chisel. The women may use it as a weapon.] Tomorrow we and our male guests will go and cut down the okom, the okom of qaput, or of baj-rara, or of $i k$. Of soft wood no okom may be cut. Come from the wood to the path and carry the okom together with the guests to the settlement and accompany this with singing and dancing. The women must meet the men and together they must go back to the settlement. There these okom must be planted from the landing place to the men's house and around it, and from there to the other end of the settlement [in a row]. Every man must sharpen three okom for his wife and daughters. If he has many children, he must sharpen five'."

\section{Taker-jamé, the age ceremony}

It is not clear whether the ceremonies were held in some special place. Kadmaerubun was certain that not all festivities were held in the settlement of those who had taken the initiative. He spoke of a feast settlement, jamé-buaq. Maqaomi and Maturbongs did not mention 
this. It is probable that after a great raid, when many settlements were to meet for a communal feast, they also selected a special place for their celebrations. In such a feast settlement there must have been several men's and women's houses. The leaders of the settlement who had taken the initiative must have had a central men's house where the ceremonies took place. Some informants said that the children (whose ages vary considerably) who were admitted at the ceremonies had to sleep in that central house. Some of the reports imply that the guests from other settlements left the festivities to return to their own settlements for a longer or shorter period. Did the hosts then stay on the site of the feast? Often there was no certainty as to what was the generally accepted custom, because each informant described a special feast in which he personally had participated. They did not distinguish feasts celebrating successful head-hunting within the tribe from those celebrating successful raids to other surrounding tribes. As a matter of fact, the heads captured at different occasions were brought together at a common feast.

"When the feast-giving settlement, joined by the men and the women from the other settlements, brought the sago grubs to the settlement", Maqaomi continued, "the leader said, 'Tomorrow the pigs! Yes, tomorrow the feast will stand on its legs'." That same evening, they started the last minute preparations for the hair feast of the next day. The children were dressed in an abdominal band which was so tight that it had to be pushed upwards from below until it fitted tightly around the lower part of the body. Someone volunteered to assist the father in making this band for his child. The father laid a carrying-bag filled wit sago grubs ready for the maker of this band. Coconut water was also needed. They would use it the following day to moisten the heads of the children. This coconut milk was tapped from the flower stalks of a coconut tree, or was squeezed from grated coconut flesh. That same night the abdominal bands were put on. The children then had to see if they could dance while dressed up in these bands.

The guests attached fibre tails to these bands, miri-ék or manggar-ék for the boys. For the girls they attached fibre strings which served as skirts. They began to decorate the children. Knots of fibre were braided into their hair. Birds' feathers were tried out so that they could see what they looked like. At night the children were given the extract of a certain tree bark before they went to sleep. This potion was prepared by the leaders, who said, "This is for tonight, the rest is for tomorrow". As far as I could gather the children went to sleep in the men's house, 
viz., the house where the leaders resided. Early the next morning, before sunrise, when the morning bird, qojum, began to sing, the children were awakened. Then, according to Jaèndé, the adults sang the following song:

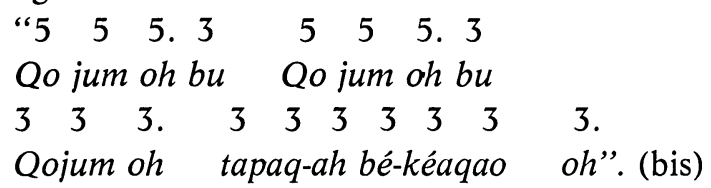

The translation of the song is, "The morning bird is beautiful. The sun sank'. It seems to be a song of praise to the rising sun, which after having set, now rises again at the sound of the morning bird. By the light of torches and blazing fires the children were dressed up and painted with red and white colours.

There was also a short ceremony for babies. They were pushed from the inside of the men's house through leaves on the roof, so that they rolled down and fell into the arms of those who stood outside ready to catch them. The children who were to be admitted then received a second potion of bark which contained some very bitter drug. "They winced for sickness; only those who had strong stomachs did not throw up", said Jaèndé.

The children came outside. They held a decorated spear, qajapo, and walked behind a leader, who held the head of the spear. Special words were recited during this ceremony; there was a monotonous repetition of the words Bomé-oh Qaput-am-oh. These words are the song names for ashes from the fire place. At some distance from the men's house sago-leafsheaths were spread on the ground like mats and the children sat down on them in rows, one child behind the other. In front of each row stood the head-hunter who was going to promote the children facing him. His wife was beside him. Behind the row he had stuck into the ground a spear which he had used during the last raid. Maqaomi said that some of the relatives of the children asked the leader, "Let my child sit in front of you".

The relatives of the children had piled up sago, meat, coconuts, bananas and ginger near the children. These were presents for the warriors who performed the ceremony. They then said, according to Jaèndé, "Here, this sago and these bananas are for you, you take them. You in your turn must give sago to the child". This payment was later on shared by the head-hunter with those who had joined him in stabbing the victim he had killed on the last raid. The parents had accompanied their children from the men's house to the place of the 
ceremony. They stood between the rows of children and danced and shouted excitedly, repeating endlessly, Qaé-oh, qaé-oh, qaé-oh (your father, your father, your father), or Qaw-ah, qaw:ah, qaw-ah (your mother, your mother, your mother), or Qamön-ah, qamön-ah (your elder brother, your elder brother), or Qamun-ah, qamun-ah, (your elder sister, your elder sister). The hair decorations were cut from every child's head and then the head-hunter moistened the edge of the hair with the coconut milk which had been prepared the night before.

Then he said to his wife, "Cut with the knife". The woman then scraped some hair from the child's head with a bamboo knife. This shaving was restricted to those children who participated in this ceremony for the first time. After the next raid, the child would take part in a second ceremony. Then his hair would be cut off in a circle around his head, leaving that on top intact. The hair which was cut off was given to the head-hunter. Jaèndé said, "The children were accompanied to the spring where the rest of the hair was cut short". (When Jaèndé spoke of children, taker maq, he always meant the boys. The girls stayed in the settlement and were decorated by the women.) Food was taken to the spring for those who had made the armlets for the boys and those who had dressed them up. At the spring the boys listened to a speech admonishing them how they should live correctly. Maqaomi and Jaro summarized this speech as follows, "You should not be gluttons, you should not be greedy for meat, nor greedy for fish, nor greedy for sago, never! Do not beat your wife because you want to eat meat; your wife will feed you fish and edible rushes, do not beat her. Do not eat to excess, but be moderate, make this into a habit. If you are greedy already, you will also be so later on." Then the children were given a small bar of sago mixed with sago grubs (they stated expressly "not a large one"). They divided this bar among themselves.

Then they were allowed to sleep for some time. They had brought their sleeping-mats with them. Later the process of decorating the children began all over again. New strings of fibre, borber, were braided into their hair, and streamers of fibre, roqoj, were tied to their hair and hung down their backs. This ceremony was performed by the fathers and elder brothers. Their faces were coloured with lime and red paint; birds of paradise were put on their heads and feathers of colourful birds were stuck in their hair. They also received armlets and leg-bands into which young light-yellow sago leaves were stuck. The text says that their appearance was changed so completely that even their own fathers and brothers hardly could recognize them under 
all these ornaments. During this decorating (at the spring or in the settlement), cassowary hair was attached to the bands the boys wore round their waists. A dagger, wajrip, was stuck into the band. Before this was done, the leader enumerated his great successes as a headhunter while everybody listened in silence. He continued and said to someone, "Stick the dagger above the hip joint", and to another he said, "Stick the dagger in the band around your arm". Then he added the following advice, "The sharp edge must point backwards, for then you will be able to kill more quickly. Do not let it point forward, don't do it, lest it should get stuck in something. I myself carry the sharp edge pointing backwards and not forwards. The small bag which every man carries [which contains all the things he needs] I will hang at your shoulder, the new carrying-bag, uaé-japi. Do not live from hand to mouth. Do not speak any other 'language' [you should not live differently from the way you have been taught]. Cause no scandal, do not begin any fight, do not rape any woman, do not carry off a woman; secret powers, waw, might strike you. Do not steal any coconuts, do not steal fish from any trap, do not steal anything that grows, do not steal tobacco. Ask the man who planted things, learn from the adult men, do not steal any sago grubs.

Do not eat alone but always in the company of other men. Always greet the others with their song names, pidoq. If anyone calls you with your pidoq, call back. If anyone praises you, offer him a present and you will be on safe ground. Make women say that you are as pleasant and beneficent as a fire, a good man, not greedy. They will choose you from among your relatives. Do not be the first to stretch out your hand [in order to receive]; stretch your hand to give fish and meat to another family; always eat a little of it [when you receive something from others]. When you are with your own family, eat as much as you want to. If you are given something by your wife's people in order to distribute it, repay them for it. If you have taken a wife, remember her relatives. As far as your elder brothers are concerned, think, 'I am only small, they have given me fish and sago. I will have to do something in return for them'. Do not eat a large piece of meat or fish or many sago grubs, or else they might say, 'He is a glutton', and then no woman will want to have sexual intercourse with you; others might warn her, 'Do not give yourself to him'. Let her fall in love with you and she will yield herself to you, because growing up you have not eaten too much meat and fish. Be no glutton, so that a woman will say, 'I will have him'. When she is a suitable wife for you and the matter gets to be 
known, the news will reach your people and someone of your father's or your mother's people will pass the news on to you. Then go yourself to the leader of her people and tell him about it. If you do not, if you simply take her and have intercourse with her, it might lead to a quarrel which will result in fighting and then someone might be killed. In such a way you cannot live in peace.

Do not chase the women of your own people. Do not laugh at your father. If you meet any women and row past them, do not tighten your mouth. It might make them think you are hungry and they might ask you, 'Do you want any sago?' Then you must answer, 'I remember the warnings, I do not make light of it' [in other words, if I look straight ahead it is not because I am hungry but because I act upon the warning]. See to it that you do not get the reputation that you force a woman to have sexual intercourse with you. If you do, you cannot stay here any longer; you will have to go to your relatives who live elsewhere, for the relatives of that woman live here.

If a woman surrenders herself to you of her own free will, inform her people, 'So and so is in love with me'. If you do not have an exchange sister and your relatives cannot provide you with a girl [for the exchange], but someone else is willing to give you a girl for the exchange, you may take her. Then you have a compensation, an exchange sister. Then an exchange can be arranged. In that case one of your own people will go to them [and you will get a wife from them]; never have any sexual intercourse with any of the women of your own people." Jaèndé added that after all this the children had become hungry and were fed.

When the sun was setting, the boys were taken back to the settlement with singing and dancing, and there they were joined by the girls. All the participants had painted themselves anew. They accompanied the children to the platform of the pig sties. The new sago fibre skirts were hanging from the platform.

Jaèndé said, "They gave a bamboo knife to the leader. He was the first to cut off the sago fibres of some skirt. He said, 'Go ahead, cut off your skirts'. Then everyone cut off the skirts and handed them to the women, saying, 'Tie knots to the lower ends of the skirt strings'." According to Maqaomi, the skirts were measured out on the bodies of the children and cut off at knee length. No distinction was made between boys and girls. Jaèndé said that the children then were rubbed with pig fat and coconut flesh. Jaèndé denied that children were painted near the spring, whereas Jaro and Maqaomi insisted that they were. 
Obviously there was disagreement as to whether the children were decorated near the spring or first rubbed with pig fat and coconut flesh and then decorated. This disagreement suggests flexibility of the ceremonial pattern according to location and time.

During this ceremony for the children, the naqaéri of the headhunters were killing the pigs which had been caged before the festivities began. Each man who shot a pig paid the pigs' owners a compensation of dog's teeth or food. While the animals were shot, other men stood around the sties beating their drums in accompaniment to their songs.

After the pigs were shot, others made long tables under which the women lighted fires to roast the pigs. All young men, however, were sent out again to gather sago grubs. They were not allowed to come back until they were called, i.e., until the pigs had been butchered and the roasted meat had been stored in the men's house. During the butchering- and the boning-process they cut many strips of fat off the pigs. These were hung on strings between poles as a demonstration of wealth and opulence.

The women lined up near this place to receive the strips. The young men were called back and, accompanied by the adults, they went towards the strings dancing and singing, each with an arrow in his hand. On this arrow they stuck a piece of the fat and gave it to one of the women. One group of women after the other received their portion. Jaèndé said, "The wives of your fathers and the wives of your brothers would not like it, if you did not hand over the fat on these arrowheads". The wives of the hosts were the last in the line of women to receive their share of the fat. Then the meat was distributed. The meat of the neck, the head, and one foreleg of each pig was given to the inhabitants of the host settlement and all the rest was divided among the guests. The man and woman who had raised a pig were not allowed to eat the meat of that particular pig. "It was their child". They exchanged the head of their pig for the head of someone else's pig.

\section{Presentation of the marks of honour}

Jaèndé said, "We slept one night". This may have been true as far as the children were concerned, the taker-maq. The adults, however, began to make preparations for the great events of the following day: the presentation of the marks of honour. About this event, which seems to have been very important, the data are very scarce. The Jaqaj informants Jaèndé, Jaro, and Maqaomi did not discuss this celebration. 
Kaedmaerubun and Maturbongs provided what details they knew.

On the evening of the taker-jamé, after the fat was distributed and the meat divided, the roqoj or feast skirts, the new armlets and legbands were hung together with the marks of honour on or in the men's house. It seems that feast skirts had also been made for the men and that these were measured on their bodies. This same night, the men who were going to be presented with the insignia began to decorate themselves, paying special attention to their hair-dos. Birds of paradise and other colourful birds were put on top. The men also renewed their body paint. They decorated their armlets and leg-bands with highly coloured leaves and fibres. They also wore their shell ornaments and strings of beads. Both men and women came to the men's house to admire the marvelously decorated men and avail themselves of the occasion for more dancing and singing. In the men's house, the men who had dressed up were busy all night adjusting their decorations. Outside, the others were singing about their heroic deeds in their honour. Not only the men who had stabbed first and were now to be presented with the marks of honour, but also their ménaqaé, and those who had been given a head for their children, spent the night singing in the men's house. Maturbongs said that the singing stopped at midnight and that then everybody finally tried to get some sleep. But before they went to sleep, said Kadmaerubun, the women and the young people danced round the men's house, from which for pure fun the men threw bunches of sago grubs and even pieces of firewood.

Early the next morning the men woke up and the wives of those who were going to receive the marks of honour entered the men's house. They lined up in two groups confronting each other as two sections in the men's house. On one side the leaders lined up with the men who were not going to receive new insignia. On the other side were the men who would be presented with the insignia, their wives and their ménaqae and their relatives in the background. The village head of Dagimon, Jannda, said that the men receiving the marks of honour earlier swallowed stimulants, so that now they were trembling. Others had to stand on their feet to prevent them from falling over.

The leader started his pidoq, his speech about his own heroic deeds. When he finished, he stood behind each man to present a mark of honour. He began with the oana, then the tok and finally the ramoq. These marks of honour were passed over the heads, so that they hung down on the men's back. Every time such a mark of honour was put on, all those who were present shouted their approval, mangger. After 
a while the men gave their marks of honour to their wives to wear in turn while dancing. Maturbongs said that at this moment the girdles of human hair, qowa, were also presented. The young men then received their head-hunting knives, which promoted them to the rank of headhunter, kuj-wir. The leader told them, "From now on you will have to abstain: do not eat any kind of catfish. Do not eat large snakes, nor any large animals which have much blood. Do not touch a woman, either married or single. If you meet one, bend your head, lest you should see her. He who complies with this, wil be quicker to have success [and kill] and quicker to get married, just as I myself did in the past."

After the presentation of the marks of honour a certain ceremony, which is referred to by all sources, took place. The leaders and those who had received the marks of honour took their spears and left the men's house. Their head-hunting companions, ménaqaé, took hold of the shafts. The great leader walked in front, followed by the others in order of dignity. Every person was joined by his kuj-wir and his takermaq. The women walked beside the long row which was formed, sometimes searching for their children who were unrecognizable under all their ornaments. Those inside and those already outside the men's house sang three songs, without the accompaniment of drums. In the settlement of Hagām I heard the text of one of these three songs. The informants did not remember the other two. The song words remembered turned out to be the words of a song which Jaèndé had taught me earlier in all secrecy.

Tapaq-oh, Dugu éabaqajn-ah, Kawa éabaqajn-ah

Qojöm are-oh

Maq-ah, qojöm are-oh

„Sun, Digul he goes over, Kao he goes over

Morning bird

Sons, the morning bird."

This is the song of a leader who came close to the territory of the Awju and then started singing: " The sun goes down across the large river [to the West]. Tomorrow when the morning bird sings, sons, we will invade the territory of the enemy".

Nejaqaé told me that once they had all emerged from the men's house and started their procession, they kept on monotonously repeating the same words: Bomé-oh Qaput-am-oh (as they did, according to other informants, in the procession of the children from the men's house to the place where the hair cutting was to take place). This procession 
went as far as the edge of the settlement, where two spears had been stuck cross-wise into the ground with a small fire burning under them. Nejaqae said that the fire prevented the souls of the people from going to hostile settlements, lest later on their owners be beheaded by the inhabitants. When everybody lined up in one long row, a shield was placed behind the last man. The man nearest the shield called to the leader, who was standing near the crossed spears, "Where are you?" Thus they pointed out how long the row was and how great the feast.

When this was over, they returned to the men's house and lined up in rows in front of it. Everybody fell silent and looked up at the sky or at the ground to see whether there were any signs, birds or butterflies or snakes or other kinds of vermin. They behaved dé-apinden, like a tree. Maqaomi explained this kind of divination, which has already been mentioned several times before in this chapter. "A bird comes flying": they think about this without saying a word and later on will voice their thoughts when the silence is broken, "She comes instead of a woman from there to here, perhaps to have sexual intercourse". Or "a bird comes flying over" can mean "she is going to that or that place; one of our women will perhaps commit adultery there later on". Or a bird of prey, joqoj, or a bird with white feathers, comes flying near. They say, "He comes instead of a man who wishes to carry off a woman".

Early that morning, said Maturbongs, some men had already been sent out by the leaders in all directions to listen and see if they could hear the sound of any birds. They had come back about this time. Everybody was waiting to hear the answer to the question about the future: will people die or will they have success on the next raid? To all the pieces of information the whole crowd would respond with a roar. Then everyone fell silent again and the leader addressed them, "Keep courage, you know the signs, even if bad tidings have been foretold. Let the men comply with the rules: do not kill anybody in your own settlement, do not molest the wife nor the fiancée of somebody else. The young people must keep to the rules of abstinence, so that we soon may find the courage again to kill many people and again present marks of honour". When he had finished speaking, everyone shouted approval and began to dance.

The ceremony of the crossed spears was later on associated with the cross erected in the village of Dagimon. What happened there on the occasion of a baptismal feast helps one to understand the meaning of the final ceremony of the head-hunting feast just mentioned. After the 
baptismal ceremonies in the church (1953) we went in procession to the large cross which had been erected in the middle of the village. In that procession the leaders participated and they held the spears in the same way and sang the song given above. For the older men and women this was an authentic ceremony, it was not mere play, as some of the younger people seemed to think at the time. The procession gathered round the cross and I gave the final blessing and thought the ceremony was over, but suddenly everybody fell silent. Everybody looked up at the sky and all at once an old man began to shout. After he had finished speaking, the usual mangger, loud roar, followed and then the crowd dispersed.

The old man was the akiaq-radé of Képi, Tambim. With the aid of his son, who was my interpreter, I wrote down the literal translation of what he said. "Grandfather, we have celebrated again the same feast as we used to do in the past. Now you must stop and not make our women weep any more because of the death of their husbands and the illness of their children. Till now we have celebrated the feasts of the parish priest, but now we have had a feast which was like a feast of our own. Now put a stop to our dying, for now we have celebrated our feast, have we not?"

According to Maturbongs this divination was the end of the feast. The guests went home. The wives and children of the hosts were tired and returned to their houses. The hosts went to the men's house. Only the new kuj-wir had to stay outside, sitting down at the side of the men's house under the eaves of the roof. These men abstained from food until the evening. When it was dark the kuj-wir went inside and shared the meal of the other men and then everyone went to sleep. The next day the kuj-wir blackened themselves and held a footrace before the guests left. If someone fell during this race he would not live long.

When the guests were leaving the leaders lined up near the exit from the settlement and inspected the carrying-bags of the guests. If anyone did not have enough meat to take home they added provisions to the bags. This was intended for those relatives of the guests who had not been able to come to the feast. They also gave other presents like spears, bows, arrows, ornaments, carrying-bags, fish baskets and mats to the departing guests. The guests promised to come back afterwards with meat, fish and sago grubs to compensate their hosts for their hospitality.

According to Kadmaerubun, all the men and women met in the men's house on the last evening before the guests' departure. That night 
young women contacted men from other settlements in order to make arrangements for marriage. Sometimes the women or girls quarrelled over the same man. However, he sometimes was able to marry both if he happened to have two exchange sisters to pay for them. The women stuck their fingers behind the festive skirts or the armlets or leg-bands of the men. If a girl who did so was still too young, she would stay with her parents. If she was old enough, the man entrusted her to his mother if the arrangements were made successfully. That same night the young men also put sago and meat on the sleeping-places of the adult men. These gifts were intended as food for the "souls" of the children of the settlement.

A few days later the men of the feast-giving settlement set out with the new warriors to a little settlement. They behaved as if they were setting out on a head-hunting raid, but the only thing they did was to erect a "sign" on the road leading to the enemy settlement. This sign consisted of a pole, with a cross-bar attached to it, which was stuck in the ground. They hung a bow, an arrow, a head-hunting knife and a head-hunting basket on this pole. Their intention in raising this pole was to show the enemy that there were new head-hunters. Near this pole they also left behind some of the ornaments they had worn during the feast.

Some days later the young men, those who had been promoted to the rank of head-hunter, went to the groves and gathered sago grubs. In this way they showed their appreciation to the leaders. They also buried the armlets they had worn during the feast. Afterwards the men set out to go hunting once again and shot a pig. They burnt the mats on which the pigs killed during the great feast had lain. A remarkable feature, reported by Kadmaerubun, is that on this occasion the skins of the drums were smashed. They pulled down the platfoms and left the feast house and the site of the feast, jamé-buaq.

\section{Raèp-jamé, the jaw feast}

The festivities were not quite finished. Several months later there was the feast of the jaw, raèp-jamé. Maturbongs described this very briefly. Apparently this feast was not a general meeting of more than one settlement. Only the owner of the jaw, nakaèri, came to celebrate this feast with his nakaèri, the warrior who had presented him with this jaw. Maqaomi and Jaro dealt with this feast extensively. According to them, the jaw owners all met at the same time. Maqaomi said, "The jaw feast, 
raèp-jamé, does not last long; it is very short. The leader says, 'Let us celebrate the jaw feast. Go and take the message to the jaw owners, nakaèri, tomorrow. Tell them that the head-hunters invite the men to come with their jaws'. The next day the message was taken to the befriended settlements. There they told the messengers, 'Be patient, we will first go and gather sago grubs to heap them up in front of you. He who has accepted the jaw will bring along his own share'. The latter then said, 'Relatives from father's and mother's sides, we need sago grubs, fish, coconuts, bananas, tubers, tobacco and ginger to offer them [to the head-hunter and his family]'.

His people set out to collect sago grubs in the morning. They laid all the food they had collected together with the jaw in the men's house and a few days afterwards took them to the man who stabbed first. The man who first stabbed the victim said to the owner of the jaw as he arrived, 'You have accepted the jaw from me; you must take it to my sago grounds'. Those who had been on the raid together, the "stabbers", marwir-arip, set out together and gathered the grubs. The jaw owner accompanied them. The relatives stayed behind in the settlement. The first "stabber" filled an extra large bag with sago grubs, then tied a whole set of strings of sago grubs to the jaw-bone and when the large bag had been filled, the jaw was laid on top. They said, 'Let us go back to the settlement, but without singing'. They returned to the settlement and were formally welcomed by the people of the settlement and the guests. Together they proceeded to the men's house where they ate. Then the leader said, 'The sun is setting already. Let us dance and sing'. The women entered the men's house where they divided themselves into two groups. On one side the "stabbers" stood with their wives, on the other the jaw owners and their relatives. The women were so laden with their carrying-bags full of food that, while they were standing behind the jaw owners, others stood behind them to support the heavy bags.

Then the two groups approached one another in a long row. With the help of his wife the jaw owner carried his bag filled with grubs and the jaw on top towards the other group. One of the co-stabbers took the bag from him as they approached and hung it on the head of the first stabber. The latter held the bag while both groups made piles of food in front of one another: coconuts, sago grubs, bananas, tubers, tobacco and ginger. If the load became too heavy for his head, he handed it over to his wife. Another woman from among his relatives helped his wife accept this bag. The first stabber returned the carrying- 
bag to the jaw owner and said, 'The jaw is for you; again it is for him who received it; jaw owner, take it with you'. Everyone returned to their own side of the house [to divide the food]. Both groups mixed and dancing and singing began and lasted all night long. The next morning the jaw owners returned home, singing and dancing. When they arrived at their settlement they were not allowed to sing any longer. They just stayed in their settlement without singing and dancing."

I have said before, on the authority of Kadmaerubun, that the skins of the drum were smashed. Both Maqaomi, informants from the Bapae district and Nejaqaé said that the real end of the feast is a new killing. Kadmaerubun himself said that some months after the jaw feast, a woman or a child was exchanged and killed. The leader of the feast made arrangements for a new raid. He often enjoined other leaders to participate in a raid organized by him. But it was also possible that instead of going on a new raid the Jaqaj lured someone to the feast in order to kill him. Nejaqaé cited the example of someone from Moin who had committed adultery with a woman from Képi. Képi lured this man to Mandaw where a feast was to be held. There the man was killed and beheaded. Mandaw paid Képi for the victim that had been delivered into their hands.

The head of the victim was taken to the settlement and roasted over a fire. The roasted head was laid on a mat and above this head an insignia, a tok, was scraped with a head-hunting knife, also tok. Then the point of the insignia tok was broken off so that it fell on the cut-off head and from there into the fire where it was burned. They said, tok kendé inoroat, "the point of the tok they break off". This ceremony was performed by a young man and they said, "If the head-hunting knife is unable to scrape off anything from the tok [literally, does not eat anything] this means that the owner of the knife will not live long". He who had taken the initiative at the feast said during this ceremony, "We will now have a real feast".

After this they all went back to the place of the feast and cleaned the men's house. The sago mats which the younger people had placed along with sago near the sleeping-places of the older men were burned together with all other remains of the feast. If these things were not done, everybody would die. 


\title{
PART IV \\ STORIES AND MYTHS
}

\author{
CHAPTER XIII
}

\section{THE ORIGIN OF THINGS}

All peoples have transmitted their histories, their philosophies of life and their experiences of importance through time and generations. The Jaqaj do this in their stories. They recount their own notions of their origins, highlighting the important task of man as the orderer of his universe. They tell of their great ancestors and their efforts to create and open up a land where subsequent generations could live and thrive. In their stories they also give meaning to the world around them, especially the sun and the moon, which represent the recurrent duality found throughout Jaqaj culture.

They distinguish between an everyday story (kèri) and a tale which has been transmitted through generations (maqaé-kèri). Sometimes these maqaé-kèri stories record purely historical events (e.g. a famous battle) but usually they concentrate on mythical events. Most of the stories recorded and discussed in the following chapters are of a mythological nature. They are narratives which establish links between the present, the past and the future.

Telling these stories is primarily a male prerogative, especially that of the akiaq-wir who, as interpreters of tribal traditions and counsellors of the group, are prominent performers in the art of story-telling. Tambim and Jaèndé of Képi, Raramuj of Moïn, Ikapé of Toba, and Mote, Taqaqaj and Ngain of Katan were all akiaq-wir. They provided the bulk of my information on this subject. Some younger men also told stories, but it was impossible to elicit any stories from the women. They certainly knew the stories because they were told in their presence. They simply did not wish to tell them to me. 
It was technically impossible to establish the geographical range of each story - its acceptance beyond the range of a particular village. The only myth wich I am sure is known throughout the area is that of the sun at Qajno. ${ }^{1}$

Obviously, the order of this world is determined by the great forces of nature. The tidal wave which sweeps the Digul river, the earthquakes, the fire the Jaqaj depend upon, and the sun and the moon are all important subjects in story-telling (this chapter). The founders of the Jaqaj way of life and the advice that they gave to their offspring also play an important part in the story complex of the people (Chapter XIV). Along with nature and history the world of the spirits plays a role in the lore of the society. Chapter XV will deal primarily with this type of story.

\section{The journey of Tomönringgaqaé \\ a. Introduction}

The Jaqaj tribal area borders on the estuary formed by the river Digul where it flows into the Arafura Sea. Here the tide is a daily phenomenon, causing the water of the river to rise and fall. The height of the incoming tide depends on the lunar phase. Around the new moon and the full moon a tidal wave can roll up the Digul like an enormous wall of water. The water erodes the banks of the river and forces its way through the forest and swamp. The tidal wave runs up the Digul as far as the mouth of the Edera, a tributary river, where it loses its force.

In this story the origin of the river system is described and attributed to this tidal wave, which digs the large rivers itself and orders the water snakes to dig the smaller ones. The contents of the story correspond to the actual geographical situation of the country. The song name of the tidal wave is Tomönringgaqaé/Tomönqambo. The story says that Tomönringgaqaé went by land from the river Pore to the river Araré, and indeed, there is a watershed at that place. On the map the common names are used: Qodaqa-moqon = Odamun; Qoba $=$ Oba. The story was told in the Jaqaj language by Raramuj, an old man of the village of Moïn.

\section{b. Text}

"From the sea Tomönringgaqaé (Tomönqambo) moved on. At Wap [at the foot of the hill Wap] he made a river-bed. Wherever he came or wherever he went, he made a river-bed. Then he pointed out the place to the water snakes. 'There is to be a small river here. You are to dig 
the river Edera'. He said, 'You, water snakes, are to dig the small rivers; I shall dig the large rivers'. After that he first dug one river, the Kao, then came back from it and dug another river, the Muyu, and came back again. Then he returned to where he had started and dug the Qodaqamoqon, pointing out to the water snakes the places for the rivers Mābur and Bapaé. He came back from the place. He came to the river Mappi and dug a river-bed; the river Nambéōmön was dug by the water snakes. First he himself dug the river Mappi; then he returned and dug the Qobaamarao. The place for the rivulets he pointed out to the water snakes, saying 'You are to dig the rivulets'. He moved up to the river Qoba, the water snakes first digging the river Masin and then the Nigera. When he had returned thence, he himself dug the river Poré. Then he went away, never to return; he went across the land near the river Poré and made for the sea along the river Araré."

\section{Mato}

\section{a. Introduction}

Tomönqambo, who made the rivers, had a wife named Mato. Drabbe says in his wordlist: 'Mato, a woman who is said to cause the earthquakes and who lives in the Digul'. She followed the same road that her husband took. Mato was a woman, a native of a country where the women wear their fibre skirts folded between their legs. The fibre skirts of a Jaqaj woman hang down straight. She had a child with her when she went searching for her husband. The child fell ill and died. She failed to find her husband. Through her care for the sick child and on her own initiative she acquired a new husband, a native of the Jaqaj country bearing a Jaqaj name. She made him prefer her to his other wives. This new alliance was extremely fertile. The founders of many groups sprang from them. Actually, there are groups of people living in the area which is mentioned in this myth, i.e. the vast marsh lands where the Emoqon and the Purmi rivers, tributaries of the Islands river, have their sources. The myth was told in the Jaqaj language by Raramuj of Moïn.

\section{b. Text}

"From the sea, Mato came to find her husband Tomönqambo. She just followed the foam. While coming along, she sowed sago in the woods by throwing away little pieces of sago fruit. She came to the river Kao, retraced her steps, threw little fruits into the wood, then entered Qodaqamoqon and threw fruit there. She said, 'Where has that man 
gone?' She went along scattering fruit; she went up the river Mappi, hoping to find her husband. She searched and scattered fruit. She turned and went up the Qobaamerao, scattering fruit on her way. When she arrived at the river Pore there was no fruit left; she threw a sago rib into the Poré. She went down the Poré. Her child was taken ill; she was almost compelled to leave it there. When the child got on its feet again, she continued on her way and took a borok [fruit] and sat down. After eating the borok, she threw away the seeds. Then she hung her mark of honour, Mato's mark of honour, on a borok tree. She hung it there in order to see how it would look hanging from somebody's head. She stayed there. She went into the Miwämön. She called for the people, but the people were not at home. There was not any raraké [medicinal herb]. She threw away sago ribs; the head of her child trembled with fever. She said, 'Have patience ... they are trying to find raraké ...' Then she reached Qaqaeréaqano and spoke, 'He may have passed here'. She called and called. She walked; she called to the people in the village of Roqajr, 'Give me raraké, are you not at home?' Then she passed on with her fruit, saying. 'He has gone through the marsh'. She looked for him there.

She stopped when she saw a footprint at Topummuka; she danced the death dance for the love of her child which she held in her arms. The shades in the hollow of a tree were listening attentively. 'Where does that woman come from who keeps on calling? She calls upon the ancestor Qaputaq'. Menequb then rushed towards Mato; he looked at her closely, 'Whose child is this woman?' He saw that she was scabby and that she was a woman with a fibre skirt folded between her legs. Mato spoke, 'Are you afraid of me? Don't be afraid'. She said, 'I called for raraké'. He said, 'Wait, I shall go and find it'. Menequb filled a bag with raraké and hastened back to Mato to give her the raraké. She accepted it and beat her child with it. She said, 'Must you go away? Just carry the child for me'. He carried it for her and said, 'I shall leave my wives'. Mato spoke, 'You leave them behind'. They arrived at Opoqir. There she put the child down and surrounded it with raraké. The child had died. Menequb dug the grave and put the child in it. He covered the bottom of the grave with tree bark, then took the child and buried it. He took the axe [a stone axe]; he cut wood and placed it around the child.

Menequb spoke, 'I am going back to my settlement and my wives'. Mato said, 'Leave them there; look, I am yours'. He said, 'Why do you force me to leave my wives?' Then they went to the sea. There he 
became the father of a people. She gave birth to one child after another: Tepo, Qaitop, Oréq, Amaqatu, Eaqatu, Kakir, Toqopé, Qoneqir, Bogoi, Oqomeqir, Bai, and Qaetemaé. Herself a child of the marsh, she gave birth there to many. There she stayed in the big pond."

\section{Baqaröm}

a. Introduction

After the tidal wave and the earthquake, fire is one of the creative powers. This is especially true in the dry season, that of the east monsoon. The Jaqaj do not find anything strange about the fact that the peaty swamps smoulder. The Jaqaj know of certain spirits whom they call jaqar (in the Nambéomön district, jaqanda). Among them there is the man Baqaröm. The origin of the fish is attributed to him. The idea that wood chips fall into the water and turn into fish comes naturally to them, because canoes are hewn out on the banks of rivers where chips easily fall into the water and float away. The narrator here was Jabaqaj, the group leader of the Kamaqajmu at Képi. The language was Jaqaj.

\section{b. Text}

"Fire caused the soil to burn. It went round about the $i k$ and borok trees. The fire dug a bed wherever there were any decaying trees. In this way the rivers originated. Everywhere ground spirits, jaqar, entered the beds and inspected the rivers. Where the fire burned a mamin tree, there was a deep river-bed with steep sides. Thus the depths came into being and jaqar set foot on the places where the fire had raged. Baqaröm came far up the river Mappi and while he stayed on the Mappi, he carved a canoe. The chips falling from the canoe turned into fish which he threw into the water. He settled on the Mappi. Later he went down the Mappi back to the sea. He put out to sea and made quantities of fish there. After that he stayed on the Digul and threw all kinds of fish into the water. For a long time he was out at sea and then he was gone."

\section{Météoqom, Qaqap, Mapur, Marshplants}

\section{a. Introduction}

Not only the origin of the sago and the fish, but also their uneven distribution throughout the area excited the amazement of the Jaqaj. In the story about Mato, the text says that she had no sago fruit left when she arrived at the river Poré. Actually the village of Moïn, which is 
situated there, has always complained about the shortage of sago. In the myth about Mapur, the woman Tamaq scattered sago ribs all over the land of Tup, so that it grew twice as densely in that area. The myth of Météoqom explains why some rivers are rich in fish and others are not.

These myths also tell that fish have the task to arrange the waterplants in the swamps and that the snake and the frog are charged with guarding the sago. Jaèndé of Képi told the story in the Jaqaj language.

\section{b. Text}

"It was Météoqom who distributed the sago. He loaded his canoe with fruit of the sago plant and departed from Masin, scattering the fruit as he went. He emptied one bag after the other. Météoqom spoke, 'You, snake Qaqap, you exist for the benefit of the sago marsh. That is where you have to stay. You guard the sago'. Qaqap said, 'You, children to whom I have given birth, go everywhere in the sago marshes. When a man or a woman steals the top of a sago tree, bite them, so that he or she will die'. Météoqom spoke, 'Snake $R a$, you belong to the plain. Stay there'. Météoqom spoke, 'You, crayfish, show yourself when the water rises. You, crocodile, your place is in the water. You, pig, you have the woods at your disposal. You, cassowary, live for the fruit trees which you must eat. Pigs, you must feed on worms'.

Qajmé cut down a tree and said, 'Tagwèk [age-mate], what is this?' Météoqom answered, 'Be off, you have cut down a sago tree'. He beat the sago and wrung out the fibres. When the sago began to dry, he made it into blocks. He put them in his bag. He hung one bag from his head, another in front at his chest, and another from his shoulder. He went home and said, 'You have received this from me. That is why it exists'. Météoqom made a weir in the river Kunda and caught fish in his traps. He put the fish in his canoe which was made of batikini wood. The fish were crowded in the canoe. He scooped some water into it to prevent the fish from dying. The fish spawned in the canoe, their tails wriggling. When the fish knocked a hole in the side of the canoe, some of them fell into the water. Fish leapt into the water. He reached Qomo ... Jamaq ... the river Ribu ... the Nambéomön ... the Mappi ... he rowed up the river Qoroja, where only a few fish left the canoe. He then returned to Tamao. The next day he went to Waptamangk and left the fish at Wap, while he went to Joda [Jodom].

The canoe with the fish drifted towards the sea. The tidal wave upset the canoe so that the fish fell into the water. They got into the centre 
of the current and thus spread in all directions. Météoqom rowed to Joda, where he went ashore and left his oar, his fishing-spear and his punting-pole. On foot he continued his way. He spent the night by the roadside and went to Okaba. There he stayed and begot children who founded the village of Mumu. He planted pajo, banggé, jopim, narim, keqao, opoq, tikém, joa, and mindé. He also planted nibung. His wife, Jaqaqaé, asked, 'What is this?' He said, 'These are various kinds of palm wood: ngao, uwaé, up, an, mi, ndoa, and qaman'. There he settled. The marshplants kumb, aj, oandébé, qakéa, éaqa, and qaqaé were sown by the following kinds of fish: the kib, tawa, un, mandoqoj, iköm, qarim, qobu, patöm, ajangk, and dudamin. The qabarumb was planted by the woman Inör. The water-lily, ndaba, is the work of the following kinds of tortoises: the tabu, aqao and naqape."

Raramuj of Moin narrated his version of the same theme in the Jaqaj language. "The sun sailed in his canoe and scattered the sago. He threw the little pieces of fruit to the frogs, mapur. In their turn the frogs distributed the sago all over the grounds. It was they who sowed the sago. Qaqap, the snake, stole sago from the frogs and dove to the bottom of the sago marsh. The frogs said, 'You, Qaqap, must stay down in the marsh. We, frogs, shall stay in the ditches. We are going to guard the sago'. Then a woman called Tamaq, came rowing along. She rowed in her batikini canoe near Déjémoqon. She laid her batikini canoe across a rivulet and let it run aground. She left her sago in the canoe and continued on her way on foot. She scattered sago ribs all over the country of Tup, so that it grew there twice as densely as elsewhere."

\section{Mopön}

\section{a. Introduction}

The moon also has its story. It is first seen in the west and last in the east, and then it dies. In this context women have their menstruation. Mopön is the owner of this source of light. He also has the best arrows. He lies and cheats in order to keep them for himself. When he is found out, he takes revenge; he shoots at his brother-in-law and throws the moon up a tree to prevent it from falling into the hands of his waylayers. But he also distributes his fine arrows among men and practically speaking, the moon is placed at the disposal of all. Mopön, however, demands that he be given the credit for making all these things. $\mathrm{He}$ must be called upon when the nights are dark and the people must say that he made the moon and put it at the disposal of all mankind. 
The moon, as well, wishes its name and story to be spread everywhere.

The Jaqaj make their shields out of the "plank roots" of certain trees. First they burn the surface so that it gets a black colour. When this has been done, they cut away certain strips so that the remaining black lines form a pattern. With lime and burnt loam the Jaqaj put on white and red colours. The figures are in red on a white background. The Jaqaj say that the man Mopön made the moon in the same way so as to be able to go hunting in the light of the moon. At the end of the story, suddenly a second character enters the scene, viz. Joqoj, who turns into a bird of prey when the moon rises. This Joqoj is said to have lifted the clouds and to have turned the sky into a vault to provide a place for the moon. Tambim, the oldest man and counsellor of Képi, was the narrator of this myth. The language was Jaqaj.

\section{b. Text}

"In the morning and in the afternoon Mopön was quite successful in shooting animals. He thought to himself, 'Let me make a source of light out of a root' [in order to be able to shoot animals at night as well.] First he worked up the root of the ronomanup. Towards evening, he put it in the ground [on something which served as a base], but the root did not give any light. It was black. Then he worked up the root of the jujun, but when he put it down it remained dark. He did the same with all the kinds of wood he knew, but they all remained dark. Finally he took the root of the mbi. He worked it up and it gave light. When the sun set, Mopön turned the root round and its light shone on his breast. He said, 'It may be all right'. He held the work of his hands high up and the light shone on his breast. He made it all black with charcoal. He said, 'I have made it right'. He cut down a new leaf of a sago tree and frayed the fresh green inner parts into threads. He threw away the thorny bark. He wrapped the root in it till it was no longer visible.

The next day he went to the forest and hung it up in the midst of the trees. It lit the whole forest. He said to the root, 'You should not give so much light all at once'. In its wood he made the ear, the face, the eye, the nose and the tongue. Then he returned to the settlement. He had wrapped it up with care. His wife said to him, 'Why have you been away for such a long time?' He answered, 'I had some work to do'. He put the moon in a bag of the kind used to carry a dead pig home. He said, 'I am going to cut down a sago tree. You had better go 
fishing'. He cut down the tree and built a cabin of leaves from which he could watch the pigs when they came to feed on the sago. Soon the pigs came to the sago. He said, 'In the afternoon I shall go and look at the sago'. In the afternoon he went. He inspected the sago. The pigs had eaten from it. Then he took the moon from his house to hide it beforehand. He went home and took his bow. The villagers said, 'It is pitch-dark, be careful so that the pigs do not kill you'. He went. He shot a pig at noon, he shot a pig in the early part of the afternoon and he shot one when the sun was setting. Then he entered the cabin close to the sago tree. He took the moon into his hands and placed it on the top of the tree. The grove was brightly lit up. A pig was feeding at the sago. He shot it. Then he carried the moon to another sago tree, placed it there and shot another pig. He returned to his cabin and looked for megapode hens. They cackled because the light was too bright, for Mopön had drawn back the sago fibres. That was the reason why the light was so bright. He shot a megapode hen. He walked on and shot another one. That very night he returned home. He took the moon with him. He came home and there he covered the moon carefully after tying it up. He went home, knocked to call his wife and said, 'Here I am'. His wife asked, 'Have you shot a pig?' He said, 'I have'. He gave her a megapode hen. He went to sleep in the men's house.

The next morning he went to his wife's house, cut the megapode hen into pieces and said, 'The brothers-in-law may come'. His wife spoke, 'Brothers-in-law, you may come and butcher a pig'. They went for the pig and cut it into pieces; the brothers-in-law of the man and those of the woman did so separately. One brother-in-law said, 'Did you shoot the pig in the dark?' Mopön replied, 'I aimed at it from hearing. When the pigs made sounds with their jaw-bones, I shot arrows at them. If you want to shoot a pig in the dark, you must aim from hearing'. They went home and divided the pork among the men and the women. The next day Mopön set out again, he shot pigs and megapode hens again and again.

The exchange brother-in-law of Mopön put the point of his bird- or his pig-arrow in a papo reed. He shot at an animal with it but the shaft split. Mopön used the right kind of reed and, coming home, he gave his exchange brother-in-law his share. The latter said, 'Exchange brother-inlaw, I shoot at animals again and again, but the reed is too weak. It splits too easily'. Mopön's exchange sister said to him, 'Exchange brother, what do you shoot with? I can never give any meat to you, because my husband always returns home without anything. The shafts 
are too weak'. She said to her husband, 'Just watch your exchange brother-in-law and find out what he shoots with'.

Mopön put his arrows in an opening of the bark of a sago tree. He took arrows made of papo reed to bring them home where they were seen by the men. For that occasion he smeared blood on the points of all his arrows. The following day Mopön said, 'Bother-in-law, let us go hunting pigs from behind the fence'. The other made as if he was asleep, but he watched Mopön closely. Mopön got up carefully and took the moon from the pig bag. His exchange brother-in-law went after him into the dark wood. When he entered it, he saw that it was quite light. He said to himself, 'There you are, my exchange brotherin-law is fooling me'. Mopön placed the moon on the top of a tree and took his arrows from the opening in the bark of the sago tree. By moonlight he walked, Mopön, secretly pulling the arrows for birds and pigs from the opening. He shot many megapode hens, birds, pigs and many small cuscus. That same night Mopön returned home. His brother-inlaw had already gone before him; Mopön followed him with the meat to the village. It was getting light.

The woman said, 'Could it be that he avails himself of some spell?' Mopön said, 'I walk with a torch'. They said, 'We have tried that again and again but birds, wood-hens and pigs fled in fear'. Mopön said, 'Go and fetch the pig. I have planted a stick in the ground there and hung cuscus from it. Go and get them'. They carried the game to the settlement. They roasted the meat on a little platform over the fire. They cut the pig and the cuscus into pieces. The brothers-in-law divided the meat till nothing was left.

Mopön's brother-in-law said, 'Brother-in-law, I observed you. You produced something like a torch. What is it?' Mopön said, 'I lit a torch'. The other replied, 'It is not a torch, I was struck by the light, it shed a good light'. Mopön said, 'I used a torch'. His brother-in-law showed him a pig arrow and said, 'Bother-in-law, did you happen to use such an arrow?' Mopön got angry, took his bow and shot at his exchange brother-in-law, saying, 'You have not invented this arrow, have you?' The brother-in-law shot back, but the arrow stuck in Mopön's skin. Then Mopön fled farther into the jungle. He came home with a sheaf of arrows which he distributed among the men. They said, 'Elder brother, indeed, you have outwitted us'. Mopön said to his exchange brother-in-law, 'You have caught me in the very act'. He produced the moon from the bag, drew back the covering and ran off with the moon. 
Joqoj called, 'Throw it to me up here in the bread tree'. Mopön threw the moon to him. The moon leapt up the bread tree, climbed to the top and stayed there. Joqoj stood on the other side. He was suddenly covered with feathers. Joqoj cried aloud. Then Mopön said, 'My name must be mentioned in all places and people must call upon me with the words, "Mopön, you have made the moon, you have thrown it up the bread tree".' Joqoj raised the clouds, saying, 'Higher ... higher ... that is not high enough, up, up'. The moon looked down. It was as if he looked into a deep hole. He said, 'My name must be mentioned in all places and people must tell the story about me'.

Thereupon Mopön in turn declared, 'I have made the moon so that the sun will not be there alone. Because the earth was dark, I have made the moon. It will get dark, but then the moon will give its light'. The people called, 'There he is, he is beautiful'. Mopön spoke, 'You must become visible in the west and come outside, then you must give light, and give up when you are seen in the east only. You must seem to die. Then the women will have their menstruation'."

\section{The sun and the moon}

Story from Képi

\section{a. Introduction}

The following are fragments of stories told by my informants at Képi and Moïn. These data were discussed with the two akiaq men of Dagimon, Qanaqao and Oèn. Although they did agree that the sun and the moon are two exchange brothers-in-law, they depicted this relationship as one of tension between two men who in spite of everything depend on each other. For them this relationship rather resembled that between an elder and a younger brother. What was always stressed was that one of the exchange partners was stronger than the other, but while he could harm the weaker one he could not kill him, for that would mean the end of an essentially complementary relationship.

According to my informants at Képi, both the sun and the moon, tapaq and kamo, were men who were married. The sun's wife was called Qojöm and the wife of the moon was called Koqomb. Both couples had a child. That of the sun was warm, that of the moon was cold. Once, when Qojöm had to withdraw for a moment, Koqomb exchanged her child for that of the sun. When Qojöm came back, she said, 'This is not my child, this one is cold. My child is warm'. She took her own child back, but afterwards Koqomb stole the child again, etc. ... According to informants at Dagimon Qojöm was not the wife 
of the sun, but of Ramuajn. This name Ramuajn, means "without a leg". 2

b. Text

"Kamo [the moon] and Tapaq [the sun] both went fishing. Tapaq shot a fish with a fish arrow. The mimbak with the arrow still sticking in it drifted towards Kamo. Kamo took the mimbak and the arrow, which stopped near him. Tapaq was the first to return home. Later on Kamo followed him. Tapaq was vexed. He thought, 'He may have picked my arrow and my fish out of the water'. Kamo spoke, 'After all, you are different from what I thought'. Tapaq gave no answer. He was silent. He was angry because Kamo had taken the arrow and the fish. Tapaq spoke, 'Let us go and look together tomorrow. I shall show you everything now that you found my arrow today'.

Early in the morning they set out. Tapaq explained, 'This is an arrow for ipaqa, megapode hens; this one is for fish; this one is for cuscus; this one is for the goura pigeons; this one is for oaks, grouse; and this one is for wood-pigeons'. He showed him the arrows for pigs, for cassowaries, and the arrows to shoot people. He showed him the spears for killing people: the qoqom, tikém, qaimön, migit, and embokendé. 'These bananas are edible; eat them when they are ripe, do not let them become soft by putting them over a fire. This is sugar-cane. Do not put it in a fire. This is qamank, eat it with salt from the ashes of the sago rib. This is iroqo [a tuber], put it over the fire. That is all, I have shown you everything. Come and enter the house and take the arrows and bow I have already made'.

Kamo entered the house. Tapaq shut the door and bolted it. Tapaq set fire to the house. Kamo was unable to get out on any side. He walked up and down the house. Kamo spoke, 'Exchange brother-in-law, you will become an aqao, a tortoise, with two arms and legs and I shall make you fat'. In his turn Tapaq said to Kamo, 'You will become the moon anyhow. Give a bright light and be cold'. Then Kamo said, 'You are there for the daytime, you are hot, make the day bright'.

Tapaq said, 'They will put you near the fence in the sago wood to shoot pigs. Today you took my arrow, you go and stand up there'."

\section{Story from Toba}

\section{a. Introduction}

The narrator of the following myth in the Jaqaj language was Ikapé, an older leader of the village of Toba. In this myth more light is 
thrown on a certain aspect of the relationship between the two partners. Theft put an end to their friendly relations and led to revenge. Still, it should be noted that the sun did not take action on the basis of mere suspicion. He investigated the case and tried to catch the criminal in the very act before he struck.

b. Text

"The moon secretly ate the sun's meat. When the sun went to inspect his fish traps or was fishing and came home afterwards there was no fish left. The meat was gone. The sun spoke, 'Who eats it?' Later on his tobacco was stolen. 'Who smokes it?' He went to his garden and filled his bag with bananas, tubers, vegetables, potatoes and he hung the bag on his back and the bunch of bananas from his arm, saying, 'I shall let him have it with a bamboo knife'. He sharpened the bamboo knife by tearing off a strip with his teeth. He cleaned it. It came sharp from his teeth.

Stealthily the moon entered the house of the sun to steal. Then the sun came to his house cautiously. The moon sat there, eating pork. He cracked the bones between his teeth. The sun heard it and said, 'Indeed, it is he who eats my food'. The moon was startled and fled for fear of the sun. He ran out of the house into the wood. He limped. One leg was gone. The bamboo knife had cut it off. He had only one leg. His figure had changed. The one leg was gone. Only one leg was left. The blood splashed about, much blood. He said, 'Exchange brother-inlaw, I rise, I am the moon'. The sun spoke, 'I give light in the daytime and heat'. The moon said, 'I am for the night, for the cold'."

\section{Story from Mandaw}

\section{a. Introduction}

A number of adults of the village of Mandaw in the Nambéomön district told me the following story in Indonesian in answer to my question as to whether or not the sun and the moon still make contact with human beings.

\section{b. Text}

"A woman was left alone in a settlement. All the people had gone fishing. The moon made a rope. When it was long enough, he threw one end of it down and slid along it. He landed in the river. He desired the woman. He hid in the tall grass. When the woman, named Borin, stepped on the rope, the moon saw her, embraced her and together 
they climbed up along the rope. Later on they descended once more to pay a visit to her family. They stayed a long time. Now her family knows where she is."

\section{The sun casts down its skin}

\section{a. Introduction}

The most widely known story is the myth which tells how the sun shed its skin on the hill Qajno. This hill is situated on the river Bapae in the Nambéomön district. The group leaders of the villages on the river Oba, Jabaqaj of Képi and Jānda of Dagimon, together with the group leaders of the villages on the river Bapaé, showed me this hill. There is nothing on the hill but reed stalks. Descending the hill on the other side, we came to a vast grassy plain where they showed me a hole in the ground. Here the snake, which is mentioned in the myth, was supposed to have disappeared. The hole was about one foot in diameter and about two feet deep. I did not notice any reverence or fear for this place. Jānda relieved himself without any concern not far from the hole of the snake. They assured me that there was no "guardian" of this place.

I shall place the names Wajru, Képi, Toba, and Katan above each part to distinguish the various versions. At the beginning (Wajru) the origin of death is ascribed to the beheading of a dying man. Such treatment can be applied to anyone. Therefore, when the sun provides a remedy against death, do anything to get hold of it.

The first Képi text tells about people on their way to Qajno. The difference in genitals and diligence seems to be important. The warleader Jabaqaj told the story.

The story from Toba first relates what the sun throws off, namely its skin. The obvious explanation is that the Jaqaj know that a snake sloughs its skin and they interpret this as a process of rejuvenation preventing death. The sun wishes to pass his vital power on to man in the form of a skin, but demands in turn that man be courageous. Therefore the sun demands that people chase away an old woman. She might keep the secret all to herself. Because of the threat, there is only one way open to man if he wishes to stay alive, viz., to increase his courage by brave deeds. Fear, which is never far off, is like the snake that cannot be caught even though it is attacked and driven out of its hole. The requirement that they should always overcome their fears by fighting stimulated the Jaqaj into aggressiveness in vital situations.

In the second Képi text a restriction is added to this general rule. 
Everybody has to show his courage, but not in such a way that communal life is rendered impossible.

In the Katan text it is interesting to note, that white people are put on the same level as the "smart snake". Those who know how to make use of innovations are endowed with great powers. It is also implied that he who refuses to co-operate in the realization of modern development will have to be satisfied with the old situation. In this version the "skin" of the sun has become a sheet of paper, a book of knowledge. At this time, bush schools had already appeared.

b. Texts

(1) Wajru

"In former times nobody died. One day it happened in a settlement that somebody was seriously ill. Because there was no longer any hope, the sick man was carried out of the house and placed on a platform. About two weeks later two old women came to fetch the man's skull, thinking that he would be dead by then. When they drew near they saw that his skin had dropped off and that only the flesh was left. They wanted to take his head, but suddenly the man said, 'What is it you have come for?' They said, 'We have come to get your head'. He said, 'I am not dead yet'. The women insisted and finally they cut off his head. He spoke, 'Now you have killed me. From now on all people will die like me. In the future, however, you will hear the sun's voice. Then gather quickly in that place, so that you may fight for what the sun will drop'."

\section{(2) Képi 1}

"Qakom too was in the canoe. ${ }^{3}$ The people in the canoe said, 'That is a beautiful woman sitting in the canoe'. When they arrived, he took a water tube. The people said, 'That man looks like a woman. What a strong man. He has breasts like a woman'. They returned to Jamaqamoqon. There they husked coconuts. The women with large genitals wore large leaves. Those with small genitals wore small ones. The lazy women used a bat of ate wood, the diligent ones used a bat of nibung wood. Then they arrived at Qoti. The women moored where there was bamboo. They departed for the river Aet. There they planted iriqo and toqomi. Thence they continued on their way towards Ahem and arrived there. From Jajomoqon, they crossed the plain on foot to Qajno."

(3) Toba

"Rupé was making a fishing-net. She was small. While she was plaiting, 
her tail was in the ground. The sun spoke, 'Rupé, who is she, why is she sitting there? Let her go away, lift her up. I am going to drop my gifts. The sun's skin I shall drop'. Rupé said, 'No, I shall stay here, I am plaiting a fishing-net'. Many men and women said to her, 'Go away, get off, clear out'. She answered, 'This is my own ground, I shall stay'. The sun dropped its skin. Ugly Rupé just looked up. She was ordered to clear out, but she spoke, 'Fellow people, I stay, this is my ground'. The sun threw the big skin to the people and said, 'Take and eat it!'

The men and the women looked up. The skin fell near Rupé. She ate it and crept into a hole in the ground. The people tried to dig her up. They caught hold of her tail, but it broke, and broke, and broke; time and again it broke. She crept deeper and deeper. They caught hold of her again, but again the tail broke. Indeed, she became very small.

The sun spoke, 'Well, then cause other people to die by cutting off their heads with a bamboo knife'. He threw down the bamboo knife to cut off arms and legs as well. He dropped the various kinds of spears: the tikém, the jao, the mbaérara, the ngotub, the jometo, and the ndé and said, 'Make attempts on other people's lives; here are spears, thrust the spears into arms, legs and bodies, stab and kill. The meat of the victim you shall eat. Here is firewood, blow it into a fire, eat what has been roasted'.

He dropped the kinds of bamboo: opoq, qama, rimp; the kind of reed, rar; and the kinds of nibung: an and jaq, for arrows. He dropped the kinds of grass: $a$, baq, pum, and kumb, for making mats. He dropped the shoots of the various kinds of palm trees: ndo and ngao; and the fibres for the sago-bags, saying, 'Plait them. Here, when you must die, this is a canoe on trestles. Put the dead on the platforms to honour them. If another settlement comes to dance, pile up coconuts for food, and bananas, wari; sago grubs you shall eat; pile worms, merèm, and jaïk you shall eat; cuscus you shall roast; the male fishes, kaèb and iköm; the kinds of fish: tawa, patöm, mandoqoj, kaba, and unu; the female fishes: tabu, naqapé, ombo, aqao, and roqoepé; and the two sexes of naqaj, baru, raqaqai, and mbai. ${ }^{4}$ Meat for roasting you shall lay on a platform. Let the fire roast it. What is tainted was not roasted well, it was not sufficiently done. Blow the fire well so that it flares up. When it is dark, you must still sit in the light. Let the fire burn well. Pile the wood up high when it is dark'.

People rightly draw conclusions from a person's eyes, whether they look good or bad. They say, 'He is already dead, the enemy has already 
struck him, I have looked at him ... this or that man is not doing well, he looks so entirely different, no good at all. Oh, I did see it. He gave us no sago, he is already a marked man, the expression of his face is no good. He is frightened to death. The enemy struck home, hid in the dark and escaped. He did not see them, his eyesight is bad. The enemies came to spy. The men sat with their wives in the house and ate meat. Smoke ascended. The enemy spoke, "They are there. They are in their settlement. They have just returned from hunting. They have not eaten yet, their bellies are not yet filled". A woman went to the bush. She saw them. She came back and said, "There are men. I have seen them. There are shields. I have noticed them. They have decorated themselves, cockatoo feathers are in their hair. The bird of paradise sat on their heads; they were decorated, they are coming as enemies to kill us".",

\section{(4) Képi 2}

"They looked up. Ajré raised the clouds. They looked up at the sun which held the clouds. Qoqur plaited the fishing-net. They said, 'Go away'. She stayed. The skin fell on a tree and dropped close to Qoqur. Qoqur escaped and crept into the ground. They dug her out, but she broke. Then they stopped. The sun threw down two varieties of bamboo, rimp and qama; the nibung tikém, and the knife made of bamboo, tok. 'Cut off heads'.

He dropped the long spear qoqom. They looked up. Ajré raised the clouds. Qajmé took the bow and the spear, Ajré took the bamboo knife. In former days they used spears made of sago bark and branches, qabar. Qajmé speared the people of his own group; he killed some of them, cut off their heads, arms and legs and put the heads over the fire to roast them. The sun spoke, 'You must not cut off the heads of people of your own group'. Qajmé raised a head and spoke, 'Sun, will I die because I have eaten the flesh of my own people?' The sun spoke, 'You will die and so will everyone'."

\section{(5) Katan}

"When the sun dropped a piece of paper, the white people were just on their way back from bathing. The paper stuck in a bamboo bush. They took it and that is how they learned about the gun. Then the sun dropped the gun. They knew how to call the gun so as to make it come to them. The gun came walking to them. They took the gun with them in the canoe. The canoe was called ami. Other people took the bows 
and the arrows. They too asked for a gun, but the sun dropped only a bamboo bow and arrows, saying, 'You did not wish to take the gun. Now I will only give a bow made of bamboo'. They were silent. They heard the bang of a gun. A hornbill dropped down. The white men went on shooting. They wrote with a pencil in a book. They were satisfied. They went down to the river. Those who stayed behind began to dance. They sang, 'Land, land of iron-wood where the current is at its strongest'. The sun said, 'You must kill each other when a man molests another man's wife. You did not wish to take the book, now you must kill each other. Those who took it are satisfied'. The people scattered." 5

\section{The mother of Bakui}

\section{a. Introduction}

This is a myth about an unmarried woman who refused to have intercourse with the sun, Tapaq, and preferred the earthworm, $A w$. She had to suffer the consequences of her refusal. The woman knew the sun and had experienced his high demands. Unwittingly she let $A w$, the earthworm, sleep with her. She discovered this afterwards, for her sleeping-mat was wet. She then turned away from the sun purposely, because his demands were too much for her. She stayed awake in order to experience what $A w$ did to her during the night. She co-operated willingly by spreading her legs. Immediately afterwards she reacted and resisted her own cowardice by cutting $A w$ into pieces and roasting them over the fire. It dawned upon her that the consequence of her permissiveness would not bear good fruit. She thought to herself: why have I been afraid of the sun and his high demands? One of the twins she gave birth to immediately committed incest as if he wanted to demonstrate $A w$ 's inferiority. All those who were born of him would die. The sun confirmed this, saying, 'It is because she was afraid of me!'

Jaèndé told the story in all seriousness in the Jaqaj language. A literal word-for-word translation of his text is found in Appendix III. The text here is a rather free translation.

\section{b. Text}

"Bakui's mother was not married. She was single. She had no husband. She slept alone. One night $A w$ lay down on her breast. When she woke up, she wondered, 'Who has copulated with me? That mat is moist with the sperm of a man'. This went on and on. The sun laid his hot hand 
on her, but she turned away because she would not have anything to do with the sun. In former days he had lain with her, but his penis was too hot.

She pretended to be asleep, pulled up her mat and kept her eyes shut. She said to herself, 'I shall stay awake and watch; I am not going to sleep'. She had pushed aside the fire but piled up the firewood so that it gave a bright light. She held her arms in a sleeping position. From the earth $A w$ rose. Carefully, as if he was afraid, he covered the fire by spreading the wood. $A w$ saw to it that it got dark. She opened her legs wide. Cautiously $A w$ lay down on her breast and had intercourse with her. She pretended she was fast asleep. When $A w$ withdrew his penis, the mat became moist with sperm. When she seized $A w$ he broke to pieces. He broke in half. She roasted him over the fire. She said, 'Why was I afraid of the sun? Surely my children will die'. The sun spoke, 'Indeed, you shall all die'. The woman became pregnant and went to the bush. She moved to another district. Her belly swelled. She gave birth to a boy and a girl, twins. Later on the son had intercourse with his sister who was born at the same time.

The son to whom she gave birth was called Qajndaoqon. From $A w$ 's children many people were born in a short period of time. The sun raised his voice and said, 'You shall die. Children whom I begot will not die. You have been begotten by $A w$, therefore you shall die. He has begotten you, because she was afraid of me. That is the reason'."

\section{Ujndöm}

\section{a. Introduction}

The same Jaènde of Képi told in the Jaqaj language the story about the man, Ujndöm, who received a special kind of banana from a bird and then set out on a journey to find the country where there would be more of these (their country of origin). When he found it he returned and showed the fruit he had picked there to his fellow men. They accompanied him to that country. This country appeared to be the country of the children of the sun. Again it was Qajndaoqon who was the counterpart in the story. Qajndaoqon was the first child of $A w$. He literally missed the boat. Again the question of guilt was raised 'Why did we move to the forest? Why did we separate, why did we not stay with the others?' The grandmother put the blame on the others: they did not want to be ordinary people who die young. But everybody knew better. Qajndaoqon left the settlement and went to the dark forest. Finally the same voice was heard, 'Those people will be my people and 
I will watch over them'. Those who followed Ujndöm would reach what is maqati, permanent; they would live.

This story is also a myth about the moon. Ujndöm is given a ripe banana (the sickle of the moon, when it is in its first quarter) in his settlement, which is situated somewhere in the west (where the moon becomes visible). He sets out on a journey with the banana. During this journey the bird that had brought the banana perches on a coconut tree, which means that the moon reaches its highest position. Finally, one morning at the end of the journey, Uindöm arrives at the settlement in the east. When the moon is in its last quarter, it is visible in the east in the early morning till just after sunrise. Then the man starts on his return journey (when the nights are dark, he uses a torch) and arrives again at his own settlement in the west. When Ujndöm arrives the villagers shout for joy, just as people do today when the new-moon becomes visible for the first time.

Yet another idea runs through the story: that of the common origin of the white people and the Jaqaj. The Jaqaj called the whites: Tapaqmaq, children of the sun. They knew that white people lived longer than they did. Ujndöm pays with nails and hinges in this myth. These articles were not known before white people arrived.

\section{b. Text}

"The bird Anangk came flying with a ripe banana and put it down at the mooring-place. It was a splendid banana that he brought. Ujndöm's son ran to the spot where Anangk had put down the banana on the river bank. Then Uindöm ordered his son, 'Take the ripe banana'. He called the men. They launched the canoe. He boarded it with his wife and child. He departed. In the afternoon they halted where the river was wide and fastened the canoe with rattan. Anangk flew to a banana. The bird came back with it and put the banana in the canoe. The next morning Ujndöm untied the rattan and departed. The same happened day after day.

One evening, when they ran aground on the bank, Anangk flew away and perched on the top of a coconut tree. Then he came down again and picked a banana. He flew back and laid the fruit in the canoe. The next morning Uindöm tied up at the embankment. He tied the bird Anangk up with rattan lest it fly away. He wondered, 'Why don't any people come?' Children came down to the river to bathe; they were frightened and fled. They ran home; they let the water from their water tubes run out and said, 'An island has come floating down'. 
Their parents had gone to beat sago or to catch fish or they were out hunting. An old woman said, 'Grandchildren, go and have another look and ask him his name'. The little children went to the embankment. They asked, 'What is your name?' He did not tell his name immediately. Once more they asked, 'What is your name?' Then he told them his name and said, 'I am Ujndöm, I am your grandfather. Are your parents not at home?' The children said, 'Our parents went to pound sago or hunt'. Ujndöm said, 'Just mention my name'. They went off repeating the name Ujndöm, Ujndöm.

When they arrived at the settlement, they had forgotten the name Ujndöm. Their grandmother asked, 'What is his name?' The children scratched their heads. The woman said, 'Some of you must go back'. One of the taller boys ran to the embankment, his heart pounding for fear. He asked, 'What is your name?' Ujndöm said, 'I am Ujndöm; why do you ask so often?' The boy said to his grandmother, 'His name is Ujndöm'. The parents returned to sleep in the settlement. Ujndöm said, 'When they come home, tell them to come here to the embankment'.

They came home and came to the embankment at once. They asked, 'What is your name?' He said, 'Uindöm'. Women and men brought sago to Ujndöm. In exchange he gave them goods. The women brought fish, the men brought meat. They put them down on the embankment. Ujndöm gave them goods in exchange. Then he told them, 'I need bananas of the kind that the bird Anangk brought me'. All kinds of bananas were brought to the river bank, but he said, 'They are not the kind I am looking for'. Then they said, 'Show us the banana which Anangk brought you'. He turned round and looked for the banana, turned back again and showed it to them. 'This is the banana which Anangk brought. I came in order to get that kind'. The villagers said, 'This one is found here too. What will you give for it? If you want to have this banana, you must pay for it. This one is expensive'. They gave them to him and loaded his canoe with them. He paid for them by giving axes to the men, the women and the children. He gave them nails, adzes and hinges. The canoe was stacked high with bananas. He said, 'Tomorrow I depart. For these I came here'. Then Ujndöm said, 'These axes should be used to make canoes and cut down sago trees; these adzes to carve canoes. They are yours. Later on, the canoe will bring me back to you again'. He lifted the stone anchor and departed to his country.

He climbed up the mast and said, 'The canoe must send me in the 
direction of the sun'. He steered that course. He said, 'Where the sun sets, there is my settlement'. He lit a torch and fixed it to the mast. Then he fixed another one. Darkness closed in and he went to sleep. He spent the night on the water. The following morning he started again, spent the night on the water and sailed again ... etc. When he came close to the settlement, the villagers yelled for joy and shouted, 'Indeed, you have sailed to a distant country, you were on your way for many nights'. He sailed to the river bank, cast the anchor-stone and threw the rattan to the people. They tied the canoe to a tree and pulled it onto dry land. The villagers - men, women and children - brought the bananas to his house and piled them up. That is why they have such bananas there. They took the shoots to the settlement. He spoke, 'I shall distribute them myself'. Women, men and children shouted for joy. They got the good bananas. He said, 'Take the bananas, they are yours. I will also present them to other people'. He also exchanged bananas with other people. Ujndöm said, 'Elder brother, on the other side there are people, children of the sun'. They said to him, 'We would like to get into your canoe; we have already been together with the children of $A w$ '. His brother said, 'We die at an early age. Allow us to live with the children of the sun'. Ujndöm left his settlement. When he left, men, women and children climbed into his canoe. All who came along were carried to the other side where they disembarked together with the people of Ujndöm. At the mooring place of the deserted settlement they planted a piece of nibung bark [in token of their departure] .

Qajndaoqom returned from the forest where he had stayed for several days. The settlement was empty. They had planted the nibung bark. Qajndaoqom said, 'How is it that the people have moved?' He began to weep. Qajndaoqom said to his mother, his wife and children, 'Mother, children, the people have left the settlement. The settlement is empty'. Leaving the forest, they then came to the settlement itself. They said, 'Why did we move to the forest, father?' The grandmother reflected and said, 'It is because they did not want to stay with us, they moved for the sake of the children of the sun, they have gone with Ujndöm. We, the children of $A w$, shall die; they, the children of the sun, will not die. That is why they moved away. When their backs are bent with old age and their eyesight has become bad, they will die. We, children of $A w$, die young'. She said, 'Let us stay here'.

Then the sun visited the children of $A w$ and said, 'Thus you shall die. Stay in the settlement. You are different, you are $A w$ 's children. 
Those people will be my people. I myself will watch over my children',"

\section{Aqamé}

\section{a. Introduction}

There is a myth which sheds light upon a special function of the drum. It was told at Katan by Moté, Taqaqaé and Ngain in the Indonesian language. Aqamé was a name for the sun. Qajmé became the leader of other people who had died. Qarabanggé were the words the children sang as they played their "spirits-men-game".

\section{b. Text}

"Qajmé died and was laid in state in a canoe on trestles. Aqamé, his elder brother, beat the drum. Qajmé said, 'For whom do you weep?' Qajmé returned to the settlement and said, 'I am alive, for whom are you crying?' He gave potatoes, tuberous plants and bananas. He loaded food into a canoe, all kinds of food. He brought cucumbers, oara banggé, then he stepped into the canoe. Beating the drum he accompanied the dead. He left Wown. All the time he was beating the drum. He left the dog-women ${ }^{6}$ behind. He went past Japeqaro, Hamanggaer, Qoija, Remé, Gogojamön and Ima. He rowed across the sea and then came back. The people whom he accompanied, returned to Wown. The platform of the dead was pulled down." 


\section{CHAPTER XIV}

\section{LIFE OF MANKIND}

\section{Ajré \\ a. Introduction}

The story of Ajré describes a journey through the Jaqaj country (see Map 5). We see how Ajré did everything better than former occupants. This lengthy myth is given here in an abbreviated form with short explanations. It was told by Tambim, the old counsellor of Képi, in the Jaqaj language.

\section{b. Text}

"Ajré came rowing down the river Kawa (= Kao). He called to the people living on the Kawa and went on his way to the river Edera ... Joda ... Nambéōmön ... Mappi ... Toba ... Miwamön ... Dakémoqon ... Képi ... Rajöm ... Masin and from there back to Joda. Everywhere people asked him, 'Who are you?' He answered, 'I am Ajré. I have come because the people of my own settlement did not give me a woman'. He stayed at Joda for five days. Then he said, 'Friend, I shall go and get you a bag full of sago'. He came home when it was still daylight. His friend spoke, 'How is it possible that he should be back so soon?' And he said, 'Friend, did you fell a tree so quickly by using fire?' Ajré answered, 'Yes'. When he came home, his friend's daughter baked some sago."

Explanation: Apparently Ajré already had a stone axe but he did not show it to the others. The importance of the axe is stressed by telling that people, before they had axes, had to burn the trunk of the tree to get it down and finish the work on it. The story goes on to tell how Ajré constructed the first real house.

(Text) "Maggots crawled on the pigskin [of the roof]. Ajré said, 'Friend, that is too bad, that is humiliating, they may fall into the sago while it is being baked'. Ajré said, 'Friend, I want to cut wood for a house'. His friend asked, 'With what do you intend to cut it?' Ajré smiled. When he had put all the wood on a pile in the settlement, he placed the poles upright in the ground, laid the rafters, fixed the joints 
for the walls, fastened the rafters, left an opening for the doorway and set out in search of roofing. He 'sewed' the leaves of the roof while the men and women were looking on. He said, 'That is how you must make the roof'.

He said to the man, 'Friend, please sit down'. Then he 'sewed' the roof until he had finished it. Next he showed it to the women. He said, 'The other settlements may adopt my way of building and when they learn it from me, they will pull down their pigskin huts and cover their houses with leaves'. He said, 'I asked people in all kinds of settlements and I would have been quite willing to teach them how to build a house, but only you took pity on me and gave me a woman'.

Then he went to find wood to pile up over the fire ... and some bark for a sleeping place. The next day he went down the river and asked his friend, 'Which part of the river belongs to you, where do you always build your weir?' His friend answered, 'This is the place', and he showed him a place in the river where the bottom was sandy. He made a weir and fastened the traps. Ajré said, 'Now you go home. I am going to the source area near the upper course of the stream where it is very narrow'. Then he sat down. With a bamboo knife he cut open the skin of his hands, his feet and his body. First an axe fell from Ajrés anus into the water. It rolled in the water. He shouted lest the weir should be upset. There was foam on the water as he shook axes from his ribs, his back, his legs and hands. The axes all floated into the traps. Some drifted to the upper course but they came back down the stream. Ajré was standing on the bank. He felt pleased because the axes had left his body. The axes shook the weir when they floated into the traps together with the fish. He saw dirt coming to the surface and cried, 'Steady! Because they have given me a woman, I put a weir in my brother-in-law's ground'. They calmed down. He put on his decorations in the mooring-place where he was. He put the big shell round his waist. He placed the shell [cut into two curls] through the hole in his nasal septum. He fastened the skin of the cockatoo on his forehead. He put the band of human hair around his waist."

Explanation: Ajré gives birth to the axes. The first fell out from his anus. Among Jaqaj males the anus has special significances. ${ }^{1}$ The decoration he puts on pictures him as a man who is allowed to wear the belt of human hair around his waist, the mark of honour of a great headhunter.

(Text) "He returned home. His new relatives looked at him. The daughter said, 'Father, whence does this man come to us?' Her father 
said, 'This is your bridegroom'. He entered the house. The father said, 'Son-in-law, why have you put on your marks of honour?' He said, 'Because you are going to place your foot on them. The axes are there. I gave birth to them'. The father said, 'Son-in-law, let us first eat. We are eager to go to the weir'. He ate and drank and smoked. When they stood in the mooring-place the water churned out of fear for his relatives. He spoke, 'This is my father-in-law. He has just given me his daughter'. He said, 'Father-in-law, look how the water is churning'. The father of axes spoke, 'Axes, go upstream, my in-laws have come'. The axes moved quickly to the source area.

They got into a canoe and with a hook he pulled up the fish traps. When the sun was high in the sky, he went into the water and loaded the canoe with the axes, traps full of axes and fish which he piled up in the canoe. He collected the contents of all the traps; they gathered the axes and the fish in the mooring-place. There were plenty of them. They put the axes and the fish in separate bags and took them home. They put the fish over the fire to roast and the axes they placed above the fire where the firewood lay. They fetched wood to roast the fish and harden the axes. The next day the woman went with her husband to her family to tell what had happened. The man and the woman were in the settlement. They entered the men's house of her younger brother. Then the elder sister called, 'Brother, come, let us go, Ajré has come to us and I have given away my eldest daughter'. They asked, 'Where did that man come from?' She said, 'He came from the source area of the river Kawa. Today he has given us these axes, because I have given him my child'. The women and the men came to look and to cut wood with the axe. She praised Ajré, saying, 'My son-in-law is a good son'.

The next time she came back with her younger brothers. They arrived and entered the house. The good man, Ajré, was there and again and again they addressed him as 'brother-in-law'. Sitting in the house, they looked at the roof and those who lived with Ajré said, 'He showed us how to do it'. They also looked at the walls of leaves. He distributed fish for them to eat, saying, 'The fish on the fireplace is yours, so are the fish in the traps. I collected these fish for you, eat them'. They ate sago, drank water and smoked tobacco. Then they went to the weir in the river. They saw that the weir was underwater. While they were at the mooring-place, the axes were restless in the water. Ajré called to them, 'This is my wife's family; they have just given me a woman'. They shook the axes from the traps and loaded them into the canoes which were filled with many fish and axes. At the embarkation place 
the relatives took them out of the canoes and put them in their bags, one bag for the fish and one for the axes of jat stone, baqaraep stone and $u j$ stone, which is the best. They carried them into the house. The next day they returned home with the bags filled with the axes."

Explanation: The stone axe was the most important part of the payment made for a bride. Ajrés act of decorating himself is part of what the Jaqaj did on important occasions, e.g. before they stab somebody. Important things should not be done without ceremony. Here the birth of the stone axe is announced. The tension between bride-givers and bride-takers is reflected in the restlessness of the axes, a restlessness which reappears as soon as the brothers of the mother-in-law come to the weir. The "meeting" also reflects the actual life situation, "again and again they addressed him as brother-in-law". The stone axe is called $u j$ in the Jaqaj language, after 'the $u j$ stone, which is the best'. (Text) "He advised them, 'If at night you dream that the edge of your axe is broken, do not set out the next day, for you might break your axe. When your wife has just given birth to a child, do not take up your axe, for it might break. When you spend the night outside the settlement and you have eaten pork, first let the smell of the pork disappear. Do not go out, stay indoors. When you have killed a crocodile, do not go out, do not take your axe with you'.

He made a canoe for his wife's family. They pulled the log from the forest to the water and at the settlement they pulled it ashore. First he cut the bottom into the right shape and thickness. Then he finished the inside. The following day they finished the canoe and called out, 'Formerly we used rafts, we used vessels made of the bark of the sago tree or the bark of other trees. Now he has taught us something new'.

He said, 'Listen, all of you, people will die everywhere; place them in a canoe, make a hole in the bottom so that the fluid of the rotting flesh can flow away. Some you may bury in the ground. The bodies of those who have fought and of those who went head-hunting must be placed in canoes and you must hang the heads from the trestles on which you have laid them in state in their canoes'.

They agreed to set out on a head-hunting raid. First they celebrated the feast of the new canoe with the guests. They gathered meat, fish, coconuts and all the other requirements in the house. After they had formally rowed out, they smashed the coconuts and distributed the fish among the children. They started after raising their battle cry at the mooring-place. They reached the area of the people they wished to 
fight and hid in the swamp. They were standing in the canoes. Ajré spoke, 'Kneel down'. The next day those people were going to empty their traps. They attacked them and killed them. They loaded the new canoes with the heads and the bodies. Then they returned to the settlement, beating the sides of the canoes to announce their success and roaring with their battle cry. The women heard these sounds and began to dance on the embankment. They accompanied the men to the settlement. The men mentioned the name of those who had killed, 'He has killed and he has killed'. They walked in procession to the settlement and roasted the heads. Ajré said, 'When you attack people of a hostile settlement, always use the trick of placing your canoes undercover in the reeds of the swamp'. Then he spoke solemnly, 'Prepare a feast'. They prepared the feast. They collected sago grubs, they put pigs in the cages. They invited the guests to come to the feast which they celebrated in the old settlement for days on end. First there was the passing of armbands, then the fixing of the decorations to the bamboo knives and then they solemnly distributed the marks of honour, 'You may wear the belt of human hair round the waist, you may hang the decorated bamboo knife round your neck, you the decorated gourd, you the string of pig's teeth'. They started dancing.

Then they went outside and moistened the heads of the children with water, cut off some of their hair with the bamboo knife, and handed them the sago fibre decorations. The guests shot the pigs, some in the cages, others while they were walking about. He [Ajré] planted a tree, saying, 'Tie their legs to that tree'. They shot and killed many pigs. They laid the pigs on a platform. The fat was hung on threads for the female guests. The meat they distributed among their families and among the guests. On the point of their arrows they presented the fat to the female guests. The following morning the guests returned to their settlements. They picked sago grubs from the bark of sago trees that had been felled before, and they collected pork as a return present. In the songs they sang of their raid in the land of the enemies. When the people returned from the feast, they were attacked in turn on a retaliation raid. Such were the goings-on there. 'Make a feast like that'. Ajré settled near the upper course of the river and there he stayed."

\section{Ujnaki}

\section{a. Introduction}

The following story ends in a similar depiction of the origin of stone axes. Here the scene is on the Islands River among the tribe of the 
Tjitak. Ujnaki, whose name contains the word $u j$, stone axe, is given a widow as his wife. It is possible that the Jaqaj actually received the stone axe via this route. The Islands River is, like the river Kao, a mountain stream. The main parts of this myth, however, do not deal with these elements but discuss the relationship between man and woman. The story was told in the Jaqaj language by old Raramuj of the village of Moïn.

\section{b. Text}

"Ujnaki lived in the Kunda where he built his weir. Secretly others placed their fish traps there. He came to inspect his traps and saw that they were full of mud. Then he went to a place in the river where the bottom was sandy and where there were many weirs. Before he had left, he had smeared his daughter's back, arms, legs, belly, breasts and eyes with the crumbs of a sago crust. He braided sago fibres in her hair, and tied bands around her waist, arms and legs. He put sago flour in her hair.

The next morning he left with his daughter for Rajamön. He said, 'I am in search of a wife. I will give you my child in exchange for a woman'. The people of Rajamön said, 'Your daughter is nothing much, we will not give you a woman'. He went to all the settlements on the river Oba .... at last he came to Kogo on the river Miwamön. There he gave his daughter Kéaqab to Qaröm. The next morning Kéaqab baked sago for Qaröm. The next day they went in search of sago grubs. The women of his family said to Qaröm, 'The girl is nothing much and she is shabby. Why do you fondle her and why have you not attracted another woman? You will have to pick the sago grubs all by yourself'. They climbed into the canoe and departed. She was sitting in the canoe. She had brought with her a fibre skirt, an axe, a string of dog's teeth, cassowary pins and a parrot skin. Qaröm did not notice it. They moored and went to the sago groves of Qaröm and descended into the marsh.

Qaröm felled a tree. She took her axe and stripped the tree of its bark. Quickly she cut open a tree and then another. Qaröm cut open a tree deeper in the marsh. He said, 'Are you still here?' She said, 'Yes, I am here'. She worked on another tree. The sago crust fell from her head, her eyes and nose while she pounded away at the sago trunk with her axe. She called, 'Do not take any sago grubs from them'. He said, 'We have already got so many'. Qaröm raised his eyes, when in all her beauty the woman went up to him. Qaröm embraced her because she was so beautiful, as beautiful as the sun. While he collected sago grubs, 
she spread sago leaves on the path and strewed sago shoots on it. Then he had sexual intercourse with her. They got up and she took a new skirt from the leaf she had wrapped around it and put the skirt on together with a string of dog's teeth, the arm strings and the shell. The men and the women came to the mooring-place. Full of astonishment they said, 'Where does that woman come from? She is beautiful'. He said, 'The men did not want her'. The woman began to dance. Kéaqab was dancing. While she was dancing so beautifully, Qaröm too began to dance.

After the men returned from their singing and dancing, Qaröm began to speak about a head-hunting raid. The next day, they set out in their canoes to raid a settlement where they drove away the people from their village and killed them. Some did not get a chance to cut off the heads of the people that had been killed, but Qaröm did, he cut off five. The next day, they hung the heads on the arms of the women. Qaröm was the first to hang three heads on the arms of his new wife. Later on they set out on another raid. There the enemies killed Qaröm. Weeping, the men returned to their settlement and said, 'Kéaqab, they have killed your husband'. She went to the water's edge and threw herself into the water for sadness at the loss of her husband. Afterwards she stayed at home thinking continually of Qaröm.

Many months later Aqaékind took her as his wife. She who was as bright as a fire. Aqaékind went to find sago grubs for her. He said, 'Let us go and get sago grubs'. Kéaqab went with im. They went into the sago grove. Aqaékind said, 'Kéaqab, you must stay here on the edge, for you have only just cast off mourning'. Aqaékind collected the grubs from the bark and ate of them. He filled two small bags for Kéaqab. She cut sago ribs to make a new fibre skirt. She sat on a hill near the spot where they were looking for grubs. She watched Aqaékind eating sago grubs. She said to herself, 'How can you eat such a lot of grubs?' Aqaékind said to her, 'There are but few grubs, I could only fill two small bags for you'. Then Kéaqab threw her fibre skirt over her shoulder like a drooping tail and got up. She said, 'I am going to gather sago shoots'. She went up into a small tree while Aqaékind was collecting sago grubs. Aqaékind cried, 'Kéaqab, are you still there?' The gathering of sago shoots was nothing but an excuse. Aqaékind came towards her, 'Are you still there?' She called to him. He looked up and saw her sitting on a branch. He asked, 'Why are you sitting there?' She said, 'Because you kept on eating sago grubs. Look, I have put on my fibre skirt'. He took an axe and cut down the tree. She leapt to another 
tree. Aqaékind roared, 'What is the matter with you?' He felled that tree too. Kéaqab escaped and danced. When the sun was setting, she danced and kept on crying the word 'ikke, ikke'. Every time he cut down a tree, she leapt to another one. Evening fell. For a long time he stood on the spot where Kéaqab was sitting. When darkness fell he went home weeping aloud. He said, 'People, my wife has run away. She wished to leave me'. The people of the settlement said, 'How was that? Was it because you ate sago grubs?' Aqaékind lied, 'I did not eat any'. He felt very unhappy, because he desired so much to have a child. The following day Ujnaki departed saying, 'Qaröm they have killed and my child has gone. I had better go too'. He rowed away, he travelled upstream (... and reached the Tjitak people [on the Islands River]. He made a weir ... cut open his skin and released the fish and the axes from his body ... . etc. ...). He went into the water."

\section{Taémenu}

\section{a. Introduction}

This is the story of a woman who was after a great hunter. She eloped with him and married him. The Moïn version was told by Raramuj in the Jaqaj language. ${ }^{2}$

\section{b. Text}

"The intestines of pigs, cassowaries and other animals he threw away. They floated down the river under the water-plants. Time and time again they emerged on the undertow in the field of water-plants.

Taémenu spoke, 'What kind of man did that? Where does he stay?' She wanted to go to him, but the nipa palm prevented her. She would have gone right through the thick growth of the nipa palm on the river, but it was so dense that she could not get through. Taemenu, the mother, walked along the bank while her daughters beat the nipa with their clubs. All day long they rowed on and when it turned dark they slept on their way. They started early in the morning and rowed and rowed ... They rounded a bend and then they arrived at Tapari. They saw smoke and said, 'There they are, mother. It must be those who threw away the intestines'. They could smell the scent of meat. They heard a voice speaking. At midnight the voice stopped. She attached a drug to a piece of wood. The man went to sleep after he had smoked. His second wife lay at the farther end of the house and his first wife lay with him. He had two children. She came rowing towards him without speaking a word. They saw two canoes, one of the second wife, 
the other one was his own and first wife's. She said, 'Let me go out first, do not make any noise'. She went ashore and made for the settlement. She saw a lot of meat on the roasting platform. Using the drug, she cast a spell on the women and enchanted him too. She entered the house and touched his foot to see if he was fast asleep.Then she went to her daughters and said, ' $\mathrm{He}$ is fast asleep'. He lay with his head near the middle door. One daughter pushed her hand under him. The mother did the same and they carried him to the canoe.

They laid him in the canoe. They took with them his tobacco leaves, his roll of tobacco and his bow and laid them beside him in the canoe. They made a fire in the bow of the canoe and departed. The mother sat in the middle of the canoe, at the back was the elder daughter and in front the younger one. They rowed during the night and returned to where they had come from. At Uwa they loaded firewood. He slept on as if he were at home. She said, 'Off we go, off we go ...' At Tikömqaqaé he turned and stretched his arm. He struck the inside of the canoe with his arm and thought he had struck the wall of his house. He said, 'Wretched house'. He moved the other hand and dropped it. He opened his eyes. There were stars in the sky. His hands shifted and he opened the mat in which he lay and asked Taémenu, 'Who are you?' She said, 'I am Taémenu, I have carried you off in a canoe'. He looked at the woman, she was good-looking; he looked at the daughter, she was too good-looking. He looked around to see the elder one, she was also good-looking. She smiled at him. He said, 'My wives are not here, nor are my children'. They said, 'They stayed behind'. He fell silent. 'Is my pipe here?' She said, 'It is, also your bow'. ${ }^{3}$ The man was homesick and said, 'You did not take my wives and firstborn son'. They said, 'He slept with his mother, so he stayed behind'. Then Taémenu said, 'You had better get your wives out of your mind, do not think of them any more'. From there they set out for Joda. They spent the night and then continued on their way overland to her district. After that he had intercourse with the mother ${ }^{4}$ and also with the daughters. They reached Joda and stood close to the house. The men said, 'That is what you call finding a husband'. They went inside. The elder sister said, 'Younger brothers, I leave the decision to you, but he already had intercouse with me'. A younger brother said, 'Well, let him keep her. We are already married'. Taémenu and Toqomor stayed at Joda. Taémenu's family went home with the meat. He went hunting. His affines came. They killed pigs and cassowaries. They returned to their settlement with the game and distributed the meat in the settlement." 


\section{Jaqandi}

a. Introduction

At one time women were dogs. The men lived with them at Wown. They had children with these dog-women. Two men discovered real women in the settlement of Makédé. This settlement was not situated on the river; a path connected it with a place called Arum where the canoes lay. In this settlement of Makédé, real women lived with men who were pigs. Therefore the text comments on cleaning the genitals. The role of Joqown, the second man who appears beside Jaqandi, is less clear. After the first meeting with the women he disappears from the scene until the end of the story, when he leads the pig-husbands to the forest. When the pigs are killed he flees, but not before he says that whoever wishes to shoot a pig must first call upon him. This myth was told in Indonesian at Katan by three older men named Moté, Taqaqaé, and Ngaèn. A similar story was told by Qaqao, the old leader of the settlement Kamaqaé on the river Bapaé.

\section{b. Text}

"Jaqandi left Wown and sat in a banyan tree. He was shooting birds. His younger brother, Joqown, kept watch at the foot of the tree. Jaqandi shot very far. His arrow fell in a sago grove. He looked through the hole in a leaf pierced by the arrow and saw two women preparing sago flour. Jaqandi looked for his arrow. The younger of the two women wanted to go a little further on to get some more sago. She saw the arrow. She hid it in a leaf. Jaqandi asked, 'Elder sister, is my arrow here?' She said, 'It is here'. He asked, 'Really?' She said, 'Really'. The woman called, 'Joqown-oh, Jaqandi-oh'. Jaqandi said, 'How is it possible that they know our names?' The two men hid. They heard the breaking of the bark of a sago tree. Jaqandi saw the sago branch which the women were pounding. He stood at the end of it. The women embraced him. The elder one spoke, 'I am first'. The younger one said, 'I am first'. The elder one said, 'I am first'. Jaqandi took the older one first, cleaned her genitals and had intercourse with her. Then he did the same with the younger one. The women wrung out the sago, put it in a bag and took it home. They cleaned some sago leaves and used them to make walls until they had partitioned off part of the women's house as a room of their own.

They returned and made a covering of leaves for Jaqandi. When the sun set the three went to the settlement. On their way they heard a loud noise in the settlement. They laid Jaqandi down, wrapped him up in 
leaves, bound them together and thus carried him into the house and laid him against the wall. They fetched a bird from the forest and plucked it so that the other women could not notice the smell of the scorching feathers. During the night they unbound Jaqandi and roasted the bird. An old woman with a disfigured face smelled the bird and asked, 'What are you two roasting? Give me a piece'. She made the hole near the rattan a little larger and saw the bird. The two women were in a cheerful mood and laughed. The old woman informed the other women that she had seen Jaqandi, a long-haired man. At dawn, the two opened the door and Jaqandi stepped outside. The other women embraced him. There were so many women that he got warm. They asked him, 'Are there any more men among your people?' He answered, 'There are a great many'. Jaqandi told them to make arm-bands of palm fibres and skirts of sago leaves.

The two women appeared to be with child. The whole night long they had intercourse with him. The women made skirts and arm-bands and picked sago grubs. They piled them up high. They put everything in a bag. Jaqandi departed. The other women made a path from the settlement to the river, as far as Arum, the mooring-place. The children that Jaqandi had by the dog-women came to meet him at the mooringplace but he ordered them to go back to the settlement. He left the sago grubs in the canoe. He went to the settlement, carrying only his oar on his shoulder and entered the men's house. When it was dark, he ordered his men, 'Go, and fetch the arm-bands, the sago grubs and the decorated skirts'. He distributed the grubs among the men according to the contributions of the women. He showed the arm-bands and the men tried them on. When an arm-band fit the man said, 'I choose the woman who has made this one'. Thus they made their choices. Some men took care that the dogs [women] would not see them. The men pilfered the cockatoo feathers, the shells used for decoration, the axes and bows of their wives, and took them all to the men's house.

They prepared the canoes. The half-worn-out canoes they cut to pieces; they told the bigger boys to come to the men's house. The girls were dogs. The men waited till the women were asleep and then they got into the canoes. They said, 'Do not beat the sides of the canoes or else the children will begin to cry'. They asked Jaqandi, 'Have you chosen a beautiful woman for me?' Jaqandi went in front. When the men were in the middle of the stream the children began to ask for their fathers. They called, 'Father . . $\therefore$. They were not there. They went back to their mothers and said, 'Father is not there'. The mothers went 
to the men's house and saw it was closed. They cried, 'How late you sleep!' Then they saw that the house was empty. They began to shout and looked for the canoes. The smashed canoes had sunk. The dogwomen wanted to close off the river. They made the ground rise. That is the reason why there are islands in the river nowadays. The men arrived at Arum, the mooring-place. Jaqandi led the way to the settlement of Makédé. The men yelled. The women rushed outside. Everyone chose her husband, saying, 'I have made this arm-band!'

The dogs were drowned in the river near Wowm and stayed in the river forever. One man who had taken a dog as his wife had gone to Togom on the Poré. Jaqandi told the women to go to the river and clean their genitals. They returned and had intercourse. Joqown took the pigs with which the women had lived until that time and drove them to the forest. The pigs smelled the men's body odours. They began to scream and wanted to have intercourse with the women. All the men appeared in the doorways. Jaqandi shot the first arrow. They all followed his example. Those who were bad shots only chased the pigs away. Those who were good shots killed the pigs.

Joqown too fled. He said, 'Call upon me near the hedge in the sago wood with the words, "Joqown, do you stand in front and I behind you"?' The men got children at Uruwé and assembled at Taqamé. There Jaqandi scattered the people to the four winds of heaven, saying, 'Land, land of iron-wood, the current is strongest there'. From Taqamé they went and assembled on the hill Qajno."

\section{Jaboq and Timon}

\section{a. Introduction}

The woman Tanipqaqaé was married to Jaboq. He was too exacting and therefore she ran away to Timon. In the latter's settlement, Kaqajr, the two men fought over the woman. A wife need not put up with a husband who does not treat her well. If a woman appeals to another man for help, the latter will stand up for her. The appeal made to him demands this. And in this story the weaker party won even though he was standing alone. The story was told in Indonesian by the older men Moté, Taqaqaj and Ngaèn, inhabitants of Katan in the Nambéōmön district.

\section{b. Text}

"Jaboq married Tanipqaqaé. He caught fish at Epoqo. His wife's relatives gave him a bag and said, 'Fill it'. His own family gave him a bag 
and said, 'Fill it'. The woman Tanipqaqaé wore only a leaf while fishing. The leaf was bright red. A man, Timon, lusted after her. One day Jaboq said to his wife, 'Let us go and get sago grubs'. Timon was hiding in the foliage. His penis stirred and his lust resulted in a seminal discharge. He was sitting quite close to her. Jaboq had intercourse with her as many as five times. The woman said, 'You asked me for sago grubs but you only wanted intercourse with me. Now stop it'.

She went farther into the bush. Jaboq was collecting sago grubs. He pushed the digging-stick, okom, beneath the bark. As he did so he fell backwards among the thorns. He asked for the fishbone, kamaré, which his wife wore in her nose, to remove the thorns from his skin. $\mathrm{He}$ returned the kamare to her. The woman devised a trick. She said she was going to gather qaqaé leaves. She walked in a circle to see if Jaboq stayed where he was. He did. She climbed on a tree which had been cut down, put a shell on it and said, 'You are to answer for me if he calls'. She ran off.

The shell answered when he called. She fell into the grass, got up again, fell again, as many as five times, till she emerged from the tall grass on the plain. She stopped at Timon's place at Kaqajr. Timon's mother was plaiting fishing-nets. Tanipqaqae passed the spot where the women relieved themselves, and stood close to Timon's mother. The mother went into the house with her, shut the door and produced sago grubs. Timon returned with sago grubs. He ate one small bag on his way; another he brought with him to the men's house; a third he gave to his mother. She pointed to the woman and said, 'Here is a woman who has come to see you. She is looking for you'.

Jaboq walked behind. He wore Tanipqaqaé's skirt round his neck. His relatives at Kaqajr said, 'Look for her in the house'. Jaboq had smeared his body with ashes. He went to Timon's men in the men's house. They had their spears ready because Timon had already informed them. They first tried to outwit him, but then they admitted that Tanipqaqae was in the house of Timon's mother. Jaboq went to that house and asked, 'Is Tanipqaqaé here?' The mother looked outside and stepped forward. Jaboq called, 'Tanipqaqaé, come outside!' Tanipqaqaé came outside and spoke, 'Why have you deceived me? You said, "Let us go and get sago grubs" and when I came out of the grove you pressed me to have intercourse with you again and again. I do not want you any more'. Then she went into the house. Jaboq returned to his settlement and called together all the villages of the Jaqaj. All of them presented themselves. Early in the morning they were in Timon's 
settlement. They stood in a line with their spears in their hands. Timon's family stood with their arms crossed. Jaboq's relatives shot their arrows at Timon. They did not hit him. Then Timon's men retaliated and drove away Jaboq's men. Timon first killed five men from .... five from ... and five from ... His men killed five people from ... His party was the only one that was victorious, although it stood alone. The Timon people returned home, quite satisfied. This was the first fight."

\section{Janggeron and Daw}

a. Introduction

A Jaqaj settlement is situated on a river. Usually there is more than one place where the canoes can be pulled ashore, since each imu has its own mooring-place. Janggeron was able to submerge at one mooringplace and emerge again at the other end of the settlement at another mooring-place. He used this opportunity to get back home without his wife knowing it and eat his fill. The main lines of this myth are clear right from the beginning. A wife gets the better of a man who cheats her.

There are several details which are of interest. Janggeron is clearly pictured as a man who is neither bright nor talented; Daw, his wife, is depicted as energetic. Nevertheless she is sorry that she has to punish her husband. The relatives of Janggeron mourn his loss but in spite of everything are proud of the fact that his name will be mentioned in the formula which is spoken when a trap is lowered into the water. To others this formula is a joke, however, because according to Tambim it runs: "Daw, you made the trap becauce Janggeron ate your meat". The relatives killed Daw out of revenge. She retaliated by announcing that she would keep part of the fish for herself. She would live in the swamp. This explains why they cannot catch fish everyday. Janggeron also remained faithful to his character. He turned into a bird which hid in the forest "for fear they should see me", just as he hid underwater for fear Daw would see him. The story was told in the Jaqaj language by the old akiaq-radé of Képi, Tambim.

\section{b. Text}

"One day Janggeron went hunting. She, Daw, also went hunting. On their return they roasted the meat. Then they said, 'Let us have a bath'. At the mooring-place Janggeron said, 'Listen'. He counted off the days on his fingers. 'In five days I shall come to the surface again', and he 
added, 'I want to stay underwater for a long time'. Then he swam underwater and came to the surface at another mooring-place. He went into the settlement and searched the bags for meat. He ate the meat, the meat of pigs, cassowaries and cuscus. He did not touch the meat of the wallabies. Janggeron dove back into the water. He placed a stick in the water. He did exactly as he had told his wife, 'When the stick moves, I am coming to the surface'. He emerged. She had noticed, however, that the water [in the mooring-place close to the house] had been astir. When he emerged he said, 'I stayed underwater for a long time'. To his wife he said, 'My belly is a water belly. I am swollen'.

They went home. The bags had been left on the mat. She said, 'Who is always eating our meat?' The next day they hunted a cuscus. She pointed it out to Janggeron. She said, 'Shoot the cuscus'. Janggeron climbed up a tree with his bow. At the top of the tree he said, 'You lied, there is no cuscus'. Janggeron climbed down; he beat his wife. He said, 'The tree has chafed my chest'. She then climbed up the tree with the spear. She speared the cuscus and killed it. She took it home with her. The next day Janggeron stayed at home. She went out hunting with the dogs. They killed a pig for her. She made a fish trap. She finished the trap. She came home with the pig. He cut the pig to pieces.

The day after he said, 'Let us go and bathe in the river'. They went bathing. The next day she came and constructed a trap at the bottom of the river. Then he said, 'Come let us go and bathe in the river'. She dove first and came to the surface again near the mooring-place. Janggeron dove and remained underwater. She counted the days until he emerged again. He said, 'I want to stay underwater for a long time. When the stick in the water moves, I shall come up'. He dove. He moved underwater. He got caught in the trap. He roared. The woman looked up. The surface of the water was covered with foam. The water became muddy because he rolled over and over. She said, 'The trap has caught him. He is done for'. She stood waiting for a long time. She counted the days on her fingers. The tears were running down her cheeks. The water was churning because he rolled over and over. Then she went home to have a look at the meat. The meat was in the house. It lay there. She said, 'I knew it was he who ate the meat time and again'.

Then she went to the spot where she had laid the trap. She looked up. The trap came up to the surface. She untied the rattan and laid him [he had turned into a fish] in the mooring-place. She removed his scales and cut him into slices. Then she said, 'Children, the trap kept 
Janggeron a prisoner; I made it because he ate the meat, the meat I had put over the fire to roast for you, women. I was angry. Let us go now. Cut him to pieces'. They cut him to pieces. They all got their share. They started roasting the meat. They mixed the fat with the sago which they had baked in leaves. They ate. Janggeron's relatives wept. They said, 'Everywhere your name will be recorded. When people use a charm, they will use your name'.

While they were roasting the fish, Janggeron's soul fled from the flesh. He turned into a bird. The people killed Daw; they put her in the fire. Then she said, 'From now on I shall assert my rights over fish. I will stay in the swamp'. Janggeron said, 'For fear they should see me, I shall hide in the forest'."

\section{Joqoj}

\section{a. Introduction}

While a man is hunting the women often hear his dogs barking but are not able to see the place where he has gone ashore. Joqoj makes the most of such opportunities. Joqoj is the name of a large bird of prey. It is the symbol of a great head-hunter or leader. The crocodile is another symbol for such a person. The leaders are expected to stand up for their people. Inside their own group they should keep their hands off the "beautiful women" of others.

The myth also refers to the Rupe figure, the old snake-woman who sat on the hill Qajno when the sun shed its skin. Here, one should pay attention to the words spoken by the sun, "Let her live; do not kill her. You have done your duty". Rupé escaped death on the hill Qajno. The sun granted continuous life to her. The story was told in the Jaqaj language by Tambim of Képi.

\section{b. Text}

"The man Joqoj built a weir and placed his traps in it. He spoke, 'Everywhere on earth women and men pilfer fish. I shall see to it that I turn into a crocodile'. He said to his own people, 'I shall go hunting with the dogs'. He asked the women, 'Where are you going?' They said, 'We are going to fish together in your grounds'. He said, 'Do'. He told his dogs, 'You stay at the mooring-place'.

He grew a tail. His arms and legs got shorter. His head became the head of a crocodile. He left a lump of sago at the mooring-place. Then he stepped into the water. First he went for the little ducks. He swallowed a good many. Then he said, 'Things are all right'. He swam 
underwater towards the women who were fishing together, seized a beautiful woman and killed her. The women fled in panic and said, 'A woman disappeared in a whirlpool; we couldn't get her out'.

Joqoj went to the mooring-place. He laid the woman in front of the dogs. The women said, 'The dogs of that man over there are baying'. The women thought he had caught a pig but actually it was a woman. In the mooring-place he cut the woman to pieces and roasted her flesh on a platform. As the sun was setting, he came to the settlement with the meat. He put the meat in a bag, a large bag. He distributed the flesh of the woman among the men, who ate the meat. The women and the men asked, 'Where did your dogs kill the pig?' He said, 'They killed it on the other side of the swamp. You heard the dogs baying at the mooring-place'.

The next day they did not set out because of mourning. 'Let us stay in the settlement', they said. At dawn the next day, the women went fishing at an early hour. [Joqoj caught another woman ... and so on .... When the sun set he returned to the men's house. When darkness closed in he distributed the meat among the men and women. The long men's house was fully provided with meat; so was the house of the women. Joqoj said, 'Qajreqambu has not had any meat yet, I have overlooked her'. He brought her some meat and said, 'Here is some meat for you'. She did not eat the meat immediately because she had just had some fish.

The next day Qajreqambu had a good look at the meat and said, 'This meat is human flesh'. First she held it before her children, 'Look at it carefully, it is human flesh. It is evident that he killed the women'. Then she showed the meat at another house, 'Look at it carefully. This is human flesh'. They covered their mouths and said, 'It cannot be true, wait, how upset the men will be'. She went from one house to another, so that nobody could say they did not know about it. That is why she examined the meat with all the women. Then she showed the meat to her sons. All the men examined it and said, 'Be careful. He has killed the women. We have eaten a fellow-man. It was like pork, but actually it was human flesh'. They put their spears in readiness. They decorated themselves with cockatoo feathers. They told the women, 'Now you go fishing together'.

Joqoj said, 'I am off with the dogs'. Some men already had gone to the spot where he had killed the women and were waiting for him in ambush. The men watched him. His tail became visible. He turned into a crocodile. His legs became short. The men were sitting behind 
him when he spotted the women. Joqoj said to his dogs, 'You stay here at the mooring-place, I am going to kill a woman'. Somebody was the first to stab, then the others stabbed him saying, 'You have deceived us'. One leg began to recover. He screamed. The men said, 'You just let out the cries of a crocodile'. He roared. They killed him in silence. After they had killed him they put him down in the mooring-place and with an axe they broke the vertebrae of his neck. They shot the dogs. Next they went to his mother in the settlement. They arrived at her house. She had put her tail [as Rupé] in the ground. They went for her, wearing their marks of honour. She asked them, 'Grandchildren, why have you come?' They said, 'We have come without any reason'. They speared her to the ground. She crept into the earth. They thrust their spears and hit her. She fell to pieces because of the thrusts. The sun spoke, 'Let her live. Do not kill her. You have done your duty'. The sun threw down the real spear."

\section{Makubonök and Ndumènd \\ a. Introduction}

The separation of the sexes in houses for men and women makes possible the deceit practised by Makubonök. The story gives the origin of the formulas used near the pig fence and the pig trap. Ndumènd lived with a boar and was pregnant with pigs in her womb. When she was killed the pigs were born. She took all the credit for this herself: "I can be called like the pigs". What all this has to do with the singing of the morning bird, Qojöm, is merely guess-work. But when the morning bird starts singing, the people set out to see whether a pig has been caught in the trap. Ndumènd's son, Tépakud, took the credit for having killed his father - a pig - from behind a fence. People then had to call upon him. The change of the cries is an indication of a change of character. The myth was told in the Jaqaj language by the old leader Ikapé of the village of Toba.

\section{b. Text}

"During the night Makubonök made for the sago which Ndumènd had cut down and he ate it secretly. In the morning she saw that there was no sago left and said, 'Who has eaten my sago?' She cut down another tree. Again her husband went there during the night and ate the sago. When the morning bird, Qojöm, was singing, he returned home and slept wrapped in his mat. At dawn when she had brought sago from her house, Makubonök ate it and said, 'I have a toothache'. Because of 
his toothache he stayed in another men's house and slept. The sun rose and again darkness closed in. Again he went. He had laid a piece of wood in his mat, so they thought a man lay sleeping there.

The following morning Ndumènd went to her sago and shouted, 'Oh, my sago, my sago, all eaten. Many pigs must have done this'. She said, 'Maybe a man ate my sago, for there are no pigs here'. Makubonök turned into a pig every time. His tail of fibres became a real tail. Her sister-in-law said, 'Build a fence in the sago marsh'. Then she made a fence from which to shoot pigs. Ndumènd had a swollen belly. It was swollen because of the many children she bore. But her children were pigs: the ate pigs, the qojöm pigs, and the gamé pigs. Then Tépakud, the son of Makubonök, opened Makubonök's mat. He was not in it. 'For sure', he tought, 'it is Makubonök who eats Ndumènd's sago'. Then he went away. He listened attentively while he was in the sago marsh. 'Wèk, wèk', went the smacking of the one who was eating the sago. Cautiously Tépakud drew nearer. He laid an arrow on his bow, aimed from behind the fence, bent his bow, looked for a deadly spot in the pig and shot.

The pig let out cries like 'ajaha ... ajaha'. Tépakud said, 'Stop it. The cry is oèn, oèn, as a pig does it'. Not far from the spot Makubonök died. He did not escape.

Tépakud returned home. He looked at the mat. Makubonök was not in it. He said to his mother, 'Mother, it is a fact. He ate the sago. I shot him in the sago marsh. He is rotting. He is dead'. Tépakud's mother went to the men's house and inspected the mat. She spoke, 'My child has killed him indeed'. While she wept, she was beaten. She fled to the outskirts of the settlement. Her name is Qojöm. There on the edge of the settlement they killed her with a spear. Then pigs appeared from her belly. Qojöm ran roaring through the settlement. She cried, 'I can be called as you call a pig'. Then the leaders said, 'Let the people call upon your name, Qojöm, in their charms'. Tépakud spoke, 'Near the pig trap and the pig fence all the settlement shall call upon my name'." 


\section{CHAPTER XV}

\section{SPIRITS AND SHADES}

\section{Rakao}

\section{a. Introduction}

One form of dangerous power is personified in the ground spirit called jaqar in the Oba area and jaqanda in the Nambéomön-dialect. ${ }^{1}$ In this story a child falls victim to the influence of a jaqar and dies. The story was told in Indonesian by the oldest men of the village of Monana in the Nambéōmön district.

\section{b. Text}

"One day the people decided to have a fishing party together with two other settlements on the river Waman. They departed before dawn. Jagikin's child was left behind under the charge of an old woman. The child, however, ran away in search of his father and mother. The old woman had to take care of many children. Rakao, a jaqanda, appeared at daybreak. He came with his dogs. The child met the jaqanda who looked like his father. The jaqanda said, 'I am your father'. He entered a hole in the hills. The old woman thought the child had gone with his parents. The child was quite happy with the jaqanda. At sunset the people returned laden with fish. The father and mother were not concerned because they thought that the child was staying with the old woman. They even gave the old woman a bag filled with fish in return for her taking care of their child. The people of the three settlements came back. The old woman distributed the fish. She said, 'Didn't your child go with you? He is not here'. All the people of the three settlements began to look for him. They let the fish rot and were angry with the old woman. They searched until it was dark. The father returned to the Waman river. He was a seer and wanted to have a look over there. When it was dark Rakao drove the dogs away saying, 'Do not eat the child's food'. The father heard Rakao mention his child's name. He thought, 'The child is with him'. He saw the place. He went home to inform his wife.

The three settlements agreed to go to the place of the jaqanda the 
next morning. The women stayed at home. The men had their spears ready. Singing, they dug a hole in the ground. They saw the child, but the jaqanda drew him further back into the hole. They dug and caught hold of the child by its skin. The father asked the jaqanda to show the child's hand, but the hand was withdrawn. It was getting dark. The three settlements went home.

The next day, the father went alone to get his child back. He killed two pigs and said, 'I belong to your people. This is my land. Return the child'. He went back home without having achieved anything. The jaqanda came to get the pigs with his dogs. He carried the child in a bag right into the settlement. Towards evening the child entered his own house, 'Father, mother, here I am'. They wished to embrace the child but it was already dead. The bag turned into sand. They mourned for the child and constructed a platform for the dead."

\section{Awaq}

\section{a. Introduction}

The ground spirit, jaqar or jaqanda, adopts the shape of a pig and afterwards that of a cassowary. Its soul turns into a crocodile. The spirit is angry because $A w a q$ and his wife have had sexual intercourse in his presence. He kills $A w a q$ and carries the corpse to Awaq's wife. $\mathrm{He}$ returns to his own place and triumphantly blows the war trumpet. Then follows the reaction of Awaq's wife and her brother. They start a search and find the jaqanda. This jaqanda figure can also be compared with the Rupé figure. The snake is a symbol of threatening forces and the people try to destroy it, but they are not allowed to kill it. The jaqanda is also seen as a symbol of threatening forces which overstep their boundaries. In contrast to the former myth where the attempt to negotiate failed, we see here the real "Jaqaj" solution: "whenever possible, troublesome people should be disposed of". The story was told in the Indonesian language by a number of adult men of Monana.

\section{b. Text}

"Awaq used to stay at Mujaq. He went on a head-hunting expedition and came to Kabéröp via Moqondaqaw, where he left his canoe and crossed the plain on foot. He waded through the swamp and entered the forest where he inspected his fence to find out whether pigs had fed on his sago. He left his wife in a shed at Ebaqamund. When he went to look for the first time, the pigs had not eaten any of his sago. One jaqanda turned into a pig. He ate the sago. Awaq arrived. He had 
his bow and arrow ready. The jaqanda had also drawn his bow. When Awaq drew his bow he exposed himself. The jaqanda shot at Awaq and immediately killed him on the spot. His wife was waiting for him. The jaqanda cut Awaq to pieces. Awaq wore a band on his arm. The jaqanda cut some leaves and wrapped $A w a q$ 's arms and legs in them. Awaq's wife was still waiting. She wondered, 'Why doesn't my husband come back? Could something have happened?' Awaq's head rolled away. The jaqanda exhausted himself searching but could not find it. The jaqanda took the bag of meat to Awaq's wife. She mistook him for Awaq coming back with a pig he had killed. The jaqanda went back again to look for $A w a q$ 's head. The woman made a fire and inspected the bag containing the pig in the light of a torch. She opened the wrappings a little. She woke up the three children and said, 'Children, this is not a pig'. She recognized the band, 'This is your father'. The woman and her three children went to their canoe. The jaqanda sought and sought and finally found $A w a q$ 's head. He threw the head towards the shed and said, 'Why did you come?' [Awaq had had sexual intercourse with his wife in the grounds of the jaqanda.] He picked up the head and took it to the woman. He threw the head into the swamp. That is why there is mud there. He picked it up again and threw it towards the mooring-place. Again he picked it up and returned to his own place and blew the war trumpet.

Awaq's wife told her brother what had happened. He said, 'We shall find out who killed your husband'. The jaqanda had eaten Awaq. His belly was swollen. He had also eaten the bones and the fingers. $\mathrm{He}$ could hardly breathe. He heard fruit fall and went to look outside, stood upright and went in again to eat. This he repeated again and again. He took his dancing-spear and sang, 'Kopio has had intercourse in the shed. Awaq has had intercourse in the hut'. He looked round. They were drawing nearer. The fruit fell. The woman's brother felt weak as he praised the wife of $A w a q$. The brother gave the command, 'Let us keep our spears ready'. The jaqanda blew the war trumpet. When the woman and the brother heard it they said, 'There are the men who killed Awaq'. They came to the spot where the jaqanda was. They thought there were a great many men, because they had heard the cracking of bones. They searched everywhere in the vicinity and saw that the jaqanda was alone. The woman and the brother put herbs in their arm-bands to show that they had seen the enemy.

The brother ordered the people, 'Go and fetch wood to make spears'. They set to work on their spears and on the decorations of the big 
spear, qoqom. The brother who made the qoqom first went to shoot birds so as to decorate it while it was still covered with bark. They said, 'Let us wait no longer, otherwise he will move'. They put on their ornaments. The brother led the way. At the mooring-place they heard the war trumpet. They began to dance and turned their buttocks in the direction of the jaqanda. They took fire with them and branches of coconut trees to burn down his house. The woman said, 'Find out if he is alone or if there are many'. The brother checked the situation once more. He saw only the jaqanda with his swollen belly. He said, 'That is not a human being'. In the morning all of them hid lest he should disappear into the ground. The jaqanda blew the war trumpet. The brother was near the doorway. The jaqanda got up and took his dancing-spear. The man said, 'Hide well. He begins to look about'. The brother waited and then stabbed the jaqanda like a cassowary. All the people stabbed him. He vanished into the ground, the spears still in his body. The brother said, 'Bring fire. Burn down the house'. The jaqanda was burned in his own house. His belly made sounds. The men fled because they feared the smell of the jaqanda. The soul of the jaqanda followed the smoke which drifted with the wind towards the river Qabo. It turned into a man-eating crocodile. In the meantime Awaq's wife had been wearing mourning clothes. The men tore them off when they returned to the settlement."

\section{The jaqar}

\section{a. Introduction}

In Jaqaj culture the seer, the so-called joqbera-radé or joqbera-taw, is an important person. In this story a seer contacts a ground spirit, jaqar, who offers him some food. A "seer" like Oaqaj is not likely to make the mistake of eating such food. This story was told in Jaqaj by Tambim of Képi.

\section{b. Text}

"Oaqaj, a seer, saw a jaqar who just emerged from the ground. The jaqar had red eyes. His hand was red. His lips were red and the hair on his skin was long. The jaqar said to Oaqaj, 'Here is some sago. Eat it'. Oaqaj answered, 'I would rather not'. The jaqar gave Oaqaj a tuberous plant, ra-toqomi, and also the stump of some kind of banana tree which grows very tall. When such a tree bears fruit, it forms bunches carrying much fruit. They are very large because they are jaqar bananas. Oaqaj told Awenöm, 'Exchange brother-in-law, please plant 
that banana stump'. The stump grew. When it became big, it began to bear fruit. The bunches bent the tree with weight. They became larger and yellow while ripening. When they were ripe, Awenöm cut them off. The enormous bunches fell on Awenöm's body and he died."

\section{Mioqop}

\section{a. Introduction}

There is also a female ground spirit, the aburi (Oba district) or aburit (Nambéōmön district). An aburi always appears in a very innocent shape, but the person who is threatened can tell appearance from reality if he pays close attention. In this story the difference is indicated by the fact that human beings step over trees which lie across their path, whereas an aburi walks around them. I was not told why an aburi does so. The deception is exposed and the aburi is shot down. The woman responsible for this dangerous situation is stabbed in the thigh. The story was told in Jaqaj by the old akiaq-radé Raramuj of the village of Moïn.

\section{b. Text}

"When Mioqop was about to enter the forest, he asked his wife Qanék to come with him. She refused. Then he took his bow and left. When he was half-way across the plain an aburi came after him and said, 'Mioqop, I have come after all, I am Qanék'. They both came to a tree lying across the path. She walked around the fallen tree and did not step over it. Mioqop said to himself, 'This is an aburi'. He let her go ahead of him and shot the aburi, who fell. He hurried back home. He arrived at his wife's house and looked in. She was there. He stabbed Qanék in her thigh with his spear, because he thought it was all her fault."

\section{The aburit}

\section{a. Introduction}

The difficulties in this story started when a woman, after confinement, did not obey the rules of abstinence. The story was told in Indonesian by Javaqaem, the village head of Jatan (Rafadup) in the Nambéomön district.

\section{b. Text}

"A woman had recently given birth to a child. She ate neither meat nor fish. She only ate bamboo sprouts and nibung-palm shoots. When she 
began to regain her strength, her own family and her husband went fishing. An aburit joined them. She went off before the others to bring fish to the recovering mother. The other women were astonished because she brought her fish before the others returned. The mother had not quite regained her strength and the aburit noticed that the woman was eating only a little of the fish. The aburit gave the mother a fishingnet. She accepted it but thought that this woman was not a human being because she allowed fish to fall into the water beside her net. She fished with the other women till it was getting dark. The women returned to Rafadup. The mother had to relieve herself and said to the others who were walking in front, 'Wait for me'. The aburit said, 'I will wait'. The mother relieved herself. The aburit opened her fishingnet. When the woman caught up with her the aburit took a robeki, a splinter of a cassowary bone, and pierced the mother's lips with it, so that she could not call out. The aburit put her in the fishing-net and tied it up. She hung the net from her shoulder and took it in a canoe from Rafadup to Ngaorom and from there to Uwé.

Ipöp, a big lizard, lived there. Ipöp took sago and roasted it. He stripped the leaf covering from the sago. He massaged the mother's breasts and mixed the sago with her milk. He ate part of it and gave the other part to the aburit. Ipöp pretended to be sick. The next morning, the aburit went to pound sago and so she did everyday until there was enough sago in the house. The aburit wanted to invite other aburit women. She said to Ipöp, 'Tomorrow I shall go and invite other aburit women. You must take care of the woman'. Early in the morning she left. Ipöp got up and interrogated the naked woman who could not speak because of the splinter of a cassowary bone. Ipöp untied the rope from which the woman was hanging and opened the fishing-net. He pulled the splinter from her lips and asked, 'Where do you come from?' The mother answered, 'I am from Qajméa and Jaqanum'. These were the names of her father's sago grounds. Ipöp said, 'I shall see you home'.

$A b o ̈ b$, the small turtle, gave her a skirt and they went off. Ipöp saw a big tree of $b a q$ wood in the neighbourhood. There was a kidu, a fish in a human shape. Ipöp said, 'You must go into the little river and become a fish. Look at me. I will climb up the $b a q$ tree and turn into a lizard'. While climbing up the tree, she changed into a lizard, her long tail hanging down. The human shapes of the kidu and of Ipöp disappeared. She spoke, 'Mother, flee and return to Rafadup'. The mother returned to her settlement. 
The aburit came with her companions. They were singing and dancing to the beat of a drum. The aburit saw that Ipöp, Aböb and the $k i d u$ had vanished and that the woman was gone. She pursued the mother as far as Ngaorom, but had no canoe. The people of the settlement saw from afar that something was cleaving the water. It was the aburit swimming. Only the braver ones dared to remain in the settlement close to the new men's house. The aburit called, 'Wait for me!' All the side-doors of the men's house had been tied up. Near the frontand back-doors a man stood behind his shield. The aburit went ashore. She inspected the settlement. Apparently it was empty, but everybody was hiding beneath the house or in the banana bushes surrounding the settlement. The aburit entered the men's house. The men shut the two doors with their shield. They set fire to the building. The aburit ran up and down the house in despair. The fire did its work. The people fled. The aburit was burned and burst."

\section{Okomit}

a. Introduction

A man is saddled with a spirit's child. He hates it and burns the child. He flees in fear of the mother who wishes to take revenge. He is saved by the shade of his father. A father usually walks in front and the son follows behind. Here the shade demands that the son walk in front. A Jaqaj man wears a fibre tail which covers his anus. Apparently shades do not wear any tails. Any meeting with a shade can be fatal. The father chases away the shade. The Jatan version was told in Indonesian by Javaqaem, the village head of Jatan.

\section{b. Text}

"The people of Qoqojāmön have their sago groves at Depé. From there Okomit went to Qoqojāmön. He dug a well there and departed for Wakedo. There he built a weir in the river and then went off again, following the Qakédéaq. Coming out of the forest, he crossed the plain and arrived at Qajndakao on the upper course of the Jadomuku. He rowed to Ngèm, thence to Qaiberokamön. He built a bivouac and left his wife behind. He departed and reached Dapora. He left his canoe there and walked to Qoqorapé, Retaqapé, Baqajtapé, Ekeraja, Aïr, and Kaqapé. There he cut down a sago tree and built a fence so as to shoot pigs from behind it.

It was already getting dark when he heard somebody weeping in Jaq. It was a woman who had died in childbed after the afterbirth had 
come out. Her shade went to Okomit and stood near the sago fence watching him. When he returned, the shade was sitting in his hut. Okomit tried to flee but the shade said, 'I have already seen you. Do not run. Let us stay together'. Okomit scratched his head. He was about to flee, but he composed himself. They sat down together. The shade left her child with Okomit and said, 'I want to fetch palm shoots. You rock the child'. Okomit said, 'I have a wound in my leg'. Every day it was the same. Okomit was sad because of the wound in his foot and because he disliked taking care of the child. However, he could not put it in a qob basket because the shade, although she went out every day, did not bring with her that which was required to make a basket. One day Okomit said to the shade, 'Now go and look near the tall tree where the cockatoo lays its eggs. Bring the nibung shoots from there. Even though it is far away, I will hear you while you are there'.

Okomit took firewood, made a fire and laid the shade's child on it. When he had burned the child, Okomit fled into the sago groves. He built a hut there which he surrounded with thorny bushes. He jumped through them into the hut and made himself comfortable.

The shade returned with a lot of nibung shoots. She smelled the odour of the roasted child. She thought, 'That is my child. He has eaten it'. She dropped the nibung shoots and rushed into the hut and saw the burned child in the blazing fire. She called Okomit a filthy turd and many other names. She went to look for Okomit. She kept calling him a filthy turd, 'You with your wound on your arse'. She smelled Okomit's odour. He had scattered thorns on the road. The shade cried for pain. She pulled the thorns from her feet, calling Okomit names, 'Filthy turd! Why have you scattered thorns here?' She walked very slowly and cried out whenever she stepped on a thorn. The moon was full. Okomit saw the shade drawing near. He had a hook ready and pulled branches toward him. The leaves rustled. The shade fled but stepped on a thorn and pulled it out from her foot.

The moon was full. She then tried another way, but again Okomit played the same trick on her. Then the shade imitated the early morning bird, hoping that Okomit would come outside. Qapao, the shade of Okomit's father, visited him. He had been attracted by his body odour. Qapao asked the shade, 'Whom do you wish to kill?' She answered, 'Okomit'. Qapao said, 'That is my son'. He began to shoot at the shade and shot and shot. He drove her off as far as the tall tree. Only then did he stop. He returned to Okomit. Qapao asked, 'Who are you?' Okomit said, 'I am Okomit'. Qapao said, 'You are my child. Stay 
in your hut till it gets light. Okomit reflected, 'If only Qapao will not kill me'. Qapao said, 'Do not be afraid of me. I am your father. Come out!' They talked together. Okomit said, 'I have a wound on my foot'. Qapao spoke, 'Walk in front of me, and do not look at my buttocks, otherwise you will die. Walk in front of me to Endomangk, Japaqaremarep, and Kadöm'. At Ndunapé Qapao let Okomit go. 'Go back to your settlement. You will lose consciousness there. Take the plant rara and make a split in your tongue. Put the ashes of the plant on it and you will live'. This was the way it happened."

\section{The shades and the boys}

\section{a. Introduction}

This story deals with shades, i.e. the souls of the dead. They may show their power and injure man. They are punished for their misdoings, but not until they have passed on their special powers, waw, to man himself. This version of the myth was told by some men from the village of Monana on the river Bapaé; they told it in Indonesian.

\section{b. Text}

"A man had five sons. He went to Qajr, leaving his wife at home. He went to the mouth of the river Ranöm to make sago there. He built a fence there in order to shoot pigs. The pigs fed on the sago. Again and again he kept a sharp look-out at Budāpé. His five boys stayed in the hut whenever he set out in the evening. When darkness was closing in, shades of the dead came towards them. The sons tied the door with rattan. The shades used their waw so that the boys fell into a deep sleep. The boys were sleeping on top of each other. The eldest boy was on the bottom, then the second and so on. A female shade opened the door and entered. She moved the four younger ones to another place and carried the eldest outside in his mat. She checked to see if he slept soundly and then carried him to Oabob, where she left him. She threw a piece of wood into the water and saw that the water had risen during the night.

While the boy remained at $O a b o b$ she rowed down-stream when the water dropped, and upstream when the water rose. The boy awoke. His hand felt mud nearby; the shade was dancing passionately. He opened his eyes, sat up on the mat and said, 'Who brought me here?' He thought, 'A shade'. He cut off a nipa branch and hid it in the mat. He ran back towards his hut. When the boy covered half the distance the shade arrived at Oabob. She danced and then tied up the mat and 
lowered it into the water. The sharp nipa branch almost cut her neck. She thought, 'Where has that boy fled? There is only a nipa branch in the mat'. She left the mat and went after the boy. She used a charm, so that all the sticks on the ground became pointed.

The boy was already quite close to his hut. Because of her waw the house sank. The doorway was on a lower level. When the boy wanted to enter the house, a piece of wood hit his eye and pierced it. Then the house rose again and the boy was hanging from it. The shade was satisfied when she saw this. She said, 'He has lost'. She danced. The other boys were sleeping. She began to eat him. First one ear, then she danced. Then the other ear, and she danced again. Then she ate his penis and again she danced. Thus she ate his arms, legs and his liver between her dancing.

The father was on his way back by dawn. He picked up a short club because he thought that his dogs had eaten the bones. But the shade had. The moon was still full. The father hid behind a large tree. The shade appeared. The father kept his club ready. When she was about to eat, the father pierced her side. He thought he heard a human sound but it was the cry of a cassowary.

The father awakened the four boys and looked for the fifth but could not find him. He returned to Qajr. All the people were anxious to help him to kill the cassowary. When they arrived at the spot, the shade had already turned into thornless sago. The shade splashed drops of blood everywhere, saying, 'All people will have thornless sago'. The shade taught the people waw before the father stabbed her."

\section{Shades appearing as birds}

\section{a. Introduction}

In these two short stories the shades adopt the form of birds. Both stories were told in Indonesian by Qambu, an adult from the village of Jarmoqojn.

b. Text

(1) "There was a man who built a little hut in the swamp from which he shot birds that came to drink there. He shot many of them. He heard the birds talking, but they were not real birds. They were shades of the dead. When the man was asleep, there came two shades. The younger one said, 'Let us kill him'. The older one spoke, 'No, we shall throw him into the water and keep him under with a piece of wood'. So they did. Then the shades left and built a weir. Water got into the man's 
eyes, ears and nose. He thought, 'Who brought me here?' He jumped out of the water and fled. He said, 'Friends, never go shooting birds on the water'. He stayed in his house forever, even relieving himself there till he got old and died."

(2) "One day people went fishing with fish poison. They caught many fish. In the evening they all returned home, except one man who went looking for more fish. When it was almost dark, the shade of a dead man appeared. He threw a piece of wood at it and hit it the first time. He threw two and three times. After that he put the fish in his carrying-bag and walked off. He gathered all kinds of branches and crept into the hole of a tree. He closed the hole with the branches and lit a fire. Then the shade took a piece of hardwood to smash the branches, but it did not succeed. Then the shade changed into a bird and started singing. The shade thought that the man would come out of the hole, but the man said, 'You stay till tomorrow morning. Then we shall fight'.

At dawn the man came out of the hole with a sheaf of arrows and spoke, 'You walk in front of me, I shall follow'. At once the man began to shoot. He went on shooting till he was close to the settlement and there were no arrows left. Then he hit the shade in the head. It died and said, 'For the present enter your house. In a short time you will die'. The man died."

\section{Ujoqot}

\section{a. Introduction}

The text was related by a young man of the village of Wajru. He told the story in Indonesian.

b. Text

"A babaé from Emeté called Nadi left Qatiamön for the settlement Hammangan on the river Bapaé. He stayed there for three months. They were celebrating a head-hunting feast there. After the feast Nadi returned to Emeté. He brought meat from the feast which he carried in a bag hanging from his shoulder. On his way he stopped to collect sago grubs. He hung the bag on a tree together with a man's thigh, another gift of the hosts. While he was searching for sago grubs he heard the thigh fall from the tree because the string broke. He repaired the string and again hung up the thigh. He continued digging for grubs. Again the thigh fell. Now he took a rope made of bamboo, tied it to the thigh and hung it up again. But again the thigh fell. Then he took strong 
rattan. He hung up the thigh and quickly looked for more sago grubs. Then he took the bag and the thigh and carried them to the settlement. On his way the rattan snapped once more. He took more rattan and suspended the thigh from his shoulder. This was repeated till he reached his settlement Qatiamön.

On his arrival he noticed that the people of Emete had already moved to Kunda. An old woman had stayed behind in a high house. Nadi did not see her. He lit a fire in each fireplace and put down the human thigh in the men's house. After the night closed in, the shades drew near. Nadi divided the pork. Then, as if he answered himself, he said, 'I have already had my share'. The shades were outside and heard him. It was not dark for long when the shades drew nearer. While he was eating, they asked Nadi for part of the meat. Nadi picked up a piece of firewood and struck at them. The shades fled, shrieking like flying foxes. Nadi went back into the house. They approached him again, asking for meat. As he drove them away a second time the thigh turned into a shooting star, kando, called Ujoqot. In the course of the night the man had to drive the shades away so often that he ran out of firewood. Then he hid himself in a big carrying-bag. The shades came to look for him. Once more he drove them out of the house. Returning, he saw that the thigh had climbed to the top of the bamboo bushes and glistened like a spark. From the tree he saw a gleam like that of a lamp. Nadi climbed a coconut tree that had a lot of fruit. He hid there. He had taken the bag of meat up with him.

The shades looked everywhere. They smelled his odour on the trunk of the tree. One shade asked another, 'Who dares to climb it?' One said, 'I do'. He climbed it with his buttocks first and his head downwards. Nadi had a coconut ready. When the shade came near, he threw the coconut at him and the shade fell down. His companions thought it was Nadi who fell down. They beat him till he was dead. Then they looked closer and said, 'It is not Nadi, it is our friend'. They threw him away and he turned into a stone. Again and again other shades climbed the tree to catch Nadi, but every time Nadi threw a coconut till there was only one left. When one of the shades was already quite close to him, he got a brain-wave. He smeared his semen on the husk of the coconut and said, 'Coconut, you must help me and jump into the river in my stead'. When the coconut reached the ground, it leapt to the river. When they heard the water move, the shades rushed to the river. The coconut, however, had changed into a babae and went into the water. Meanwhile Nadi quickly climbed down and ran to the river. There he 
found a canoe. There were many fish traps in the canoe as well as an oar. He rowed as far as the bifurcation of the river Emeté. The thigh flew away like a shooting star and dropped close to him. Nadi pulled up a trap and Ujoqot crept into it. Then Nadi let the trap go. The shooting star remained in the trap. Nadi rowed on. A little later the shooting star flew away. Nadi pulled up another trap and the shooting star crept into it, etc. ..." 


\title{
PART V \\ OPINIONS AND ATTITUDES
}

\author{
CHAPTER XVI
}

POWER AND SPIRITS, BELIEFS AND PRACTICES

\section{Power and spirits}

Several times the terms rara and waw have been mentioned. Usually rara are leaves or herbs taken by men as drugs or attached to utensils in order to restore or heighten their forces. Rara is a medicine for men and their fishing-baskets, pig traps, weapons, drums or canoes. The Jaqaj were not sure of the effectiveness of these "tonics"; they said, "We just try; we hope it will be all right". In the case of waw, things are slightly different. Waw does not denote a typical force proper of certain things, but it is a high degree or intensity of a quality which raises its bearer above others of the same kind. Whereas rara was preferably attributed to inanimate things, waw was more often ascribed to living beings. The intention of a waw owner must be taken into account, whereas rara could be applied without further ado. People had to find the right way of approaching and dealing with waw, so that they could draw the greatest possible profit from it or defend themselves effectively against it. Waw called for more respect than rara, because it exercised a stronger influence for good or evil in life. In dealing with waw, a whole gamut of gestures, actions and words had evolved.

War-leaders, poqoj-wir; counsellors, akiaq-wir; and seers, joqberawir, possessed waw. The war-leaders gave orders, tumi képaq; the counsellors gave advice, tibu- or akéaq-tumi; and the seer had his maqaw-tumi, secret language and hidden names. Whenever these authorities spoke, the others listened tumi-ain-amön, without a word. 
The Jaqaj still honour the names of those persons they believe to have been the first to occupy the area which is now the property of their offspring. Their common name is babaé. Thus they mentioned for Képi Bakui, for Toba Oanamo, for Dagimon Tanipak, for Wajru Majtem, and for Mandaw Wajamémé. General terms to indicate these characters are "the old one", poqura, or "grandfather", api. Each of them had a secret name. Thus the secret name of the babaé of Kemaqaé is Taqamé. People believe that these babaé still live among them in the neighbourhood of the village or in a village well, babaé-pit. Oanamo was said to be present in a large stone.

Once I paid a visit to a babaé-pit at Enèm. Jabaqaj of Képi was my guide. In the water there were small pieces of wood, one of which had been smeared with white clay, a second one with red earth and a third with charcoal. ${ }^{1}$ The babaé appear to their descendants in all kinds of shapes, the more usual one being that of a little man, radé ndumaqaé. The village head of Dagimon, Jānda, told me how once a poqura had appeared to him on the plain of Dépé. The poqura had addressed him as foster father, natu, for Jānda happened to have a foster child that came from the area of this poqura and was looked upon as his child. In a way, both the poqura and Jannda were foster fathers of the child. The poqura asked Jānda if he had something edible with him. Jānda gave him a piece of meat. As he gave it, Jānda held his lower arm pressed against his upper arm, because this was the way something ought to be presented to a babaé. Only in this way can one feel whether or not the babaé pulls the arm towards him. The poqura then asked Jannda if he smelled something. Jānda replied, "I smell human blood". The poqura then answered that Jannda would hear more of it at the settlement of Jarmoqojn (the present Hāgam), where someone had been killed by a poqura. Afterwards he heard that a man from Moin living in that settlement had been killed by a crocodile. On the occasion of a feast in the settlement of Jarmoqojn, this man of Moïn had stolen a cassowary egg. The people of Jarmoqojn had warned him that their babaé would know where to find him.

The people of Kamaqaé said that their babae had the shape of a crocodile and lived in a pool near the settlement. He was looked after by a young woman of the settlement who was said to be a joqbera-taw, a seer. Whenever someone of the settlement shot a pig, she would roast part of it and put it in a piece of split wood near the pool, saying: "This is your share, aqandènd, and now I will leave". Their babaé could be sent by the village people to take revenge for some wrong they 
had suffered. When the babae returned, the people noted the smell of the water and thus knew that he was back again. The villagers then held a meeting near the house of the woman who took care of him. The babae related to the woman where he had been and showed her the arm of the victim as a piece of evidence of what he had done.

A babaé can also adopt the shape of a woman's husband. He will suddenly cross her path, but the woman knows that this man is not her husband because she is certain that her husband is elsewhere at the time. If such a woman then has sexual intercourse with this babaé, he will make himself known to her and the woman will die soon afterwards. Finally, the stories and myths tell how some babae changed into birds or into other animals.

Statements made about babaé are contradictory. Some claim that there are many babaé who differ from place to place, but who keep in contact with each other under the ground. Others claim that there is only one babáe who appears in various places. Drabbe defines the babaé in his vocabulary as "a kind of supreme being; lives in the abode of the dead; has made everything; is friendly; people do not fear him". Maturbongs reported that there are many ancestors but there is only one babaé who is called babaé-tapaq, babaé-sun. My own views are based on information given by Jaèndé. I once used Maturbongs' term babaé-tapaq, babaé-sun. Quite unexpectedly Jaèndé became terribly angry and shouted at me, "Babaé jaqajre, tapaq kandire", i.e. "babaé are human beings, the sun is something completely different".

The babae are considered to be relatives who were closely involved in the genesis of the land and the culture of the Jaqaj. They are benefactors and their names can be invoked by those who are using things these ancestors made or invented. They are invoked for daily needs and in cases of illness. They are offered presents. Maturbongs said that they not only supervised conjugal fidelity but also the observance of all regulations in the life of the Jaqaj. Because of this they were feared because they punished all transgressions. We shall see below that the babaé also functioned in some magical practices of the tribe.

Another category of spirits is that of the ground spirits, jaqar or moqon-maq, a child of the ground. Another name for jaqar is bana, a term which can be translated as "spirit". Like the babaé and the sun, the jaqar can be addressed as grandfather, api. A jaqar resides at the source area of a river, where he pushes the water out of the ground. A jaqar will attack anybody who violates his territory. He takes revenge on men and women who have sexual intercourse there. After drinking 
water from his river, they will discharge blood and eventually die. People who gather food too often at the same place may be shot with an arrow by a jaqar. This will cause them to get ulcers. The jaqar also revenges any theft or act of adultery committed in his territory. A jaqar usually appears in the shape of a very large cassowary, but occasionally in that of a crocodile or a pig.

Nejaqaé of Mandaw told me, "Qadaq of Képi once stood behind his fence, intent on shooting a pig. The pig, however, said, 'Do not shoot', and suddenly Qadaq saw that it was a jaqar. The jaqar was enveloped in a bright light and threatened Qadaq. When Qadaq ran back to Képi, he felt like he had been hit in the thigh by a sharp piece of wood. The jaqar then said, 'Let Jara open the wound. You will return here and you will have to stay with me here on this spot. If you stay in your own settlement, you will die. You will recover after two months. I will give you a medicine. You are not allowed to light fire, not even when it is dark. When it is dark you must set out hunting and in one night you will shoot five pigs or cassowaries'." A jaqar, like a babaé, can appear to a woman in the shape of her husband and then force himself upon her. If she does not recognize him as a jaqar she will die, though it is said that a woman may be impregnated by a jaqar.

In the Nambéōmön district a jaqar was given meat that was put in a forked post. In the Oba district people said that they tied pieces of straw to the platform where they roasted their meat and thus prevented the jaqar from stealing any of it. They added, however, that they also used to give something to a jaqar whenever the little bird, kopio, brought the early morning message to them that a pig had been caught in a trap.

An aburi (in the Nambéōmön called aburit) is a female being. Sometimes she was reported to be the wife of a jaqar, but others said that she was the shade of a woman who had died in childbirth. In order to fill the children with respect for the shields they also called a shield an aburi. These aburi would punish a husband who ill-treated his wife. The aburi adopted the shape of one of the man's wives and crossed his path. Jaèndé said that his own father, Kamborö, died after meeting such an aburi. He told the following story about his father's death.

"From Képi the people moved back to the source area of the Nanggéao and settled on the hill Dawmaqon. One day Kamborö shot a cassowary which was eating fruit. Then he went to check his fish traps. $\mathrm{He}$ ordered his wives to come along with him, but they refused. Then he got up and said, 'You had better go home then!' He beat his wife, 
Ebé, and threw a piece of wood at Atuain but he missed. He went after her, wading through the water. She fled into the house. He said, 'I will row to my fish traps with Qateraqap. You others must go home'. But Qateraqap too turned back and went home. Then Qaqamön, an eldery man, said, 'Why do you want to go and check your fish traps? You had better go home'. He rowed all by himself to his fish traps. He went to Wakimoqon and checked his traps. He removed the fish and returned home. Then the aburi, who came from Wakimoqon, struck him. He rowed down the river on his way home. When he arrived he said, 'Light a fire for me'. Then he asked, 'The persons I met at Wakimoqon, was it you?' They answered, 'No, it was not us, we stayed at home because you beat us'. Then he lovingly looked at his child Jaèndé and said, 'It was your wish to grow up in your father's house, but nothing will come of it'. The people then returned to Képi. He said, 'I am ill, I cannot see anymore'. The next day he died at Képi."

Jaèndé also said that when a man was alone in the bush and his wife - after he had treated her badly - came after him, he should take a good look at her and see whether or not the woman stepped across a tree or walked around it. In the latter case it was not his own wife, but an aburi. He then had to shoot the woman.

On my journeys I sometimes saw a path which was closed off with two crossing branches. The bearers said that the road was closed because the decaying corpse of an aburi lay there. Once I heard that there were women who were able to conjure up aburi and then order them to carry somebody off. They mentioned the name of one woman in particular (she was from Moïn) whom they called an aburi-wawqambu, a woman who has the power of an aburi. An aburi can also cross the path of women and punish them if they break the food taboos.

The treatment given to aburi, jaqar and shades (cf. below) was different from that enjoyed by the babaé. The babaé were honoured (they wore marks of honour and were invoked), but jaqar, shades and aburi were fought against and sometimes killed. The Jaqaj, however, agreed that the jaqar and aburi wanted to have their share of the food available in the area.

The qoqo is a heap af leaves, branches, bones and feathers inside a space staked off with three sticks. These small enclosures are found outside the settlement near the sago grounds. The pile is a collection of what may be called hunting trophies because the men on their way home from hunting drop some relics here from the place where they hunted or from the game which they shot. The qoqo punished any- 
body who stole something from the sago groves, especially if he cut off and stole the top of a sago tree in bloom. This qoqo also punished people who gathered coconuts from trees marked with the taboo sign of the mourning period.

The boqonomodöm was the piece of a tree trunk that was so hard that it took many years before it decayed. Such pieces of wood were found near the sago grounds. Jabajmu of Képi told the following story about them. "Whenever children go to the bush, we tell them, 'You must not beat on the boqonomodöm, or else you will die. Once long ago, Okāt, the little son of Inemon, beat on a boqonomodöm and he died. If you see a boqonomodöm, walk on the edge of the path, do not come close to it'." This boqonomodöm gets up at night and adopts the shape of a human being. In daylight it turns again into a piece of wood.

The spirits, bana, of the deceased are called idöm when they are derived from people who died a natural death and toqojia when the people died by violence. These shades have been discussed often in this book. They were said to be avengers and/or benefactors. Therefore they were honoured as well as feared.

\section{Beliefs and practices}

The various data about power and spirits are summarized in the following discussion about the universe of the Jaqaj and their ways of availing themselves of opportunities and steering clear of calamities.

The Jaqaj express their idea of their universe by the term témémoqon, which can be translated as "sky-earth". When this term is used as the subject of a verb, the verb is in the singular. ${ }^{2}$ They never raised questions about its origin. This indifference is surprising, since they asked questions about the origin of the moon, the stars, the animals and man himself.

The two loftiest beings in this universe are the sun and the moon; both of them are married. When mentioned together as tapaq-kamo, sun-moon, they are depicted as older and younger brother, as exchange partners, as friends and antagonists. The sun is older and stronger than the moon. The sun is called a moké poqojerèp, a "big soul", and the moon is said to be a moké arépaqatoqomb, a "fake big soul". They said that the sun had a mark of honour but that the moon wore one which he had counterfeited. The sun has all the really good things, while the properties of the moon are mere sham. The sun is called maqati, permanent. The moon is different. Although outwardly the 
moon is also impressive, it is obvious that there is something wrong with him. He has his phases and at regular times he disappears and reappears. This process is compared to the menstruation of women. "It seems as if you die, then the women have their monthly periods". People spoke of the new moon, kamo noqoké; the full moon, kamo képaqojn; and the crescent of the moon, kamo-oana. This word oana is the same term as the one used for the tusk of a boar, batik-oana, and recurs in the term for the highest mark of honour, the oana, given to warriors at the end of their careers. The sun and moon point out their respective tasks to each other: the sun is for the day time, ata-èr; the moon is for the night, rira-èr. Solar and lunar eclipses were interpreted as "turning away from mankind". They said that somewhere a settlement had been massacred or a beautiful child, a kamo-maq or moon child, had been killed. When the eclipse of the moon was complete, they put a piece of wagéi bark in their mouths, chewed it and spat the sap in the direction of the moon. During a solar eclipse, white dogs and white pigs were killed and light-skinned people were requested to stay outside.

Stars, mint, are significant only if they are shooting stars, kando, which is also the name of a little bird. Both birds and stars are associated with the "souls" of people "flying away". A seer was called in to explain whose soul had flown away.

Lightning is caused by a group of sky men, peindöd. They have long tails and are red-skinned; their voices are high. When they fell a tree or rip up someone's land they are fetching the soul of the tree or that of the landowner. As for rain, the Jaqaj pretended that it could be chased away by passing their hands under their armpits and afterwards blowing over them in the direction where they wanted the rain to go; that settlement was then mentioned by name. Whenever there was a rainbow, the little children were sent inside. Winds are connected with the seasons: the southeasterly wind, béréka, blows in the dry season, $k a ̈ m$, and the northwesterly wind, taqaé, in the wet season, aqapu. Each season has its own illnessess. Käm-aqapu means a year.

The "double-poled unity" that the Jaqaj attributed to the phenomena of the sky, they also ascribed to things on earth. The earth is a unit of land and sea, moqon-qamaqaw. Mythical beings originated in the sea and disappeared into it. Their land to which their ancestor Ajré came, descending from the river Kao, was already inhabited by another people at the time. The contrast between swamps and forests appealed to the Jaqaj; they distinguished qobu-wir, people of the forests, from 
janiti-wir, people of the swamps. The Jaqaj are aware of the fact that parts of their country are extremely beautiful. Older men, however, were more interested in the places where they won or lost battles.

Plants are important as food, oa, and as medicines, rara. Food is usually mentioned in paired terms, thus: nèpèr-pajo, banana-coconut; baj-toqomi, sago-tubers; jangk-janggo, fish-meat. Sago is the staple food; the sago tree is essential for nourishment, clothing and housing. This explains the strong emotional attachment of the Jaqaj to the sago palm. Thus the true woman was discovered in a sago marsh; the presentation of sago is a token of marriage; and sexual intercourse takes place at the edge of the sago grove. An altruist is distinguished from an egoist by his willingness to share sago grubs. The song about the capricorn "penetrating to lay its eggs" in the sago tree uses the same term as that used to denote sexual intercourse. The junction of two sago leaves in the sago gutter is the symbol for a good exchange marriage. Destroying a man's rinsing gutter evokes the fear that the children of the owner will die soon; therefore it means a casus belli.

Gathering sago can be performed individually but women prefer to do it communally. When fishing together women do not divide their catch afterwards; the yield of pounded sago, however, is always divided among the participants. Sago was also presented to the dead in baked form by hanging it from the platform or near the grave of a relative.

Sago was sown by the sun and by Mato and spread all over the region by Météoqon and Tamaq. Its protection was entrusted not only to man but also to animals, to the qoqo and the boqonomodöm.

When we consider its importance both in life and in myth, it is surprising that the Jaqaj do not plant sago or take better care of the existing groves. Little was done to stimulate the fertility of their sago. Only once I heard of a man from Képi who tried to improve his sago compound. This man, called Mari, took a bag filled with earth from the river Gondu and spread it in his sago marshes so as to promote the growth of his sago trees. A man who cuts down a sago tree may say, "Red earth, give me sago". 3 After making a hole in the bark, he may rub small pieces of borok fruit into it to express his hope that the tree will yield much sago. These practices, however, were not always followed by everyone and were not considered really necessary. They said that the soul, moké, moved from the tree that was cut down into another tree; the sago looked after itself.

The planting of banana shoots is done by women. They invoke the names of the mythical beings Kapaqajt and his wife Méwa, who planted 
a banana shoot which, in the course of one night, grew and bore fruit. They say, "Kapaqajt, you have planted a banana bush with a thick stem" 4 and turning to the shoot, "Bring fruits here and do not die". With other garden products they invoke the name of Méwa, because Kapaqajt took the seeds from "the inside of her thighs".

According to Maqaomi of Képi the planting of a coconut required that a hole be dug in the evening and a namo leaf be put in it. Early the next morning the coconut must first be raised towards the sun with the words, "Grandfather, I want to plant this coconut so that it may grow quickly and start bearing fruit when it is still small". 5 When they wished the tree to grow quickly and to bear fruit as soon as the tree had reached a man's height, the man approached the hole walking backwards and planted the coconut from behind his back.

Coconuts were of great significance in the rites performed in connection with Jaqaj festivities. When a canoe made its maiden voyage the leader crushed a coconut. Shortly before they set out on a raid, the men piled up a number of coconuts on the ground and the leader took a human skull, placed it on top of the coconuts and said, "Coconuts are not real [heads], we will set out". After the raid, the relatives ate the coconuts which hung from the platforms of their deceased and collected the coconuts that had fallen from the trees belonging to them. These coconuts were given in payment to the head-hunter who cut off the signs of mourning. During the wedding-feast a coconut was cut to pieces over the heads of the wedding couple immediately after the bridegroom hung a freshly captured head on the arm of his bride. Both groom and bride ate from the broken coconut. During the children's hair feast ceremony coconut milk was used to moisten their hair before it was cut off.

Obviously the Jaqaj saw a close similarity between the coconut and the human head. The story which says that the coconut originated from a human skull points in that direction. Because of this likeness the coconut was also related to the captured head of an enemy. The canoe feast and the mock raid mentioned above also refer to this association.

The question arises as to whether there is any connection between the fertility of the coconut and the dead. Coconuts which were hung from the platforms of the dead usually sprouted well before the final mortuary rites. The sprouting of the coconuts, however, did not get much attention; the emphasis was laid on the resemblance between the coconuts and the mourners rather than on the power of the deceased. The coconuts were prohibited during the time of mourning and thus 
they could sprout into new life. Similarly, there was a prohibition on the relatives. They retired from public life and finally awoke to a new life. To a widow they said, "Now you need no longer remember the dead, now you are free and you may start looking for a new husband".

The pig and the cassowary are also seen as a twin unit: batik-kujo. It has already been mentioned that the tusks of a boar were used for the oana. It is important to remember that the ancestor Taémenu was said to have given birth to pigs. Also according to the story of Jaqandi, in former times men were pigs and women dogs. Raising a pig established a special bond between the woman and her animal.

The cassowary is the only other big animal in the area. Its impressive appearance provides a good shape in which a ground spirit, jaqar, can cross the path of a man. The cassowary, however, is also said to be a coward. This may be the reason why the Jaqaj said of the enemies that had been killed, "There are some cassowaries lying there. You had better bring them here". They also used the expression, "We are going to hunt cassowaries", when they meant "We are going head-hunting".

Among the other animals some birds occupy important places, namely the above-mentioned morning bird, Qojöm; the birds of prey, Qanaqaé and Joqoj, whose names are used as names of honour of great leaders; and birds as transmitters of souls and messages. All of them represent power or spirits.

The opposite of meat is fish. The most powerful of them is the crocodile, often mentioned in relation to the ancestors, babaé. Fish originated from the chips of wood which fell into the water when Baqaröm hewed his canoe. Another version says that fish came from the body of Ujnaki together with the axes. There is still another version which says that Taémenu gave birth to the fish. Météoqom was responsible for spreading the fish. The fish sowed the water plants. The Jaqaj noticed that among fish some are leaders which swim at the head of large shoals.

Catching fish is not merely a matter of technique. Women use rori leaves in their baskets and men attach onöngkab leaves to their traps. Moreover, they also appeal to the sun, the ancestors and the spirits, addressing them by the term api, grandfather. One morning the village head of Dagimon, Jānda, invited me to come along with him to check his fish traps. When we left the village Jānda said that in former days everybody said aloud the name of his group when he left the settlement. Thus he would have shouted the name of the Kamokopimu-qambi, for he was Kamokopimu. We followed a sunlit lane, méta, through the 
rushes. Jannda stood in the bow of the canoe with a fishing-spear in his hand. Suddenly I heard him say, "Grandfather, give me some fish". 6 I asked him to whom he was speaking. He looked up at the sun and said, "There. He hears me speak". ${ }^{7}$ A little further on there was a knot in the rushes. Here he had tied up the rushes after placing his traps. He brought the end of the fish trap to the surface, opened it and pulled out a fish. He said, "Grandfather has given". He tied up the rattan again and lowered the trap into the water, raised it again and repeated this action twice and said, "Grandfather, you must send fish into my traps, out of love for your grandchild", 8 and after the third time he added, "Danggi, now you must come here. Leave the other grounds where there are many fish. Kidu and tauwi, here is your way". ${ }^{9}$ Jānda said that Danggi was a maqaé radé, literally "a man of the past"; his wife was Topum, who had made fish. Rowing on, Jānda caught some more fish but several traps were empty. On our way back he said, "Grandfather, there is no fish, I am displeased with you". ${ }^{10} \mathrm{He}$ told me that when rowing back fishermen should leave the swamp with a song, éb. In this éb the song name of the swamp is mentioned.

When the swamps begin to dry up, fish poison is spread in the little creeks. Towards evening people usually have caught lots of drugged fish. When they have eaten their fill, they start singing and dancing. Later that same night, when the leader gives a sign, the men go out with burning pieces of wood in their hands. They go to the little rivers and throw the pieces of wood in a large curve through the air, so that a shower of sparks falls down. The fireworks keep the fish drugged during the night. They remain floating on the surface so that they can be collected the next morning. Once, when in the course of such a collective fishing-party too many fishes died, Jaèndé called upon the sun for help because he thought that the situation had become rather dangerous. He asked the sun to set everything all right again. He said, "You set everything all right. [Fish] do not lie with your bellies upwards, lie with your bellies down and sleep".11

The above are the most important plants and animals. I would like to add a few general remarks. Among the plants, only the sago tree is said to have a soul, moké. An animal also has a soul but this soul is a more potent vital element than that of the sago tree. It may have intentions of its own and can interfere with other beings. The animals divide among themselves any work that has to be done (cf. what was said in Chapter XIII concerning the frogs and the snakes, the fish and the water-plants, the birds and the transmission of messages). Often they 
are at the call of the ancestors (cf. Tomönringgaqaé and the snakes). The stories also demonstrate that a man can change into an animal and that animals can turn into human beings. Those who are going to make such a change begin by imitating the sound of the animal which they will turn into.

The Jaqaj were not allowed to eat both fish and meat on the same day. The smell of the blood of the meat might chase away the fish. Fish are also chased away by menstrual blood. It is equally possible that fish flee when a little boy is wearing the dagger of an adult. The Jaqaj believe that the violation of existing rules always has a repercussion on the catching of fish.

Tools must also be discussed with regard to power and spirits. The babaé Ajré created the stone axe in his body and his instructions made mention of dreams. For men the bow is next in importance. A good bow made by father and son needs the application of rara or an aproach to a bana. Nejaqaé of Mandaw said, "For a bow bamboo or nibung-palm wood is used. After a first rough carving the bow is wrapped in grass and kept under the leaf roof of the men's house. The bow may not be exposed to any light for a certain period".

Eventually the partly finished bow is taken outside again and rubbed with a rori leaf, the leaf of a plant grown by the carver himself. It is the same leaf as the one he smokes whenever he is sick. While he rubs the bow with this leaf he says, "This is the leaf of the rori. Do not miss in shooting. Go straight for the animal. You must hit it well." ${ }^{12}$ During this rubbing process the carver sits on a tree stump holding the bow upright between his knees. Then the bow is polished with the leaf of the ramaqadip tree with the words, "The bow must be heavy. It must be really good for shooting, so that I will not miss my prey". ${ }^{13}$ Then the bow is rubbed again, now with the leaf of the monombak plant, the carver using the same formula over and over. Finally the point of the new bow is dipped in the bleeding wound of a pig shot with an arrow. A piece of meat is stuck to the point with the words, "Meat attaching to this bow, you should not miss ... on the contrary, you must hit the animal."14 Significantly the carver added, "Kugu diqajarép-amön" which is roughly translated as, "I hope it will be good". When I asked the carvers how the leaves could actually influence the bow, they replied, "The leaves are not the point, but they do give strength to the bow so that it has power over the pigs. Pigs like to eat leaves because they grow fat on them". When this medicinal process was complete, a cassowary toe-nail was tied to the upper end of the bow. This nail, 
kiaq, tapped against the bow while the hunter walked along. The sound of the tapping kept spirits at a distance.

A man and his bow were inseparable. Taémenu, who carried off a man when he was asleep, offered him his bow and arrows as soon as he regained consciousness in her canoe. Néjaqaé said that a Jaqaj man regarded his bow as a spirit, bana-apinden, or as a human being. He said, "At home a bow is nothing but a bow. But take it into the bush and the bow says, 'Father, why do you throw me to the ground like this? You will not catch anything'." When a hunter saw a pig he said to his bow, "You must aim well. Don't be afraid. Look inside [i.e. concentrate]. Do not look to the right or left." 15

Jabajmu told the following anecdote about the origin of a good bow. "A man who failed when trying to shoot megapode hens and pigs said, 'I will first go and get some sago grubs. I have seen the children of Uwaé [i.e. the nibung tree] dancing'. The next day he gathered sago grubs. He was not allowed to eat any of them in the sago grove. They were destined for Uwaé. When during the night he stood before Uwaé, Uwae descended from the creaking tree and said to the helpless man, 'What kind of man are you? What have you come here for?' He replied, 'I need a bow. Give me a bow'. He had to get rid of the man, so Uwaé said, 'I have no bow'. The man replied, 'I have seen you climb the tree with a carrying-bag full of meat. I have seen it myself'. Uwae did not want to give the bow immediately because it was a very good bow. The man was persistent and remained standing there saying, 'Grandfather, you must give it to me. I cannot shoot any megapode hens, nor any cassowaries, nor any pigs. My bow is no good at all'. Finally $U$ waé climbed up the tree and brought out a bow. He showed it to the man on all sides and asked, 'Would you like to have this one?' He replied, 'Grandfather, not this one but the other one which you hold there. That one is an excellent bow'. Uwae gave it to him and also gave him a charm for hunting cassowaries and pigs. He said, 'This medicine here is for megapode hens. Put it under the arrowhead on the shaft. This one here is a medicine for pigs and the other one is for cuscus. You must rub it on your forehead. Let the others submit to the prohibition on fish and meat. You may go to any part of the country you wish and you will shoot all kinds of animals, megapode hens, cassowaries, pigs and cuscus'."

Obviously, a bow is useless without arrows. According to Jabajmu, there are certain things which can be placed on the arrow shaft before the point is affixed. The hunter can also smear his forehead with 
doqowk-rara, a type of leaf which is a cuscus medicine. He will then feel a tingle or itch at this spot when he is about to encounter a cuscus. $\mathrm{He}$ can also dip the bow or arrow itself in ipaqa-rara, a medicine which helps him aim well when shooting a megapode hen.

Hunting is a serious business. They say, "Don't ask a man anything when he is hunting. He will not answer anyway. If he did, he would have no success in the hunt". While a man is hunting and someone dies in the settlement, he will notice that the relations between things have been disturbed, for the animals which he shoots do not die. This is one of the reasons why the hunter needs more than just a bow and arrows. It is necessary for him to tie fibres or human hair to the weapons. They, together with the other "medicine", will make the weapons more efficient. These leaves or hair are more than mere decorations. They are real rara.

Another item of importance is the pig trap. There are special kinds of medicine for pig traps (i.e. top-rara). In the trap they put some sago together with a piece of baqaé wood. Sometimes the sago is mixed with $k i t$ leaf or the trap itself is rubbed with it. These leaves are used to attract pigs to the trap. But the medicine alone is insufficient. Before the medicine is applied to the trap, certain ancestors, babaé, such as Tepakud and Qojöm, are invoked over the pig trap or over the fence which acts as a hunting blind. One such incantation goes, "Udia, you were the first to make a trap for me. Udia, you were the first to build a fence for me. Joati, you were the first to train my dogs". ${ }^{16}$

Power and spirits are of equal importance for the canoe, the peace pipe, the drum and other utensils. The use and meaning of water and fire could also be mentioned here, but most of this information has already been given in preceding chapters. Instead of repeating this I want to conclude this section by giving an example of how people could be freed from the bad influence of waw if they had been struck by it.

There were several ways to protect a canoe against unlawful use by others. A man of Képi, Qaja, said, "The owner of a canoe placed a little piece of wood on the path and said to it, 'When someone rows away stealthily and later on does not put back [the canoe], you must hit the thief well; if I myself put back the canoe, my body odour smells, it is me [don't hit].' ${ }^{17}$ If anyone came along who had used his canoe recently, the owner would say to him, 'Have you rowed out from the place where I have my canoe and have you come back again?' If the culprit admitted that he had, the owner would say, 'I do not wish to 
fight over it, I have laid down a waw' [which means: "You have already been struck"]. ${ }^{18}$ The guilty man would then beg him to free him from this waw. In the morning the owner of the canoe went to the sleeping-place of the culprit and called him outside. He then either sprinkled him with water or beat him with the kidu-rara plant until the leaves of the branch fell off. Meanwhile the canoe owner would say, 'Out, I have freed you'." 19 


\section{CHAPTER XVII}

\section{CONCLUDING REMARKS}

The Jaqaj, living on the tributaries of the river Mappi, always found abundant food in the sago groves, the forests and the swamps, so that there was no need for them to work hard on food production. Still, there was not always so much food that they could live with no worries. The food difficulties, however, were of minor importance compared with those caused by their internal fighting once they had settled in this country and divided it among the various groups of their tribe. Certain plots of land were inherited by the descendants, wir-dé, of the ancestors, babaé, who had occupied them or taken them by force from the original owners. Their social framework, the division into qari and $i m u$, was based on an optative descent system which dominated property and marriage arrangements. Individual and collective cooperation and opposition between the sexes, the wir-bor and the tajbor, between the qari, between the imu, and between the settlements, buaq, resulted in fragile social groups subject to never ending controversies among the composing units.

Men and women entered into numerous relationships patterned after the model of the exchange marriage. The community accepted the authority of three functionaries: the war-chief, poqoj-radé; the counsellor, akiaq-radé; and the seer, joqbera-radé. The first two of these formed a pair of complementary opposites and co-operated in the affairs of the visible world. The third was the intermediary between the Jaqaj and the invisible world.

\section{Akiaq-wir, counsellors}

Traditional advice, akiaq-tumi, has been discussed in the course of this book. It refers to the ideal male and female, to pregnancy and birth, to the education of children, and to the attitude of the adults towards war and its organization. Here I would just like to discuss a few short formulations of social values and moral judgements which are frequently referred to in daily life. 
a. Qadékén - rakoamön, thoroughly - superficially.

Jabajmu of Képi once said ja-radé qadékèn kinano, taj rakoarmön, "men do things thoroughly, women superficially". Jabaqaj of Képi expressed the same concept when he asserted, "Lazy women use a bat of ate wood [which is light], the diligent ones a bat of nibung wood [which is heavy]". In the same sense the Jaqaj contrast the sun and the moon. The story says that the bow, the arrow shaft and the arrowhead of the sun were better than those of the moon. Whenever the sun shot a pig, it was really dead. When the moon did so, it was not. The sun smoked real tobacco, the moon a substitute. The sun planted bananas, sugar-cane, hot spices and cucumbers, all of which were excellent; those of the moon were no good. The mark of honour of the sun was a real ramoq; the moon only pretended that he had a mark of honour. The story about the mother of Bakui expresses the same idea, i.e. her children, begotten by Aw, would die because she was afraid of the sun, his penis being too hot. Along similar lines of thought I often heard people use the contrasting terms qadéarép - jaqati. In different contexts these words can be translated as: true - not true, or real - not real, or serious - light-hearted.

\section{b. Diaqandamön - kandigkèn, together - alone.}

The Jaqaj attach great value to being and working together. They are afraid of being alone. He who happens to be alone is the one who will be attacked by the idöm, jaqar and aburi. Jaèndé showed a special respect for the sun and said that the sun stands apart, tapaq kandire. A similar respect is voiced in the story about Jaboq in which it is said of him and his group, "It was the party that was all by itself which was victorious".

\section{c. Amör, mutuality.}

The principle of reciprocity demands that good and evil be repaid. In the eyes of the Jaqaj good is that which supports relationships; bad is that which destroys them. Amör is achievement and counter-achievement; good is requital in both its forms, that of benevolence and that of revenge. The reward of good is found in the advantages enjoyed by both parties simply because things run smoothly; this joy is called tambi, peace or balance. The reward of evil is warfare, tok. Other short expressions include mendaq baire, "exchange-marriage is good", and amör-ain mateba, literally "omission of requital don't do it" (i.e. do not omit requital). The same idea is present in the term ero, share; 
ero-an means to distribute. A man or woman is called ero-qambo, or eroqambu, when he or she shows a readiness to share. However, one should remember that the Jaqaj only applied these rules to their own people. Outsiders were always suspected of being enemies.

\section{d. Tom-jamba mateba.}

Offences against sex regulations always raised the question of the initiative in the trespass. Tom means the initiative of the female, jamba the initiative of the male. Any endeavour to have sexual intercourse should be avoided as long as the families and the leaders of the partners have not given a green light to the arrangements.

e. Aènd mareba, don't steal.

This advice names the sun as supervisor; the ancestors, animals and even qoqo as avengers; and "dying young" as the punishment.

\section{f. Pipi mareba, don't suspect.}

Suspicion voiced in the community was always feared. Usually it gave rise to quarrels and fights.

g. Et mareba, don't call a person names.

h. Päpa, shame.

Akiaq tumi as the verbal formulation of ideals and values found its counterpart in $p \bar{a} p a$, the feeling of having failed or having fallen short of one's own or others' expectations. Even when he could not be blamed, a man might feel ashamed, as for example when he returned from a raid without a captured head, baba-amön. The feeling became acute when he really was to blame. From experience he knew that his failure might have consequences deriving either from nature or his fellow-men (e.g. fish withdrawing from the swamps, material loss, not receiving the honour hoped for). He was conscious of guilt even before his misdemeanour had become public. Of course these feelings increased when the trespass became public knowledge and the community condemned and punished the perpetrator.

It was usual to defend one's reputation by means of lies or taking up arms. In the latter case, the culprit told his accuser to mind his words. When this incident resulted in a fight, its outcome greatly influenced the further settlement of the case. The fact, however, that the culprit had taken up his weapons was considered a breach of the rules of good companionship. Ultimately such persons were not tolerated, even if 
they were wir-poqoj, leaders; if they indeed went too far they were expelled or otherwise dismissed.

The feeling of being personally guilty might become so strong that the offender fell ill. A sick person was advised to confess his failures to an akiaq-radé for "then he would recover". The severest accusation that could be levelled against an offender was aq pappa-ain, "you don't know shame", in other words, "you have lost the feeling for what is proper and improper". Such a person might be "sold" to another settlement and killed there.

\section{Poqoj-wir, war-leaders}

The Jaqaj conceals his awareness of his weakness and misdemeanour by means of a show of boldness. He jealously guards his prestige and personal honour. The preference for optative descent, the uncertainty of qari-and imu-bonds, the untrustworthiness of war alliances and the fact that they were invaders in another people's country demanded strong and resourceful leaders and fighters so that the social framework would not collapse.

This urgent need motivated the games of the boys, the promotion of the young men to $k u j$-wir, the connection of head-hunting raids with mourning and marriage, the distribution of marks of honour, and finally the outspoken and ritualized expression of their intention to start a new cycle of feasts by conjuring up a new war once a full cycle had been completed. Even the women wanted the men to live up to their ideals and they forced them to start a raid by calling them names or hanging a woman's skirt in the men's house.

When the government and the mission first opposed head-hunting practices the people told Father Meuwese, "Without captured heads the women will not be able to have children". This statement, combined with the custom of hanging captured heads from the arms of brides during the wedding-feast, suggests that the Jaqaj considered headhunting to be essential for fertility. This supposition is not, however, supported by other facts. Tambim of Képi had three wives and many children and had never captured a head. Apparently the idea that fertility depended on "heads" was not taken too strictly. Tambim was an acknowledged akiaq-radé and therefore did not need to seek further recognition. It seems more probable that the bridegroom hung a head from the arm of his bride because the head was proof of his courage and guaranteed his ability to care for the safety and livelihood of his wife and children. The bride held sago in her hand as a symbol of her 
share in their co-operation. The leader of the ceremony demonstrated his authority by ostentatiously mentioning his heroic deeds, pidoq.

Neither did the head of a victim further the fertility of the coconut tree or the vitality of man. The head-hunters' courage during the raid was the real source of new vitality. Their bravery enabled them to lead their mourning relatives back to full participation in life. Once Meuwese made a patrol among the tribes surrounding the Jaqaj. He went alone, without the protection of a police escort. The Jaqaj admired his bravery so much that they gave him permission to cut off the signs of mourning in their settlements. He was entitled to do so because he had proved his courage.

The Jaqaj did not attach any special waw effect to captured heads. The fleshy parts and the picked out brains were eaten, the lower jaw was cut loose and given to the nakaèri, the skull became a war trophy and the basis of ménaqaé- and nakaèri-relationships. A captured head was not decorated; the exhibition and dancing were arranged to honour the man who captured it. For similar reasons the spears with which the victim had been killed were stuck in the ground in enemy territory or in the well near the home settlement. The women used to dance with them just as they would dance with their husbands' bows after their deaths. The skulls were hung in the men's house as a homage to the living and from the platforms of the dead as a token of honour to the deceased head-hunter. After the period of mourning the skulls were simply thrown away. The souls of the victims, toqojia, stayed with the head-hunter and helped him to catch others in a following raid. The head-hunter's prestige enabled him to order the life of the community and thus maintain order and renew life.

\section{Joqbera-wir, seers}

The Jaqaj honoured the past in their traditional lore, akiaq-radé, and tried to master the present, poqoj-radé. They were also aware of the unknowable but powerful background of their universe, témé-moqon. The joqbera-radé was their go-between with the spirit world. Some of his tasks have been discussed above. Here I want to discuss some symbols and images used by the Jaqaj to express their belief in the significance and the power of that hidden world.

The principal need they expressed was that of "permanence", not only with regard to themselves but also for nature in general. Acknowledging the perishable situation of all generations, they pleaded for permanence against and beyond death. 
Several times I have mentioned the morning bird, qojöm. The day of the hair feast of the children was opened with the qojöm song, "The morning bird is beautiful, the sun has set". The procession after the presentation of the marks of honour started by singing, "The sun passes over the river Kao [to the West], morning bird, sons, morning bird". The Jaqaj saw a relation between the singing morning bird, the rising sun, and the hope for a new and glorious day.

The song sung when the festivities reached their apex makes mention of the two song names of the ashes in the fireplace, qaput-bomé; they are sung out in endless repetition. The fire that is still glowing in the ashes will blow up again.

The same notion recurs in the manner of distributing sago grubs. The Jaqaj distinguish between grubs which are not fully grown, qondinaput, and the grubs which are on the point of beginning a new life as beetles, qondin-arép. The former were given to the children, the latter to the adults. When people set out to collect them, their qondin song referred to the similarity between the act of penetration of the capricorn into the fibres of the sago tree and that of the man in copulation. New life is procreated.

Then there is the opposition between dark and light. The marks of honour go through a process resembling a rite of passage. First they are decorated with black feathers and then wrapped in leaves and stored in the men's house. Shortly before the presentation they are brought into the open while the old decorations are removed and white feathers and brightly coloured beads are attached in their place. After the headhunters were honoured the young men received their head-hunting knives. They were painted black with charcoal, qaput-bomé, and were named after the young sun, noqoki tapaq, whereas the older, experienced men were called "permanent sun", maqati-tapaq.

\section{Sun and moon}

Finally, mention must be made of the two most convincing symbols of the Jaqaj's hopes for permanence, viz. the rising sun and the new moon. They bear witness to his close association with the great powers of nature in what, to him, are the most glorious but also the most perilous moments of his life. The Jaqaj motivated their head-hunting raids by explaining that they wished to be everlasting like the sun, maqati-èr. Setting out on a raid, they decorated themselves with the qajngga, the nose ornament consisting of two standing crescents, the symbol of the waning and rising moon. An old head-hunter received as the highest 
mark of honour the oana, the boar tusk shaped like the crescent of the moon. The tokens of vitality and prowess were his most beloved decorations. On festive occasion the Jaqaj male presented himself as the man he most of all wished to be, the resourceful fighter who relies on the model set by the sun and the moon. Yet, even in his glory, he did not fully succeed in concealing the inner feelings of insecurity which went along with his orientation towards prowess. His most conspicuous decorations were moon symbols, and the moon, when compared to the sun was, in his view, a mere bungler. 


\section{NOTES}

\section{Introduction}

1 For a description and analysis of Marind-anim culture see J. van Baal, Dema, The Hague: Martinus Nijhoff, 1966. An ethnographic description of the neighbouring tribes does not exist. Some notes about the Awju people have been edited by Fr Trenkenschuh, o.s.c., in his Asmat Sketch Book 3, Hastings, Nebraska 68901 U.S.A.: Crosier Missions, 1971.

2 The annual report to the United Nations for 1961 averages rainfall over a period of seven years as $3242 \mathrm{~mm}$. a year with 162 rain-days annually.

3 A. Perk, Landbouwkundige ontwikkeling in het Mappi gebied, Hollandia 1955. A stencilled report for the Department of Economic Affairs, Agriculture and Cattle Raising Section.

4 Files, R. C. Mission, Képi.

5 Jaqaj population
A. Men

\begin{tabular}{|c|c|c|c|c|c|c|c|}
\hline \multirow{2}{*}{$\begin{array}{l}\text { Names of the } \\
\text { Villages }\end{array}$} & \multicolumn{6}{|c|}{ Ages of the Men } & \multirow{2}{*}{$\begin{array}{l}\text { Total } \\
\text { Men }\end{array}$} \\
\hline & $0-1$ & $2-5$ & $6-11$ & $12-17$ & $18-44$ & $45+$ & \\
\hline 1. Masin & 14 & 34 & 57 & 33 & 122 & 20 & 280 \\
\hline 2. Wajru & 13 & 13 & 32 & 14 & 57 & 7 & 136 \\
\hline \multicolumn{8}{|l|}{ 3. Kandajmu/ } \\
\hline Kotup & 17 & 34 & 39 & 23 & 91 & 15 & 219 \\
\hline 4. Rajöm & 4 & 15 & 14 & 12 & 29 & 3 & 77 \\
\hline 5. Moïn & 11 & 34 & 42 & 27 & 81 & 16 & 211 \\
\hline 6. Emeté & 13 & 29 & 49 & 10 & 67 & 2 & 170 \\
\hline 7. Togom & 14 & 18 & 40 & 24 & 43 & 11 & 150 \\
\hline 8. Képi & 16 & 33 & 46 & 22 & 86 & 21 & 244 \\
\hline 9. Toba & 13 & 21 & 27 & 17 & 53 & 8 & 139 \\
\hline 10. Rèp & 19 & 35 & 28 & 20 & 74 & 11 & 187 \\
\hline 11. Enèm & 19 & 33 & 23 & 23 & 62 & 11 & 171 \\
\hline 12. Kogo & 13 & 14 & 28 & 15 & 70 & 16 & 156 \\
\hline 13. Kadöm & 19 & 16 & 46 & 22 & 75 & 13 & 191 \\
\hline 14. Wanggaté & 8 & 25 & 32 & 26 & 85 & 28 & 203 \\
\hline 15. Dagimon & 16 & 25 & 22 & 14 & 64 & 7 & 148 \\
\hline 16. Jamuj & 6 & 16 & 17 & 8 & 43 & 6 & 96 \\
\hline 17. Hagām & 15 & 21 & 32 & 21 & 93 & 20 & 202 \\
\hline 18. Katan & 21 & 23 & 36 & 17 & 72 & 25 & 194 \\
\hline 19. Jatan & 16 & 28 & 39 & 11 & 61 & 10 & 165 \\
\hline 20. Mandaw & 8 & 13 & 15 & 2 & 43 & 4 & 85 \\
\hline 21. Mur & 9 & 21 & 33 & 5 & 50 & 8 & 126 \\
\hline 22. Monana & 12 & 25 & 18 & 20 & 54 & 15 & 144 \\
\hline 23. Kapagoind & 8 & 7 & 5 & 2 & 15 & 3 & 40 \\
\hline 24. Koba & 25 & 26 & 26 & 7 & 69 & 6 & 159 \\
\hline 25. Ima & 16 & 14 & 17 & 6 & 43 & 6 & 102 \\
\hline 26. Gogojāmön & 11 & 14 & 22 & 11 & 44 & 18 & 120 \\
\hline 27. Jodom & 5 & 6 & 16 & 10 & 41 & 7 & 85 \\
\hline Sum Total & 361 & 613 & 800 & 422 & 1,687 & 317 & 4,205 \\
\hline
\end{tabular}


B. Women \& Total

\begin{tabular}{|c|c|c|c|c|c|c|c|c|}
\hline \multirow{2}{*}{$\begin{array}{l}\text { Names of the } \\
\text { Villages }\end{array}$} & \multicolumn{6}{|c|}{ Ages of the Women } & \multirow{2}{*}{$\begin{array}{c}\text { Total } \\
\text { Women }\end{array}$} & \multirow{2}{*}{$\begin{array}{c}\text { Total } \\
\text { Men \& } \\
\text { Women }\end{array}$} \\
\hline & $0-1$ & $2-5$ & $6-11$ & $12-17$ & $18-44$ & $45+$ & & \\
\hline 1. Masin & 15 & 37 & 40 & 29 & 119 & 19 & 259 & 539 \\
\hline 2. Wajru & 9 & 12 & 31 & 11 & 61 & 9 & 133 & 269 \\
\hline \multicolumn{9}{|l|}{ 3. Kandajmu/ } \\
\hline Kotup & 10 & 29 & 31 & 18 & 104 & 19 & 211 & 430 \\
\hline 4. Rajöm & 5 & 12 & 12 & 5 & 45 & 3 & 82 & 159 \\
\hline 5. Moïn & 29 & 34 & 39 & 14 & 113 & 20 & 249 & 460 \\
\hline 6. Emeté & 14 & 18 & 28 & 12 & 92 & 4 & 168 & 338 \\
\hline 7. Togom & 11 & 16 & 16 & 11 & 69 & 15 & 138 & 288 \\
\hline 8. Képi & 22 & 38 & 43 & 20 & 87 & 50 & 269 & 513 \\
\hline 9. Toba & 10 & 25 & 35 & 11 & 82 & 17 & 180 & 319 \\
\hline 10. Rèp & 14 & 23 & 25 & 20 & 101 & 27 & 210 & 397 \\
\hline 11. Enèm & 8 & 26 & 18 & 14 & 74 & 23 & 163 & 334 \\
\hline 12. Kogo & 10 & 23 & 21 & 19 & 88 & 19 & 180 & 336 \\
\hline 13. Kadöm & 16 & 18 & 32 & 19 & 105 & 19 & 209 & 400 \\
\hline 14. Wanggaté & 16 & 22 & 23 & 14 & 92 & 41 & 208 & 411 \\
\hline 15. Dagimon & 10 & 13 & 25 & 13 & 65 & 23 & 149 & 297 \\
\hline 16. Jamuj & 11 & 12 & 20 & 6 & 59 & 25 & 133 & 229 \\
\hline 17. Hagām & 22 & 23 & 32 & 15 & 83 & 30 & 205 & 407 \\
\hline 18. Katan & 13 & 20 & 33 & 14 & 84 & 33 & 197 & 391 \\
\hline 19. Jatan & 14 & 20 & 27 & 8 & 65 & 29 & 163 & 328 \\
\hline 20. Mandaw & 12 & 16 & 20 & 5 & 49 & 13 & 115 & 200 \\
\hline 21. Mur & 12 & 28 & 29 & 6 & 66 & 24 & 165 & 291 \\
\hline 22. Monana & 15 & 21 & 32 & 12 & 72 & 21 & 173 & 317 \\
\hline 23. Kapagoind & 7 & 12 & 4 & 5 & 29 & 4 & 61 & 101 \\
\hline 24. Koba & 20 & 41 & 13 & 13 & 70 & 15 & 172 & 331 \\
\hline 25. Ima & 17 & 20 & 15 & 7 & 48 & 12 & 119 & 221 \\
\hline 26. Gogojāmön & 3 & 13 & 24 & 14 & 54 & 11 & 119 & 239 \\
\hline 27. Jodom & 10 & 14 & 12 & 13 & 44 & 14 & 107 & 192 \\
\hline Sum Total & 355 & 587 & 680 & 357 & 2,020 & 539 & 4,537 & 8,742 \\
\hline
\end{tabular}

6 See Chapter XIV, section 1. In a song white people are said not to be descended from Ajré and not coming from the Kao; see page 159, song no. 6. The language of the Jaqaj is related to that of the Boazi on the river Fly and to that of the Marind-anim on the south coast.

7 P. Drabbe, m.s.c., Talen en dialecten van Zuid-West Nieuw Guinea, Posieux/ Fribourg (Swiss): Inst. Anthropos, Micro Bibliotheca, 1954 Vol. XI, deel 3: 'Gegevens over drie talen met praefixale vervoeging'.

8 J. Boelaars, m.s.c., The linguistic position of South Western New Guinea, Leiden: E. J. Brill, 1950.

9 P. Drabbe, m.s.c., 1954 (Talen en dialecten), p. 1.

10 Photographs of Jabajmu and other leaders are added as plates 19 and 20.

\section{Chapter I}

1 See Introduction, note 5.

2 See Map 1. 
3 See Map 2.

4 The first is by J. Verschueren (not published), the second by N. A. Nieland, Controleur I Binnenlands Bestuur, Bijlage Memorie van Overdracht, Onderafdeling Mappi, 1953. The third is by J. R. Butter, Memorie van overgave, 1959, Dienst van Economische Zaken, Afdeling Landbouw en Veeteelt, Subressort Mappi. See Appendix II.

5 See P. Drabbe, m.s.c., 'Gegevens over drie talen met praefixale vervoeging', in: Talen en dialecten, 1954, Annex II.

6 See page $17 \mathrm{ff}$.

7 See Chapter II, section 2, c, page $34 \mathrm{ff}$.

8 R. Firth, 'A note on descent-groups in Polynesia', Man 1957, Vol. LVII, p. 4.

9 See Chapter III, section 2, p. $58 \mathrm{ff}$.

10 At the moment when a man stabs an enemy he shouts his group name.

11 See Map 2.

12 Idem.

13 Idem.

14 See Chapter II, section 2, c, p. 34 ff.

15 See Map 2.

16 An exchange "sister" is a woman given to a man in order to exchange her with the sister of another man, who then becomes his wife. The exchange sister becomes the wife of the other man.

17 North of Qajomoqon (see Map 2).

18 At Képi Tambim chose thirty trees for his sons. On a patrol between Koba and Monana a bearer pointed out, within the space of an hour, eight trees which he had personally selected.

\section{Chapter II}

1 Aröm, or locally also nobo.

2 See Chapter I, section 3.

3 Sister-in-law = nokon, or locally also moqotu or ménéj.

4 G. P. Murdock, Social Structure, New York: Free Press, 1965, p. 142.

5 Idem, p. 223.

6 Each case has its own history. The issue of a case depends on the actual balance of power between the parties who are involved. My informants stressed how the Jaqaj would react to such misconduct, if the father and those who stand up for him were able to lay their hands on the culprit and if the brothers of the wife caught in adultery did not defend her against such actions.

7 See p. $43 \mathrm{ff}$.

8 My data on this point are not exact because with regard to many persons who were said to belong to a qari at Képi, my informants did not know to which qari they originally belonged. The informants were particularly uncertain about deceased persons of the older generation.

9 See p. 46. 
10 The terms jando-é/wu should not be mistaken for the terms abur-é/wu. The abur-wu is a FaSi or a MoSi who, being the next female relative, suckles the child when the actual mother is unable to do so. The word abur means breast. The child fed by this relative is therefore called abur-maq. The parental couple of which the wife suckles the child are called abur-é/wu. Drabbe translates abur-é as "shame father" and abur-maq as "shame son", indicating the special relationship between a man and a boy who have homosexual intercourse. Chapter V, section 2, will show that the Jaqaj use other terms for this relationship (see p. 84).

\section{Chapter III}

1 See plate 1 .

2 See plate 2.

3 See Map 2.

4 The village is clearly divided into two halves. At one side live the Kamaqajmu and the Marapèmu (the settlements of Oaqatemoqon and Ebéababa), and at the other side the Ikimu and the Aqaoèmu (the settlements of Apaw and Kupeqaé). The men of the Ikimu who lived with the Aqaoèmu at Kupeqaé appear to live in the village precisely at the place where the Ikimu join the Aqaoèmu. Of the six Aqaoèmu who lived with the Ikimu at Apaw four live in the village again with the Ikimu; two have settled elsewhere. Of the four Kamaqajmu who lived with the Ikimu at Apaw, three in the village have returned to the Kamaqajmu; one still lives with the Ikimu. The two Ikimu, who lived with the Kamaqajmu at Oaqatemoqon, also live with them in the village.

5 See plate 3.

6 See plate 4.

7 See plate 5 .

8 See plates $6 a$ and $b$.

9 See plates $7 a$ and $b$.

10 See plate 8 .

11 See plate 9.

12 See plates $10 \mathrm{a}$ and $10 \mathrm{~b}$.

13 See plates 11a and $11 \mathrm{~b}$.

14 See plate 12.

15 See plate 13.

16 See plate $14 \mathrm{~b}$.

17 See plate 15.

18 The description of this function is taken from the head of the local government of the Mappi territory, Mr. F. J. M. Cappetti, in his 'Bijlage van de Bestuursnota', Tup, Augustus, 1954.

19 The Qomimu of Emeté said, "Janaqatik passed on the akiaq to Tamank, Tamank to Jandit ..."

20 The Qomimu of Emeté added to the information given in note 19: “... Jandit to Bagejei, Bagejei to Bagera”. The latter also became the radé-poqoj. 


\section{Chapter IV}

1 See plate 16.

\section{Chapter V}

1 The child also learns the numerals. These are diaqand $=1 ;$ kajaqamaère $=$ 2 ; diaqand kajaqamaère $=3$; kajaqamaère kajaqamaère $=4$; a number of five is already referred to as aripade = many.

2 While making a survey in the villages of Képi and Dagimon (Oba district), and in Kamagaj (Nambèomön district), I found out that on an average each woman had given birth to seven children, of which usually two and often three had died in infancy.

\section{Chapter VII}

1 A number of these songs have been tape-recorded. They have been studied by the late Mr. J. Kunst while he was the musicologist at the Royal Tropical Institute in Amsterdam. From him I received the following valuable information.

"I have listened to these songs several times very carefully and I would like to make the following remarks:

a. There is no essential difference between the singing of the men and that of the women and children. Only the part-singing of the men is stronger than that of the women; it is more ausgeprägt. We found that there is no part-singing in the children's songs.

b. The intervals in the songs sometimes reach that of a fifth, but in the majority of the cases that of a fourth.

c. The short-phrased melodies are always falling and end in a long, low tone, which in its turn is followed by a brief, communal yell.

d. A number of scales used in the singing of the men had the following tones:
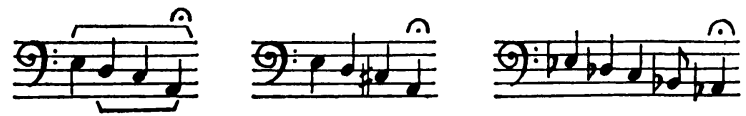

For the singing of the women I noted down the following tones:

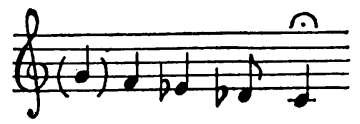

and for the children's song:

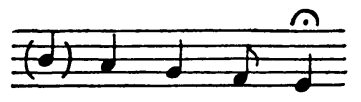

e. As far as the rhythm is concerned, these songs are sung slovenly, so that the tones now and then overlap one another, and so-called seconds and thirds 
are heard briefly. This "slovenliness" is one of the attractions for the singers, whose gift for part-singing is proved in a number of songs, which seem to be sung by two different parties, of which one sings alternately long tones (e-g-c and a), while the other sings a much more lively melody which uses all the tones of the scale and, after repeated rising and falling of the melody, usually ends in the lowest tone, in unison with the other party. This manner of part-singing evidently produces many more consciously double tones, especially thirds and seconds and, incidentally, also a fourth.
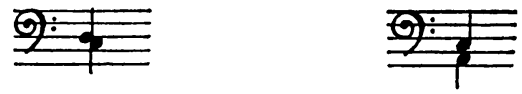

This elementary polyphony is sometimes strengthened by the interjections which are sometimes heard and which are apparently sung by the younger men. They consist of overlapping tones and together with the tones sung by older men they give the impression of fleeting major and minor thirds.

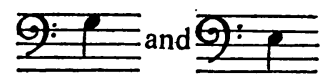

f. The songs of the men and the women are accompanied by beating on the drums at strictly set intervals. The frequency is that of about two per second. It is only gradually that the song reaches a conformity and even then this is only approximate. On other occasions, however, there seems to be no conformity with the drumming whatsoever as far as the rhythm is concerned. g. Sometimes there is a cantor, who starts the song and is soon joined by the other men. I wrote down one of these solos:

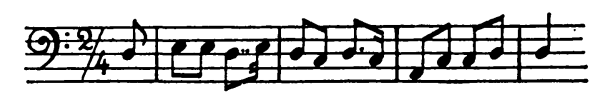

The choir then joins in.

h. The distance between the penultimate and the last (and lowest) tones, which in the majority of the cases is a third, is usually filled with a kind of portamento. That lowest tone usually seems to be sung in what Father Schmidt has called a "Flick-o" (which I would translate as "stop-gap-o"), which is a vocal $o$, not belonging to the text of the song itself, but merely a sound at the end."

2 Even new-comers, foreigners, get a pidoq. I was called WanggiaqamboQemamaèt. This name happened to be the pidoq of a man called Madob, who had died shortly before I arrived at Képi, and with whom I had a resemblance in stature. One day a woman, Qobuj, addressed me as her mendaq (exchange brother) because Madob had been her mendaq.

3 The following are the most common dances, explained by the Jaqaj as follows:

a. The dance of the bird of paradise, the kéaqab-tate (plate 17). In this dance a number of spears of the qajapo type are laid on the ground in a straight line. In the middle of this line two women sit on their heels and 
sway with their arms over their heads. Around this "nest" - for this is what they wish to depict - the other women dance in pairs and circle round the centre. They alternate, so that the two women who are the "nest" are relieved by others and do not stay long on this "nest".

b. The banana dance, népèr-taté (also called the water-sugarcane-dance, qabarumb-taté). In this dance a woman revolves about her own axis. It expresses the swaying to and fro of the banana trees or the sugarcane in the wind.

c. The dance of the nibung tree, the ngao-taté, is a dance in which the feet are turned over all the time, as if they were the leaves at the top of the nibung tree turning in the wind.

d. The trestle dance, kaptöm-taté. The women cross their legs like the legs of a trestle used to support the gutter for rinsing sago.

e. The dog dance, qaké-taté, is an imitation of the way a dog scratches the ground.

f. The dance of the bird of prey, joqoj, the joqoj-taté. The women stretch out their arms like the wings of a bird.

g. The dance of the butterfly, the rur-taté. Shuffling steps are made, ankles together.

h. Finally, there is a dance whose name I do not know. The women dance together again; one woman hooks her leg round the leg of another woman and thus they dance together.

4 See Chapter XV, section 9 (page 249).

\section{Chapter VIII}

1 I did not make a detailed study of the medical values ascribed to either plants or animals. Information gathered from hearsay is presented. I also heard that women ate plants which supposedly caused sterility, viz. tapaka and batik-rara-dé. There is also a form of frenzy into which a man may work himself before a fight or while dancing during festivities by eating ginger, qamank. Such a person is called bogwé in the Nambéomön district. If he loses consciousness and falls to the ground, the women surround him and spit water onto his face. They say, "You, yourself [come] to your senses again". A man in the group puts his hands in his own armpits and then holds them under the nose of the patient. I never saw this frenzy occur among women.

2 Fr Drabbe writes muku-idém, grey hair.

3 For further information about spirits and their influence on health, see Chapter XVI (p. 252 ff).

4 Fr Drabbe writes jamaé-moqon.

\section{Chapter IX}

1 The tok is a bamboo knife used in cutting off the heads of enemies, and therefore tok also means war, intra- or extra-tribal. For extra-tribal war the term $k u j$ is preferred.

2 Oqoté lies on the river Nanggéao, not far from Moïn; see Map 3.

3 This text was paraphrased by informants as follows: "Life is short, let us grab the chance of killing. The sun can take liberties. It has a long life, we have not". 
4 The reaction of the women reflects the train of thought of the Jaqaj on the subject of fighting with other settlements. It was not the intention of the Jaqaj to massacre a neighbouring settlement completely, for on another occasion they might need the assistance of that same settlement to meet a common enemy. The killing was only a question of retaliation and both parties expected this of each other. Retaliation was the necessary condition for the peace made afterwards. When both parties had suffered about the same number of losses, they could begin peace talks. Moïn had killed the men of Képi who had visited the men's house at Moïn; now it was Képi's turn to take revenge. Moïn knew that this was going to happen and so they let it. Therefore, the women too could behave as if they did not see or hear anything.

5 The people of Képi gained a victory over Moïn and they now returned home full of joy. They called the spirit of Békébai who had been killed earlier and whom they had now revenged. "Rise, do not leave your sons behind again like you did when you died. Go with us to Képi, together with Araoa whose head we cutt off in revenge for your death." When asked whether Békébai (or at least his soul) would hear the summons, our interpreter answered, "Nobody cares. It is only a way of speaking. They only wish to say, 'We have taken revenge, you can be satisfied now'." To my mind it is remarkable that this informant felt that this summons did not necessarily call up Békébai himself.

6 To support this discovery by Verschueren, I wish to remind the reader of the term naröm, which was discussed in the context of kinship terminology (Chapter II, section 3, p. 45).

7 The informants said that this was because all the men of Ndoqajape had eaten strong herbs and the force emanating from them might have an adverse influence on the little children of Jaèndé.

8 Jabajmu of Képi informed me that this custom of first burying herbs in the ground was not known in the area around Képi itself. It was done in the villages at the headwaters of the Oba river.

9 According to the story told to Verschueren, Togompatu was one of the buffer states. Nevertheless children had been taken from Togompatu in the recent past. Anyone who calls to mind how inter-village alliances were kept or broken by the Jaqaj, cannot be surprised at the behaviour of the Jaqaj against their extra-tribal allies.

10 According to our Képi informants this ritual head-hunting of sago grubs was not known in their village. This custom and that of burying herbs (note 8) may have been adopted from the Awju living north of the Oba headwaters.

11 The people of the Miwāmön had also come to Togompatu in their canoes along the river Pasawé. Togompatu therefore was attacked from both sides: from land by the settlements of the Oba, and from the river by the settlements of the Miwāmön. Immediately before the attack, people from the Miwāmön came by a roundabout way to the bivouacs of the people of the Oba district. They had agreed that the attack was to take place the following night.

12 It is remarkable, however, that the guests now come and give their hosts a piece of their minds. When I asked my informants whether the hosts became angry, they answered: "They accepted this. They did not mind this insolence, they simply awaited the development of things at Togompatu. That had to 
be seen to first. They would deal with Kogo afterwards." The events, as will be shown, made Kogo so ashamed, that later on one scornful laugh was enough to punish Kogo for the way they had behaved on the raid.

13 The women cried, "Qaw-ah, your mother", which means "think of your mother, do not disappoint her".

\section{Chapter X}

1 See Chapter XI, p. 169 (muku-jamé) and Chapter XII, section 1.

2 See Chapter XII, section 4, taker-jamé (p. $183 \mathrm{ff}$.).

3 On these war songs, tok-éb, see Chapter XI (p. $157 \mathrm{ff}$.).

4 J. Verschueren, m.s.c., Nieuw Guinea, uw naam is wildernis, Bussum: P. Brand, 1950, p. 68.

5 See note 2.

6 J. van Baal, Dema, The Hague: Martinus Nijhoff, 1966, p. 717.

7 See Chapter II, section 3, pp. 44-45.

8 The qoqom might have had the same function as the pahuj among the Marind; see J. van Baal, Dema, pp. 724, 731. The spears in the spring, however, still had their points. The kupa, a club, was not used by the Jaqaj. Jaro knew it only as a weapon of the Marind.

9 See plate 4 .

10 See the myth about Jaqandi, Chapter XIV, section 4 (p. 229 ff.).

11 See the story of $A j r e ́$, Chapter XIV, section 1 (p. $220 \mathrm{ff}$.).

12 In 1950 I witnessed such a peace-treaty on a large scale, when, on the initiative of Father Verschueren, the Jaqaj tribe and the Awju tribe made peace as a preparation for the great christening-feast at Képi. Verschueren had left all the arrangements to the leaders themselves. See J. Verschueren, quoted by J. Boelaars, Nieuw Guinea, uw mensen zijn wonderbaar, Bussum: P. Brand, 1953, p. 158.

13 There are two sources of information on the feast. In the myth of Ajré the procedure of this feast is described and once I saw it celebrated in the village of Dagimon on the occasion of the first baptismal feast in that village. This feast was arranged by the leaders themselves as much as possible in the old style. When the decorated canoes, which I shall discuss presently, came back from the swamps, an old man burst into tears and said, "Just like it was in the past", maqaé-apinden.

\section{Chapter XI}

1 I recorded the songs at Képi. My informant, Japoméné, was the one who sang them.

2 See Chapter XIII, section 2 (p. 199 ff.).

3 See the story of Ajré, Chapter XIV, section 1 (p. $220 \mathrm{ff}$.). According to this story the Jaqaj are the descendants of Ajré, who came from the river Kao, a tributary of the river Digul in the foot-hills area. The whites originated elsewhere.

4 See Chapter XIII, section 1 (pp. 198-199), the song names of the tidal wave. 
5 See Chapter XVI, section 2, p. 257: the sun has the real arrow, the moon has a fake arrow of papo reed.

6 See Chapter XII, section 3, p. $173 \mathrm{ff}$.

7 See plates $18 \mathrm{a}$ and $\mathrm{b}$.

8 See Chapter XII: Festivities following the head-hunting raid.

\section{Chapter XII}

1 According to Maturbongs, Jaèndé was entitled to ramoq, but he only wished to be called radé-poqoj instead of ramoq-radé. Ponaki of Wajpaqari had killed twenty men and twelve women and was entitled to oana, but he wished to have the ramoq only.

2 See Chapter XII, section 1, p. 170.

3 See Chapter X, section 3, pp. 153-154.

\section{Chapter XIII}

1 See section 7: The sun casts down its skin (p. $210 \mathrm{ff}$.).

2 But they also said, that the wife of the moon was called Raepeti. The wife of the sun is Qojöm and Koqomb is the wife of a person called $A k u j$, about whom nothing else is known. All these names were mentioned only after there was a great deal of thinking and discussion.

3 The story was told in the Jaqaj language.

4 P. Drabbe, m.s.c., 'Gegevens over drie talen met praefixale vervoeging, Jaqaj, Marind, Boazi', No. 5 (see Introduction note 7). The Jaqaj distinguish three genders: masculine, feminine and neuter. The first can be applied to spirits, human beings and everything which, in the myths, has human characteristics, like the sun, the moon and the stars. The familiar animals actually happen to be like human beings and their sex can be recognized. Accordingly, they fit into the categories of masculine and feminine if sexuality is relevant. The remaining animals all have a gender in the legends which is independent of their natural sex. It depends on whether one sees them or thinks of them as if they were males or females. Thus the crocodile is masculine while the cassowary is feminine, because the former originally was a man and the latter originally a woman. The tortoise with the snakelike neck, naqapé, is a woman, the wife of a crocodile. Anything in a myth which is not or has not been human at one stage or another is neuter. Also, the animals which the myths do not discuss are neuter, unless one wishes to stress their natural or physical sex.

5 The Jaqaj understood, once Western civilization was established, that they would make more progress by knowledge than by outrage. They said that for the white people things were much easier. Once they told me a story about a white man who stepped into a canoe. When he put his foot on the bottom of the dug-out, it immediately turned into a motor launch.

6 "Dog-women": see Chapter XIV, section 4 (p. 229 ff.).

\section{Chapter XIV}

1 See Chapter IV, section 2, p. 69 (no. 12). 
2 Another version of this story was told in Indonesian in the Nambéōmön district by the older men of the village of Mur.

3 In the Mur version, the man longed for his "wari" (kava). The function of this wari, a drug, is indicated by the saying: "He ate and his belly swelled, he drank some wari and his belly became normal again".

4 In the Mur version: "The woman demanded that the man have intercourse with her. His penis did not penetrate far enough, not farther than the labia. A large fish came out of the genital parts of the woman, a sawfish. When he withdrew his penis, all kinds of fish came out of her. When all the fish were out, her belly was normal again. First she rested. The dogs had laughed when they saw the man and the woman having intercourse. The man cut off their tongues and said, 'Do not cry, weep and stay like this'. He left the dogs that had laughed behind and took along other dogs that had not laughed."

\section{Chapter XV}

1 See Chapter XVI, section 1, p. 254 ff.

\section{Chapter XVI}

1 The sticks in the water resemble the spears in the village well.

2 In his catechism Father Drabbe contrasted "Tuhan Allah témé-moqon kéboamok" (God made sky and earth) with the verb in the singular because the object is "singular", and "Tuhan Allah ndomakèn éarboondodona" (God made everything) with the verb in the plural because the object is "plural".

3 Kaènd ka-na-ponokon. red earth do-me-give.

4 Kapaqajt aq aqa-péaqa kéko poqojamön koinden. Kapaqajt you you-plant stem thick-with to-here.

Similar formulas are used when planting tobacco, tamangkjak; kava, wari; cucumber, oara-banggé; tubers, toqomi and mugupaq.

5 Api-oh kodé pajo naqamör noqo-péaqa, Grandfather, this coconut now I wish to plant, qapaqaépakén taparin ndumaqaé repakén, quickly it may grow not high,

kanekén tabeki.

then it may bear fruit.

6 Api, jangk taqa-na-ponokon.

Grandfather, fish do-you-me-give.

7 Anokondin tumi éa-r-bekoka.

My word he-now-hears.

8 Api, jangk kakap-agan t-aqa-rimberok, éowmu-aqao.

Grandfather, fish trap-to do-you-send-in, grandchild-loving.

9 Danggi, anemaé kédékáqan t-aqa-nam, nanik moqon-aqan mateba Danggi, come this-to do-you-come, other plot-to don't

kidék-apé jangk aripade, kidu, tauwi, janggor-aqan.

here fish many, kidu, tauwi, road to.

10 Jangk boraqaé api, janggo tabombak-amön oqor-aqa-metame. Fish is not Grandfather, body bad-with I-against-you feel. 
11 Tapaq-ah qadékèn t-aqa-boamék ngon-amön ma-na-boppomin-apé. Sun-ah truly do-you-cause belly-with do-they-lie-up-don't.

kind-an qadékèn t-aqa-boppomin bob-aqan. sleep-to truly do-you-lie face-down.

12 Kodé rori-re qao-apekaqabaqao, qadékèn janggo-arép-aqan qadékèn This rori-is not-shoot wrongly, truly game-itself-to truly t-aqa-péaqao. do-you-hit.

13 Mi endaqaw-arép amereba, ama-perak, qadékèn amanaé Bow heavy being, shooting truly being na-noqo-mimbak. being-shall-I-shoot.

14 Janggo amonnönggab mi-aqan, aq oabekakèn épéqon janggo-aqan Meat tying bow-to you not-miss but game-to t-aqa-péaqajaq. do-you-hit.

15 Qadékèn t-aqa-péoqadi, raqap mateba, kind maqaw-aqan Truly do-you-aim afraid be-not, eye inward-to n-aqa-bekapenöm-apé. do-not-you-look to the right or the left.

16 Udia top aqa-kèn aqa-na-poano, Udia, jataka, aqa-kêm Udia trap you-self you-for-me made Udia, fence you-self aqa-r-petat, Joati you-now-erect, Joati qaké aqa-kèn aqa-r-apekomok. dogs you-self you-now-train.

17 Toko aènd-amön amaberamön wak-amön ama-métèmberok-ain toko When stealthily row-away later-on lay back without then aènd-radé t-aqa-baka qadékèn; toko anggaép qadékèn amamétèmberok thief-man do-you-hit truly; when I-self truly lay-back abeqond amabeqaim toko anggaép. body-odour smelling then I-self.

18 Anok waw b-oqo-kakakon. I magic have-I-laid down.

19 Karium, to-aqa-komateqo. Out, have you freed. 


\section{APPENDIX I \\ DIVISION OF WORK}

Men

building the frame of the houses

for the men and the women:

cutting wood, carrying, and

erecting,

binding work with split rattan;

sewing the roofing;

laying the roofing,

building the walls of sago ribs in the houses for the men;

making hunting- and fishing-gear for men:

spears, bows, arrows;

manufacturing domestic utensils, water tube, sago beater, sieve

clips;

making weapons: spear, shield, dagger, drums, hunting-horns; making anus cover, mourningsymbols for men,

ornaments for men, cutting shells,

making dyes;

shooting birds (also for women);

digging springs in the sago-grounds and repairing weirs in the swamps and building hiding huts,

fish- and pig-traps;

hunting together with others;

scraping fish poison, hunting with bow, arrow and spear; choosing sago, cutting sago trees, pounding and carrying sago home;
Women

sewing the roofing,

building the walls of sago blades in the houses for the women; manufacturing fishing-baskets;

manufacturing fire tongs for getting the sago from the hot ashes; making perineal bands, skirts, ribbons (after childbirth), mourning-costumes for women, ornaments for women, strings of beads;

fishing together with other women, fishing with a basket, gathering bundles of weed; catching drugged fish; gathering edible plants;

pounding sago and carrying it home; 


\section{Men}

picking sago larvae;

picking woodworms;

laying out gardens, coconut- and banana-bushes and ground-fruits, the preparation of the food

(cf. women, on a small scale),

picking coconuts, providing their own firewood and water;

the care of the children, especially the boys after their admission to the house for the men;

fighting with bow and arrow, spear and shield;

beheading the slain;

wearing the marks of honour;

interpretation of the traditions and giving advice;

making contact with the spirits and shades;

pronouncing formulas (blessings

and curses);

searching and using medicinal

herbs;

the direction of the festivities;

making and singing songs;

being precentor, drumming, dancing with the men.

\section{Women}

picking sago larvae;

planting banana-bushes near the village;

the preparation of the food:

baking sago, meat and fish for husband and children;

rarely picking coconuts, providing firewood and water;

the care of the little children and the older girls;

fighting with wooden crow bars;

dancing with the hunted head; carrying the skulls of deceased relatives;

interpretation of the traditions and giving advice;

making contact with the spirits and shades;

pronouncing formulas (blessings and curses);

searching and using medicinal herbs;

contributing their share to the feasts, especially by raising pigs; making and singing songs; being precentor, drumming, dancing with the women.

Husband and wife went together to their sago grounds by land or by canoe. In times of danger they saw to it that they stayed fairly close to each other.

The women sometimes entered the men's house on festive occasions. The men entered that part of the women's house where their own wives had their places. There the men could also be nursed when they were ill. 
APPENDIX II

NAMES OF THE GROUPS

\begin{tabular}{|c|c|c|c|}
\hline Villages & Verschueren & Nieland & Butter \\
\hline $\begin{array}{l}\text { Masin } \\
\text { Wajru }\end{array}$ & $\begin{array}{l}\text { Toqom moqon-wir } \\
\text { Uwé } \\
\text { Kabaqajmu } \\
\text { Janaqojmu } \\
\text { Qanimu }\end{array}$ & $\begin{array}{l}\text { idem } \\
\text { idem }\end{array}$ & \\
\hline $\begin{array}{l}\text { Kandajmu/ } \\
\text { Kotup }\end{array}$ & $\begin{array}{l}\text { Kunda-wir } \\
\text { \{atimu } \\
\text { Wajmu } \\
\text { Imbé-wir } \\
\text { Ojoqota-qari } \\
\text { Obaqam-wir } \\
\text { Eketaqaj-wir } \\
\text { Kandajmu } \\
\text { Momenimu } \\
\text { Tapajmu: } \\
\text { \{ Jerokajmu } \\
\text { Kabajmu }\end{array}$ & $\begin{array}{l}\text { name of the } \\
\text { settlement: } \\
\text { Piaj } \\
\text { idem }\end{array}$ & \\
\hline Rajöm & $\begin{array}{l}\text { Qajmeqajmu } \\
\text { Tamaqajmu } \\
\text { Bandajmu } \\
\text { Qomeqajmu }\end{array}$ & idem & \\
\hline Moïn & $\begin{array}{l}\text { Waqatu-wir } \\
\text { Manggajmu } \\
\text { Tanggapajmu } \\
\text { also: } \\
\text { Moqojbimu } \\
\text { Paqajmu }\end{array}$ & $\begin{array}{l}\text { also: } \\
\text { Dimajmu } \\
\text { (see Togom) }\end{array}$ & \\
\hline Togom & $\begin{array}{l}\text { Dimajmu } \\
\text { Qajmeqajmu } \\
\text { Erokoajmu }\end{array}$ & $\begin{array}{l}\text { omits: } \\
\text { Dimajmu } \\
\text { (see Moïn) }\end{array}$ & \\
\hline
\end{tabular}




\begin{tabular}{|c|c|c|}
\hline Villages & Verschueren & Nieland \\
\hline Emeté & $\begin{array}{l}\text { Gandajmu } \\
\text { Bapajmu } \\
\text { Dadimu } \\
\text { Qomimu } \\
\text { Aperimu }\end{array}$ & idem \\
\hline Képi & $\begin{array}{l}\text { Aqaoèmu } \\
\text { Ikimu } \\
\text { Marapèmu } \\
\text { Kamaqajmu }\end{array}$ & idem \\
\hline Toba & $\begin{array}{l}\text { Qabunimu } \\
\text { Qajimu }\end{array}$ & $\begin{array}{l}\text { Kabanjemu } \\
\text { Kondomi } \\
\text { Sinu (Biokoq) }\end{array}$ \\
\hline $\begin{array}{l}\text { Waman } \\
\text { (Jamuj) }\end{array}$ & $\begin{array}{l}\text { Tamaqojmu } \\
\text { Qabunimu }\end{array}$ & $\begin{array}{l}\text { Distinction: } \\
\text { Waman: Wambajmu } \\
\text { Manggajmu } \\
\text { Tenggenemu }\end{array}$ \\
\hline
\end{tabular}

$\begin{array}{ll}\text { Dagimon } & \begin{array}{l}\text { Tamaqojmu } \\ \text { Kamoqopimu } \\ \text { Miaqajmu }\end{array}\end{array}$

\begin{tabular}{|c|c|c|c|}
\hline $\begin{array}{l}\text { Jarmoqojn } \\
\text { (Hagām) }\end{array}$ & $\begin{array}{l}\text { Jarmoqojn } \\
\text { Kajmu } \\
\text { Qajnaqajmu } \\
\text { Aqajbaqajmu }\end{array}$ & $\begin{array}{l}\text { addition: } \\
\text { (on the river } \\
\text { Bapaé) } \\
\text { Ronamembara }\end{array}$ & \\
\hline Répi & $\begin{array}{l}\text { Gètému } \\
\text { Tanggipejmu } \\
\text { Béagajmu } \\
\text { Tinggipejmu }\end{array}$ & $\begin{array}{l}\text { Kajtemu } \\
\text { Makobimu } \\
\text { Bajekajmu } \\
\text { Tenggepajmu }\end{array}$ & $\begin{array}{l}\text { Kajtimu } \\
\text { Mohowimu } \\
\text { Bagajmu } \\
\text { Temgapajmu }\end{array}$ \\
\hline Enèm & $\begin{array}{l}\text { Wanggajmu } \\
\text { Bapejmu } \\
\text { Nari-qari } \\
\text { Oqomemu }\end{array}$ & idem & $\begin{array}{l}\text { idem } \\
\text { omits: } \\
\text { Oqomemu }\end{array}$ \\
\hline Kogo & $\begin{array}{l}\text { Baniému } \\
\text { Tinggenimu: } \\
\left\{\begin{array}{l}\text { Qaqaimu } \\
\text { Janggepop-wir } \\
\text { Tapaqa-qari }\end{array}\right.\end{array}$ & $\begin{array}{l}\text { idem } \\
\text { moreover: } \\
\text { Kajemu }\end{array}$ & $\begin{array}{l}\text { Banjemu } \\
\text { Gagajemu }\end{array}$ \\
\hline
\end{tabular}




\begin{tabular}{|c|c|c|}
\hline Villages & Verschueren & Nieland \\
\hline Kadöm & $\begin{array}{l}\text { Tambaqajmu } \\
\text { Gandemu } \\
\text { Kakumé } \\
\text { Yajimu } \\
\text { Abaqajnimu }\end{array}$ & $\begin{array}{l}\text { idem } \\
\text { has instead of } \\
\text { Abaqainimu: } \\
\text { Makatemu }\end{array}$ \\
\hline
\end{tabular}

\begin{tabular}{lll}
\hline Wanggaté $\quad$ omitted & Kamkajmu \\
& Topemu \\
& Kakjemu \\
& Bariemu
\end{tabular}

\begin{tabular}{|c|c|c|c|}
\hline Katan & $\begin{array}{l}\text { Gandajmu } \\
\text { Kamakajmu } \\
\text { Geimeqajmu }\end{array}$ & $\begin{array}{l}\text { Katowa-wir } \\
\text { Kaimeremu } \\
\text { Abaqajmu }\end{array}$ & $\begin{array}{l}\text { Kamakajmu } \\
\text { Kamarajmu } \\
\text { Mijagam } \\
\text { Karapimu }\end{array}$ \\
\hline Jatan & $\begin{array}{l}\text { Oaj } \\
\text { Jagepitemu } \\
\text { Mujaq }\end{array}$ & $\begin{array}{l}\text { idem } \\
\text { moreover: } \\
\text { Digita }\end{array}$ & $\begin{array}{l}\text { Wāj } \\
\text { Mujaq }\end{array}$ \\
\hline Davora & $\begin{array}{l}\text { Mujaqa } \\
\text { Umametemu }\end{array}$ & idem & $\begin{array}{l}\text { Mujaga } \\
\text { Momitumu }\end{array}$ \\
\hline Mandaw & $\begin{array}{l}\text { Emoqojn } \\
\text { Ribaqamoqojn }\end{array}$ & idem & idem \\
\hline Mur & $\begin{array}{l}\text { Jaduhamangk } \\
\text { Maburmugu-wir } \\
\text { Japaqajemu } \\
\text { Jaqojemu }\end{array}$ & $\begin{array}{l}\text { idem } \\
\text { moreover: } \\
\text { Embamogojn }\end{array}$ & $\begin{array}{l}\text { Jaduhamag } \\
\text { Jaguhimu }\end{array}$ \\
\hline Monana & $\begin{array}{l}\text { Jaqujemu } \\
\text { Japaqajemu } \\
\text { Bapému } \\
\text { Qomeqejemu } \\
\text { Kapopojnd } \\
\text { Wandemuqojnd }\end{array}$ & & $\begin{array}{l}\text { Jaowimu } \\
\text { Bafimu } \\
\text { Komajmu }\end{array}$ \\
\hline Koba & $\begin{array}{l}\text { Ronpoqura-wangga } \\
\text { Noqoj-wangga } \\
\text { Barumaq }\end{array}$ & & \\
\hline
\end{tabular}




\begin{tabular}{|c|c|c|c|}
\hline Villages & Verschueren & Nieland & Butter \\
\hline Gogojamön & $\begin{array}{l}\text { Rimbaqan } \\
\text { Niqoj-wangga } \\
\text { Anuimu }\end{array}$ & & \\
\hline Ima & $\begin{array}{l}\text { Ronoqowa-wir } \\
\text { Bapému }\end{array}$ & & \\
\hline
\end{tabular}


APPENDIX III

\section{BAKUI-IN-WU \\ (Bakui-his-mother)}

Bakui-in-wu maqaé boqamön ku-tabu gani-amön Bakui-his-mother formerly of no use she-was, spinster-as-a énekem bé-raqaé kind-an ku-bajnonqk arupqamör. her husband he-was-not sleep-to she laid down she by herself.

Aw kakan ura-kén bob-aqan ké-o-ne-bajnonqk.

Kind-ruk

$A w$ then dark-at breast-on he-(on)her-down-he-laid. To sleep-from ku-bep-qaqaém endaqam(a)kén ku-menomon ku-paq anok kérékkén she-up rose also she wondered she said me (with)who éa-qaqaéb oangga kopéamön kabi-aqan. Nanaman he-had intercourse sperm it-moistened mat-on. On and on kajndenamön. Tapaq jando-kir ké-o-péréb kudé so. $\quad$ Sun hand-hot he-(on) her-laid this(she) ku-beromon tapaqèr. Tapaq maqaé ké-qaqaéb she-turned away sun-because of. Sun formerly he-had intercourse éa kirambak. Jaqati kind-an ku-puèn, kabi penis hot-too. As if sleep-to she laid down, mat(with) ku-bep-qowk, kind jateqond-kén ku-bek(e)-tupu mok. she-over-covered, eye seemingly she-down-closed.

Kupaq, anok-kén n-oqa-bendebu, kind-an oa-puèn-qajkire, She said, I [stress] let-I-stay awake, sleep-to not-lay down-not, jateqond-kén réka ku-ber-qaqanak réka am-(e) ménéaqajaq. stealthily firewood she-aside-pushed fire on to kindle.

Kind-an marep ku-kunémök. Moqon-rék ké-bep-qaém. Aw jateqond-kén Sleep-to arms she spread. Earth-from he-up-rose. $A w$ stealthily raqap-an réka a-bek-ramboqoa am(e) naqajn a-ber-qaqanak. fear-for firewood down to extinguish causing pushing aside. Aw-kén ut am (e) naqajn, kudé ramu qadékén am(a)ku-rumok, $A w$-this dark causing, she legs thoroughly down-opening, Aw qajomaen(e) kén bob-aqan am-o-nuèn ké-o-nekedök, Aw slowly breast-on her (on) laying he her (on) down laid, ké-qaqaéb. Qatubu-amön aperobu. Am-o-ber-aput oangga he had intercourse. Corpse-as being. Her (from) withdrew sperm 
kabi-apé apaqaqaénda ku-o-kéoqodi ta-oa-tak-kan. Aw mat-on being in she-him-embraced almost-to-go when. $A w$ ku-pitök-kan, ké-rdajkermon. Uj ku-beqono, she seized-when, he broke to pieces. Stone-axe she took, ku-baqajkamok dodo, ku-o-nonggab, réka-aqan she cut in the middle, she him divided, fire-over ku-ber-qotoqot, réka-aqan ku-péakon dodo she over-roasted, fire over she roasted by halves ku-p-o-nonggab, muku ku-péakon, kèndé ku-péakon, she-down-him-divided, head she roasted, tail she roasted, ramu marep ku-péakon. Ku-paq: anok tapaq-èr raqap legs arms she roasted. She said: I sun-because of fear t-oko-namo-an. Maq taqao nanababu. Tapaq ké-paq having I had-because. Children surely they will die. Sun he-said ayok éaqa-babu-an kajnden-amön. Kudé taw kandöm you you die will so-as. This woman belly ku-bèn, qobu-aqan ku-tak. Nanik moqon-aqan she-got pregnant, wood-to she went. Another place-to ku-roqo. Kandöm poqojarap ko-poao. Kudé taw she removed. Belly big it became. This woman ku-pekaku, ku-menöng-kaké kudé taw she gave birth, she both she gave birth this woman éar-qaqaéb arép-kadum, ku-menöng-kaké-amön. he had intercourse him-with, she-both-gave birth as.

Aw-kén ké-o-poa ku-pekaku éké Qajndaoqon. $A w$ [stress] he-her-begot she gave birth name Qajndaoqon.

Maq ke-o-poa Aw-kén wir kakan ki-biriak Child he-her-begot $A w$ people afterwards they sprang qapqaép. Tapaq tumi ké-é-be-kemberok ayok quickly. Sun word he-them-down-threw you [plural] nan-é-babu; maq anokkén n-ok a-poako oa-kababu will-you die; children I [stress] if I [plural] beget not-die qajkire. Ayok Aw-kén bé-péa kajnden-amön not. You [plural] $A w$ [stress] he-begot so-as para-babu-an; anok-èr raqap-an toroka-èr. you [pl.] die-will; me-because of afraid of that is why. 


\section{APPENDIX IV}

\section{RECURRENT JAQAJ TERMS}

abur breast

abur-é husband of abur-wu

abur-wu FaSi, MoSi who suckles an abur-maq

abur-maq suckling

aburi( $(t)$ female ground spirit

ada-wir invited guest attending a feast (opposed to abaqa-wir, invited

guests who stayed away)

Ajré ancestor of the Jaqaj

akiaq traditional advice

akiaq-tumi/tibu advice

akiaq-radé/taw male/female counsellor

amör reciprocally

amör-ain-amön without compensation

api $\mathrm{FaFa}, \mathrm{MoFa}$, grandchild, Brgr-

child, Sigrchild, grch of parallel-

and cross-cousin, ancestor, spirit

aröm affinal relative

babaé ancestor

baj sago

bana spirit

bana-maq child of a spirit

batik pig

batik-jamé pig feast

batik-oana tusk of a boar

bor blood relative, friend

buaq settlement, village

dépi sperm

diaqandamön together with

éamé-moqon abode of the dead

éb song

éb-éké song name

enékèm/enékum husband/wife

$e$-qari father's people

ero to share food

et to call names

emu his/her grandparent, his/her grandchild ia male genital

ia-radé male

idöm shade of the deceased

imu group

jakatep goods

jakatep-amön against payment

jakatep-nati goods instead of an

exchange sister

jamba initiative in sexual intercourse

by the male partner

jamé feast

jamé-èr because of feasts

jando-é foster father

jando-wu foster mother

jando-maq foster child

janggo meat

jangk fish

jaqar/jaqanda male ground spirit

jaqati lie, not true

jaqati-re not true, for fun

jo female genital

jo-moké clitoris

joqbera contact with the spirit world

joqbera-radéltaw male/female seer

$k a k i$ relative in another settlement

kamioarup first wife

kamo moon

kamo oana crescent of the moon

kando falling star

kandöm kuben pregnant

kéame, kuame, koame he (she, it) is there

kéaqab bird of paradise

képaq he said

kèri story

kud head-hunting basket

$k u j$ head-hunting raid

kuj-radé/wir head-hunter/s

maémeta secondary wife 
maq child

maqati permanent

maqati-èr to be permanent maqati-tapaq everlasting sun maqaw inside, interior, deep maqaw-tumi secret language maqaé former, of the past maqaé-kèri myth

mar spear

mar-pit well with spears stuck in it ménaqaé partner in killing and

beheading a victim

mendaq exchange partner in marriage mim quarrel

$m o$ anus

mo-é anus father

mo-maq anus son

mokélu/o soul (male/female)/core

moké kérium the soul has left

moké-maq soul which gives life to

an unborn child

moké-radéltaw soul of a deceased

moqon earth

moqon-bana ground spirit

moqon-maq ground spirit

moqotu sister-in-law

muj water

muj-bana water spirit

muku head

muku-éké head/skull name

muku-jamé head/skull feast

\section{naé my father}

nakaèri partner, one possessing the skull, the other the jaw

nama-éb mourning song namön/namun male/female elder brother/sister, elder cousin

naröm term used between friends, one of whom borrowed the name of the other

nati exchange brother/sister

natik giver of an exchange sister

natu children from two exchange marriages

parents and children related by adoption

ndajin reciprocal term used between

friends, one of whom gave his

child the name of the other

ndat canoe on trestles

nit boraqaé the breath has gone nobo affinal relative (general term) nokon affinal rel., women speaking

to women

noqoki tapaq young men

oana mark of honour made out of the tusk of a boar

pajo coconut

pāpa shame

paqadi penis

pidoq song name; speech of war-

leader mentioning his heroic deeds

pipi suspicion

poqoj-radé/wir war-leader/s

poqoj-tok mark of honour (a

decorated bamboo knife)

poqura old term for a jaqar

qadéarep true

qadékén thoroughly

qajomaèneken slowly

qapaqap quickly

qajndaw men's house

qajndaw-inebaq male affines

qajngga shell nose ornament (two

crescents)

qari sub-group of imu

qondin sago grub

qonoqomör festive meal

qoqom big spear

qowa waist-band made of human hair

radé/wir poqoj leader/s

radélanokondin my husband

ramoq mark of honour (a decorated gourd)

ramu-mendaq secondary mendaq

rara medicine

rara-wir-kineqaéb killing medicine

ringgi anus

roqoj woman's skirt

rumba outside, corpse

taém sago-leaf sheath

takwèk/takwowk born on the same day, male/female

taj-bor relative through the mother

taj-rara love medicine

taker-éke hair name

taker-jamé hair feast

taker-maq hair feast candidate

tamangkjak tobacco

tao to beat the canoe with an oar 


\author{
tapaq sun \\ tapaq maqati old man \\ tapaq kandikén sun standing apart \\ tapaq-kind-kan under the eye of the \\ sun \\ taqam food taboo \\ taté dance \\ taw/taj woman/women \\ taw anokondin my wife \\ taw-jamé wedding-feast \\ tibu-tumi see akiaq \\ tok war, bamboo knife, mark of \\ honour \\ tok-éb war song \\ tok-radé/wir head-hunter/s \\ tom initiative in sexual intercourse \\ by the female partner \\ tom-éb songs about forbidden \\ intercourse
}

toqojia soul of beheaded enemy tumi word, speech, language

$u j$ stone axe

uwa womb

wamba scrotum

watoq body

waw supernatural power

wèk/wowk younger brother/sister/ cousin

wir people, men

wir-bor relatives through the father

wir-dé family tree

wir poqoj leaders

wuri women's house

wuri-inebaq female affines

wu-qari mother's people 


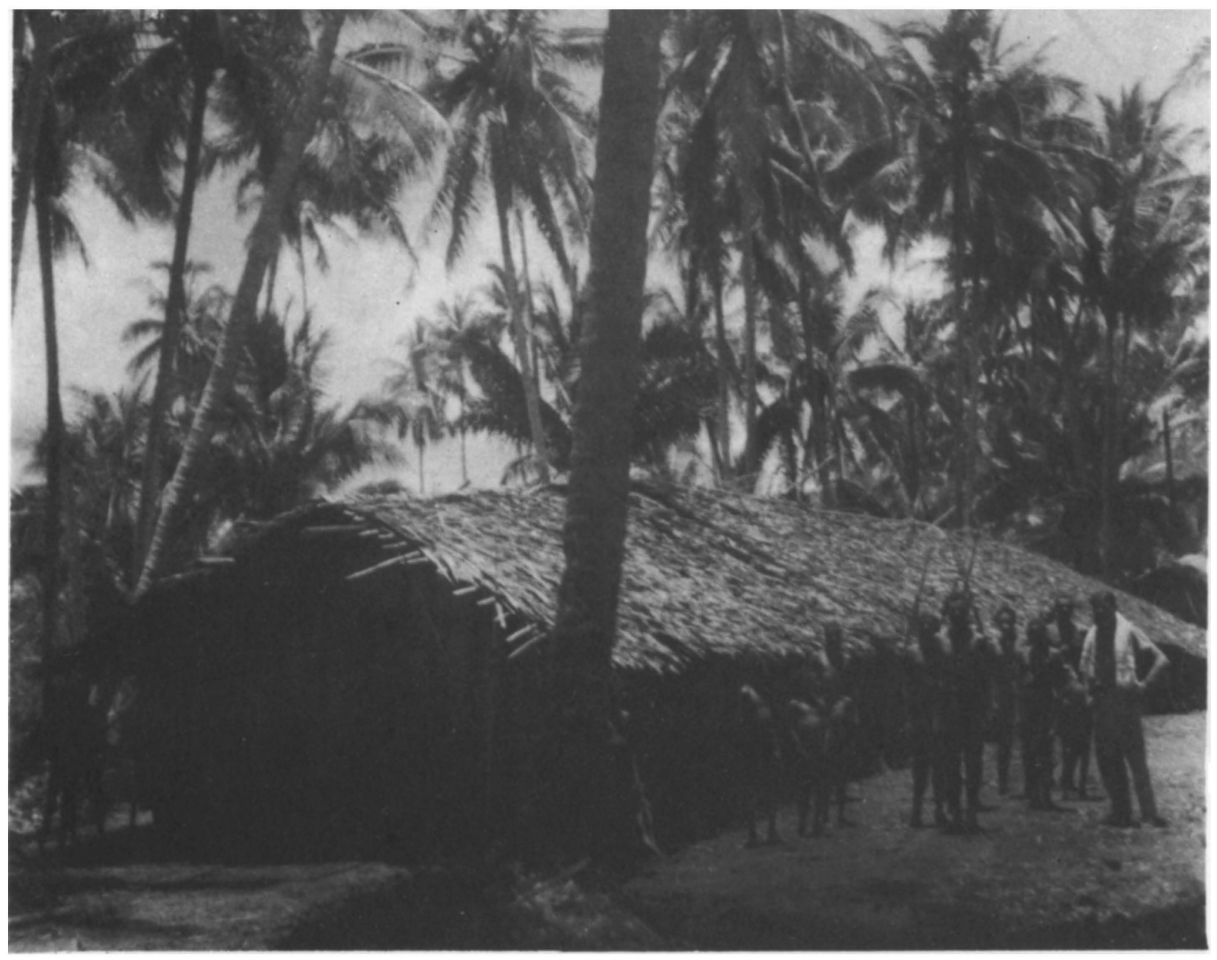

Plate 1. Men's house.

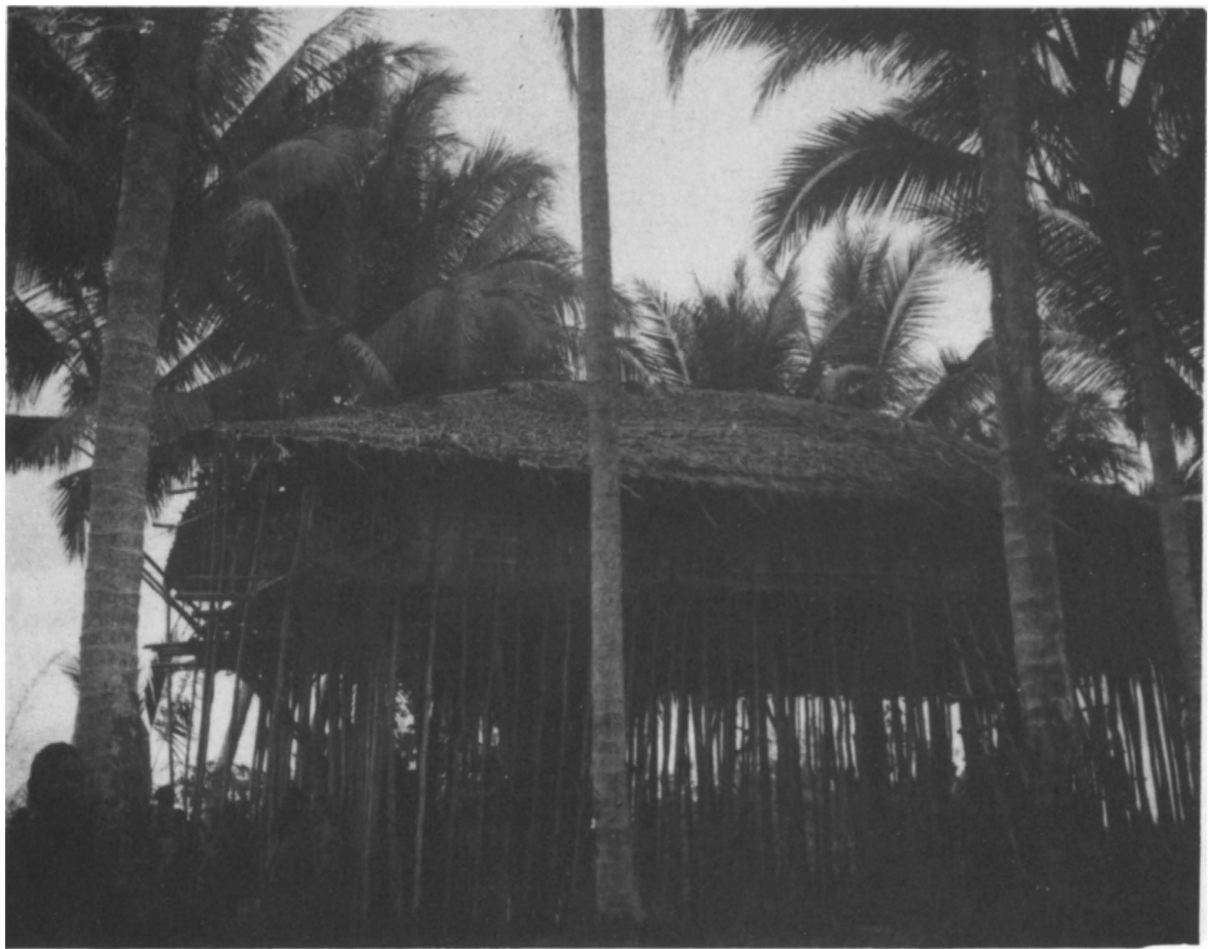

Plate 2. Women's house. 

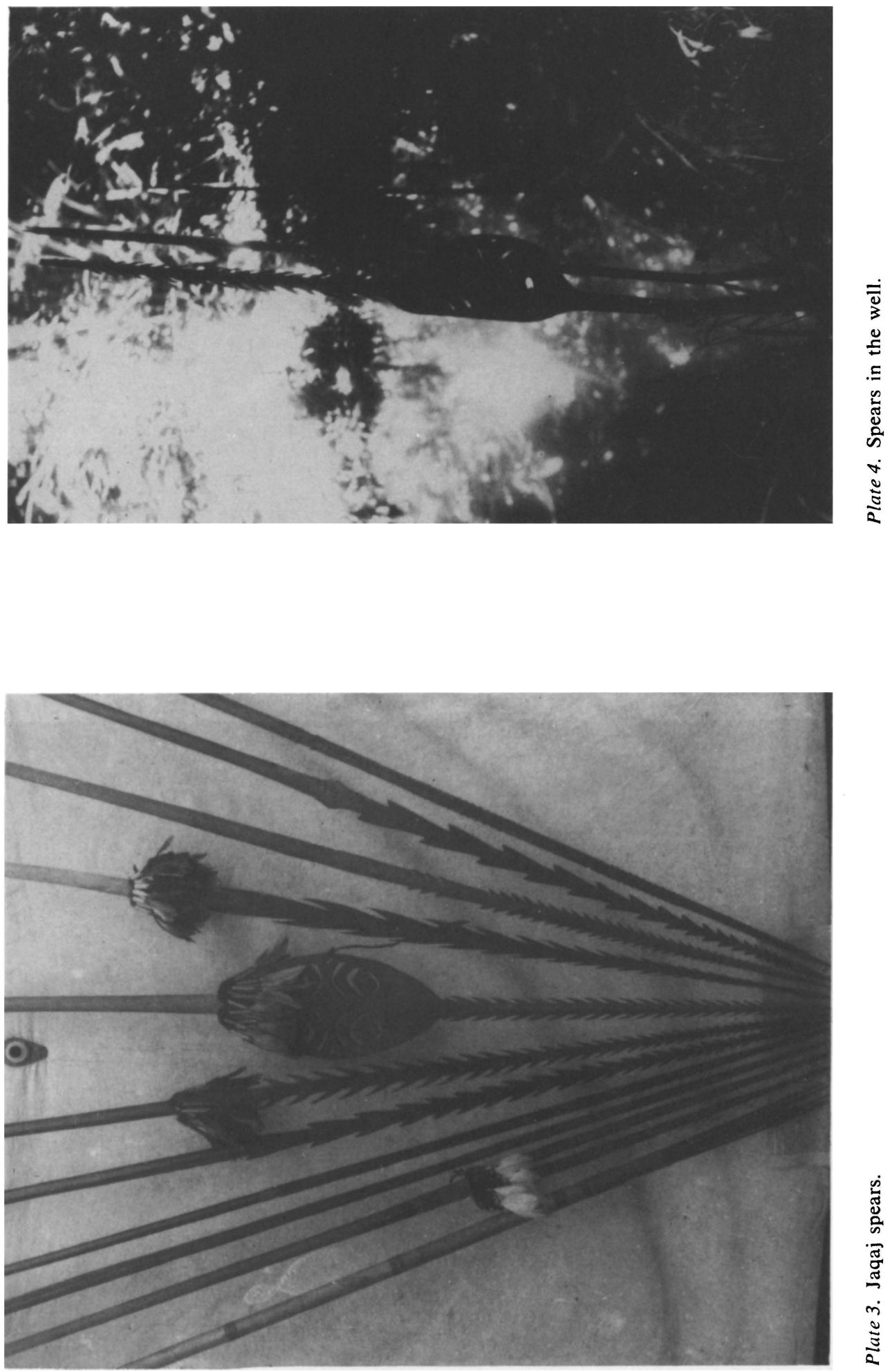


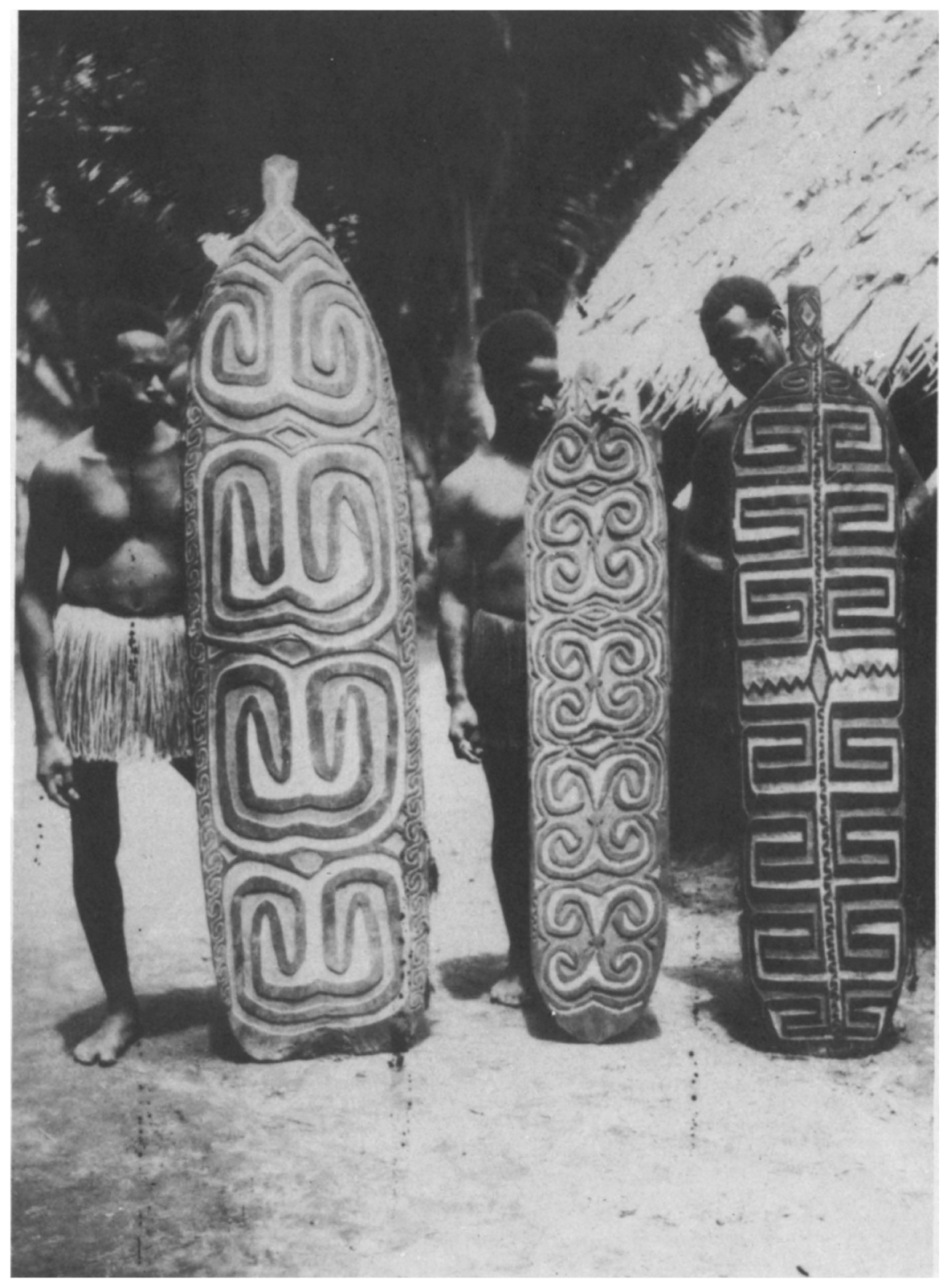

Plate 5. Shields. 

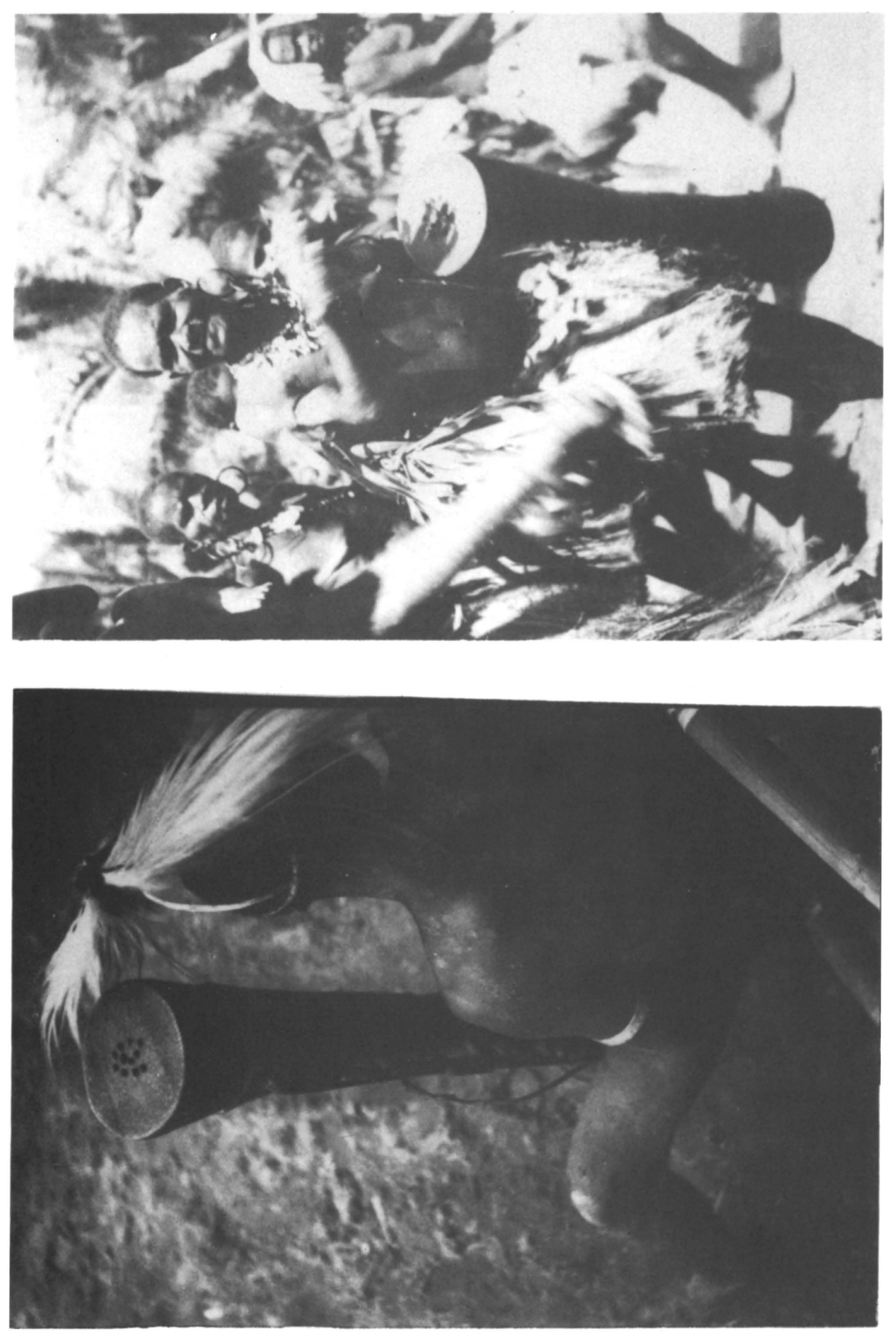

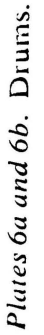



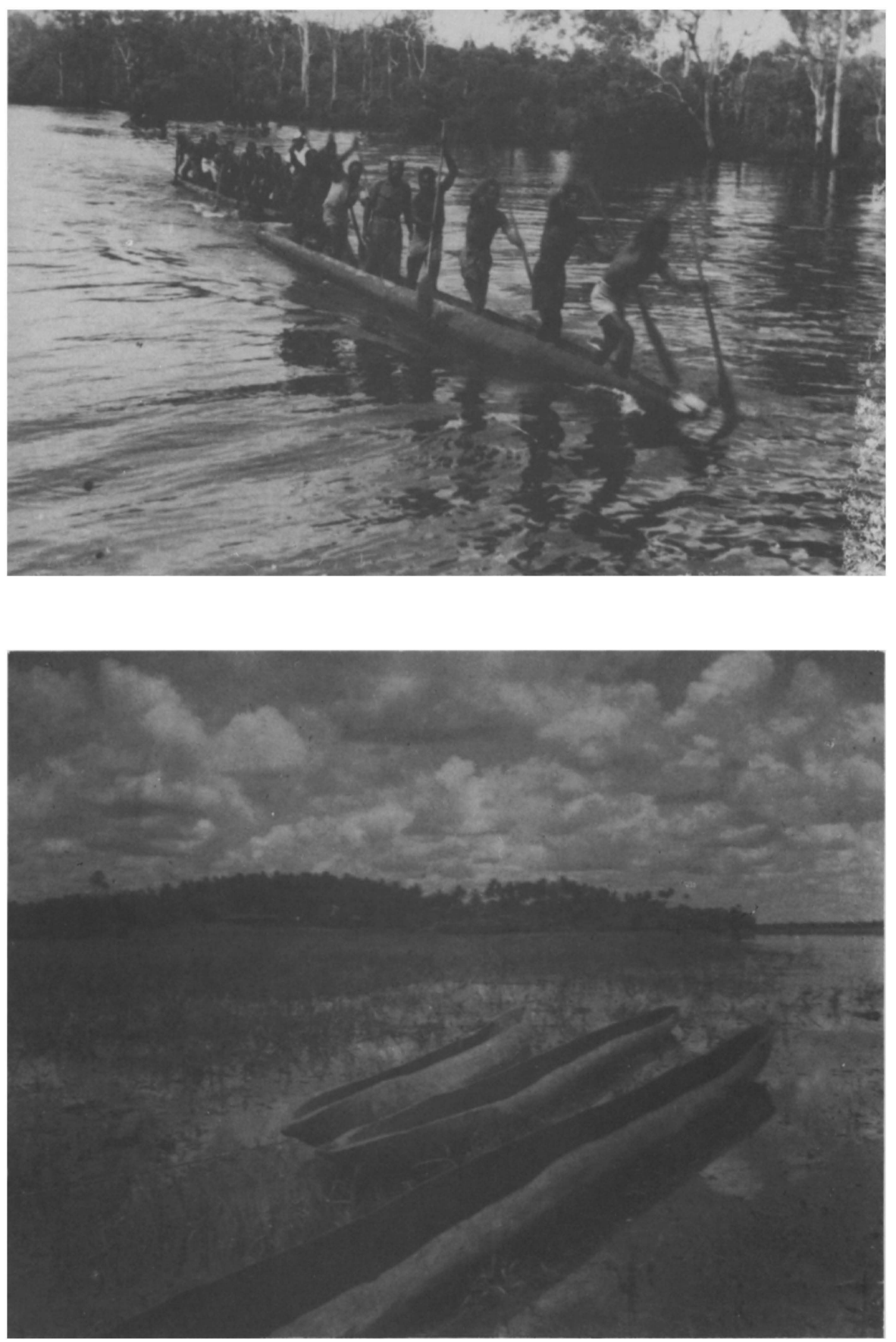

Plates $7 a$ and $7 b$. Canoes. 


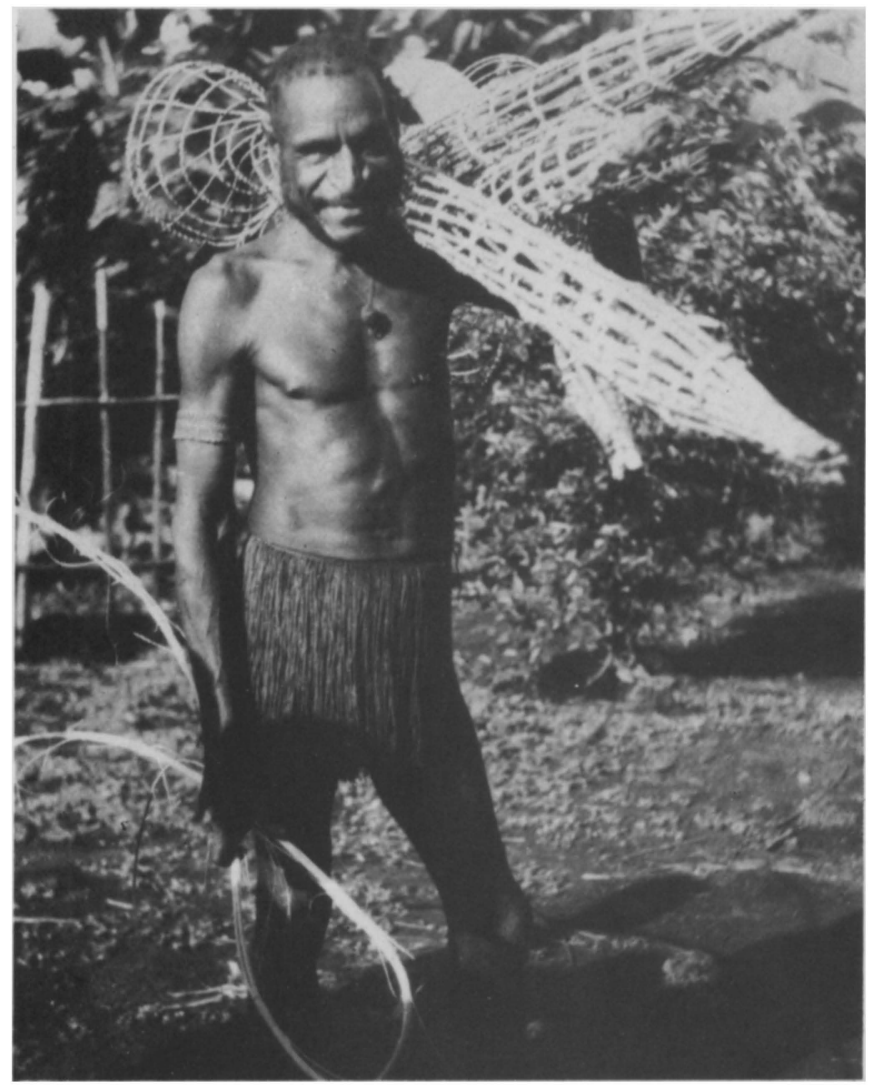

Plate 8. Fish traps.

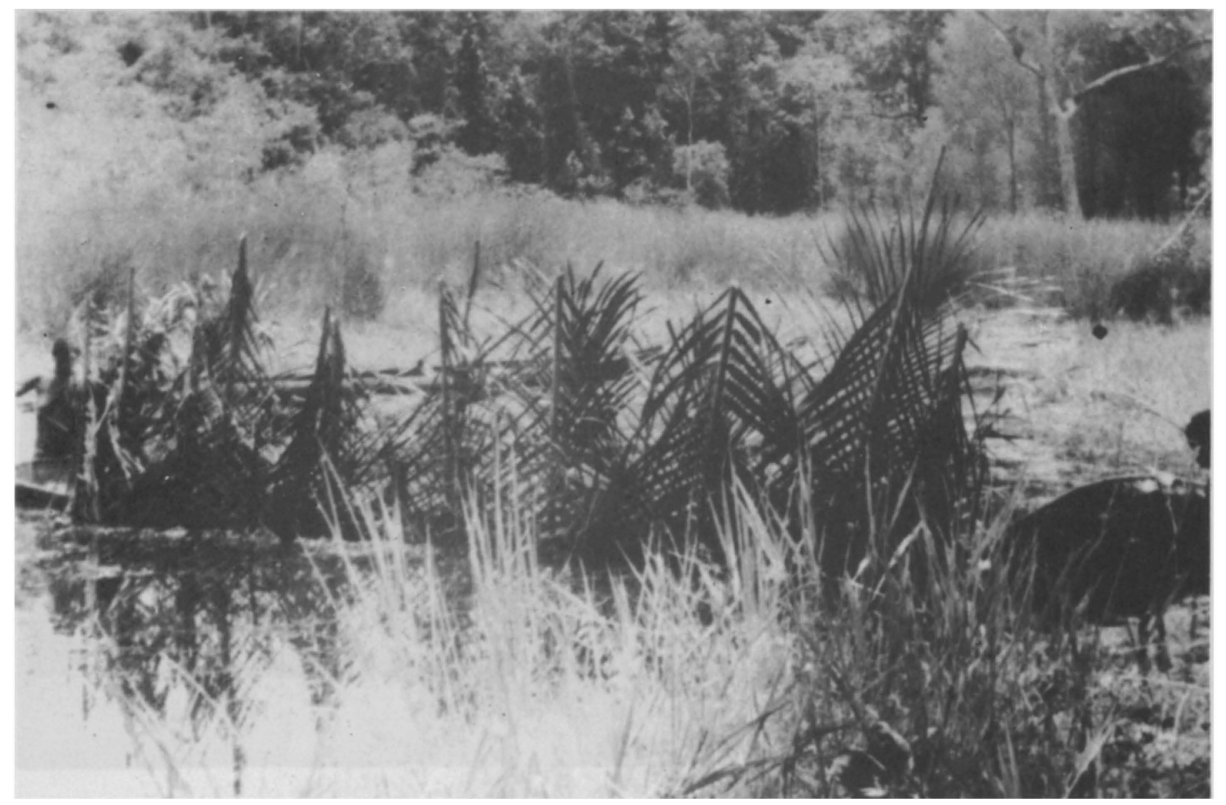

Plate 9. Weir. 


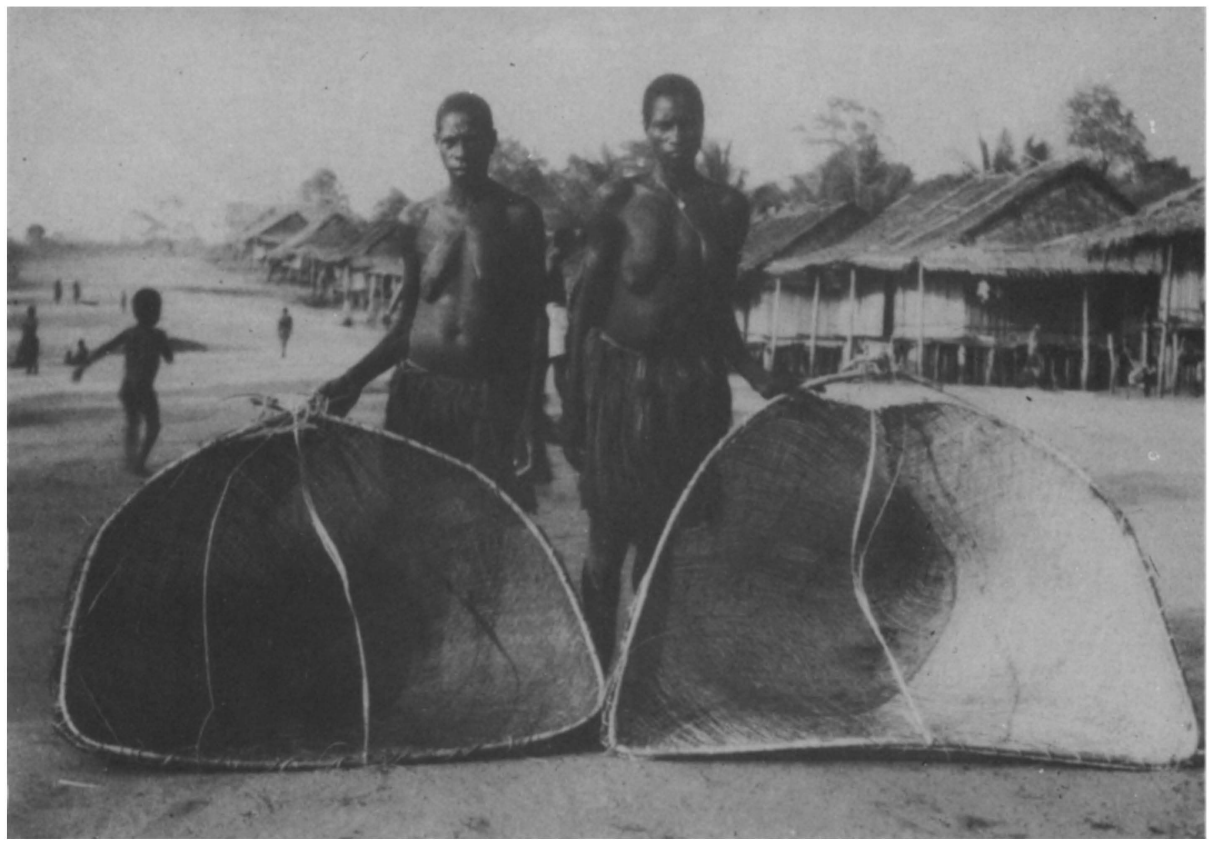

Plate 10a. Fish basket.

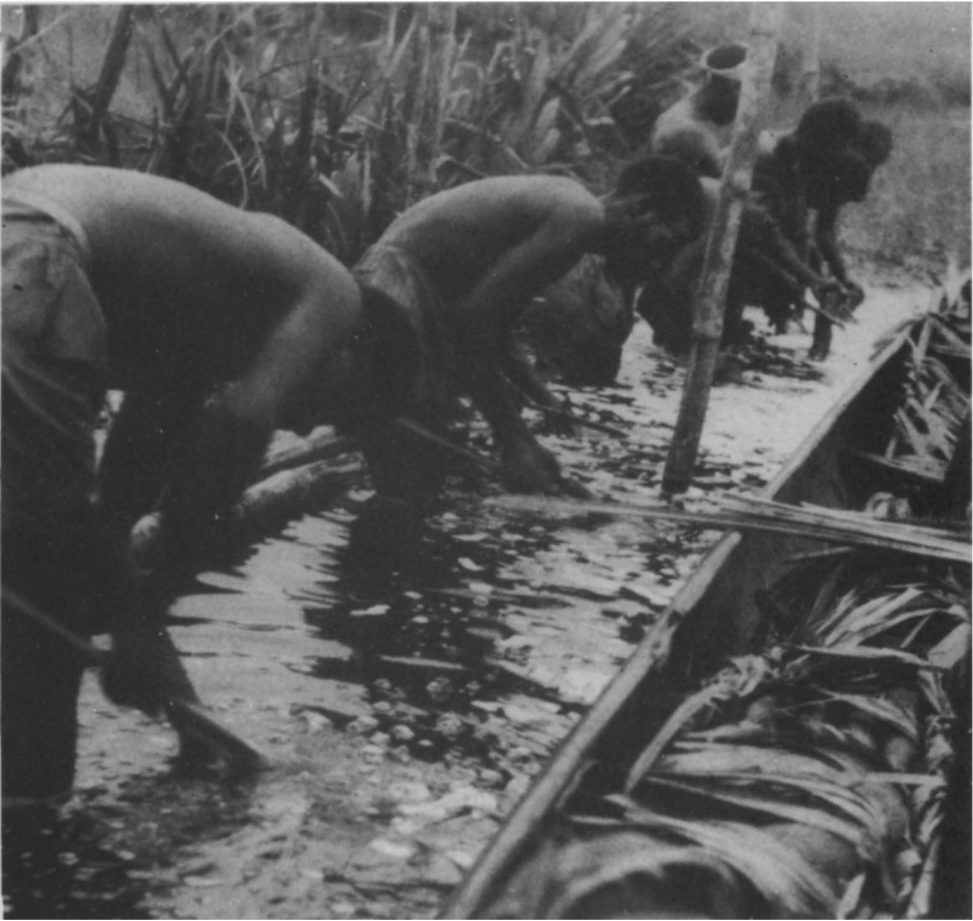

Plate 10b. Fishing with fish poison. 

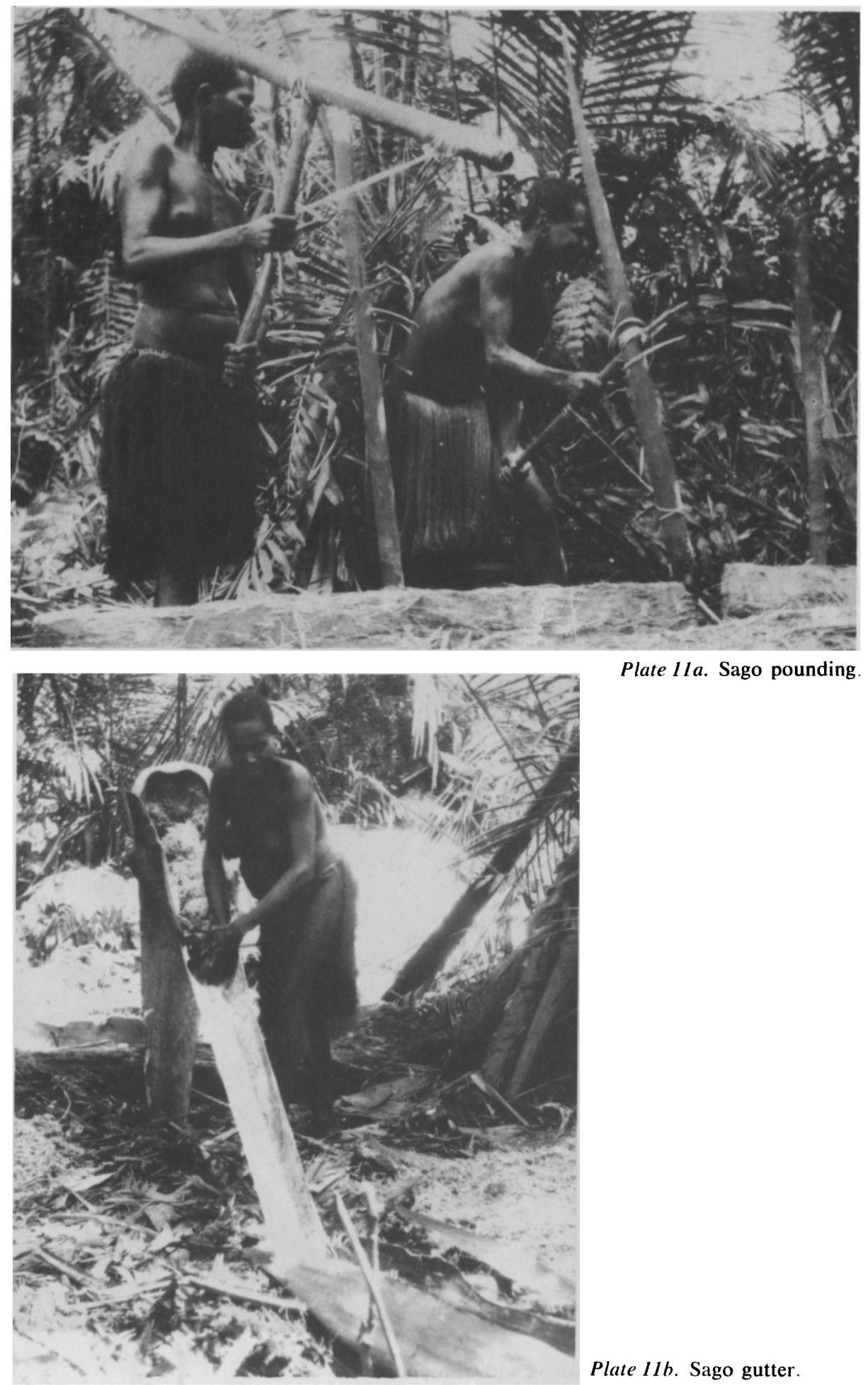

Plate 11a. Sago pounding

Plate 11b. Sago gutter. 

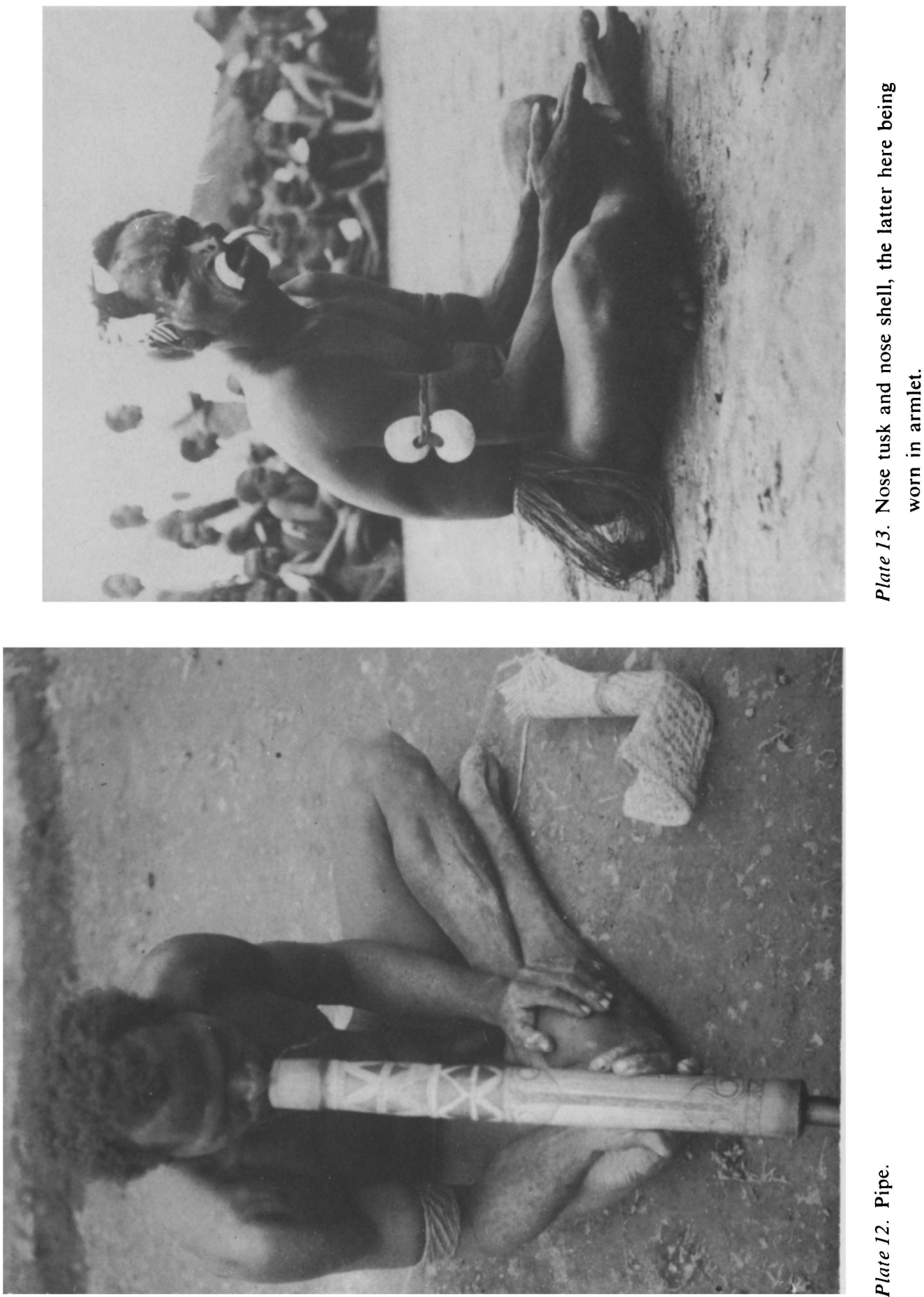

$\stackrel{0}{2}$
$\vdots$
$\frac{1}{2}$ 

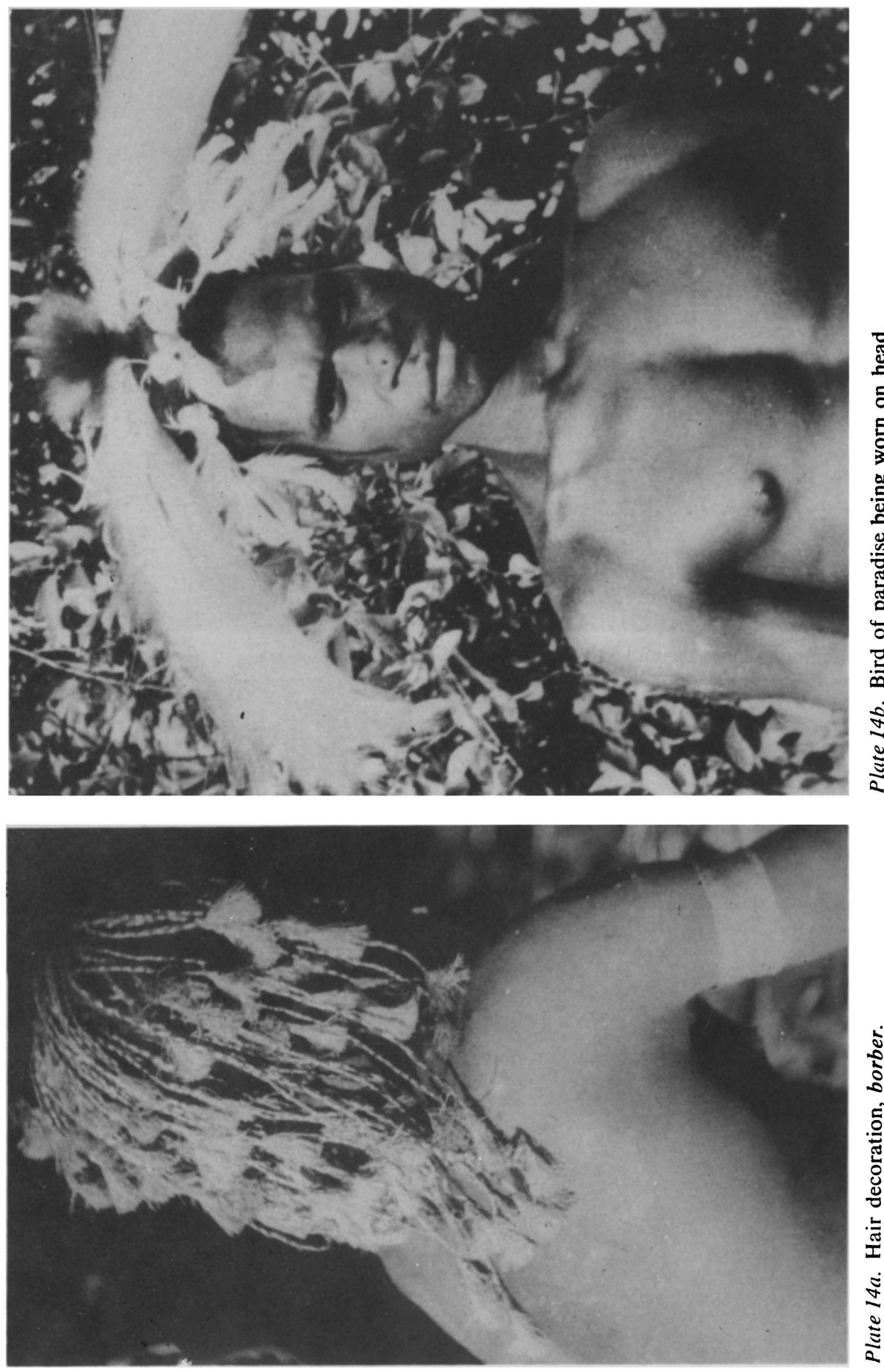


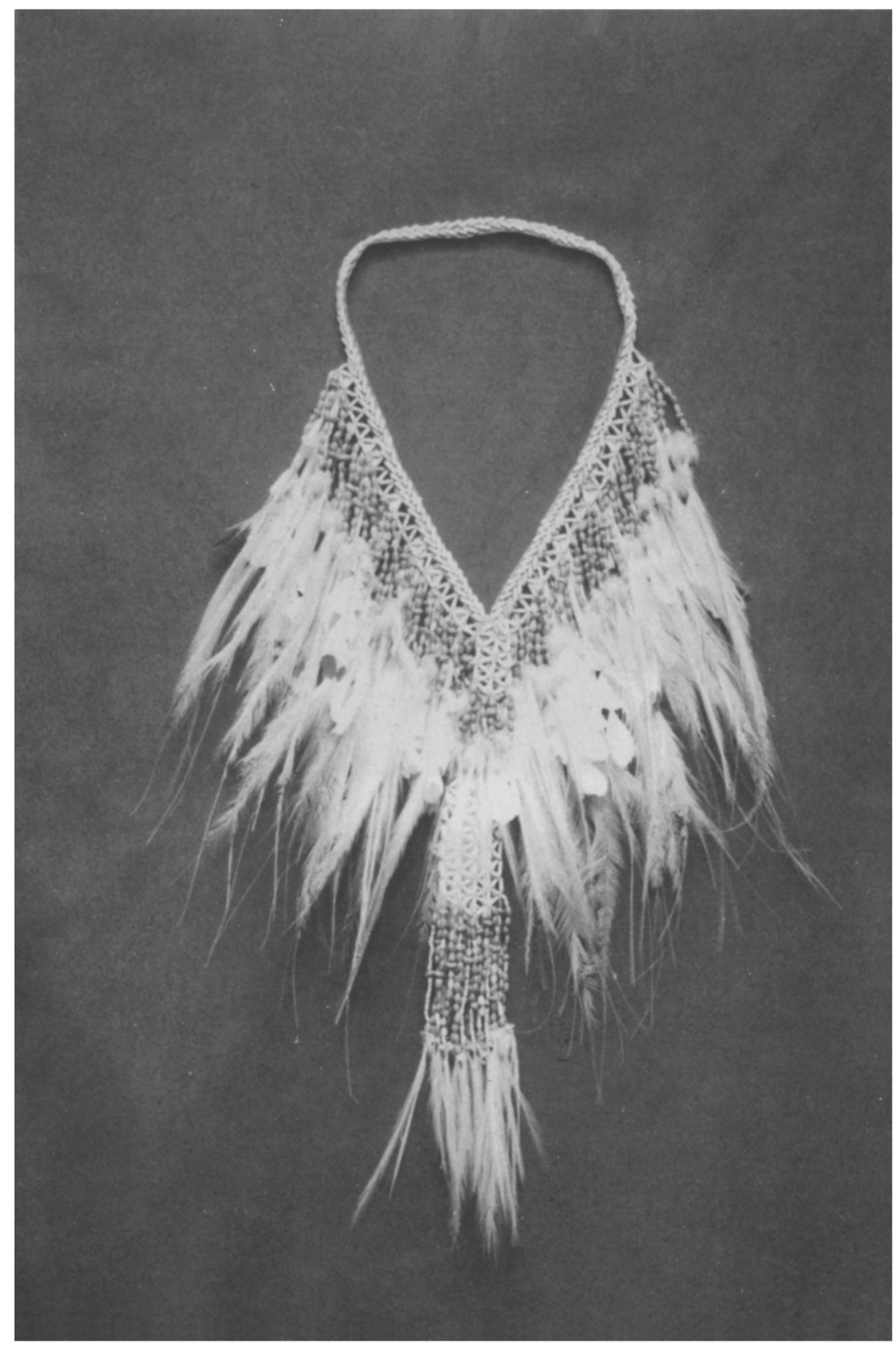

Plate 15. Mark of honour, ramoq. 


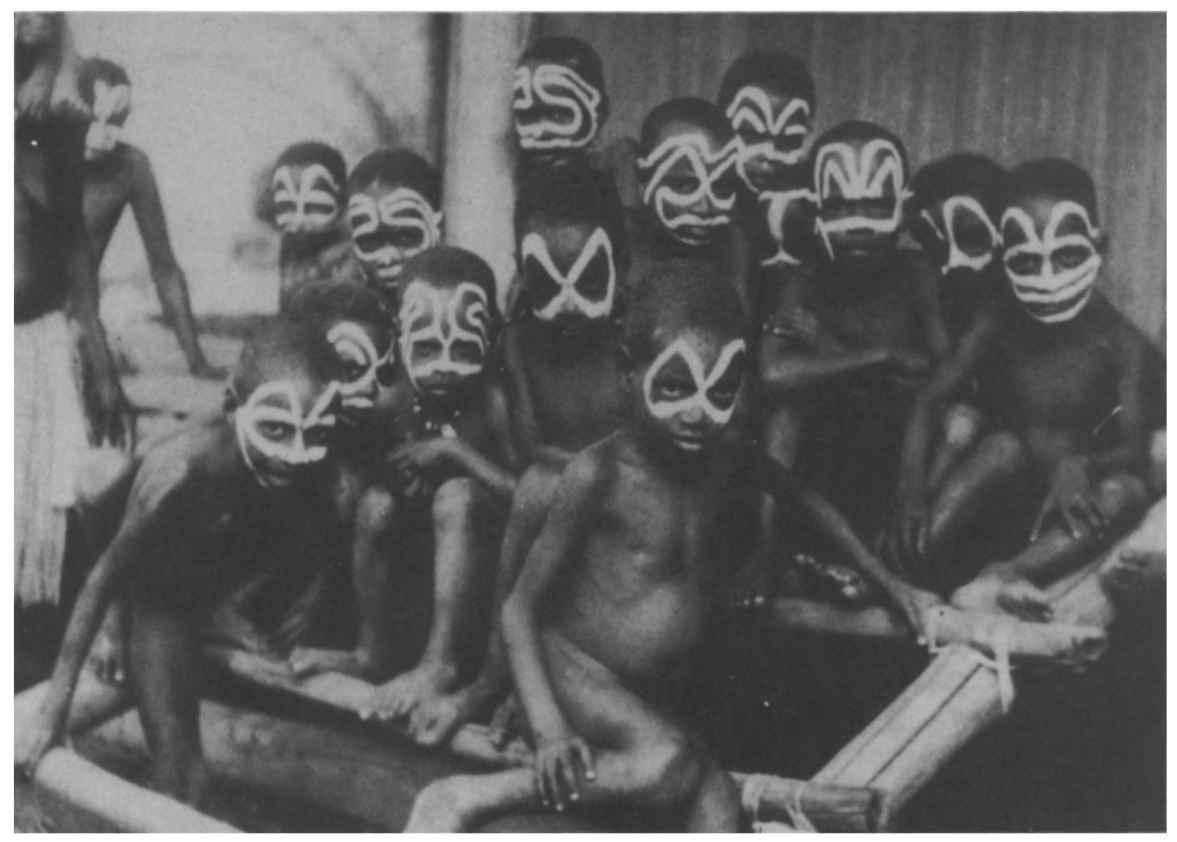

Plate 16. Butterfly motif.

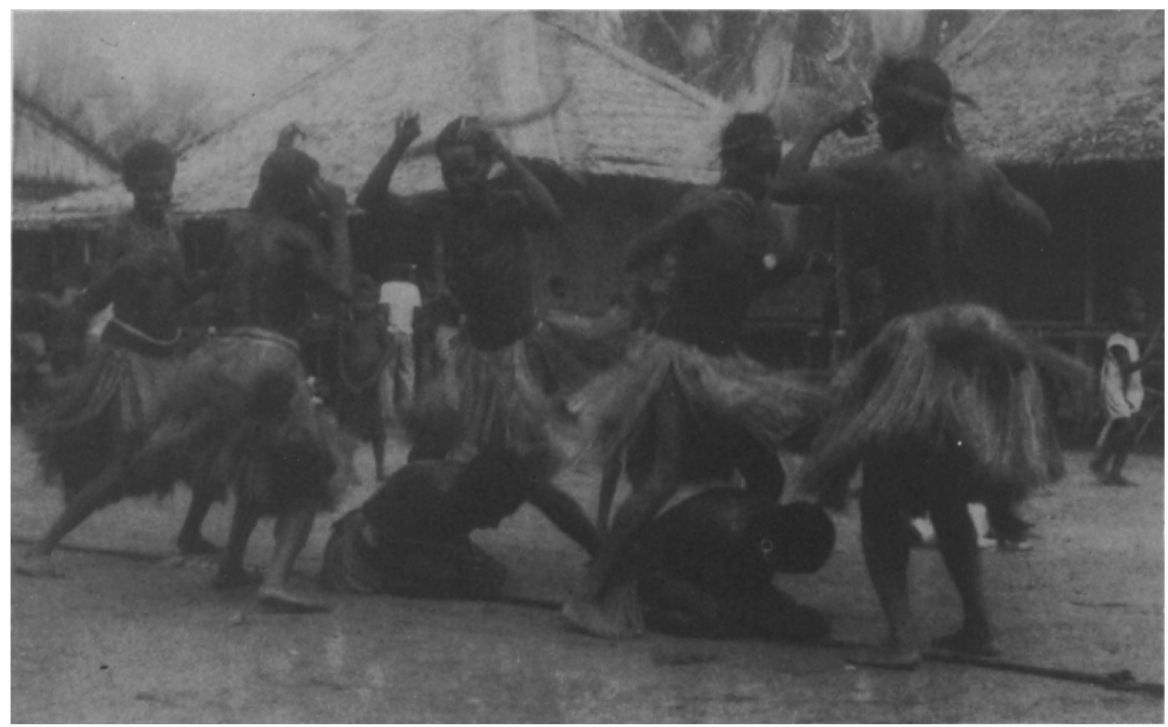

Plate 17. Kéaqab-taté, dance of the bird of paradise. 


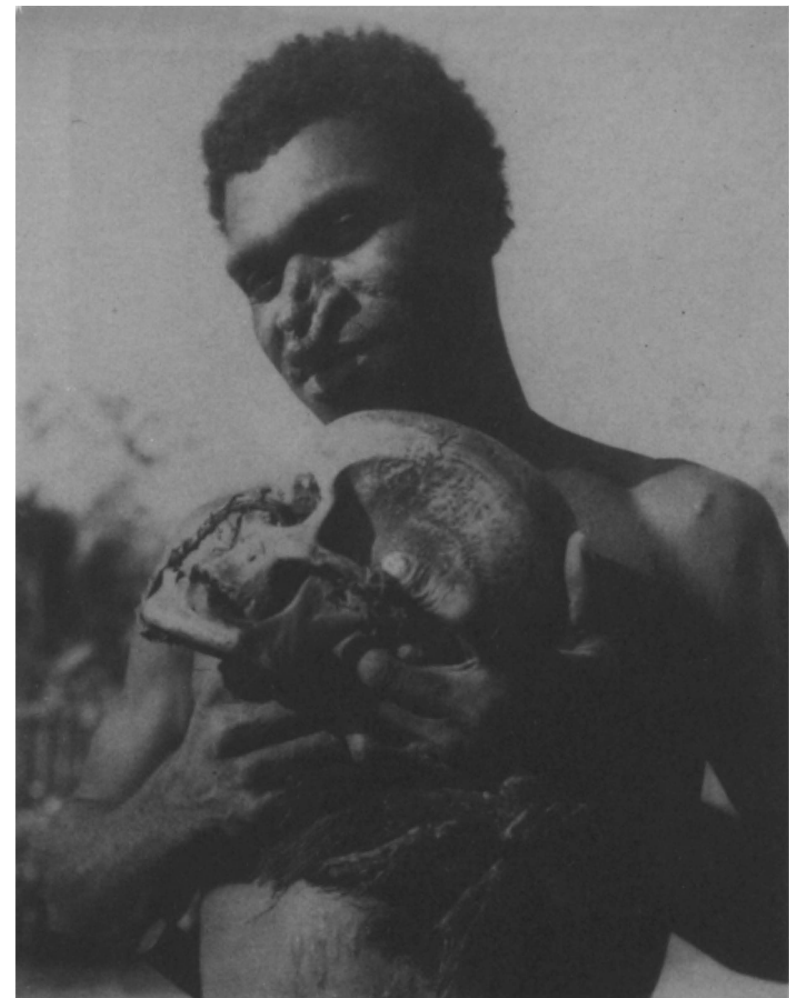

Plate 18a. A Jaqaj with the skull of an ancestor.

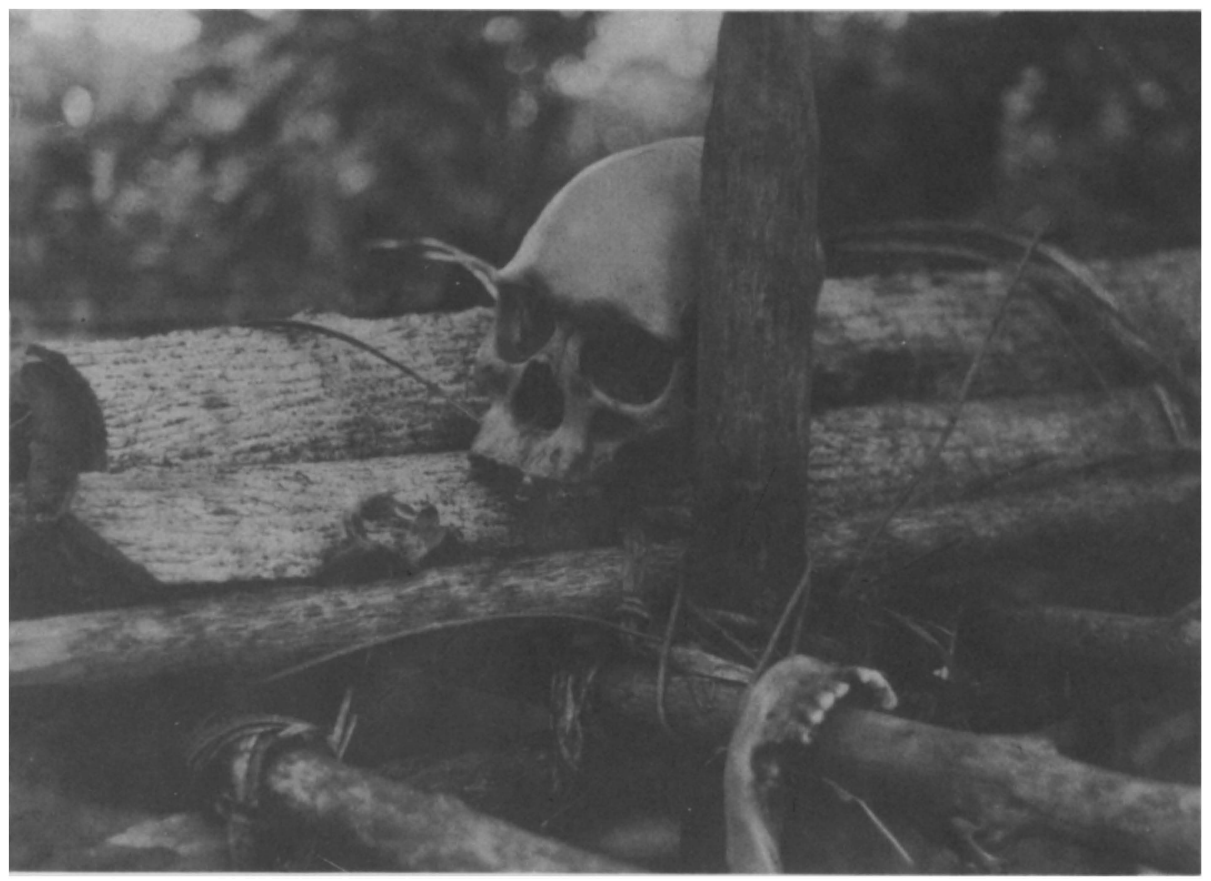

Plate $18 b$. Skull of a victim of a head-hunting raid 


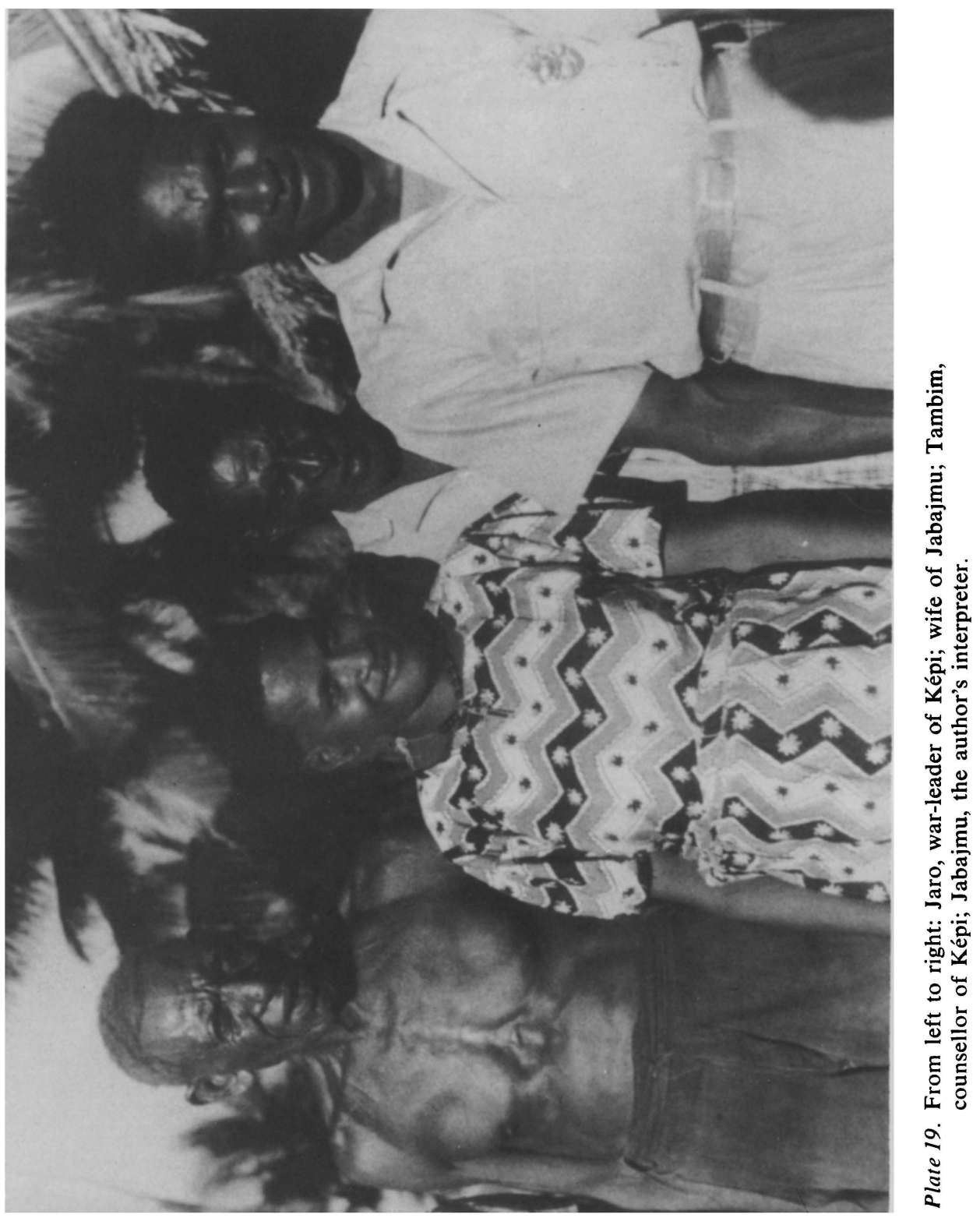




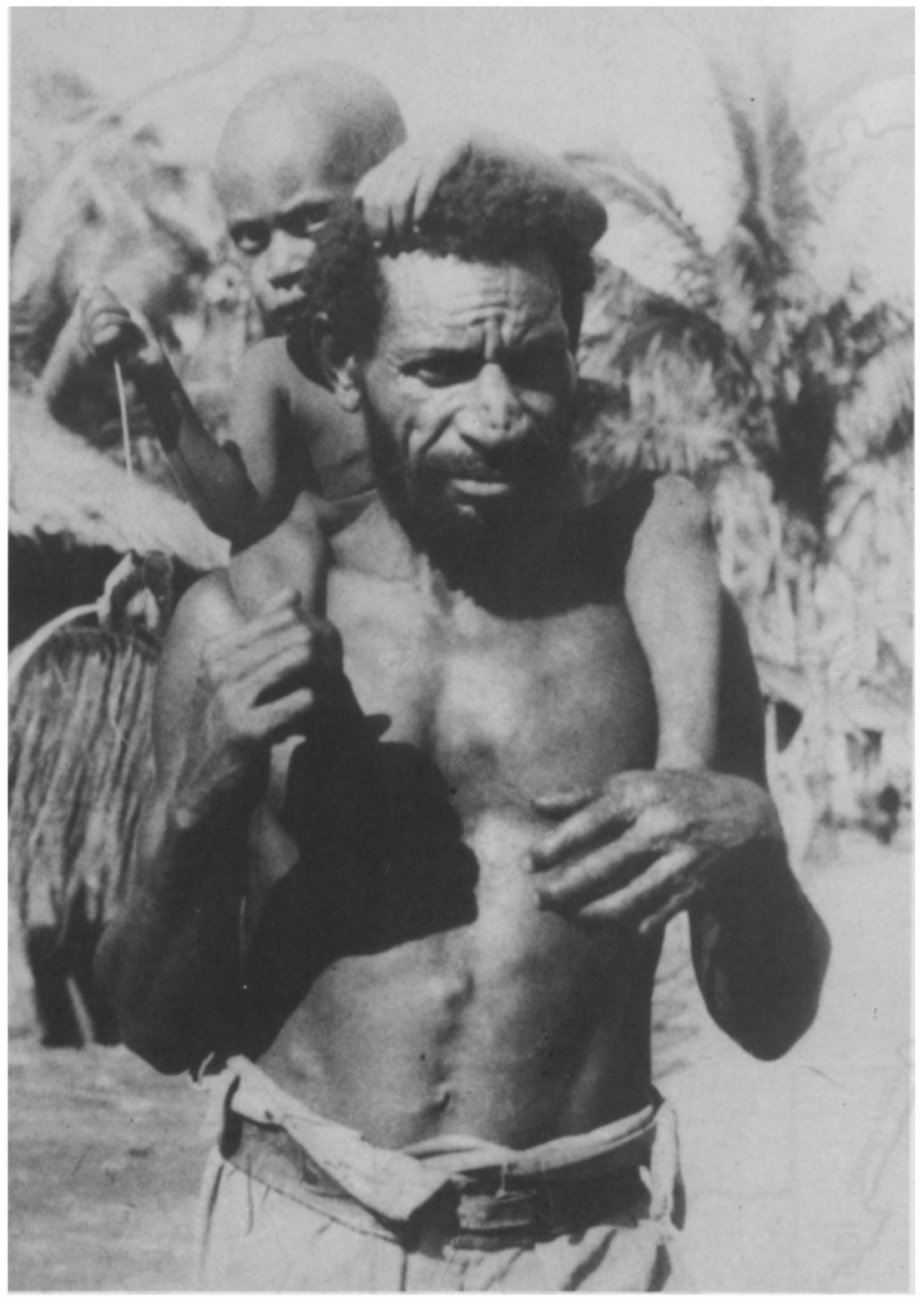

Plate 20. Jaèndé, war-leader. 


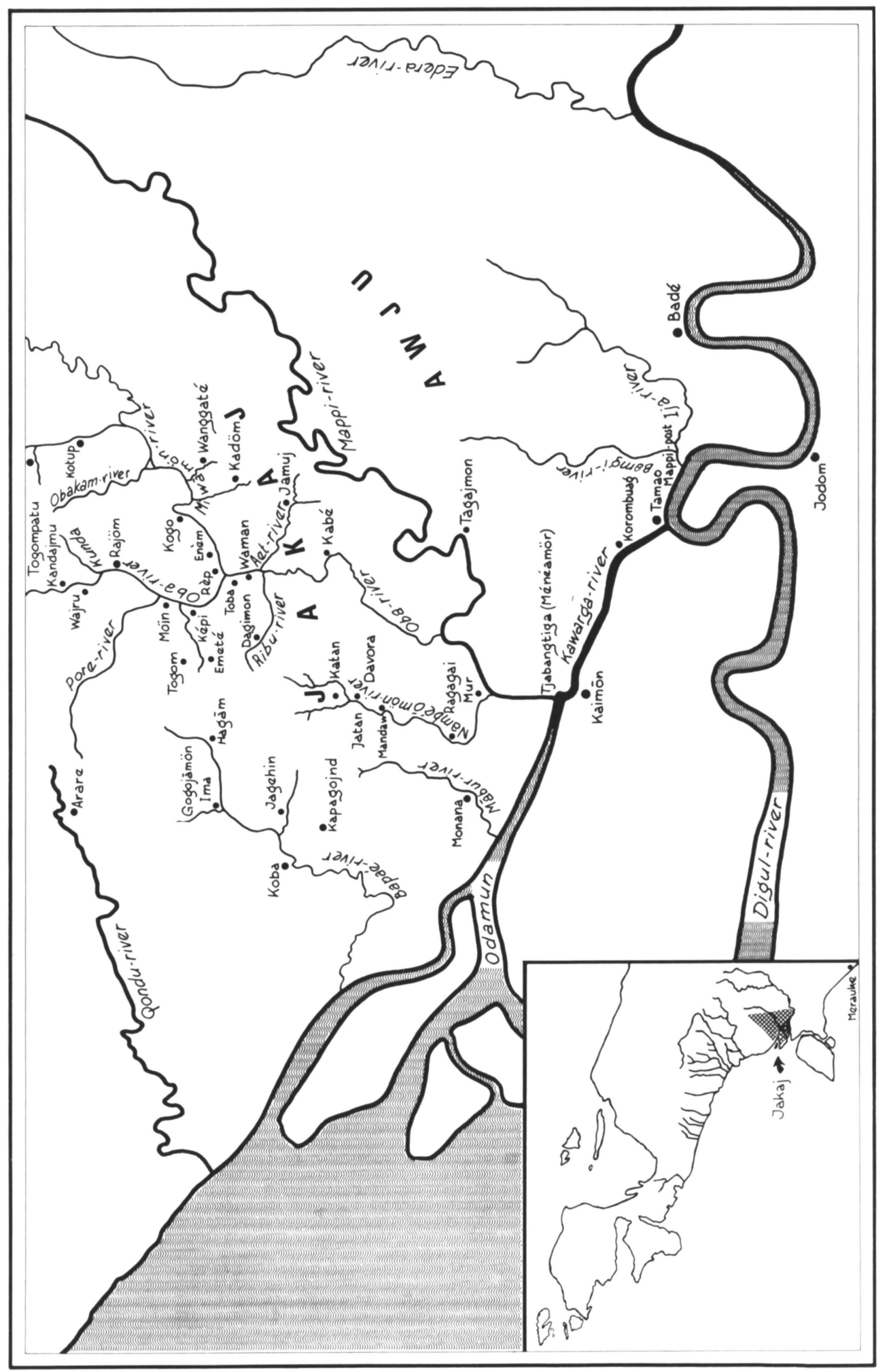

ن 


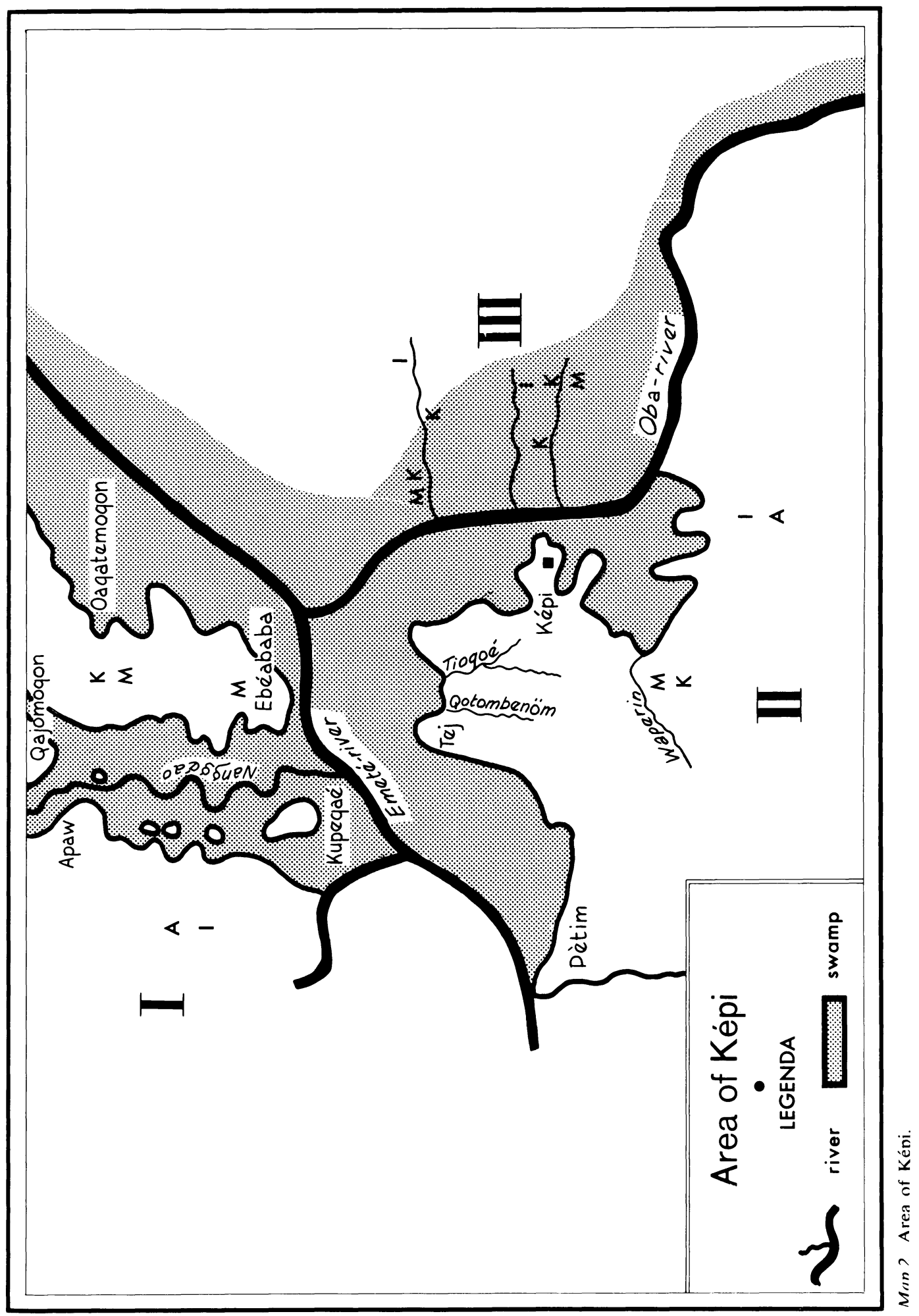




\section{The fights of Képi}

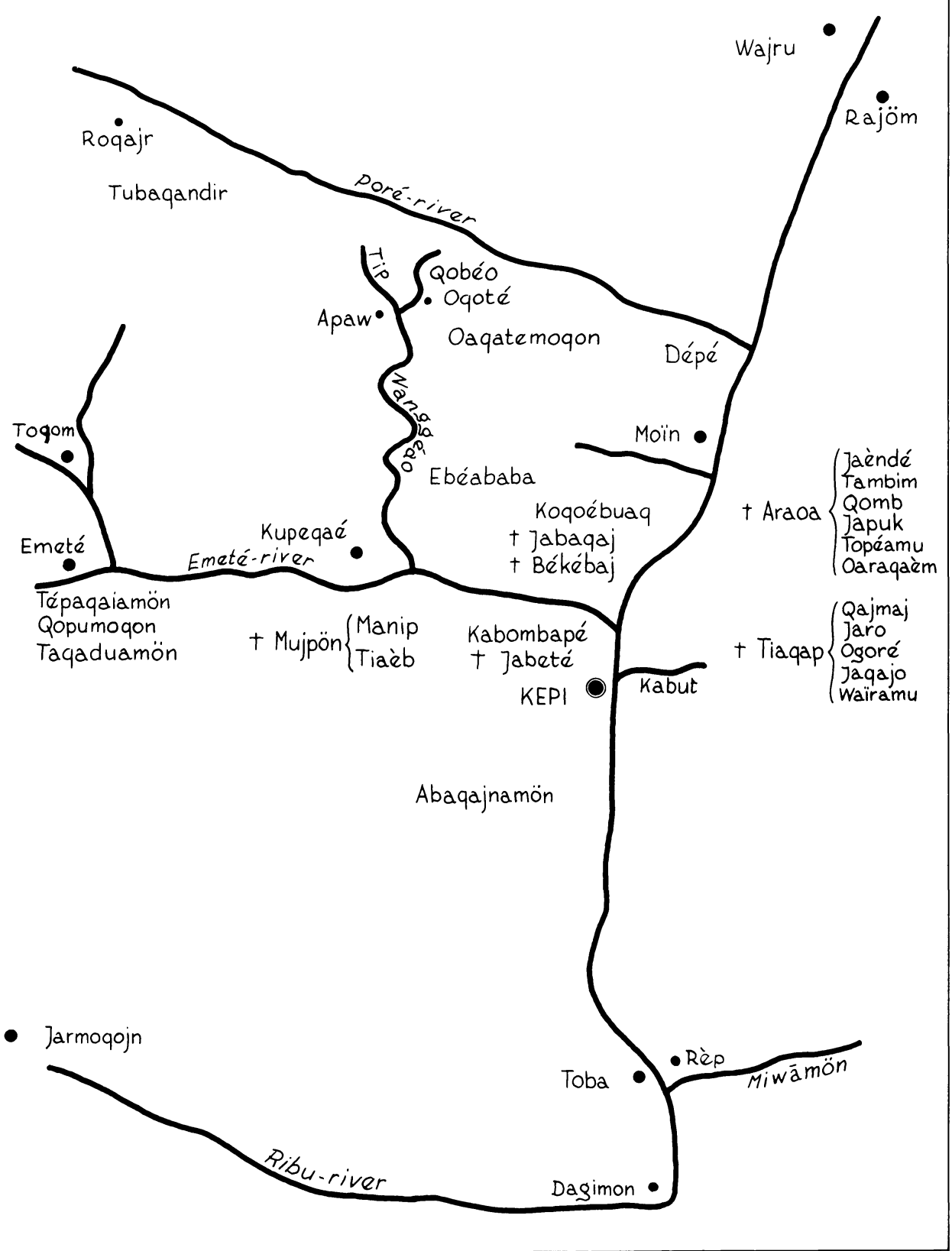




\section{The raid on Togompatu}

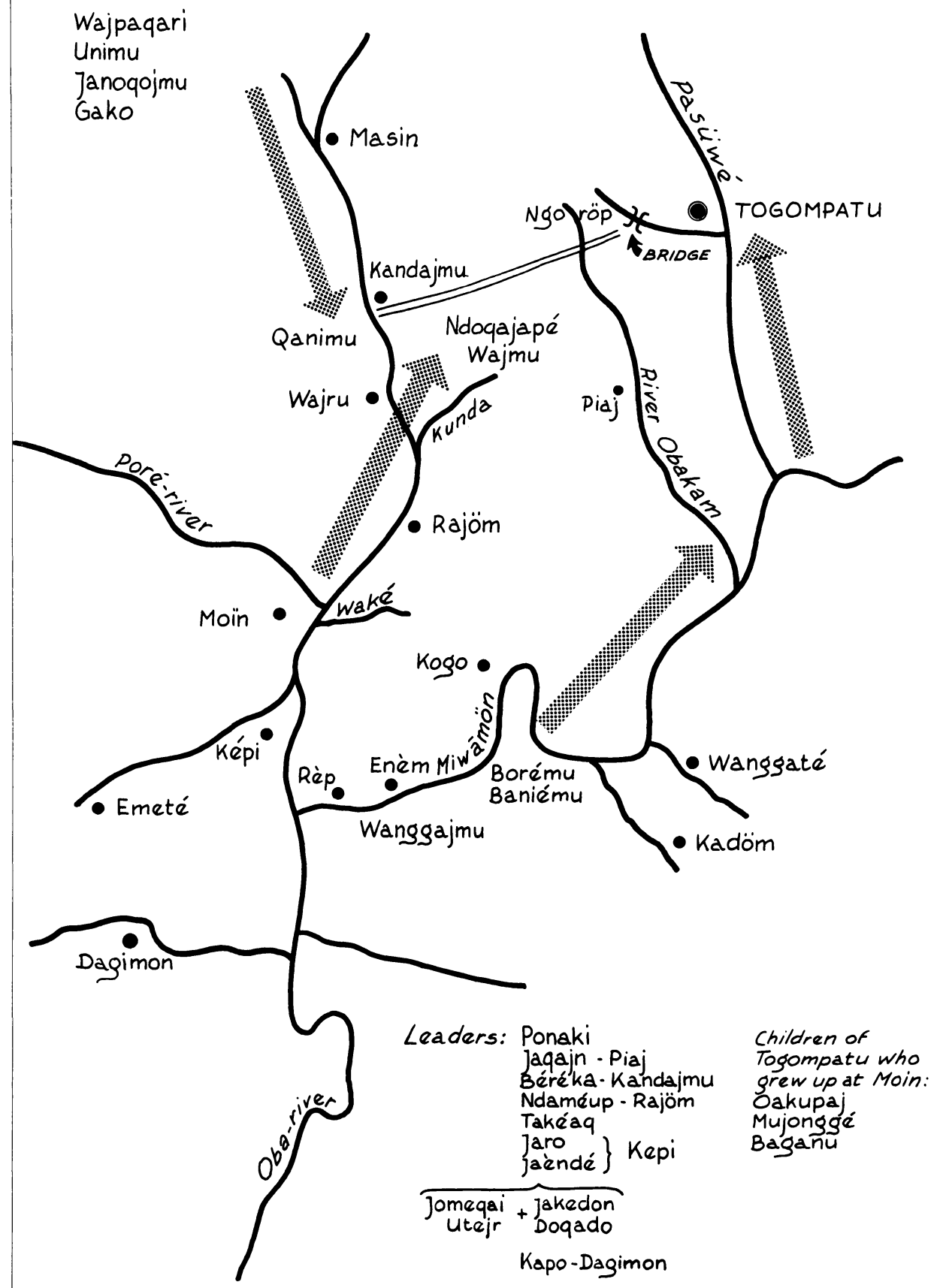




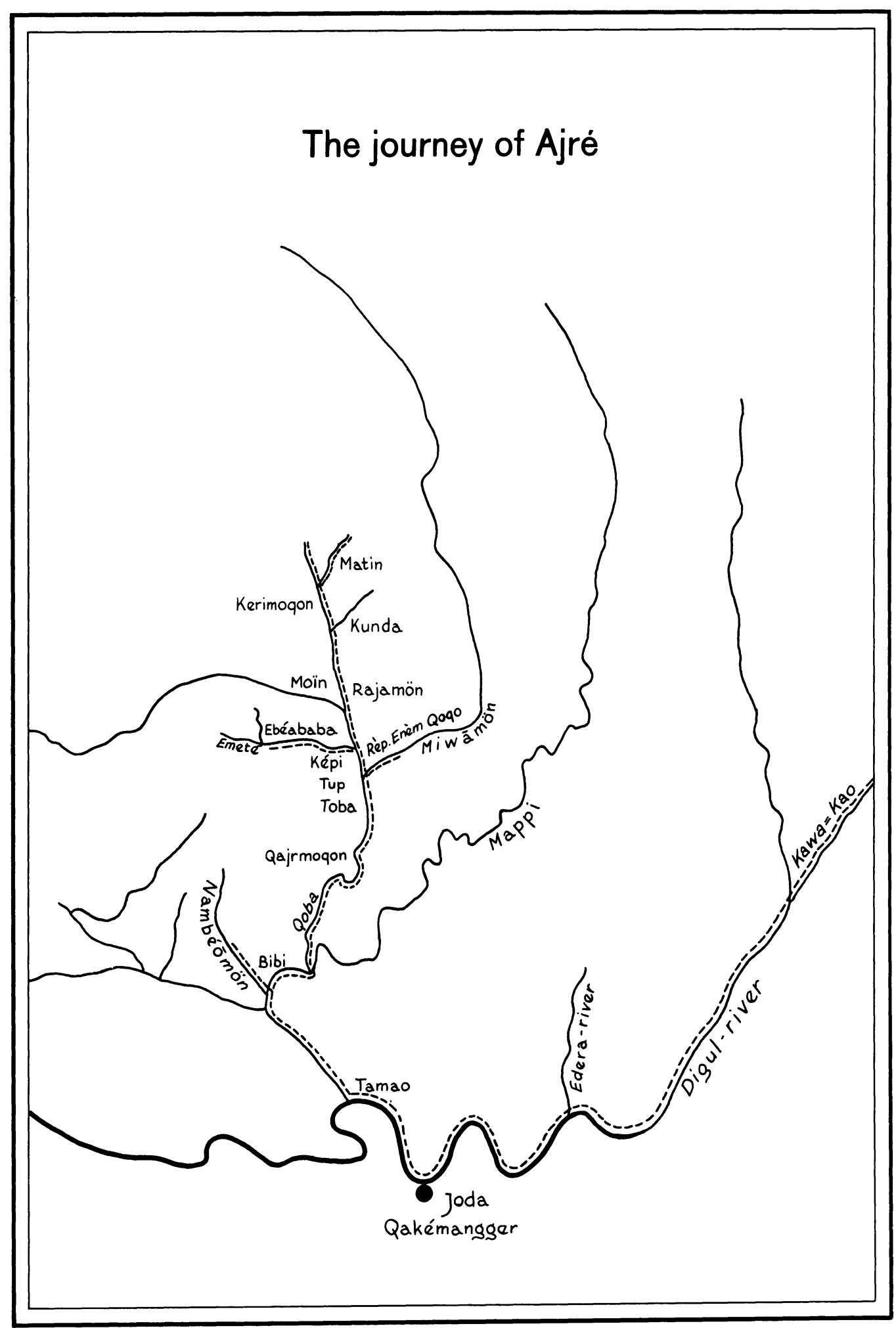

Map 5. The Journey of Ajré.

Downloaded from Brill.come4/26/2023 01:45:47PM 